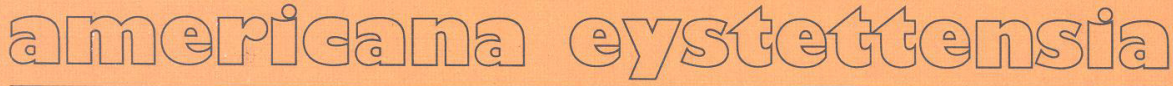

Franz Obermeier

Brasilien in

Illustrationen des

16. Jahrhunderts

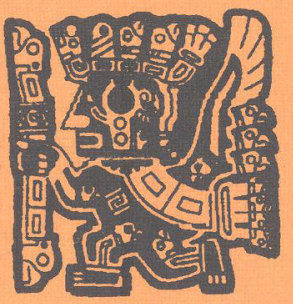

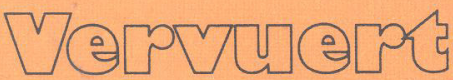


Brasilien in Illustrationen des 16. Jahrhunderts 


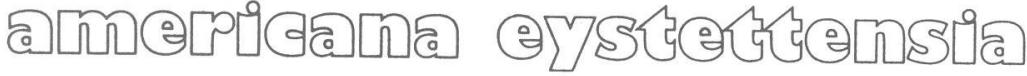

Herausgeber: Karl Kohut und Hans-Joachim König

Publikationen des Zentralinstituts für LateinamerikaStudien der Katholischen Universität Eichstätt

Serie B: Monographien, Studien, Essays, 11

Publicaciones del Centro de Estudios Latinoamericanos de la Universidad Católica de Eichstätt

Serie B: Monografías, Estudios, Ensayos, 11

Publicações do Centro de Estudos Latino-Americanos da Universidade Católica de Eichstätt

Série B: Monografias, Estudos, Ensaios, 11

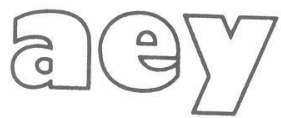


Franz Obermeier

\title{
Brasilien in Illustrationen des 16. Jahrhunderts
}

\author{
Unter Mitarbeit von \\ Roswitha Kramer
}

Vervuert Verlag · Frankfurt am Main 


\section{0 of 8206}

Gedruckt mit Unterstützung der Universitätsbibliothek Eichstätt, Abteilung Bischöfliche Seminarbibliothek

UHWE ATH WOAEK KEL

Die Deutsche Bibliothek - CIP-Einheitsaufnahme

Obermeier, Franz:

Brasilien in Illustrationen des 16. Jahrhunderts /

Franz Obermeier. Unter Mitarb. von Roswitha Kramer.

- Frankfurt am Main : Vervuert, 2000

(Americana Eystettensia : Ser. B, Monographien, Studien, Essays ; 11)

ISBN 3-89354-960-9

(C) Vervuert Verlag, Frankfurt am Main 2000

Alle Rechte vorbehalten

Gedruckt auf säure- und chlorfreiem, alterungsbeständigem Papier

Printed in Germany: Rosch-Buch, Scheßlitz 


\section{Inhalt}

Vorbemerkung

Kap. 1: Frühe ikonographische Dokumente über den südamerikanischen Indianer (1493-1557)

1. Reisebericht und Ikonographieforschung

2. Die französische Tradition

3. Die deutsche Tradition

Kap. 2: Das Brasilienkorpus der Reiseberichte von Thevet, Léry und Staden (1557-1585)

1. Thevet und die Bildfolge

Die Singularités (1557/58) und die Cosmographie universelle (1575)

Die Porträtsammlung Thevets (Les vrais pourtraicts et vies des hommes illustres, 1584)

2. Textillustration und autonome Aussagestruktur in den Holzschnitten Lérys (Histoire d'un voyage faict en la terre du Brésil, ${ }^{2} 1580$ )

Léry und die Trachtenbücher

Das Verhältnis des Bildmaterials zum Text

Die Holzschnitte in Lérys Buch und Thevets Illustrationen

3. Zwischen Historiographie und Ethnologie: die Illustrationen in Stadens Warhafftige Historia (1557)

Stadens Reiseerlebnisse und das Authentizitätsproblem

Staden und die deutsche Bildtradition

Staden und die französischen Reiseberichte von Thevet und Léry

Kap. 3: Brys America (1590-1634) oder die Sprache der Bilder

1. Theodor de Bry: vom verfolgten Hugenotten zum erfolgreichen Verleger 73

Die Selbstporträts von Theodor und Johann Theodor de Bry

Theologie und leyenda negra

2. Das Korpus der Brasilienreiseberichte: das Emblem der verkehrten Welt oder die Illustration der Anthropophagie

Bry und Staden

Bry und Léry

Das Fortleben von Brys Bildmaterial

3. Aussageintention und Bildlichkeit: die Bedeutung der Stiche in Brys Reiseberichtkollektion 
$\begin{array}{ll}\text { Bibliographie } & 117\end{array}$

Quellen 117

$\begin{array}{ll}\text { Forschungsliteratur } & 125\end{array}$

Anhang: Verzeichnisse der Illustrationen und Konkordanzen 137

Vorbemerkung zu den zitierten Ausgaben 137

Die Illustrationen in Stadens Warhafftige Historia 138

Ikonographische Konkordanzen 140

1. Staden und Bry (America, 1990) 140

2. Staden, Léry und Bry (America, 3. Buch, lat. Ausgabe, 1592) 142

3. Bry, America, Bd. 3: lateinische und deutsche Ausgabe 145

4. Die Illustrationen von Thevets Singularités und ihr Fortleben in der Cosmographie

$\begin{array}{ll}\text { Abbildungsverzeichnis } & 148\end{array}$

Verzeichnis der Tabellen $\quad 150$

Nachweis der Rechte 151

Bildtafeln 153

$\begin{array}{ll}\text { Abstract } & 201\end{array}$ 


\section{Vorbemerkung}

Die vorliegende Arbeit wurde ursprünglich als Hausarbeit zur Laufbahnprüfung für den höheren Bibliotheksdienst (Herbst 1996) bei der Fachhochschule Köln, Fachbereich Bibliotheks- und Informationswesen geschrieben und wird hier mit Genehmigung des Prüfungsausschusses in einer stark überarbeiteten Version veröffentlicht.

Frau Dr. Roswitha Kramer vom Zentralinstitut für Lateinamerikastudien hat durch ihr sachkundiges Lektorat und zahlreiche weiterführende inhaltliche Hinweise an dem Werk mitgearbeitet. Ich danke Herrn Prof. Dr. Kohut, Universität Eichstätt und Herrn Dr. Holzbauer, Direktor der Universitätsbibliothek Eichstätt, die die Veröffentlichung dieser Arbeit in der Reihe Americana Eystettensia ermöglicht haben.

Eichstätt, Dezember 1999

Franz Obermeier 



\section{Kap. 1: Frühe ikonographische Dokumente über den südamerikanischen Indianer (1493-1557)}

\section{Reisebericht und Ikonographieforschung}

Das Verhältnis von Text und Bild hat in der wissenschaftlichen Forschung der letzten Jahre verstärkt Beachtung gefunden. Dies liegt sicherlich daran, dass im Gefolge von Derrida oder strukturalistischen Analysen das Augenmerk der Forschung auf die verschiedenen Formen der Schriftlichkeit und die Konstituierung von Texten durch unterschiedliche mediale Vermittlung von Information gelegt wurde. Die Zeichentheorie von Peirce und die große Beachtung, die die Semiotik in den heutigen Sprach- und Literaturwissenschaften gefunden hat, taten ein Übriges, um das Phänomen "Text" nicht mehr allein unter verbalen Gesichtspunkten zu betrachten, sondern verstärkt auch Randbereiche der Texte, die oft in nichtsprachliche Bereiche übergreifen, ins Auge zu fassen. Dazu gehören natürlich die phatischen Erscheinungen der Sprache bei der Rezitation sowie Mimik und Gestik und in der traditionellen Vermittlung von Texten die Gestaltung von Büchern und ihre Illustrationen. Die Illustrationsgeschichte der frühen Buchdruckerkunst hat schon seit langer Zeit ein großes Interesse gefunden, sowohl von bibliothekarischer als auch von kunsthistorischer Seite. Weniger beachtet wurden dagegen die symbolischen Bezüge der Illustrationen zu den Texten, außer vielleicht in einigen evidenten Bereichen, wie im Einfluss der barocken Emblematik auf die Buchillustrationen, Ex-Libris und auch die Bildlichkeit der Barocklyrik. Erst in neuerer Zeit hat das verstärkte wissenschaftshistorische Interesse dazu beigetragen, auch die Formen der Wissensvermittlung durch illustrierte Werke genauer zu durchleuchten.

In diesem Buch soll an einem ausgewählten Textkorpus die Kontinuität einer ikonographischen Tradition von den Südamerikaberichten des 16. Jahrhunderts bis hin zu Brys America (Bd. 3, lat. 1592, dt. 1593) aufgezeigt werden. Es wird sich erweisen, dass dieselben Vorbilder von der Mitte des 16. Jahrhunderts bis in die erste Hälfte des 17. Jahrhunderts und noch weit darüberhinaus tradiert werden. Anhand des ausgewählten Materials soll ferner die in dieser selektiven Übernahme begründete Intention herausgearbeitet werden, also beispielsweise wie die Buchillustrationen der frühen Reiseberichte vom zeitgenössischen Urteil über die Indianer geprägt sind. Es geht dabei weniger darum, aus dem Bildmaterial eine eigene Anthropologie herauszuarbeiten, was den Rahmen dieser Darstellung sprengen würde. Ziel ist es vielmehr aufzuzeigen, wie sich das illustrative Material zu den Texten selbst verhält und welche symbolischen internen Bezüge zwischen den einzelnen figurae, meist Holzschnitten bzw. Kupferstichen ${ }^{1}$ bestehen.

\footnotetext{
${ }^{1}$ Es existieren verschiedene Begriffe zur Bezeichnung der Illustrationen in der Zeit. Bei den Brys finden sich die Termini eicones für die direkt nach den Vorgaben von Jacques Le Moyne de Morgues in seinem Floridabericht (America, lat. 1591, Teil 2) gestochenen Kupfer, figurae
} 
Die Auswahl eines französischen und eines deutschen Korpus von Südamerikareiseberichten und ihrer Rezeption durch Bry ist dabei nicht willkürlich. Im Laufe der Analyse wird sich zeigen, dass sich vielfältige Filiationen zwischen der Ikonographie der Vorbilder der Brys und ihrer Reiseberichtkollektion aufzeigen lassen, die laut Sturtevant $(1976,419)$ wissenschaftlich kaum beachtet wurden und einen wesentlichen Beitrag zum Verständnis der Intention dieser Werke darstellen. Zudem sind die ikonographischen Vorbilder des dritten Bandes der berühmten Reiseberichtsammlung, also die Bücher von Staden, Léry und Thevet im Gegensatz zu den uns nur teilweise überlieferten Aquarellen von John White über Virginia und Jacques Le Moyne de Morgues über Florida vollständig erhalten und ermöglichen damit einen direkten Vergleich.

Die französischen und deutschen Brasilienreiseberichte des 16. Jahrhunderts gehören zu den frühesten Beispielen von Texten der Reiseliteratur, denen nicht nur mehr oder weniger willkürlich Abbildungen beigegeben sind, sondern in denen die Illustrationen einen Zyklus vom Leben der indianischen Bevölkerung abbilden, der sowohl von der Menge der Holzschnitte als auch von der Bedeutung her in der damaligen Zeit einmalig ist. André Thevets Les Singularités de la France antarctique erschienen 1557/58 und stellen damit eine der frühesten europäischen Publikationen über Brasilien dar; Jean de Lérys Replik darauf wurde erstmals 1578 unter dem Titel Histoire d'un voyage faict en la terre du Brésil publiziert und erlebte zahlreiche Neuauflagen. Thevet hatte das ikonographische Material seines Brasilienreiseberichts auch in seiner Cosmographie universelle von 1575 verwendet und durch neue Illustrationen ergänzt. Die Warhafftige Historia von Hans Staden erschien 1557 in Marburg und wurde zu einem der meistaufgelegten Reisebücher überhaupt. Brys Sammlung von Reiseberichten, in die das bildliche Material Thevets, Stadens und Lérys und der Text von Léry und Staden eingingen, erschien ab 1590 und bildet von der Qualität her einen Markstein in der Entwicklung der Illustrationen von Reiseberichten. Die Inspirierung an Holzschnitten von Thevet, Léry und Staden im dritten Band dieser Sammlung von 1592 ermöglicht es, anhand des Südamerikakorpus die Intention der Brys exemplarisch an diesem Bildmaterial herauszuarbeiten.

Das Interesse der Wissenschaften an den frühen Reiseberichten hat mehrere Wurzeln. Vor der Herausbildung der Fachwissenschaften in der zweiten Hälfte des 18. Jahrhunderts waren diese frühen Berichte stets ethnologische, naturkundliche und geographische Quellen. In Ermangelung anderer Informationen und angesichts der spärlichen archäologischen Befunde spielt dies vor allem für die heutige Ethnologie eine große Rolle. Die religiösen Vorstellungen vieler mitt-

für die von den Brys gelieferten (selbst wenn Vorbilder wie bei Léry oder Staden nachweisbar sind). Der Begriff imagines verweist auf die technische Perfektion der vom Stecher geschaffenen Werke und findet sich vor allem ab dem 7. Buch, also nach Theodor de Brys Tod. Die Karten schließlich werden als tabulae, die Pläne als delineationes bezeichnet. Vgl. hierzu auch Duchet 1987, $11 \mathrm{ff}$. 
lerweile ausgestorbener Stämme wären ohne die frühen Reiseberichte überhaupt nicht bekannt. Ohne Thevet wüßten wir zum Beispiel nur sehr wenig über die Mythologie der Tupinamba-Indianer der brasilianischen Küste. Auch die Anthropologie und die Literaturwissenschaft befassen sich in jüngster Zeit immer stärker mit diesem Themenbereich, der bisher als Gebrauchsliteratur wenig Beachtung fand. Durch den Einfluss, den die Reiseliteratur auf Montaigne, die frühe sozialutopische Literatur und später auch auf das Menschenbild der Aufklärung, insbesondere den zweiten Diskurs von Rousseau über den Ursprung der Ungleichheit unter den Menschen (1755) ausübte, haben diese Texte eine erhebliche anthropologische Bedeutung.

Die Erforschung der Ikonographie hat lange Zeit allenfalls am Rande dieser verschiedenen Ansätze eine Rolle gespielt. Dabei hat sich aber schon bald gezeigt, dass nur wenige der frühen Illustrationen einen direkten ethnologischen Quellenwert besitzen, da sie meist erst in Europa in Auftrag gegeben wurden. Die Beispiele von begabten Zeichnern, die selbst in Amerika vor Ort waren und anhand von Skizzen "Feldforschung" betreiben konnten, sind selten. Hier muss man den Franzosen Jacques Le Moyne de Morgues und den Engländer John White nennen ${ }^{2}$, deren Aquarelle die direkten Vorlagen für einige von Brys Stichen im ersten Buch seiner Kollektion bildeten. Der deutsche Reisende Hans Staden hat dagegen künstlerisch wenig anspruchsvolle Skizzen als Vorlagen für die Holzschnitte in seinem Reisebericht vermutlich selbst gezeichnet. Auch die Illustrationen bei Benzoni (Historia del mondo nuovo, Venedig 1565), von denen Bry dann in seiner Kompilation einige kopiert hat ${ }^{3}$, sind skizzenhaft und wenig aussagekräftig. In den Holzschnitten Thevets und Lérys sind allenfalls der reiche Federschmuck oder die Waffen und Keulen ethnologisch exakte Abbildungen, die sicher durch die Beschreibungen der Autoren den Künstlern bekannt waren. In einigen Fällen, wie z. B. in der Cosmographie Thevets wird die Idealisierung des Indianers auf Kosten der Authentizität verstärkt, was von einer rein ethnologischen Betrachtungsweise des Bildmaterials abhalten sollte.

Vielversprechend sind in diesem Forschungsbereich vor allem neue Ansätze, die versuchen, der eigenständigen Semantik der Stiche vor dem Hintergrund des

${ }^{2}$ Le Moyne de Morgues hielt sich zwischen 1564 und 1565 in Florida auf; er starb 1588 in London. Seine Stiche wurden 1591 posthum veröffentlicht und sind vermutlich aus der Erinnerung nach Skizzen ausgeführt. John White hielt sich mehrfach in Amerika auf (1585, 1587 und 1590). Seine Aquarelle gehen ebenfalls mit großer Wahrscheinlichkeit auf Skizzen zurück, die er zwischen 1585 und 1587 vor Ort angefertigt hat (s. Honour, 1982, 30f; vgl. ferner Hulton 1984 u. 1990).

${ }^{3}$ Folgende Holzschnitte in der zweiten Auflage von Benzonis Historia (1572) werden von Bry zum Vorbild genommen: $3 r=$ Bry, 4. Buch, Stich 3, 156; 49v = Bry, 4. Buch, Stich 20, $175 ; 52 \mathrm{v}=$ Bry, 4. Buch, Stich 23, 178; 161r = Bry, 6. Buch, Stich 24, 239 und dasselbe Motiv Stich 25, 240; 178v = Bry, 6. Buch, Stich 29, 244. Ich zitiere die Stiche der Brys hier und im Folgenden nach der Seitenzählung der Ausgabe von Sievernich (America, 1990). Zur Zitierweise der Primärtexte Lérys, Stadens und Thevets s. Anhang, 135. 
zeitgenössischen Wissenshorizonts gerecht $\mathrm{zu}$ werden. Eine der wichtigsten Analysen, die diese Ansätze mustergültig verwirklicht, ist die Arbeit von Bernadette Bucher (1977) ${ }^{4}$. Dieses Buch, ursprünglich eine Dissertation an der Sorbonne, setzt sich ausgehend von der strukturalen Anthropologie von Claude Lévi-Strauss zum Ziel, die symbolischen Bezüge der Illustrationen bei Bry zu entschlüsseln und macht hierfür das Thema der nackten Indianerfrau, die mit hängendem Busen dargestellt wird ("la sauvage aux seins pendants"), zum Ausgangspunkt der Überlegungen. Es handelt sich aber um mehr als nur die motivgeschichtliche Studie eines Elements; die Frauendarstellung dient vielmehr als Schlüssel zu einer Darlegung der inneren Semantik der Stiche, die als Einheit betrachtet werden.

Bucher orientiert sich in ihrer strukturalen Analyse der semantischen Oppositionen in den Stichen der Kannibalismussequenz bei Bry vor allem an LéviStrauss' Le cru et le cuit (1964) und der darin konstatierten kulturstiftenden Funktion des Unterschieds zwischen roher und gekochter Nahrung. Bucher stellt fest, dass die Abbildungen bei Bry eine negative Transformation der klassifikatorischen Ordnung aufbauen. Anstelle der üblichen europäischen Assoziationen Altern/Verhärtung werde die Opposition Altern/Verflüssigung der Materie konstatiert. Die Opposition flüssig/fest bezieht sich hier auf die Körperteile des im Ritual verspeisten Opfers bzw. den flüssigen Sud aus seinen Eingeweiden. Daneben finden sich in sexuell deutbaren Gesten auf diesen Stichen auch Anspielungen auf Übertretungen auf einer anderen Ebene, z. B. der Homosexualität ${ }^{5}$.

Auch wenn die dieser Analyse zugrunde liegenden kulturellen Assoziationen zwischen Alter und Zustand der Materie nicht notwendig zwingend erscheinen, so hat diese Untersuchung das Verdienst, die Stiche nicht in erster Linie als ethnologische Dokumente anzusehen, sondern den Ansatz für das Verständnis der Illustrationen in der Eigengesetzlichkeit ihrer Semantik und im Bezug zum epistemologischen Hintergrund zu suchen. Die "sauvage aux seins pendants" wird in der Analyse zu einem mythologisch-ikonographischen Zentrum, das die Degradation der Neuen Welt ausdrückt und in der Schilderung der kannibalistischen Riten mit einem Code des Alters und der Nahrung verbunden ist. Die Autorin unterliegt allerdings der Versuchung, die deutlichen Unterschiede in den Darstellungen der nackten Frauen zu nivellieren und den Text- und Bildkontext im Einzelnen nicht genügend in Betracht zu ziehen.

Der Vorwurf, Bucher habe das Verhältnis zwischen Text und Bild nur am Anfang ihrer Analyse berücksichtigt, ist dann in der Tat auch von der Kritik

${ }^{4}$ Eine gute Zusammenfassung der wichtigsten Thesen dieser Arbeit findet sich in dem Aufsatz der Autorin von 1982.

${ }^{5}$ Vgl. Bry, 3. Buch, 1. Teil, Stich 10 (America, 1990, 126), wo einige Indianerinnen sich gegenseitig an das Geschlechtsteil fassen. Die Frauen auf dem zu Grunde liegenden Holzschnitt bei Staden (1978, 1. Buch, Kap. 22) sind winzig und ihre Gesten wenig eindeutig, sie ähneln aber in der Gestik denen bei Bry. 
erhoben worden. Michèle Duchet $(1987,40)$ fordert, Text- und Bildcode als eine Einheit verschiedener "homologer Codes" anzusehen, die im Grunde aber beide mit unterschiedlichen Mitteln demselben Zweck dienen, nämlich einer "représentation du monde de la conquête hautement signifiante" (ebd., 42).

In diesem Buch sollen diese fachspezifischen Aspekte allenfalls am Rande berührt werden. Es geht vielmehr darum aufzuzeigen, inwieweit die Illustrationen der frühen Südamerikareiseberichte Träger eigener Aussagen sind und damit zur Gesamtaussage beitragen. Ferner soll dargelegt werden, wie trotz der Tradierung zahlreicher ikonographischer Elemente durch geringfügige Veränderungen, Kollokation der Holzschnitte und Stiche innerhalb einer Serie von anderen Stichen und Text-Bild-Bezügen diese Aussagen bei Bry einem historischen Wandel unterliegen, der einem gezielten ikonographischen Programm entspricht, das sicherlich in allen Fällen in enger Zusammenarbeit zwischen Drucker, Künstler und Autor entstand.

Ausgehend von diesen theoretischen Prämissen soll hier versucht werden, sowohl der inhärenten Symbolik der Stiche als auch dem vielfältigen Text-BildBezug und - soweit im Rahmen einer ikonographisch ausgerichteten Untersuchung möglich - der ideologisch-epistemologischen Bedeutung der Stiche vor dem Zeithintergrund gerecht zu werden.

Vor der Analyse der Illustrationen in den frühen Südamerikareiseberichten müssen einige Bemerkungen zu den frühesten Abbildungen südamerikanischer Indianer und ihrer Kultur auf Karten, in Büchern und in anderen Kunstgattungen erfolgen, da diese Werke direkte Vorbilder für die späteren Buchillustrationen waren. Insbesondere die Darstellungsweise der Karten hat noch das Werk der Brys entscheidend beeinflusst. Außer Acht bleiben soll hier die Tradition der Amerika-Allegorien, da zu diesem Thema schon eingehendere Forschungen vorliegen (vgl. z. B. Poeschel, 1985).

Obwohl die ersten Entdeckungsfahrten nach Amerika bei den Zeitgenossen auf reges Interesse stießen und die frühen Reiseberichte - wenn auch mit zeitlicher Verzögerung - intensiv rezipiert wurden, ist das ikonographische Korpus dieser Texte ${ }^{6}$ vergleichsweise gering. Dies hat sicherlich mehrere Ursachen. Die ersten gedruckten Dokumente über die Neue Welt waren wenig umfangreich etwa der bekannte Kolumbusbrief oder die Briefe von Vespucci - und wurden in schmalen Heftchen veröffentlicht. Zudem standen die Illustratoren vor erheblichen Problemen, da sie insbesondere bei den Menschendarstellungen nur auf eine kaum entwickelte Tradition zurückgreifen konnten. Die Illustrationen in den mittelalterlichen Reiseberichten und den frühen Kosmographien stellen vor allem

\footnotetext{
${ }^{6}$ Neben dem ansprechend bebilderten Ausstellungskatalog L'Amérique vue par l'Europe (1976), den zahlreichen Illustrationen bei Duviols (1985) und Mythen der Neuen Welt (1982) - um nur die wichtigsten Werke zu nennen -, liegt zu dem Bereich der frühen Illustrationen von Dokumenten über die Neue Welt eine kommentierte bibliographische Untersuchung von Sturtevant (1976) vor, der auch das wenige erhaltene Material umfassend abgebildet hat.
} 
Kuriosa und angebliche körperliche Abnormitäten der fremden Völker in den Vordergrund und gehören damit eher in den Bereich der Mirabilia-Darstellungen des Mittelalters. Unser heutiges Konzept der Erfahrung und insbesondere der kritischen Sichtung der vorhandenen Informationen hat sich erst im Laufe der Jahrhunderte herausgebildet, was indirekt auch dem Einfluss der Reiseliteratur zu verdanken ist, in der sich der Bezug auf reale Ereignisse trotz des Weiterlebens phantastischer Elemente als darstellungstechnisches Problem erweist, das bei einigen Autoren, so u. a. Léry, eine durchaus allgemeine erkenntniskritische Dimension erhält.

Typisch für diese mittelalterlichen Illustrationen der Reiseliteratur - etwa den vielgelesenen Bericht von Mandeville - ist die Darstellung von Menschen mit Wolfsköpfen oder Menschen ohne Kopf, letztere findet sich noch in einer Illustration von Lafitaus Mœurs des sauvages américains von 1724 (Abb. bei Honour 1982, 23). Die frühen Illustratoren kannten natürlich diese Traditionen, auch die Buchmalerei hat z. B. bei den Kreuzzugsberichten, Editionen des Milione von Marco Polo oder Pilgerreisen nach Jerusalem schon früh auch exotische Elemente integriert. Dennoch ist im Vergleich etwa zu der bedeutenden religiösen Illustrationskunst, die durch Einblattstiche, Blockbücher und den beginnenden Buchdruck weite Verbreitung fand, bei den Illustrationen der Reiseliteratur der Bezug auf eine feste ikonographische Tradition nicht möglich, die sich bei religiösen Themen in den diversen Künsten etabliert hatte und von den Illustratoren ohne Scheu zu Rate gezogen bzw. mit geringfügigen Abweichungen kopiert werden konnte und von den Zeitgenossen auch verstanden wurde. Die Illustratoren der frühen Reiseliteratur betraten künstlerisch Neuland, und viele der heute meist unbekannten Künstler waren von ihrer Ausbildung her nicht in der Lage, das gegebene Thema angemessen zu behandeln.

In diesem Kontext muss die Studie von Alegría (1978) gewürdigt werden, auch wenn sie nur Illustrationen und Kunstwerke aus den ersten zwei Jahrzehnten nach der Entdeckung Amerikas behandelt, während Sturtevant (1976) bis 1590 fortschreitet, dem Erscheinungsjahr des ersten Bandes der Reiseberichtkollektion der Brys, die nach seinem Urteil eine eigenständige und kaum erforschte ikonographische Tradition für die folgenden Jahrhunderte begründet (Sturtevant 1976, 419f). Alegrías Analyse bringt allerdings nur einen deskriptiven Katalog der einzelnen recht disparaten Illustrationen in verschiedenen frühen Editionen von Reiseberichten. Nach seiner Meinung werden besonders die Szenen illustriert, die die Grausamkeit der Indianer zeigen, so eine Vespucci-Schilderung, nach der einer seiner Seeleute hinterrücks von Indianern getötet wurde (Alegría 1978, Abb. 14, S. 57). Bei der Zeichnung der Frauen wird allerdings immer das Muster der langhaarigen Eva aus Abbildungen des Paradieses aufgegriffen. Alegría deutet dies als einen Verweis auf das Goldene Zeitalter, was aber angesichts des anderen Typus von Schilderungen der Grausamkeit wenig stichhaltig erscheint. Bei den frühen Illustrationen überwiegt die Darstellung des Königs Ferdinand, der den Schiffen des Kolumbus den Befehl zur Ausfahrt gibt. Den Hintergrund bildet oft eine Meereskulisse, wobei einige nackte Gestalten am 
Bildrand die Indianer der neuentdeckten Länder darstellen. Alles in allem bleibt der disparate Eindruck dieses Bildmaterials, das sicherlich mehr auf einzelne Aufträge von Druckern für Illustratoren als auf ein durchdachtes ikonographisches Konzept zurückgeht. Die Bildung ikonographischer Zyklen in den Werken von Thevet und Staden in der Mitte des 16. Jahrhunderts erscheint damit als entscheidender Fortschritt.

Eine der wenigen kunstgeschichtlichen Untersuchungen der Illustrationen in der Reiseliteratur des 16. Jahrhunderts neben der mehr typologisch deskriptiven von Quetsch (1983) findet sich in der Studie von Colin (1988). Trotz ihrer Fundiertheit vermittelt diese Arbeit den Eindruck einer disparaten, katalogartigen Untersuchung verschiedener Tendenzen in der Kunst jener Zeit, wobei die einzelnen Intentionen der Texte und Dokumente und der zeitgenössische Wissenshorizont nur am Rande gestreift werden. Auch das Menschenbild wird in dem Kapitel über den Einfluss des mittelalterlichen Konzepts des "Wilden Mannes" auf das Indianerbild nur in einem Teilaspekt behandelt. Wertvoll sind jedoch die Analysen des dritten Teils, der erstmals bisher vernachlässigte Abbildungen auf den oft schwer zugänglichen Karten der Diepper Schule berücksichtigt. Die Analyse der Dokumente umfasst ca. ein Drittel der Arbeit und ist damit zu knapp angesichts des anschließenden chronologischen Katalogs, der die relevanten zeitgenössischen Karten und Buchillustrationen genau beschreibt und die restlichen zwei Drittel der Arbeit einnimmt. Erwähnung verdient ferner die Studie von Frübis (1995), die zwar nicht sehr umfangreich ist, aber dennoch ausgewogen die kunstgeschichtlichen Aspekte mit dem ideengeschichtlichen Hintergrund in Beziehung setzt. Ihre Analyse von Brys Reisesammlung macht jedoch Defizite deutlich. Die Verfasserin erkennt zwar den Gegensatz zwischen manchen idealen Naturschilderungen Amerikas und dem kalvinistischen Indianerbild, arbeitet aber die originäre Verurteilung der "religionslosen" indianischen Bevölkerung nicht genug heraus. Deren Götzendienst wird bei den Brys nicht als harmlose Verblendung unschuldiger Naturkinder aufgefasst, sondern vor allem in dem von Frübis nicht berücksichtigten dritten Band (1592) als bis zur Anthropophagie gesteigerte Grausamkeit von Völkern auf der niedrigsten Kulturstufe dargestellt.

\section{Die französische Tradition}

Aufgrund des geringen französischen Engagements in kolonialen Angelegenheiten setzt auch die französische Dokumentation über Indianer relativ spät ein. Die frühen Darstellungen finden sich vor allem auf Karten, die im Stil der Zeit mit üppigen Illustrationen versehen wurden ${ }^{7}$. Diese Karten verfolgen natürlich immer auch staatspolitische Ziele, deshalb finden sich auf ihnen häufig Abbil-

${ }^{7} \mathrm{Zu}$ den zeitgenössischen Karten insbesondere der Schule von Dieppe vgl. Colin 1988, $11 \mathrm{ff}, 141 \mathrm{ff}$. 
dungen des Fällens von Brasilholz, was zu weiterem lukrativen kolonialpolitischen Engagement in Südamerika auffordern sollte (vgl. Colin 1988, 150), und sie enthalten schon sehr früh auch exakte ethnologische Angaben. Aus der französischen Tradition sei hier die Karte des französischen Kartographen Jean Rotz erwähnt, der 1539 nach Brasilien gereist war und seine Erkenntnisse in dem Boke of Idrography verarbeitete, einem illuminierten Weltatlas, der 1542 König Heinrich VIII. zum Geschenk gemacht wurde. Die Karte von Brasilien zeigt eine Tötungsszene, in der der Gefangene um die Hüfte mit Stricken gefesselt ist, die im Boden befestigt sind. Ferner ist eine Szene zu sehen, in der Indianer mit Federschurz im Kreis tanzen, sowie ein Kampf zwischen Indianern und eine Darstellung des Grills mit menschlichen Gliedmaßen (Abbildung in schwarz-weiß bei Menninger 1995, 153). Außerhalb der Karten finden sich nur sehr vereinzelt Darstellungen in der Kunst; so gab es einen heute zerstörten Fries an einer Wand der Kirche St. Jacques in Dieppe, der vermutlich von dem Reeder Jean Ango in Auftrag gegeben wurde und einige südamerikanische Indianer zeigte ${ }^{8}$. Ferner ist ein Flachrelief aus Holz erhalten, ursprünglich das Straßenschild eines Handelshauses, das sich heute im Museum von Rouen befindet und ebenfalls das Fällen von Brasilholz neben einem Seestück zeigt (vgl. die Analyse dieses Objekts in Hamy 1907, passim).

Als ein Beispiel für das bebilderte Kartenmaterial in Büchern sei hier eine weitverbreitete Karte italienischer Herkunft behandelt. In der von dem Italiener Ramusio zusammengestellten Reiseberichtkompilation Navigationi et viaggi findet sich eine von seinem Illustrator, dem Venezianer Gastaldi, gezeichnete Brasilienkarte mit Indianern9 (Tafel 1). Da die Sammlung der Reiseberichte von Ramusio eine der weitestverbreiteten ihrer Art und sicherlich Vorbild für Brys America und die zahlreichen bis ins 18. Jahrhundert erschienenen Kollektionen unterschiedlichster Reiseberichte war, kommt ihr große Bedeutung zu. Die Karte kann als charakteristisch für die Zeit angesehen werden. Die Indianer sind wie damals üblich in das von ihnen bewohnte Festland, dessen Umrisslinien annähernd geographisch exakt gezeichnet sind, hineinprojiziert. Dies war natürlich neben einem tradierten Verfahren zur Illustration damaliger Karten auch ein Trick, um die Unkenntnis über die Geographie des damals noch weitgehend unbekannten Inneren des neuen Kontinents zu verschleiern. Die Karte zeigt die Küste von Brasilien. Es ist ein typisches Langhaus abgebildet, in dem ein Indianer in einer Hängematte liegt ${ }^{10}$, während andere am Boden kauern. Im Hintergrund fällen in einem angedeuteten Wald einige Indianer mit europäischen Äxten Bäume, deren Stämme sie auf ihren Schultern an die Küste tragen, wo sie

${ }^{8}$ Vgl. Colin 1988, 137ff; eine Abbildung des Frieses ist auf einem Stich des 19. Jahrhunderts erhalten, vgl. ebd., Abb. 78.

${ }^{9}$ Bd. 3, 1556, 427f; abgebildet bei Sturtevant 1976, 435.

${ }^{10}$ Colin $(1988,96)$ interpretiert dies etwas überzogen als eine Illustration der tradierten Faulheit der Indianer. Es sollte wohl einfach deren private Lebensweise gezeigt werden. 
zwei Europäer erwarten. Das Fällen von Brasilholz ist im Übrigen eines der ältesten auf Karten Brasiliens dargestellten Motive, das sich schon auf einer Karte von Lopo Homem-Renéis in einem Atlas von 1519 findet $^{11}$. Nicht umsonst hat Brasilien, das nach der Entdeckung zuerst Terra da Santa Cruz hieß, später die heutige Benennung nach dem zum Färben verwendeten Holz, seinem Hauptexportprodukt, erhalten.

Einer der Europäer reicht den Indianern ein Gefäß, ein Symbol für die guten Beziehungen zwischen Indianern und Europäern oder ein metonymischer Verweis auf den Tauschhandel, durch den die Indianer für das gefällte und ans Meeresufer transportierte Brasilholz begehrte europäische Metallprodukte oder Stoffe erhielten. Ferner ist auf der Karte ein Indianer dargestellt, der mit Pfeil und Bogen auf einen Vogel in einem Baumwipfel zielt, wohl ein Verweis auf die große Geschicklichkeit der Indianer im Umgang mit diesen Waffen. Eine andere Gestalt, der Größe nach ein Kind, hält in der einen Hand einen Bogen, in der anderen Hand einen Vogel, vermutlich einen Papagei, der auch ein beliebtes Tauschobjekt war. Das Kind wendet sich mit einem anderen Indianer, der einen gefällten Stamm Brasilholz in Händen hält, der Gruppe der Europäer zu. Dies deutet darauf hin, dass diese Indianer ebenfalls am Tausch interessiert sind. Auch der Bogen selbst könnte ein Tauschobjekt sein, da einer der Europäer einen gleichartigen in Händen hält. Man sieht, welch große Anzahl an ethnologisch korrekten Informationen diese wenigen Abbildungen auf der Karte enthalten. Die wichtigsten Tauschprodukte wie das kostbare Brasilholz, die Vögel und Waffen werden abgebildet und zugleich rudimentäre Angaben über die Wohnhäuser der Indianer und ihre Hängematten gemacht. Nach eben diesem Muster funktionieren noch jahrzehntelang die verbalen und visuellen Informationen der Kosmographien und anderer Bücher über die Einwohner Brasiliens. Die Karten enthalten gleichsam wie heutige Reiseführer eine Rubrik über die besten Erwerbungen, die man in diesem fremden Land machen konnte. Für die Ikonographie ist bedeutend, dass auf diesen Karten mit die ersten Belege der Darstellung südamerikanischer Indianer zu finden sind, die alle nackt und ohne Federschmuck gezeichnet sind. Weitere Details wie etwa der Lippenschmuck oder das teilweise abrasierte Kopfhaar sind angesichts der geringen Größe der Figuren nicht erkennbar.

Wie wichtig die Karten für das damalige Bild der Indianer waren, zeigt eine Stelle in Lérys Histoire (1975 [ ${ }^{21580], ~ 218 f), ~ w o ~ e r ~ g e g e n ~ K a r t e n ~ p o l e m i s i e r t, ~}$ die die Indianer zeigen, wie sie Menschenfleisch am Spieß braten, wohingegen die Tupinamba Fleisch prinzipiell durch Rösten auf dem boucan (Grillrost) konservierten. Diese Stelle zeigt deutlich, dass die Darstellungen der Karten zur Verbreitung eines Allgemeinwissens beitrugen, gegen das ein Verfasser von Reiseberichten anschreiben musste, wenn er es revidieren wollte.

${ }^{11}$ Vgl. die Abbildung in Portugaliae Monumenta Cartographica, 1987, I, Nr. 22, Text 55f. 
Im Jahre 1550 ist ein Fest mit verkleideten Seeleuten und echten brasilianischen Ureinwohnern Teil des triumphalen Einzugs von König Henri II in Rouen. Massa hat dieser Entrée einen fundierten Aufsatz (1975) gewidmet. Eine zeitgenössische Beschreibung dieses Festes mit einem Holzschnitt, der brasilianische Ureinwohner darstellt, ist erhalten (Tafel 2) ${ }^{12}$.

Die feierlichen Einzüge eines Königs in Städte seines Reichs und die daran anschließenden Festivitäten bilden einen festen Bestandteil der Inszenierung des königlichen Selbstverständnisses im 16. Jahrhundert und werden im Zeitalter des Absolutismus noch einmal eine Steigerung an Prunk und Pomp erfahren. Rouen war zur damaligen Zeit der Einwohnerzahl nach immerhin die zweitgrößte Stadt in Frankreich und konnte sich als wichtigster Hafen neben Bordeaux auch eine entsprechend teure und exzeptionelle Inszenierung dieser Entrée leisten. An dem Fest nahmen ca. fünfzig aus Brasilien stammende Ureinwohner teil, die durch die Handelskontakte Frankreichs mit Brasilien nach Rouen gekommen waren. Einige normannische Seeleute traten nackt in Indianerbemalung auf, um die geplanten Massenszenen eindrucksvoller zu gestalten.

Diese Entrée ist vermutlich einer der Anlässe zu dem berühmten Essai “Des cannibales" von Montaigne (Essais, livre I, 31). Der französische Autor spricht zwar von einem ebenfalls belegten Aufenthalt zu einer späteren Zeit unter der Herrschaft von Karl IX., also um 1562, dennoch mag die Erinnerung an die damals zwölf Jahre zurückliegende Entrée durchaus die Situierung dieser Begegnung in Rouen mitbedingt haben. Montaigne schildert in dieser kurzen Episode, wie er sich bei einem Aufenthalt in Rouen mit Hilfe eines Übersetzers mit einigen Indianern unterhielt, die schonungslos die europäischen Machtstrukturen (Herrschaft eines Kindes über Erwachsene) und die Unterschiede zwischen Arm und Reich kritisierten. Auch wenn der französische Autor die Festivitäten im Zusammenhang mit der Entrée nicht selbst erlebt hat und die Indianer hier nur zu Trägern seiner eigenen Sozialkritik macht, bildet doch die Erinnerung an die spektakulären Darbietungen dieses Ereignisses einen der Anlässe für diese berühmte Passage in dem ideengeschichtlich bedeutenden Essai, der die erste prinzipielle, wenn auch nur gedankliche Infragestellung europäischer Überlegenheit über ursprüngliche Kulturen in der damaligen Literatur darstellt.

Für die Untersuchung der Ikonographie sind einige anlässlich der Entrée von 1550 entstandene Illustrationen von Bedeutung, die vermutlich die ersten Abbildungen südamerikanischer Indianer in der französischen Kunst darstellen. Schon vor dem eigentlichen Fest war eine Art Programm über die Abfolge der einzelnen Schaustellungen gedruckt worden. Ein Jahr später erschien dann in Rouen der schon erwähnte Bericht, der in den die Indianer betreffenden Teilen

${ }^{12}$ C'est la deduction du somptueux ordre plaisantz spectacles et magnifiques théâtres dresses [...], Rouen 1551. Ein Nachdruck wurde erstmalig 1850 herausgegeben von Ferdinand Denis: Une fête brésilienne célébrée à Rouen en 1550. Margaret Mac Gowan hat den Text 1974 faksimile erneut ediert. Eine Abbildung des Holzschnitts findet sich u. a. bei Duviols 1985, 162. 
1850 von dem Brasilienforscher Ferdinand Denis wiederaufgelegt und kommentiert wurde. Ferner ist eine handschriftliche Beschreibung in der Bibliothek von Rouen erhalten und eine Miniatur, die diesen Einzug zeigt ${ }^{13}$. Der Kunsthistoriker Ambroise Firmin-Didot $(1870,408)$ hat diese Miniaturen Jean Cousin zugeordnet und vermutet, dass dieser Künstler auch an den Illustrationen des 1551 gedruckten Berichts beteiligt war. Laut Firmin-Didot (409) gilt dies auch für den Holzschnitt mit brasilianischen Ureinwohnern, der trotz des groben Schnitts und der Vielzahl der Kleinszenen an die Kunstfertigkeit Jean Cousins erinnert. Diese Zuordnung, die leider in der Forschungsliteratur zum Thema, zum Beispiel in der Einleitung von Margaret Mac Gowan (1974) zum Faksimilenachdruck der Festbeschreibung, nicht weiter verfolgt wurde, ermöglicht es uns, auch hypothetisch eine interessante Filiation von diesen ersten Buchillustrationen südamerikanischer Indianer zu den Illustrationen in Thevets Singularités anzunehmen, die der Cousin-Schule zugesprochen werden können. Wenn der besagte Holzschnitt des Buchs von 1551 aus der Schule Cousins stammt, so war mit Sicherheit in Fachkreisen bekannt, dass er oder seine Werkstatt erstmalig mit der damals völlig neuartigen Aufgabe betraut worden waren, Indianer abzubilden. Man kann davon ausgehen, dass dementsprechend auch Thevet und sein Drucker La Porte hierüber informiert waren, und so ist es nicht verwunderlich, dass sie sich 1557 bei der Suche nach einem Illustrator mit entsprechenden Fähigkeiten für die Singularités an Cousin wandten, der nicht nur ein bedeutender Künstler war, sondern auch als einziger schon Beweise seines Könnens in diesem Themenbereich geliefert hatte.

Denis hat auch erstmalig den Holzschnitt der Entrée mit den brasilianischen Ureinwohnern abbilden lassen, der von großer Bedeutung ist. Aus den erhaltenen Dokumenten wissen wir, dass nach dem feierlichen Einzug des Königs zuerst das indianische Leben in einer nachgebauten brasilianischen Kulisse zur Schau gestellt wurde, sodann ein Kampf zwischen Indianern und ihren Feinden aus einem anderen Stamm und schließlich eine Seeschlacht zwischen einem französischen und einem portugiesischen Schiff inszeniert wurde. Die ideologische Komponente ist klar ersichtlich. Die Indianer, die den Franzosen bereitwillig im Tausch gegen Eisenprodukte das zum Färben benötigte Brasilholz liefern, sind diesen wohlgesonnen und kämpfen mit ihnen gemeinsam gegen den kolonialen Gegner, die Portugiesen. Das Ziel der Darbietung ist es, beim Zuschauer die vollständige Illusion des indianischen Lebens zu erreichen: die echten oder falschen Indianer liegen in Hängematten, rudern in Einbäumen oder tanzen auf den Dorfplätzen. Sie tragen das schwere Brasilholz, das sie gegen französische Äxte und Messer eintauschen, zum Flussufer. Auch die Szenerie legt Wert auf Authentizität: auf den Bäumen sitzen Papageien, die indianischen Langhäuser sind originalgetreu nachgebaut und wie in Brasilien üblich durch einen Palisa-

${ }^{13}$ Für genaue bibliographische Angaben zu diesen Dokumenten vgl. Massa 1975, $105 f$. 
denzaun geschützt. Nach der Darbietung der indianischen Kämpfe geht das Dorf der Feinde wie bei einem echten Überfall in Flammen auf.

Der Holzschnitt ähnelt sehr stark den Indianerdarstellungen auf den damaligen Karten, die hier sicher Vorbild waren. Er ist also kunsthistorisch eine Art Übergangsglied zwischen den Kartenillustrationen und der eigentlichen Buchillustration von Texten und damit für die Reiseberichte vorbildhaft. Im Gegensatz zu den Karten hat die Landschaft auf diesem Holzschnitt aber eine gewisse Tiefe. Links ist wie auf den Karten ein Ufer abgebildet, auf dem die Kanus fahren. Einige Indianer tragen die Brasilholzstämme zur Küste. Den Mittelpunkt des Bildes nimmt die zentrale Kampfszene ein, in der Indianer mit Wurfspießen und Pfeilen aufeinanderstoßen, sicherlich ein Verweis auf die Kampfszenen während der Festivitäten. Im Vordergrund des Holzschnitts sind zu beiden Seiten die ethnologisch zutreffend gezeichneten Langhäuser mit Palisadenzäunen zu sehen. Die Mitte wird zusätzlich von einigen hohen Bäumen und Einzelszenen eingenommen, in denen Indianer in Hängematten liegen, auf Bäume klettern oder mit Pfeil und Bogen nach Vögeln schießen. Im Hintergrund deuten schließlich zwei ebenfalls symmetrisch gebaute brennende Dörfer wiederum auf die Kampfszenen hin, die Teil der Darbietung waren. Beachtenswert ist außerdem die Tanzszene im linken mittleren Bildteil. Die Lebensfreude und der Müßiggang der Indianer wurden in der Folgezeit ein beliebtes Motiv der Reiseberichte, das noch zu Anfang des 17. Jahrhunderts auf Stichen dargestellt wurde ${ }^{14}$. Hier handelt es sich aber um einen etwas ungeschickt gezeichneten Tanz um einen Baum, bei dem die Teilnehmer sich an den Händen halten. Das üppige Blattwerk des Holzschnitts soll wohl den Urwald darstellen, der hier ebenfalls in Form einer Baumkulisse nachgebaut wurde.

Die ethnologischen Details lassen erkennen, dass die Darbietungen für die damalige Zeit einen hohen Grad an Authentizität hatten, was angesichts der zahlreichen indianischen Teilnehmer nicht weiter verwundern mag.

Es stellt sich die Frage, weshalb eine Stadt wie Rouen für eine so wichtige Gelegenheit wie den Besuch des Königs ausgerechnet das indianische Leben als Thema wählte, auch wenn die Darbietung nur ein Teil von größeren Festlichkeiten war. Die naheliegende Antwort ist, dass Rouen als wichtiger Seehafen und Zentrum der Normandie einen Großteil seines Reichtums aus dem einträglichen Handel mit Brasilholz bezog, das vor der Entdeckung künstlicher Farbstoffe durch die moderne Chemie eines der wichtigsten Mittel zum Färben war. Auch andere Produkte der Kolonien waren begehrte Luxusobjekte, für die

${ }^{14}$ Auf einem Stich von Du Viert aus dem Jahre 1614 werden tanzende Indianer, die anlässlich eines Kolonialisierungsversuchs in Maragnan (heute São Luis in Nordbrasilien) 1614 nach Frankreich kamen, abgebildet. Der Stich wurde einzeln verkauft und auch einer Ausgabe des nicht in den Handel gelangten Buchs des Kapuzinermissionars Yves $<$ d'Evreux $>$ Suitte de l'Histoire, Paris 1615 (heute in der New York Public Library) beigebunden. Vgl. die Analyse in Obermeier 1995, 96. 
Unsummen bezahlt wurden. Im Selbstverständnis der Bürger von Rouen muss diesem kolonialen Handel eine so große Bedeutung zugekommen sein, dass dieses Thema auch dem König auf unterhaltsame Weise dargeboten werden sollte. Zugleich handelt es sich vor allem bei der anschließenden Seeschlacht, die unzweifelhaft auf quellenmäßig belegte koloniale Konflikte mit den Portugiesen anspielte, um einen diskreten Wink, die bis dahin nur zögerlich verfolgten kolonialen Interessen Frankreichs stärker als bisher zu fördern.

\section{Die deutsche Tradition}

Die aus dem deutschsprachigen Raum stammenden Abbildungen von Indianern können sich mit der französischen Tradition der Qualität und Menge nach durchaus messen. Die vermutlich erste überhaupt erhaltene Darstellung südamerikanischer Ureinwohner stammt aus einer deutschen Offizin ${ }^{15}$ (Tafel 3). Dieser um 1505 entstandene Holzschnitt, vielleicht bei Froschauer in Augsburg gedruckt, zeigt wohl brasilianische Küstenbewohner (also wahrscheinlich auch Tupinamba) und illustriert die Schilderungen des 1504 erstmals auf deutsch erschienenen Vespuccibriefs, der von kannibalistischen Praktiken bei den Indianern berichtet. Eine Legende am unteren Rand des Holzschnitts bringt in nuce die Informationen, die sich auch bei Vespucci finden. Ein Exemplar des Holzschnitts ist in der Bayerischen Staatsbibliothek (Signatur: Einblatt, V, 2) erhalten, ein anderes in der New York Public Library ${ }^{16}$ mit geringen Textabweichungen in der Legende, die auf einen Nachdruck hindeuten ${ }^{17}$. Der Holzschnitt zeigt auf der rechten Seite vor einer Meereskulisse mit europäischen Schiffen drei Männer mit Pfeil und Bogen und einem mannshohen Speer. Sie tragen Lippenpflöcke und Steine als Brustschmuck. Alle Figuren sind mit einem Federschmuck um Kopf, Hals, Lenden und Knöchel bedeckt. An einem Ast hängt der zerstückelte Leichnam eines europäischen Seemanns über einem Feuer zum Trocknen, eine direkte Anspielung auf die Schilderungen bei Vespucci, der davon sprach, dass die Indianer das Fleisch der Getöteten in den Rost hängen. Links sieht man eine Laube angedeutet, in der sich einige Frauen mit Kindern aufhalten. Eine Frau beißt gierig in einen abgehackten Arm des getöteten Seemanns. Eine andere küsst einen Mann, der neben ihr steht und scheint gleichzeitig einen abgetrennten Fuß zu ergreifen, der auf einer Art Tischplatte liegt. Die erotische Szene ist sicherlich eine Anspielung auf die auch bei Vespucci erwähnte sexuelle Freizügigkeit unter den Indianern. Links von dieser Gruppe steht eine in Rückenansicht abgebildete Frau mit einem Federschmuck um die

${ }^{15} \mathrm{Vgl}$. Sturtevant 1976, nach 424; vgl. auch die Analyse in Alegría 1968, $65 \mathrm{ff}$.

${ }^{16} \mathrm{Vgl}$. zu dem Exemplar in der New York Public Library Eames $(1922,758)$ und Schuller 1930. Eames widerlegt die falsche Angabe bei Harrisse (1958-60, No. 20, Jahr 1497), nach der sich ein weiteres Exemplar des Einblattdrucks im British Museum befinden soll.

${ }^{17}$ Vgl. hierzu Leidinger 1925, 179, Abb. des Holzschnitts im unpag. Anhang des Aufsatzes. 
Hüften, der dem später bei Staden, Thevet und Léry beschriebenen enduape ähnelt. Daneben sitzt eine Mutter, die ein Baby stillt und sich gleichzeitig zwei Kindern zuwendet, von denen eines einen Vogel in der Hand hält. Die Frauen tragen denselben Federschmuck wie die Männer. Die Verweise auf den Kannibalismus bilden das Zentrum des Holzschnitts. Die drei Männer wenden sich gleichsam von den Frauen ab, nachdem sie ihnen den getöteten und zerstückelten Europäer zur Zubereitung und zum Verzehr gebracht haben, und scheinen sich von neuem auf die Jagd zu begeben. Neben einigen ethnologisch korrekten Details wie den Wangensteinen oder Teilen des Federschmucks, der möglicherweise die Nacktheit der bildfüllenden Figuren vermeiden soll, finden sich auch einige Unkorrektheiten, so z. B. die Bärte der Männer. Der Holzschnitt ist als erstes Beispiel einer ikonographischen Tradition der Kannibalismusdarstellungen bedeutend. Die Frauen, die in abgetrennte Körperextremitäten beißen, finden sich auch bei Staden (dort schwingen sie abgetrennte Beine in der Luft) und noch bei Bry. Es handelt sich um einen der wenigen Belege für die Orientierung Stadens an der Tradition deutscher Indianerabbildungen.

Dieser Holzschnitt bleibt aber ein Einzelfall, auch wenn dies vielleicht an mangelnder Überlieferung des spärlichen und für die Zeitgenossen oft ephemeren Materials liegt. In Wolfenbüttel ist noch ein Flugblatt erhalten mit der Überschrift "Das sind die new gefunden menschen [...]", das ebenfalls um $1505 / 6$ vermutlich von einem Nürnberger ${ }^{18}$ oder Leipziger ${ }^{19}$ Drucker angefertigt worden ist und bärtige Männer zeigt, die wie die Gestalten auf dem Münchner Flugblatt Federröcke tragen. Die Gestalten sind wie in dem Columbusbrief $L a$ Lettera dell'Isole (Dati, 1493) vor eine Meereskulisse mit Schiffen projiziert ${ }^{20}$. Die ethnologisch nicht authentischen Bärte der Männer verweisen wie im Fall des oben beschriebenen Augsburger Holzschnitts auf das im Zeitkontext dominante Konzept des "Wilden Mannes", das aus der mittelalterlichen Vorstellungswelt stammt und problemlos auf die Bewohner der Neuen Welt übertragen wurde. Der ausführliche Text unter dem Holzschnitt erinnert an die Berichte von Vespuccis Mundus Novus, vermutlich vermittelt durch die Ausgabe Augsburg, 1505.

In diesem Kontext ist auch ein Holzschnitt aus Lorenz Fries' Begleitschrift Uslegung der mercarthen (Straßburg, Johann Grüninger, 1525; weitere Auflagen 1527 und 1530) zu seiner deutschen Fassung der 1516 von Waldseemüller erstellten Karte erwähnenswert, der beim Bericht über die Insel-Kariben hundsköpfige Kannibalen beim Zerteilen einer Leiche zeigt (Abb. Frübis 1995, 53 u.

${ }^{18}$ Vgl. auch die Beschreibung und Abbildung des Flugblatts im Katalog der Wolfenbütteler Flugschriften (Harms, 1989, III, 470f).

${ }^{19}$ Falk 1987, 40 wohl nach der älteren mit Fragezeichen versehenen Zuordnung in Die Neue Welt in den Schätzen einer alten Bibliothek, 1976, 44.

${ }^{20} \mathrm{Vgl}$. die Abbildungen bei Falk 1987, 42 (Columbus-Brief, Florenz 1493) und das Flugblatt ebd., 43. 
Menninger 1995, 145). Wieder stehen zwei Gestalten am Schlachttisch, eine davon mit erhobenem Beil, was auf die Tradierung des Topos der VespucciAusgabe (Straßburg 1509) hindeutet, die ihrerseits ältere Kannibalismusdarstellungen aufgreift. Ein anderer zeitgenössischer Einblattholzschnitt mit ähnlichen Tierallegorien nach dem Entwurf des Nürnberger Künstlers Georg Pencz mit Texten von Hans Sachs (entstanden um 1550) zeigt, wie die Hasen die Hunde zerhacken und den Jäger über dem Spieß grillen (Abb. bei Menninger 1995, 147).

Bei den Buchillustrationen sind diejenigen zu Diß Büchlin saget, einer deutschen Bearbeitung der Quatuor Navigationes von Vespucci (erschienen bei Grüninger, Straßburg 1509), charakteristisch für die Zeit ${ }^{21}$. Das Titelblatt zeigt, wie der Reisende vom spanischen Königspaar Abschied nimmt. Dem Text selbst sind drei Holzschnitte beigegeben. Der erste stellt die Landung der Europäer bei den Indianern dar (Blatt D IIII). Der zweite (Blatt Bv, Tafel 4) zeigt als Sittenschilderung im Hintergrund die Zerteilung eines menschlichen Körpers auf einem Schlachttisch und im Vordergrund eine indianische Familie und daneben einen Wasser lassenden Indianer. Trotz des harmonischen Paars im Vordergrund machen die Anthropophagieszene und die Darstellung einer öffentlichen Verrichtung natürlicher Bedürfnisse aus dem Holzschnitt die Allegorie einer "verkehrten Welt" im Vergleich zu europäischen Normen (vgl. Kohl 1985, 324). Die Darstellung des indianischen Paars greift die Tradition des "Wilden Mannes und der Wilden Frau" auf (ebd., 318). Schon gegen Ende des 15. Jahrhunderts hatte sich in Nachfolge der Darstellungen des "Wilden Mannes" der bildliche Topos der "Wilden Familie" herausgebildet, der im 16. Jahrhundert auch unabhängig vom Kontext der Reiseberichte fortlebt (vgl. Frübis 1995, 27). Kohl (1985, vgl. Abb. S. 319) verweist auf einen Holzschnitt von Hans Leonhard Schäufelein. Auch Frübis führt diese Abbildung auf. Sie dient zur Illustration der "Klag der wilden Holtzleüt vber die vngetrewen Welt" von Hans Sachs, 1545, und wurde im gleichen Jahr von Hans Guldenmundt in Nürnberg gedruckt (vgl. Frübis 1995, Abb. S. 49, Text 26ff).

In der frühen Neuzeit gewinnt die Gestalt des "Wilden Mannes" durchaus ambivalente Züge. So wird sie in dem Text von Hans Sachs, den die Abbildung bildlich umsetzt, zum Wortführer einer Kritik an der korrupten Zivilisation. Im Mittelalter war die auf Wandteppichen und Schmuckkästchen oft dargestellte Figur Teil des Themas der "vier Gesellschaftszustände" des Armen, des Reichen, des Handwerkers und des "Wilden Mannes" und zeichnete sich durch unzivilisierte Verhaltensweisen vor dem Normkontext der Zeit aus, wozu z. B. zügellose Sexualität gehörte. Von da an war der Schritt bis zum Kannibalismus als scheinbarer Steigerung menschlicher Triebhaftigkeit nicht mehr weit. Da auch Vespucci in den Beschreibungen seiner Briefe die südamerikanischen

${ }^{21}$ Ein Faksimile-Nachdruck erschien unter dem Titel The first four voyages, Providence, 1930. 
Indianer analog zum tradierten Bild des "Wilden Mannes" beschreibt, lag eine ikonographische Angleichung an eine schon bestehende Tradition nahe. Die sexuellen Gesten der Frauen auf dem Titelblatt der Rostocker Vespucci-Ausgabe von 1504/05 (Epistola Albericii, De novo mundo) oder auf den frühen Kannibalismusdarstellungen wie in Grüningers Vespucci-Ausgabe von 1509 drücken diese Triebhaftigkeit der Wilden aus, was auch die heute etwas schwer nachvollziehbare Rekurrenz des Motivs ungezügelter Sexualität im Kontext der Kannbalismusdarstellungen bis hin zu den Brys erklärt.

Es gibt aber auch harmonisch wirkende Darstellungen der "Wilden Familie". Ein von Frübis $(1995,51)$ abgebildeter Kupferstich eines "Meisters bxg", entstanden zwischen 1470-1490, der sich heute in der Albertina in Wien befindet, zeigt ein behaartes Paar mit zwei Kindern vor einer Landschaftskulisse sitzend. Natürlich denkt man hier gleich an den oben behandelten 1505 vermutlich von Froschauer gedruckten Münchner Holzschnitt, der links eine sitzende Frau zeigt, die ebenfalls ihr Kind in den Armen hält und daneben Männer, die sich von der Gruppe der Frauen entfernen. Die Harmonie der Szene wird nur durch die Kannibalismusdarstellung des Hintergrunds zunichte gemacht. Der Münchner Holzschnitt ist damit ein guter Beleg für die frühe Übertragung von ikonographischen Gestaltungen der "Wilden Familie" auf die Bewohner der Neuen Welt. Der zeitgenössische Leser kannte diese Darstellungstradition und war in der Lage, die moralische Wertung des Holzschnitts in seinem allegorischen Gehalt und Traditionsbezug mühelos zu entziffern.

Der dritte Holzschnitt in Grüningers Vespucci-Ausgabe zeigt schließlich nach einer Schilderung des Texts, wie eine Indianerin hinterrücks einen an Land gegangenen Seemann erschlägt (Blatt E IIIv). Die Frauengestalt ähnelt dabei sehr stark den zeitgenössischen Darstellungen der Hexe (Kohl 1985, 321ff). Sie verweist zugleich auf die "aus theologischer Sicht in der Frau als Geschlechtswesen implizit angelegte Gefahr” (vgl. Frübis 1995, 115). Bei der Mörderin handelt es sich zudem um eine alte Frau, was später bei den AnthropophagieSchilderungen Lérys in der Betonung der Gier der alten Frauen nach Menschenfleisch aufgegriffen wird und auch in einigen Illustrationen Brys einen Nachklang findet.

Besonders der zweite Holzschnitt mit der Thematisierung der Anthropophagie ist in unserem Kontext von Bedeutung. Der Vordergrund wird von einer Familienszene eingenommen, die an eine Szene auf dem Münchner Holzschnitt von 1505 erinnert. Im Hintergrund des Holzschnitts ist ein Mann dargestellt, der auf einer tischartigen Unterlage mit einem Beil Leichenteile zerhackt. Dabei sieht ihm eine Frau zu, die ihre Brüste streichelt ${ }^{22}$. Das Motiv des Zerhackens hat eine Parallele im Repertoire der Heiligenlegenden (vgl. Kügelgen 1996, 202

${ }^{22}$ Vgl. die Abbildung in Kügelgen 1996, 201. Das autoerotische Motiv taucht hier erstmals in Verbindung mit dem Kannibalismus auf; zur Analyse dieses Motivs bei den Brys s. unten
$95 \mathrm{f}$. 
und zugehörige Abbildungen). Es findet sich aber auch in frühen Reiseberichten. Auf einem Holzschnitt in einer Mandeville-Ausgabe von $1484^{23}$ schwingt ebenfalls ein Mann ein Beil über einem Schlachttisch. Neben ihm steht eine Frau, die einen Arm in die Höhe reckt und links davon eine weitere Gestalt als Zuschauer oder Helfer. Vögel tragen die Leichenteile fort (vgl. Frübis 1995, 83, Abb. 33). In der Gestalt von Mann und Frau um eine Schlachtbank ist bereits die Konstruktion der Vespucci-Illustration von 1509 vorweggenommen. Es stand also schon eine bildliche Tradition zur Verfügung, die von den Künstlern nur auf den neuentdeckten Kontinent übertragen werden musste.

Einen der zahlreichen Nachklänge dieses Motivs, das Anthropophagie mit europäischen Schlachtsitten gleichsetzt, sehen wir z. B. auf der Randleiste der von Hans Holbein illustrierten Weltkarte von Sebastian Münster in dem von Simon Grynaeus herausgegebenen Novus Orbis, Basel 1532. Auf dieser Randleiste findet sich auch wieder die seit den frühesten Illustrationen über die Neue Welt tradierte Darstellung von aufgehängten Leichenteilen und einem am Spieß gebratenen Bein ${ }^{24}$. Die bekanntesten Versionen des "Zerhackens" und "Am Spieß Grillens" sind in den zahlreichen Ausgaben von Münsters Cosmographia ab 1544 enthalten. Diese räumlich nicht lokalisierten und damit austauschbaren Abbildungen, die sich im ohnehin sehr knappen Amerikateil und auch im Asienund Afrikateil von Münsters Buch finden, stellen einen nackten Mann dar, der auf einer Schlachtbank Leichenteile zerhackt, wobei ihm eine Frau diesmal aktiv zur Hand geht. Eine andere Abbildung bei Münster zeigt, wie eine Leiche ohne Kopf mit angewinkelten Beinen am Spieß gebraten wird ${ }^{25}$. Léry wird dann gegen diese letztere Darstellungsform, die er von den Karten - vielleicht von der oben erwähnten, von Grynaeus herausgegebenen Weltkarte - kannte, polemisieren (Histoire, 1975 [21580], 219). Auch auf Brasilienkarten portugiesischer Provenienz sind derartige Abbildungen einer am Spieß gegrillten Leiche ${ }^{26}$ zu sehen. Die Filiation dieser Motive dokumentiert, dass sich schon bei den frühen Anthropophagie-Darstellungen eine Tradition herausbildete, die über einen längeren Zeitraum wieder aufgegriffen wurde und ein eindeutiges moralisches Werturteil über die Menschenfresserei enthielt. Diese Abbildungen fanden vor allem durch Münsters zahlreiche Neuauflagen der Cosmographie eine weite Verbreitung und bestimmten damit die Vorstellung vom Indianer.

${ }^{23}$ Johannes von Mon/tuilla Ritter. Das erste Büch/DO ich Johan von Monteuilla Ritter Geborn vsz Engeland von einer stat genant Sant alban [...] - ich obgenanter Otto von Demeringen Thümherre von latyn vnnd/ frantzoyscher sprach zů tútsch gebracht han. Straßburg: Johannes Prüß.

${ }^{24}$ Vgl. Kügelgen 1996, 203, abgebildet in Quetsch 1983, II, Abb. 156.

${ }^{25}$ In der erweiterten lateinischen Ausgabe Münster Cosmographia, 1550, MCXLVII (am Spieß Grillen) und MCLXXIX (Zerhacken einer menschlichen Leiche).

${ }^{26}$ Vgl. z. B. eine Karte von Diego Homem im Atlas von ca. 1565, veröffentlicht in Portugaliae Monumenta Cartographica, 1987, II, 57ff, Abb. 176. 
Daneben gibt es auch eine andere Tradition von Abbildungen, in denen der exotisch pittoreske Aspekt in der Zeichnung von typischen Vertretern der Indianer in den Vordergrund tritt und auf die Darstellung der Anthropophagie verzichtet wird. Diese Abbildungen finden sich in der ersten Hälfte des 16. Jahrhunderts allerdings nicht im Kontext der Illustration von Reiseberichten, die wohl nicht auf eine sensationelle Darstellung der Anthropophagie verzichten wollten, sondern bei namhaften Künstlern als Schmuck von handgeschriebenen Büchern oder exquisiten Holzschnitten, die anfangs nur einem kleinen Publikum zugänglich waren, sowie in einzelnen nachfolgend noch zu behandelnden Trachtenbüchern.

Es gab im 16. Jahrhundert vor John White und Jacques Le Moyne de Morgues nur wenige bedeutende Künstler, die in qualitätsvollen, aber im Rahmen ihres Gesamtwerks eher peripheren Werken Abbildungen der Indianer Südamerikas lieferten. Hier sind Albrecht Dürer und Hans Burgkmair zu nennen. Von Dürer gibt es eine Zeichnung eines Tupinamba-Indianers in einem gedruckten, handillustrierten Stundenbuch Maximilians I., die ca. 1515 entstand $^{27}$. Die Abbildung verweist im religiösen Kontext des Stundenbuchs auf die Erschaffung der gesamten Welt, also auch Amerikas, und auf das politische Programm der Habsburger, den neuentdeckten Völkern die christliche Religion zu bringen (vgl. Frübis 1995, 116ff). Burgkmair hat in dem bekannten Triumphzug Kaiser Maximilians bei den Leuten aus Kalikut (Indien) einige durch ihre Attribute als Indianer identifizierbare Gestalten auftreten lassen (vgl. Sturtevant 1976, Abb. S. 423). Diese Gestalten verweisen symbolisch auf das von den spanischen Habsburgern beherrschte Weltreich. Die Vorlagen für die erstmals 1526 gedruckte Holzschnittversion dieses Triumphzugs wurden von Albrecht Altdorfer um 1512-1516 gefertigt und sind heute in der Albertina in Wien (vgl. Frübis 1995, 118 und 140, Fußnote 114). Burgkmair wird auch eine lavierte Federzeichnung zugeschrieben, die einen Indianer mit Federrock nach Art der Tupinamba-Darstellungen und mit einem mexikanischen Schwert zeigt (abgebildet bei Honour 1982, 27). Vermutlich handelt es sich bei diesen Werken um nicht nach dem Leben gezeichnete Abbildungen.

Erhalten sind ferner die 1529 von Christoph Weiditz (ca. 1500-1559) gemalten idealtypischen Bilder von Azteken am Hofe Karls V., Aquarelle, die in einer Handschrift von Weiditz' Reisen nach Spanien (1529) und in die Niederlande $(1531 / 32)$ überliefert $\operatorname{sind}^{28}$. Der aus Straßburg stammende Porträt-Medailleur, der übrigens auch ein Porträt-Medaillon von Cortés geschaffen hat,

${ }^{27}$ Das Original ist heute in der Bayrischen Staatsbibliothek; vgl. die Abbildung in Sturtevant 1976, 422.

${ }^{28}$ Das Trachtenbuch des Christoph Weiditz, von seinen Reisen nach Spanien (1529) und den Niederlanden (1531/32), nach der in der Bibliothek des Germanischen Nationalmuseums zu Nürnberg aufbewahrten Handschrift. Hg. v. Theodor Hampe. Berlin: Christoph de Gruyter, 1927. 
kam 1529 an den Hof von Karl V. in Toledo und zeichnete dort einige von Cortés nach Spanien gebrachte aztekische Aristokraten und eine Gruppe von Gauklern aus Tlaxcala ${ }^{29}$. Die Aquarelle waren zwar Einzelstücke, blieben aber dennoch einem größeren Publikum nicht unbekannt. Reflexe dieser Aquarelle finden sich z. B. bei den noch zu behandelnden Holzschnitten von Jost Amman für Weigels Trachtenbuch (1969 [1577]), was darauf hindeutet, dass zumindest Kopien dieser Originale zirkulierten. Auch Bry hat die Darstellung der aztekischen Geschicklichkeitsspiele als Motiv auf einem Stich im sechsten Band seiner Reisebeschreibung von 1596 kopiert $^{30}$. Weiditz (1927) hat diese Zeichnungen vermutlich für ein Kostümbuch gefertigt, das als erstes Werk die Tradition der später auch gedruckten und im 16. Jahrhundert ungemein beliebten Trachtenbücher begründete, in denen jeweils Frauen und Männer verschiedener Völker und Kulturen mit der typischen Landestracht abgebildet wurden. Bei der Besprechung von Lérys Bildmaterial wird sich zeigen, dass auch dessen Illustratoren sich an der Darstellungsform der Trachtenbücher orientiert haben (vgl. unten 47ff).

Angesichts der relativ großen Anzahl von im 16. Jahrhundert nach Europa gelangten südamerikanischen Indianern hat das Fehlen von porträtgetreuen nach dem Leben gezeichneten Illustrationen Verwunderung erregt (vgl. Falk 1987, 55). Vielleicht ist hierin ein Indiz dafür zu sehen, dass die Europäer diese Indianer nicht als Individuen, sondern als amorphe Masse und idealtypische Vertreter eines fremden Volks wahrnahmen, bei deren Abbildung es nicht auf Wahrheitstreue ankam, sondern wo einige Attribute der fremden Kultur und typische Kleidungsstücke wie in den Trachtenbüchern und den erwähnten Skizzen von Weiditz genügten. Illustrationen von namentlich bekannten Individuen indianischer Herkunft finden sich neben den winzigen Darstellungen von Indianerhäuptlingen bei Staden erstmals in der noch zu besprechenden Porträtsammlung von Thevet (1584), die drei nach der Phantasie gezeichnete Abbildungen von Indianerführern enthält. Zum ersten Mal nach dem Leben gezeichnete und auf Porträtähnlichkeit achtende Abbildungen zeigen die 1614 nach Frankreich gebrachten und dort getauften sechs Indianer aus Nordbrasilien (Maranhão) im Reisebericht des Missionars Claude < d'Abbeville > Histoire de la mission des peres capucins en l'isle de Maragnan von 1614. Die Stiche stammen vermutlich von dem in Paris tätigen Flamen Du Viert, der die anderen Illustrationen in dem Buch von Claude < d'Abbeville > signiert hat. Drei der damals auf dem Totenbett notgetauften Indianer sind unter Bezug auf die seit Thevet und den Brys eingebürgerte Bildtradition fast unbekleidet und mit Attributen ihrer ursprünglichen Stammeskultur gezeichnet. Die drei in Paris feierlich getauften Indianer tragen

${ }^{29} \mathrm{Vgl}$. die Abbildungen in Sturtevant 1976, 426. Originale im Germanischen Nationalmuseum Nürnberg (cod. $224744^{\circ}$ ).

${ }^{30}$ Die Indianer-Gaukler sind auch Teil der Randleiste des Stadtplans von Cuzco in Brys 6. Buch, 1596 (America, 1990, zwischen 228 und 229; abgebildet auch in Kügelgen 1996, 211). 
dagegen europäische Kleidung und als Symbol der Unschuld die Tauflilien in ihren Händen. Hier ist also der symbolische Gehalt der Darstellung in der Progression vom nackten unzivilisierten Wilden zum getauften, nach europäischer Sitte bekleideten Indianer zu sehen ${ }^{31}$.

Der quantitativ geringe, aber qualitativ bedeutende Beitrag deutscher Illustratoren zum Korpus der Indianerdarstellungen zeigt umso deutlicher den einzigartigen Stellenwert von Stadens Werk im 16. Jahrhundert. Erst mit ihm setzt ein richtungsweisender deutscher Beitrag zur Visualisierung der Neuen Welt ein, dem im Werk der Brys ein langandauerndes Nachleben gesichert sein sollte. Selbst das Bildmaterial der damals auf portugiesisch veröffentlichten Bücher über Brasilien ist relativ gering. Die meisten der Texte über Brasilien wurden erst im 19. Jahrhundert gedruckt, sogar ein Buch von so zentraler Bedeutung wie Pero Magalhães de Gândavos Historia da Provincia Sancta Cruz, Lissabon 1576 enthält nur wenige eher zufällig angebrachte Illustrationen. Die Abbildung B1. 32v zeigt die Tötung eines 1564 in São Vicente angespülten "Meerwunders", eine typische Monsterdarstellung in der Art der noch bei Thevet übernommenen Bilder von Fabeltieren ${ }^{32}$. Ein weiterer Holzschnitt illustriert die Tötung des mit Stricken gefesselten Gefangenen nach dem Ritual der brasilianischen Indianer ${ }^{33}$. Der Holzschnitt hat Vignettengröße und steht vor dem Kapitel 12, das dieses Thema behandelt. Beim Vergleich mit diesem spärlichen Bildmaterial tritt die Bedeutung deutscher und französischer Texte für die Visualisierung der Neuen Welt umso klarer hervor.

${ }^{31}$ Claude < d'Abbeville > , 1614, 347v, 255v, 358v, 361v, 363v, 364v. Vgl. die genaue Analyse in Obermeier 1995, 123-129. Weiteres zeitgenössisches Bildmaterial über diese Kolonialepisode siehe ebd., 96-98.

32 Diese Abbildung wird von einem undatierten deutschen (!) Flugblatt eines Augsburger Druckers kopiert, was zeigt, welches Interesse diese naturkundlichen Monstrositäten fanden, (vgl. die Abbildung in Duviols 1985, 75). Nach Angabe in den European Americana, I, 1980, 110 befinden sich zwei Exemplare dieses Flugblatts in der Stadtbücherei Zürich, heute Zentralbibliothek Zürich.

${ }^{33}$ Sturtevant (1976, 451, Fußnote 41) spricht in diesem Zusammenhang von einer Vorbildfunktion des themengleichen Holzschnitts der Cosmographie. Es liegt hier aber sicher wie bei Thevets und Stadens Abbildungen des Tötungsrituals nur eine analoge Beschreibung und keine Abhängigkeit zugrunde. 


\section{Kap. 2: Das Brasilienkorpus der Reiseberichte von Thevet, Léry und Staden (1557-1585)}

Die Werke der französischen Reiseschriftsteller André Thevet und Jean de Léry haben in der kritischen Literatur nicht zuletzt wegen ihres Einflusses auf Montaigne eine breite Resonanz gefunden ${ }^{34}$.

$\mathrm{Zu}$ den Illustrationen in den Werken von Thevet und Léry liegt bisher keine umfassende Untersuchung vor. Neben dem noch zu würdigenden Aufsatz von Frank Lestringant (1978) über die Illustrationen in Thevets Werken ist noch ein Beitrag von Angela Enders (1993a) in weiten Passagen einschlägig. Enders sieht in den Illustrationen der Reiseberichte zurecht eine Anlehnung an die emblematischen Darstellungsformen von pictura, subscriptio und inscriptio (Bild, Erläuterung unter dem Bild und Textkommentar). Die Illustrationen dienten jedoch nicht der künstlerischen Gestaltung der Wirklichkeit, sondern nur der Unterstützung der inhaltlichen Aussage (ebd., 109). Sie bedienten sich der emblemartigen Struktur ohne jedes spirituelle Interesse (111). Auch die Textkommentare in der Bildunterschrift hätten nur eine interpretierende Erläuterung des bildlich Dargestellten zum Zweck, ohne eine heilsgeschichtliche Ausdeutung zu versuchen. Landschaftsdarstellungen spielten auf den Illustrationen eine untergeordnete Rolle. Auch in der Wahrnehmung der Autoren (besser gesagt der durch die Erzählerinstanz vermittelten Autorenwahrnehmung) werde Natur nur unter dem Nützlichkeitsaspekt gesehen oder, wie bei Léry, als Erinnerung ästhetischen Erlebens bzw. Zeichen der Größe des Schöpfers. Thevet und Léry würden in ihren Abbildungen exotische Details der Flora und Fauna Amerikas bevorzugen, die jedoch hinter den Möglichkeiten der Schilderung des Texts zurückblieben (111). Die exotischen Details auf den Abbildungen sollten, wie auf dem Holzschnitt "Comment usent les sauvages envers leurs malades" (Singularités 1982, 88v; Cosmographie 1953, 146), die Fremdheit der dargestellten Sitten unterstreichen. Die Verwendung europäischer ikonographischer Muster zur Darstellung des Indianers in Form von wohlproportionierten Gestalten der Antike, die im Übrigen den Beschreibungen der Autoren entspreche (Enders 1993a, 123), verhindere eine wirklichkeitsgetreue Wahrnehmung und Darstellung. Die Ikonographie biete damit keine verläßliche Information über die Neue Welt, sondern bilde Stereotype ab, die die fremden Erscheinungen der eigenen Kultur zuordneten.

Enders' Gedanken sind sicher interessant, können aber keine Allgemeingültigkeit für die Reiseillustrationen der Zeit beanspruchen. Die Autorin unter-

${ }^{34}$ Die wichtigsten Arbeiten sind Lestringants Monographie über Thevet (1991), seine Arbeit über die Hugenotten in Amerika (1990) und seine Untersuchung des Kannibalismusmotivs in der Reiseliteratur (1994). Ein Überblick über den Forschungsstand zu beiden Autoren bei Obermeier 1995, 101-111. Zur Rezeption der Autoren durch Montaigne vgl. Enders 1993b und die Kritik dieser Arbeit in Obermeier 1995, 101-103. 
schätzt die eigene Bildsprache der Illustrationen zu ihrer Zeit, die sehr wohl dazu geeignet sind, komplizierte Sachverhalte des Texts auszudrücken, und für den Betrachter oft sogar eine eindeutigere Aussage enthalten können als der Text selbst, was sich vor allem bei einigen Illustrationen Lérys, insbesondere in der Rezeption dieser Abbildungen bei Bry zeigen wird (vgl. die Analyse der Teufelserscheinungen oder der Abbildung indianischer Tänze unten 98ff u. 101ff). Die exotischen Details spielen eine untergeordnete Rolle im Vergleich zu dem im Zeitkontext neuen Charakter eines ikonographischen Zyklus, der trotz der Heterogenität des Materials das herausragendste Merkmal von Thevets Bildmaterial darstellt, was analog auch für Staden gilt. Die fehlenden Landschaftsdarstellungen dürfen angesichts des kunsthistorischen Zeitkontexts nicht weiter verwundern, Enders berücksichtigt hier das Vorbild der Projektion von charakteristischen Szenen in Kartenumrisse zu wenig. Auch die antikisierende Zeichnung der Indianer muss als Bezug auf die einzig verfügbaren künstlerischen Vorbilder für die Darstellung nackter Menschen gesehen werden. Für die Autoren selbst haben diese Schilderungen wohlgestalteter Ureinwohner schließlich den Zweck, den in Reisebeschreibungen tradierten Topos missgestalteter, riesenhafter oder behaarter Indianer zu widerlegen. Schließlich wird sich zeigen, dass auch das Bildmaterial selbst erhebliche theologische Implikationen enthält, besonders in der Rezeption durch die Brys. Zuerst aber sollen nun die Illustrationen in Thevets und Lérys Büchern gewürdigt werden.

\section{Thevet und die Bildfolge}

\section{Die Singularités (1557/58) und die Cosmographie universelle (1575)}

Das Werk des Franziskaners André Thevet bildet einen wesentlichen Beitrag zur französischen Brasilienliteratur im 16. Jahrhundert. Seine Singularités de la France antarctique (1557/58) sind eines der ersten Bücher über Brasilien, das in Europa erschien.

Wenige Jahre vor den Singularités hatte Thevet 1554 und nochmals 1556 bereits seine Cosmographie du Levant in Lyon veröffentlicht, in der er über seine Palästina- und Ägyptenreise berichtete. Auch dieses Buch enthält Illustrationen, von denen zumindest einige auf Bernard Salomon, den Illustrator des Druckers Jean de Tournes zurückgehen. In der zweiten Auflage von 1556 kommen zu den fünfundzwanzig ursprünglichen Holzschnitten noch neun hinzu. Im Vorwort bezieht sich Thevet erstmals auf die didaktische Funktion dieser Abbildungen "il n'y ha savoir plus certain que celui qui nous est acquis par la vuë" (1985, LXIX). Die Holzschnitte zeigen vor allem Curiosa, also unbekannte Tiere und Pflanzen, Pyramiden, den Koloss von Rhodos und Moscheen in Istanbul. Thevet nimmt in seinen späteren Werken keinen dieser Holzschnitte wieder auf, vermutlich weil ihm die Platten nicht mehr zur Verfügung standen, er inspiriert sich aber in den relevanten Illustrationen der Cosmographie von 1575 an diesen frühen Illustrationen, die nun vor einen szenischen Landschafts- und Illu- 
strationshintergrund projiziert werden ${ }^{35}$. Dies entspricht wohl auch der damaligen künstlerischen Weiterentwicklung der Buchillustration, die von einfachen Abbildungen von Objekten, Kuriositäten oder Tieren hin zu ausgefeilteren, sequentiellen oder szenischen Kompositionen ging.

Bei den Singularités sind wir ausnahmsweise in der Lage, auf Informationen außerhalb des eigentlichen Texts zurückgreifen zu können, die auch die Illustrationen betreffen. Der Vertrag zwischen Thevet und dem Drucker Ambroise de la Porte ist nämlich im Minutier Central des Notaires Parisiens (Notariatsarchiv) in den Archives Nationaux erhalten ${ }^{36}$. Er wurde am 18.12.1556 geschlossen, vermutlich lag das Manuskript zu dem Zeitpunkt schon fertig vor. Thevet verdiente zwanzig Écus an dem Buch, zwölf erhielt er nach Einholung der Druckerlaubnis ("privilège", das für 10 Jahre galt), acht nach Abschluss des Druckes und zusätzlich 30 Freiexemplare. Um die Illustrationen kümmerten sich Drucker und Autor gemeinsam. Der Vertrag enthält zusätzlich die für die damalige Zeit außerordentliche Klausel, dass im Falle eines Neudrucks Thevet noch einmal bezahlt werden sollte. Aus diesen Fakten kann man den Rückschluss ziehen, dass Autor und Drucker mit einem großen Erfolg des Buches rechneten. Vermutlich ist dieser Vertrag eine der frühesten erhaltenen urheberrechtlichen Vereinbarungen avant la lettre zwischen einem Drucker und seinem Autor für einen Nachdruck und als solcher auch buchgeschichtlich bedeutend. (Meist wird in diesem Zusammenhang sonst als Erstbeleg Miltons Paradise lost von 1667 zitiert.) Die Illustrationen werden explizit in dem Vertrag erwähnt, was zeigt, dass ihnen von den beiden Vertragsparteien große Bedeutung für das Buch beigemessen wurde. Das Privileg, das in der Erstausgabe nach dem Titelblatt abgedruckt wurde, stammt vom 18.12.1556. Durch den Tod des Druckers Ambroise de La Porte 1557 verzögerte sich der Druck bis Ende 1557/Anfang 1558.

Parallelen bei einigen Vogeldarstellungen finden sich zwischen Thevets Singularités und der Histoire de la nature des oyseaux (1555) von Pierre Belon. Dieser war mit Thevet persönlich bekannt, da er den Franziskaner auf einem Teil seiner Orientreise begleitet hatte (Belon 1997, 17). Diese Gruppe von einfachen naturkundlichen Skizzen bei Thevet ist im Übrigen weit entfernt von der Qualität der übrigen ethnologischen Skizzen der Cousinschule in diesem Werk. In seiner Einleitung zur Neuausgabe von Belons Histoire (1997, XLII) äußert Philippe Glardon die Vermutung, dass Thevet aus Bewunderung für das Werk seines Freundes seinen Reisebericht von derselben Gruppe von Künstlern illustrieren lassen wollte. Dies dürfte zumindest für die ähnlichen Tier- und Pflanzendarstellungen zutreffen. Thevets Illustrationen des Condors (Tupi: $p a$, Singularités 1982, 45r), des Fisches tamouhata (ebd., 48r), des toucan (91r) und

35 Vgl, hierzu Thevet 1985, LXVII-LXXIII.

${ }^{36}$ Der Vertrag ist abgedruckt bei Parent 1974, 307, Bewertung 113f. Das Datum "VCLVII" am Ende der Transkription des Vertrags 307 ist ein Druckfehler für “1556". Vor dem Text und in der Analyse steht das richtige Datum. 
vielleicht eine Landschaftsskizze (28r) ähneln Vorbildern in Belons Werk. Auf jeden Fall wurden Thevets Singularités wie Belons Histoire mit den Typen des Druckers Benoît Prévost gedruckt (vgl. Belon 1997, XLII), der wohl für den verstorbenen La Porte eingesprungen war. Die typographische Abhängigkeit der Texte legt nahe, dass der Drucker, der schon Belons Werk hergestellt hatte, auch die Übernahme einiger Illustrationen des früheren Buchs vermittelt hat, ein zur damaligen Zeit sehr häufiges Verfahren, billig Bücher zu illustrieren.

Thevets Werk stellt einen der ersten zusammenhängenden Zyklen über das Leben fremder Völker dar (vgl. auch Lestringant 1978, 583). In den Singularités findet sich zum ersten Mal die folgenreiche antikisierende Darstellung der "sauvages" in Anlehnung an die dominierende Zeichenkunst der Renaissance, die im Werk der Brys dann eine gemeineuropäische Verbreitung finden sollte.

Das Buch des französischen Kosmographen ist zugleich ein bedeutendes Beispiel für den frühen Einsatz von künstlerisch hochwertigen Illustrationen in einem Reisebericht. Gaffarel hat als erster die These aufgestellt, dass die Holzschnitte der Singularités von Jean Cousin (1490-1561), einem bedeutenden Buchillustrator der Schule von Fontainebleau, stammen könnten (Thevet 1878, XVII). Die Bedeutung von Jean Cousin dem Älteren aus Sens, der u. a. auch als Maler und Bildhauer tätig war, für die französische Buchillustration liegt darin, dass er den Stil der italienischen Zeichenkunst in Frankreich heimisch machte und damit für zahlreiche Künstler, die später nach dem damaligen Sitz des Hofs "Schule von Fontainebleau" genannt wurden, stilbildend wurde ${ }^{37}$. Typisch für seine Figurenzeichnungen sind die langgezogenen Körper in einer angedeuteten Landschaftsperspektive, die uns dann in Thevets Buch begegnen werden. Cousin gab 1560 in Paris sein Livre de perspective heraus, das auch die technischen Errungenschaften italienischer Künstler in der Perspektive vermittelt hat ${ }^{38}$.

In dem schon erwähnten Vertrag zwischen dem Drucker La Porte und Thevet, der erstmals von Parent $(1974,306)$ veröffentlicht wurde, wird ein "maistre Bernard de Poiseulne" als zuständig "pour ce faire tailler figures" für das Buch erwähnt. Baudry $(1983,8)$ hat unter Bezug auf diesen Vertrag diese Zuordnung übernommen und liest den Namen als "Bernard de Poisduluc". Ein Künstler dieses Namens ist selbst unter Berücksichtigung der verschiedenen möglichen Schreibungen in zeitgenössischen Dokumenten nirgendwo bezeugt (ebd.). Auch Lestringant folgt in seiner Ausgabe der Singularités (vgl. Thevet, 1997, 7 u. Fußnote S. 323) dieser Zuordnung und bestreitet generell die ältere an Cousin, ohne jedoch hierfür Beweise zu bringen. Vielleicht handelt es sich bei der Angabe in dem Vertrag um eine bloße Absichtserklärung des Druckers und

${ }^{37}$ Zur Schule von Fontainebleau vgl. das reichhaltig bebilderte Buch von Zerner 1969. Der Beitrag Cousins zur Buchillustration wird dort leider nicht eigens gewürdigt.

${ }^{38}$ Abbildungen aus diesem Buch siehe bei Harthan 1981, 94, 95. Bei den Figuren S. 95 ist der Vergleich mit den künstlerisch hochwertigen Menschendarstellungen in Thevets Singularités besonders deutlich. 
Thevets, diesem Künstler die Illustrationen anzuvertrauen, was später nicht verwirklicht wurde. Jedenfalls ist die Übereinstimmung zumindest der qualitätsvollen Holzschnitte mit dem Stil Cousins zu auffallend, um eine Zuordnung an Cousin oder seine Werkstatt allein durch die Erwähnung eines sonst gänzlich unbekannten Poisduluc im Vertrag in Frage zu stellen. Wahrscheinlicher ist es m. E., dass Bernard de Poisduluc allenfalls der Schneider war, während Cousin und seine Schule die Vorzeichnungen lieferten. Vielleicht hat er auch die einfacheren Holzschnitte gänzlich selbst ausgeführt. Es bestand in der damaligen Zeit zumeist eine klare Trennung zwischen Formenreißern und ausführenden Handwerkern. Die Qualitätsunterschiede in den Illustrationen der Singularités erklären sich wohl daraus, dass Thevet mit den drittklassigen Produkten Poisdulucs nicht zufrieden war und zumindest einige anspruchsvolle Holzschnitte liefern wollte und deshalb wohl Cousin und seine Werkstatt bat, neben den Vorzeichnungen auch den Schnitt zu übernehmen, was einige der subtilen, an Cousins Bücher erinnernden qualitätsvollen Holzschnitte auch deutlich zeigen. Vielleicht wurden auch gleich zu Beginn einem unbedeutenden Künstler wie Poisduluc die einfacheren Pflanzenbilder anvertraut, während die überwiegende Anzahl der Menschendarstellungen von vornherein der Werkstatt Cousins zugeteilt wurde.

Dass Thevet und sein Drucker La Porte Jean Cousin und seine Werkstatt zumindest für den größten Teil der Illustration der Singularités aussuchten, liegt vielleicht auch an der bereits erwähnten Mitarbeit Cousins an den Illustrationen zu der Entrée von Rouen 1550. Thevet, der seiner Cosmographie du Levant schon 1554 zahlreiche Abbildungen beigegeben hatte und zeit seines Lebens auf die anspruchsvolle ikonographische Gestaltung seiner Werke achtete, wollte einen der angesehensten Künstler seiner Zeit zurate ziehen, der sicher auch wegen seines Könnens als Illustrator eines Reiseberichts in Frage kam.

Die Zuordnung Gaffarels dürfte zumindest für einen Teil der Holzschnitte stimmen, auch wenn genauere stilistisch vergleichende Untersuchungen zwischen den Werken Cousins bzw. seiner Schule und den Holzschnitten in Thevets Werk fehlen. Brun $(1969,58,301)$ hat bei den Abbildungen 41v, 71v (auf den Illustrationen $73 \mathrm{v}$ und $85 \mathrm{v}$ unter Vorbehalt) das Monogramm von Cousin festgestellt. Eine große Anzahl von Holzschnitten stimmt im Stil mit diesen drei überein (B1. 46v, 57r, 76v, 77r, 82v, 83r, 88v, 124v, 156r, 164r), während andere, ebenfalls subtil gezeichnete, mit dem Lothringerkreuz gekennzeichnet sind wie Illustrationen einer zeitgenössischen Amadisausgabe (6v, 31r, 45r, 89v, 105r, 114r, 151r) und ebenfalls eine große Feinheit des Schnittes aufweisen. Die restlichen sieben Holzschnitte, von denen sechs nach Ansicht von Brun "très médiocres" sind, hat er keinem Meister zugeordnet.

Bei den anderen von Brun nicht erwähnten Holzschnitten habe ich in der nachfolgend aufgeführten Liste die Zuordnung ergänzt. Da m. E. das Lothringerkreuz nicht unbedingt auf einen bestimmten Meister beziehbar ist, sondern auch eine Art Zeichen für die Fertigstellung eines Holzschnitts (bon à tirer) sein kann und sich auf zahlreichen anderen zeitgenössischen Holzschnitten, auch solchen, 
die etwa Geofroy Tory zugeschrieben werden, findet (vgl. Firmin-Didot 1863, 177) und zudem die stilistischen Unterschiede zwischen den so signierten Holzschnitten und den von Cousin signierten gering sind, habe ich die hochwertigen Holzschnitte insgesamt Cousin und seiner Schule zugeordnet. Duviols $(1978,38)$ schließlich schreibt die Holzschnitte ebenfalls Jean Cousin und zusätzlich Jean Goujon und Germain Pilon zu, ohne hierfür Beweise anzuführen.

Eine Zuordnung an den weniger begabten Meister oder einen seiner Schüler ist leicht erkennbar, da es sich meist um sehr einfache Darstellungen von Menschen und bildfüllende Abbildungen von Pflanzen und Tieren handelt. Bei einigen Tierdarstellungen wie z. B. beim toucan (91r) ist ein deutlicher Qualitätsunterschied zu sehen, der an eine Mitwirkung von Jean Cousin oder einem erfahreneren Künstler seiner Schule denken lässt. Sehr wahrscheinlich handelt es sich auch um Künstler einer Werkstatt, die die Illustrationen gemeinsam ausführten. Auffallend ist, dass die Menschendarstellungen des weniger begabten Künstlers immer einen Baum und äußerst grob und flächig gezeichnete Menschen daneben ohne Beachtung jeglicher Perspektive enthalten (Tafel 6). In dieser Serie fällt einzig die Darstellung 105r (Tafel 5) aus der Reihe, die eindeutig eine viel geschicktere Hand verrät als die anderen themengleichen Bilder. Hier hat, wie der Vergleich mit Abbildungen aus dem Livre de perspective ${ }^{39}$ zeigt, eindeutig der Meister Cousin oder ein anderer erfahrener Künstler seiner Werkstatt den Anfängern gezeigt, wie man das gegebene Thema, nämlich einen Baum in Verbindung mit Menschen darzustellen, perspektivisch exakt und ästhetisch ansprechend löst.

Ein weiteres Argument, das deutlich auf mindestens zwei verschiedene Künstler hinweist, auch wenn es keinen absoluten Beweischarakter hat, ist das Format der Holzschnitte. Die von mir Jean Cousin oder einem anderen begabten Künstler zugeschriebenen weisen allesamt das Format $10,5 \times 8 \mathrm{~cm}$ auf, während die anderen qualitativ minderwertigen Holzschnitte (mit der einzigen Ausnahme der nur sehr grob gezeichneten Landschaft 28r) überwiegend ein sehr viel größeres Format, nämlich 10,5 x $17 \mathrm{~cm}$, aufweisen. Größere Holzschnitte sind natürlich einfacher zu schneiden und konnten deshalb auch an einen weniger begabten Holzschneider vergeben werden bzw. dieser Künstler hat das Format auch angesichts seiner Fähigkeiten und Techniken von sich aus gewählt.

Auffallend ist beim Vergleich mit dem Inhalt der Holzschnitte, dass sich der Meister Cousin eindeutig die künstlerisch anspruchsvolleren Teile vorbehalten hat, die viele Personen zeigen, z. B. die Kampfszenen oder die Schilderung der Anthropophagie, während er dem weniger begabten Mitarbeiter die einfacheren Pflanzendarstellungen (einfache Umrissdarstellungen, die nach gezeichneten Vorlagen leicht zu erstellen waren) oder Darstellungen von Bäumen mit wenigen Menschen- und Tierzeichnungen überlassen hat. Bei diesen Holzschnitten fällt der qualitative Unterschied nicht so ins Gewicht, da diese Illustrationen überwie-

${ }^{39} \mathrm{Vgl}$. etwa die Menschengruppe vor einem Hintergrund mit Bäumen in Harthan 1981, 95. 
gend dokumentarischen Wert haben. Die frühen Reiseberichte des 16. Jahrhunderts waren immer zugleich naturkundliche Quellen und haben als solche auf die exakte Schilderung der Tier- und Pflanzenwelt großen Wert gelegt.

Die von Cousin erstellten Holzschnitte sind auch die anthropologisch relevanten, da sie die wichtigsten Bereiche der Fremdkultur - Alltags- und Festgebräuche (Tafel 5, 7, 9), Kriegswesen (Tafel 15) und Anthropophagie (Tafel 8, 13) - schildern. Wir wissen aus dem erhaltenen Vertrag zwischen Thevet und seinem Drucker, dass sich beide gemeinsam um die Illustrationen kümmerten. Thevet hat wahrscheinlich selbst den Wunsch geäußert, dass das künstlerische Hauptaugenmerk auf die Menschendarstellung und die damit verbundene ikonographische Veranschaulichung von fremden Sitten gelegt werden sollte, während er sich bei den Pflanzendarstellungen mit weniger anspruchsvollen Holzschnitten zufrieden gab. Die thematische Verteilung der Holzschnitte auf verschiedene Künstler vermutlich einer Werkstatt ist damit nicht nur als Konzession an deren unterschiedliche Begabung, sondern auch als Korrelat zum inhaltlichen Programm zu verstehen, in dem die Schilderung der fremden Sitten der Tupinamba in der Tat den größten Stellenwert einnimmt, was sich verständlicherweise auf der Ebene der Illustrationsqualität zeigen musste.

Die Kampfszene auf dem Holzschnitt 71v (Tafel 15, Abb. 1) illustriert nicht nur ein damals auch in Anlehnung an die antike Literatur in den Texten genau beschriebenes Phänomen, sondern ist zugleich als ein Zeichen für die Wildheit des Menschen im Naturzustand zu interpretieren. Der besagte Holzschnitt reiht sich im Übrigen in eine ikonographische Tradition ein, indem er ein themengleiches Werk des Künstlers Jean Mignon ${ }^{40}$ kopiert. Kampfszenen nackter Männer bilden für die an Proportionen und Körperdarstellungen der Renaissancezeichnung geschulten Künstler eine gute Gelegenheit, ihr Können unter Beweis zu stellen; von Pollaiuolo gibt es eine Radierung mit Kampfszenen unter nackten Männern (um 1471/72), ein Meister N. H. zeigt auf einem um 1522 entstandenen Holzschnitt einen Kampf unter Nackten und Bürgern in einem Wald ${ }^{41}$. In der Cosmographie wird der Holzschnitt der Singularités mit der Kampfszene neu gestaltet (Tafel 15, Abb. 2). Auf einem 1599 von dem bedeutenden niederländischen Kartographen Willem Blaeu in Amsterdam geschaffenen Globus ist in den Umrissen von Südamerika eben diese Kampfszene in deutlicher Anlehnung

${ }^{40} \mathrm{Vgl}$. Colin 1988, 111; der Holzschnitt Mignons ist dort als Abbildung 67 reproduziert.

${ }^{41}$ Vgl. die Abbildungen bei Frübis 1995, 168 (Pollaiuolo) und 169 (Meister N. H.) als charakteristische Beispiele aus einer breiten Tradition. 
Tabelle 1: Illustrationen der Singularités und ihre Übernahme in der Cosmographie - Zuordnung zu verschiedenen Künstlern

Die Zuschreibung an Cousin ist mit einem * ausgedrückt, die an einen weniger begabten Künstler durch ein + . Das erste Zeichen bezieht sich immer auf die Bewertung von Brun, sofern er den Holzschnitt erwähnt hat. Zuordnungen, die ich in Zweifel gezogen habe, sind in der Liste durch $+^{*}$ ausgedrückt. Die zweite Spalte benennt die noch zu analysierenden Übernahmen in die Cosmographie von 1575 ohne Änderungen (x). Wenn ein Thema in der Cosmographie behandelt ist, aber ein neuer Holzschnitt gefertigt wurde, ist dies mit xy bezeichnet. Die Liste der Übernahmen ist vollständig, wobei die wenigen Illustrationen in Thevets Buch, die nicht Brasilien betreffen, z. B. im Kanada-Teil, bei der genauen Analyse außer Acht bleiben können. Angemerkt sei noch, dass die von Lussagnet 1953 veröffentlichte Auswahlausgabe natürlich nur das Bildmaterial der Brasilien betreffenden Teile der Cosmographie enthält, die in dieser Edition auch erstmals wieder veröffentlicht wurden. Die Paginierung der Illustrationen in der Originalausgabe der Cosmographie findet sich im Anhang (s. unten 147f).

6v Löwenjagd in Afrika

Sing. Cosmo.

$18 \mathrm{v}$ Palmen

20v Produktion von Palmwein

28r Landschaft mit Vulkan

31r Bewohner von Guinea beten Götzen an *

41r Rhinozeros und Elephant *

45r Vogeldarstellung (pa) *

46v Produktion von cahouin, dem Wein der Indianer

48r Riesenfisch

50r Fisch

53r hetich (Kartoffel)-Wurzeln

57r Essen und Trinken bei den Indianern

61v Bananenbaum

66v Herstellung der Fußschellen zum Tanzen aus Früchten eines ebenfalls abgebildeten Baums * $\quad x y$ $+$ xy

xy

$+$

*

* $\quad x y$

* $\quad \mathrm{x}$

* $\quad \mathrm{xy}$

*

*

$+\quad \mathrm{x}$

* $\quad \mathrm{x}$

$+$

$+$

$\mathrm{X}$ 
71v Kampfszene

*

72v Fällen eines Baums

73v Provokationen vor dem Kampf

76v Tötung eines Gefangenen

77r Zerteilung des toten Körpers

$82 \mathrm{v}$ Bestattungsriten

83r Tänze und Bankette

85v Tränengruß der Indianer

$88 \mathrm{v}$ Heilung von Krankheiten durch Schamanen

89v Ananas

91r Vogeldarstellung (toucan)

98v Tierdarstellung (uhebehasoub)

99v Faultier (haut)

101r Tabakrauchen und Feuermachen

105r Baum (choine)

109r Tierdarstellung

114r Pflanzendarstellung (manioc)

$115 \mathrm{v}$ Vogeldarstellung

$117 \mathrm{r}$ Fällen eines Baums (ähnlich 72v)

$120 \mathrm{v}$ Indianer ernten Früchte von Bäumen

124v Amazonen kämpfen gegen Männer

126v Amazonen töten Gefangene durch Pfeilschüsse

133v Fisch

147v Tierdarstellung (Büffel)

151r Kanadische Indianer auf der Jagd

156r Überfall kanadischer Indianer

164r Musizierende kanadische Indianer tragen ihren Häuptling 
an Thevets Illustration als Zeichen für die Wildheit der Bewohner des ganzen Kontinents kopiert worden ${ }^{42}$. Schon frühere Karten enthalten solche Schlachtszenen, so eine Amerikakarte aus der Schule von Dieppe von N. Vallard um $1547^{43}$.

Die Holzschnitte von Cousin wurden später für die Auflage der Singularités im Kleinformat (1558) grob kopiert. Gaffarel, der zwar laut Titelblatt seiner Edition die Ausgabe Paris 1558 nachdruckt, hat einige wenige dieser Graphiken in seine Ausgabe aufgenommen (Thevet 1878, 137, 187, 201, 202, 218, 266, $330,421)$. Kompositorisch wiederholen diese Abbildungen die Holzschnitte der Pariser Ausgabe, der Schnitt ist aber viel gröber und weist auf einen Kopisten hin, der für die billigere Ausgabe in Antwerpen die Illustrationen nach den bestehenden Vorbildern lieferte. Nissen (1969, Nr. 4111, 406), der nur die bei Plantin erschienene Antwerpener, nicht aber die Pariser Ausgabe kennt, glaubt in diesen Kopisten die Antwerpener Holzschneider Arnaud Nicolai und Assuerus van Londerzeel zu erkennen. Eine Zuordnung an Jean Cousin sieht er als fraglich an, vermutlich aufgrund seiner Unkenntnis der Pariser Ausgabe, deren Illustrationen Vorbild für die Antwerpener Edition waren. Cousin ist sicher nicht direkt an der Antwerpener Ausgabe beteiligt gewesen.

Das zweite wichtige illustrierte Werk Thevets stellt seine Cosmographie universelle von 1575 dar. Thevet greift in diesem Buch das eigentlich mittelalterliche und schon damals als obsolet empfundene Genre der Kosmographie auf, von der es zahlreiche andere Beispiele wie z. B. von Sebastian Münster und Petrus Apianus gibt. Ethnologisch sind die Brasilien betreffenden Kapitel dieses Werks dennoch von großer Bedeutung, da Thevet hier neue Informationen zum Ritus der Anthropophagie und vor allem zu den Mythen der Tupinamba vermutlich von sich in Europa aufhaltenden portugiesischen Seeleuten oder Rückkehrern aus der inzwischen von Portugiesen eroberten Festung Villegagnons erhalten hat. Diese Informationen sind nur in diesem Buch und in keiner anderen zeitgenössischen Quelle überliefert.

Wie sieht nun das ikonographische Material der Cosmographie aus? In der oben erstellten Liste wurde der Brasilien betreffende Teil der Übernahmen aufgezeigt. Da Jean Cousin (der Ältere) schon 1561 starb, verwundert es nicht, dass der Stil der neu in die Cosmographie aufgenommenen Illustrationen sich leicht von den früheren unterscheidet. Die Tradition der Schule von Jean Cousin wurde aber von seinem Sohn und seiner Werkstatt fortgesetzt, weshalb davon auszugehen ist, dass diese gemeinsam für die Illustrationen der Cosmographie verantwortlich sind. Da zudem ein großer Teil des Bildmaterials der Singularités direkt übernommen wurde, ist es wahrscheinlich, dass auch der Auftrag für die

${ }^{42}$ Der Globus wurde gezeigt in der Ausstellung "Bild der Welt”, Landkarten aus fünf Jahrhunderten, im Stadtmuseum Regensburg, 15.11.96-23.02.97 (im gleichnamigen Katalog nicht abgebildet).

${ }^{43} \mathrm{Vgl}$. die Abbildung bei Frübis 1995, 44; Original in der Huntington Library, San Marino. 
Illustrationen des Buchs von 1575 an den Sohn von Jean Cousin und dessen Werkstatt ging, wo die alten Druckstöcke noch bereitlagen. Dies zeigt auch, dass Thevet mit der Arbeit der Illustratoren, die er ja schon von ihrer Mitarbeit bei den Singularités her kannte, offenkundig zufrieden war.

Lestringant (1978) hat in seiner Analyse der Ikonographie der Werke Thevets in einem Aufsatz herausgearbeitet, daß in den Pflanzen- und Tierdarstellungen das Hauptaugenmerk auf der dokumentarischen und weniger der künstlerischen Qualität der Abbildungen liegt. Die anderen Illustrationen sind oft als Zusammenfassungen mehrerer Handlungen angelegt, so der Holzschnitt in den Singularités 1982, 101r (Tafel 9, Abb. 2), der zugleich den Transport von manioc, das Rauchen von Tabak (petun) und das Feuermachen darstellt. In der Cosmographie von 1575 wird der größte Teil des ikonographischen Korpus der Singularités wiederaufgenommen, der Schwerpunkt verlagert sich aber von der Darstellung von Tieren oder Pflanzen auf die des nackten Menschen, der in antiker Darstellungsart ästhetisch ansprechend gezeichnet wird, selbst auf Kosten der ethnographischen Richtigkeit. So wird das rasierte Kopfhaar der Tupinamba durch eine kurze, der Antike nachempfundene Frisur ersetzt (Lestringant 1978, 589). Léry dagegen kopiert zwar in seinen Illustrationen stellenweise Thevet, bringt aber keine Darstellungen der Hinrichtung des Gefangenen oder der Zerlegung seines Körpers, was die Idealisierung der Tupinamba im Vergleich zu der Darstellung bei Thevet noch verstärkt.

Lestringant hält die Holzschnitte Thevets für moderner als seine Darstellung fremder Fakten im Text, die einer veralteten enumeratio verpflichtet seien. Er konstatiert in seiner Analyse einen Unterschied zwischen den grausamen Szenen, in denen der "Wilde" hässlich und verzerrt dargestellt wird - z. B. die Kampfszene bei Thevet $(1982,73 v$; Tafel 15) oder die Zerteilung des getöteten Gefangenen (ebd., 77r; Tafel 8, Abb. 1.) - und anderen Stellen, die eine "apollinische" Vision des Indianers zeigen. Wo dieser dann für die Europäer arbeitet, so beim Fällen des Holzes in dem neugefertigten Holzschnitt der Cosmographie $(950 \mathrm{v})$, ist er positiv und ästhetisch ansprechend gezeichnet. Die Folge ist, dass der Text in Thevets Büchern weniger homogen ist.

Diese interessante Analyse Lestringants lässt m. E. auch Rückschlüsse auf die Rezeption zu. Thevet wurde sich wohl bewusst, dass sich das Interesse der zeitgenössischen Leser nicht in erster Linie auf Flora und Fauna richtete, sondern auf Aussehen, Körpergestalt und Sitten der Indianer, sich also ausgehend von der Kunst ein Bild des schönen, wohlgestalteten und an antike Darstellungen erinnernden Indianers entwickelte, das er durch die Ikonographie der Cosmographie nur noch verstärken wollte. Die Illustrationen Thevets, die zahlreicher sind als die wenigen Holzschnitte in Lérys später erschienenem Buch, haben ohne Zweifel großen Einfluss auf das Bild des "sauvage" in der europäischen Kunst und Literatur gehabt, wovon auch die direkte Übernahme des Bildaufbaus und Inhalts vieler Holzschnitte im Buch Lérys und die edlen Körper der Indianer auf den Stichen der Brys ein beredtes Zeugnis geben. 
Lestringants Analyse ist sicher zutreffend, auch wenn er den Unterschied zwischen den künstlerisch anspruchsvollen Holzschnitten und den Atelierarbeiten nicht berücksichtigt. Darüber hinaus sieht seine rein inhaltlich ausgerichtete Analyse auch nicht, dass die extreme Zeichnung von Körperhaltungen in den Kampfszenen einfach durch das zu behandelnde Thema vorgegeben ist. Auch die anderen für ihn im Sinne des frühen Manierismus "apollinisch" wirkenden Holzschnitte zeigen oft eine leichte Verzerrung der Körper. Zudem darf man an ein Buch aus der Mitte des 16. Jahrhunderts keine modernen Ansprüche im Hinblick auf die Kohärenz des inhaltlichen oder ikonographischen Materials stellen. Diese wird dann eher durch eine weitgehend künstlerische Unifikation in den neugeschnittenen Illustrationen der Cosmographie oder im Werk der Brys erreicht.

Deshalb seien hier über Lestringant hinausgehend einige Holzschnitte genauer in den Blick gefasst. Aussagekräftig sind vor allem diejenigen Illustrationen, die in der Cosmographie zwar inhaltlich dasselbe Thema behandeln, für die aber ein neuer Holzschnitt erstellt wurde. Angesichts des großen Arbeitsaufwands stellt sich die Frage, warum eben diese Holzschnitte geändert wurden. Dass die Originalblöcke schon teilweise zerstört oder durch den Druck zu stark abgenutzt gewesen sind, ist bei der großen Anzahl an Übernahmen zwar möglich, aber als Erklärung nicht ausreichend. Also müssen andere, inhaltliche oder künstlerische Gedanken diesen ikonographischen Wandel mit bedingt haben, was nur eine genaue Analyse dieser Holzschnitte zeigen kann.

Insgesamt hat Thevet mit neunzehn Holzschnitten über die Hälfte des gesamten Bildmaterials der Singularités in die Cosmographie übernommen. Einige Tierdarstellungen und ein Teil der recht primitiven Holzschnitte mit Abbildungen von Bäumen entfallen wohl aus ästhetischen Gründen. Bei allen neu hinzugekommenen Illustrationen, die mit Ausnahme der Porträts ein größeres Format (ca. 15,5 x 13,5 cm) als die der Singularités $(10,5$ x $8 \mathrm{~cm}$ bei den qualitätsvollen Holzschnitten) aufweisen, ist eine sehr starke Anlehnung an das Vorbild der jeweiligen Darstellung in den Singularités spürbar, was auch nicht weiter verwundern kann. Die Darstellung der Produktion des aus gegorenem Saft hergestellten alkoholischen cahouin ist dem Vorbild sehr nahe, die Version der Cosmographie ist jedoch vom Bildaufbau und der Zeichnung der nackten Körper der kauernden Frauen her sehr viel anspruchsvoller. Hier dürfte wohl die Qualitätsfrage entscheidend gewesen sein. Dies gilt ebenfalls für die Kampfszene (Tafel 15, Abb. 1, 2), wo in der späteren Version die Körper der nackten, kämpfenden Indianer durch die Schraffuren erheblich an Wirkung gewinnen. Analoges gilt für die Darstellung der Tötung des Gefangenen (Tafel 13, Abb. 1, 2). Hier ist ein interessantes ethnologisches Detail feststellbar: in der Ausgabe der Singularités trägt der Indianer einen Federschmuck, der in der Version der später entstandenen Cosmographie $(1953,945 \mathrm{v})$ weggelassen ist. Dieselben künstlerischen Qualitätsunterschiede sind auch zwischen den anderen neugeschaffenen Holzschnitten feststellbar, wo die Version der Cosmographie jeweils 
qualitativ eine Verbesserung gegenüber der früheren darstellt, auch wenn das Faultier immer noch ein mannshohes Ungetüm ist, aber das menschenhafte Gesicht des Holzschnitts der Singularités verliert, das an mittelalterliche Monster erinnerte, an die 1575 keiner mehr glaubte.

Die Cosmographie enthält im Brasilienteil auch einige nicht auf Vorbilder der Singularités zurückgehende neue Holzschnitte, die hier nicht außer Acht bleiben dürfen. Es handelt sich zum einen um die Abbildung des von Villegagnon in seiner Kolonie 1556 errichteten Forts, im Augenblick, wo es von den Portugiesen angegriffen wurde (abgebildet auch in Thevet 1953, 13). Thevet hatte in seinem Buch von 1557/58 kaum etwas über die Geschichte des französischen Kolonialprojekts geschrieben und auch die Lage der Festung auf einer Insel nur am Rande erwähnt. In der Cosmographie geht er auf die Geschichte der inzwischen untergegangenen französischen Kolonie ein und erhebt beispielsweise an die Adresse der später in die "France antarctique" gekommenen Kalvinisten einige ungerechtfertigte, aber durch den historischen Kontext der Religionskriege verständliche Vorwürfe, den Untergang der Kolonie mit verursacht zu haben. Im Grunde zeigt sich aber, dass sich der Reisebericht zwischen dem Erscheinen der Singularités - die, wie der Titel schon sagt, das Hauptaugenmerk auf die wunderbaren und im Vergleich zu Europa neuen Phänomene legen und der Veröffentlichung der Cosmographie ändert. An der Schwelle zur Neuzeit gewinnt der historiographische Teil eine größere Bedeutung, was sich im Laufe der Zeit zu einem Genremerkmal entwickeln sollte (vgl. Obermeier 1995, 227ff, 368ff). Thevet wollte sich wohl an diese Tendenz angleichen, und nichts lag näher, als im Text auf die Geschichte der Kolonie einzugehen und auch als historisches Dokument eine Ansicht dieser Kolonie beizugeben. Allerdings wissen wir aus zeitgenössischen Dokumenten, dass der Kampf um die Festung sicher nicht so spektakulär war, wie uns dies der Holzschnitt vielleicht suggerieren sollte.

Weitere Holzschnitte illustrieren neue Bereiche. So widmet Thevet einem Indianerführer namens Quoniambec ein Porträt, das nachfolgend (43ff) im Vergleich mit der Replik als Kupferstich in der Porträtsammlung Thevets von 1584 behandelt wird (Tafel 10, 11). Ein weiterer Holzschnitt (Thevet 1953, 222) zeigt das Fällen des Brasilholzes und seinen Transport an die Küste, vermutlich ein Ersatz für den sehr primitiven Holzschnitt in den Singularités (Thevet 1982, 117r). Ähnlich wie bei der schon behandelten Karte von Ramusio (s. oben 16f; Tafel 1), ist die Szenerie hier in eine Umrisskarte des Landes projiziert. Dies ermöglicht, in Simultantechnik gleichzeitig das Fällen der Bäume, den Transport an die Küste und den Weitertransport auf Schiffen zu zeigen. Das Vorbild der Karten erklärt auch, dass bei Thevet die Küstenlinien wie auf einer Karte aufgegriffen wurden. Eine weitere Abbildung illustriert eine in der Cosmographie erzählte Episode, in der der schon erwähnte Quoniambec seinen Landsleuten mit europäischen Waffen Angst einjagt (Thevet 1953, 230). 
Als Ergebnis läßt sich festhalten, dass das Korpus der Illustrationen von den Singularités bis hin zur Cosmographie trotz der Übernahme des größten Teils des Bildmaterials einen Wandel erfahren hat. Auch wenn die Bebilderung der Cosmographie keine absolute Einheitlichkeit erreicht, wie Lestringant (1978, 589) zu recht bemerkt, so spürt man doch die Dominanz der qualitätsvollen Illustrationen in dem späteren Werk und damit eine stärkere künstlerische Einheitlichkeit, die schon auf die Homogenität der Werke der Brys vorausweist. Hier dürften aber auch inhaltliche Überlegungen eine Rolle gespielt haben. Die moderneren Holzschnitte wurden mit Ausnahme der wohl zu den mirabilia zu zählenden wenigen neugestalteten Tierdarstellungen (haut, toucan) zur Illustration zentraler ethnologischer Angaben des Texts verwendet. Auch einige der rein naturkundlichen Darstellungen, die aber wichtige Bereiche aus dem indianischen Leben behandeln, wie etwa die Darstellung der hetich-Wurzel oder einiger Baumarten, werden in der Cosmographie übernommen.

Die Auswahl und die Neugestaltung der Illustrationen in der Cosmographie sprechen dafür, dass Thevet und der Drucker sich bewusst wurden, welche Bereiche der Singularités das besondere Interesse des Lesers gefunden hatten und damit auch den Käufer der Cosmographie interessieren konnten, dem hier durch neue Illustrationen auch künstlerisch anspruchsvolleres Anschauungsmaterial geboten werden sollte, das neben einem Kaufanreiz auch den gestiegenen künstlerischen Ansprüchen der Buchkäufer gerecht werden sollte.

\section{Die Porträtsammlung Thevets (Les vrais pourtraicts et vies des hommes illustres, 1584)}

Im Jahr 1584 hat Thevet die Stichsammlung Les vrais pourtraicts et vies des hommes illustres mit Abbildungen berühmter Zeitgenossen veröffentlicht und darin zum ersten Mal Kupferstiche ("gravures en taille douce") als Buchillustrationen verwendet. Das Buch enthält unter anderem eine der ersten Abbildungen von Gutenberg. Diese Porträtsammlung zeigt mustergültig die Bedeutung der künstlerischen Illustrationen für Thevets Werke. Der Kupferstich spielte in der französischen Buchillustration erst seit Thevet eine größere Rolle. Die Technik war in Frankreich zwar schon bekannt, das erste französische Buch mit Kupferstichen wurde schon 1488 publiziert, blieb jedoch ein Einzelfall. Die frühesten Kupferstiche wurden im Hochdruckverfahren erstellt und unterschieden sich damit auch technisch trotz der größeren Feinheit der Zeichnung nicht wesentlich von den Holzschnitten. Der eigentliche Kupferstich im Tiefdruck erfordert eine Doppelzylinderpresse, was wohl die Drucker lange Zeit abhielt, dieses aufwendige Verfahren in größerem Stil bei den Buchillustrationen einzusetzen. Für die tradierten Holzschnitte genügte eine Tiegeldruckpresse. Erst seit der Mitte des 16. Jahrhunderts finden sich häufiger Kupferstiche in Büchern, besonders in Porträts zu Beginn eines Buchs, die durch den Kupferstich wirklichkeitsgetreu wiedergegeben werden konnten, ferner als Pläne in Architekturbüchern oder 
emblematischen Werken. Besonders in Paris hält sich der Holzschnitt allerdings noch länger als etwa in Lyon oder Lothringen (vgl. Brun 1969, 95-102).

In seiner Porträtsammlung rühmt Thevet sich, als einer der ersten Autoren Kupferstecher aus Flandern nach Paris zur Illustration seiner Werke geholt zu haben:

J'ai attiré de Flandre les meilleurs graveurs, et, par la grace de Dieu, ie me puis vanter estre le premier qui ai mis en vogue à Paris l'imprimerie en taille douce. (Kap. $43^{44}$ )

In der Tat sind die ersten Pariser Kupferstiche von aus Flandern stammenden Künstlern hergestellt worden, da dieses Kunsthandwerk in Paris zur damaligen Zeit noch nicht verbreitet war. Es gab zwar schon vor Thevet vereinzelte Kupferstecher in Paris, die Idee, ein ganzes Buch aus Kupferstichen zusammenzustellen, war aber neu und erforderte wohl geschulteres Personal als die damals in Paris ansässigen Künstler. Die große Bedeutung der flandrischen Stecher ist bekannt und erreicht im Werk von Hendrik Goltzius ([1558-1617], 1983) zu Beginn des 17. Jahrhunderts einen ersten Höhepunkt.

Die Porträtsammlung Thevets enthält auch einige Stiche von Indianern, die hier nicht außer Acht bleiben sollen. So z. B. findet sich auf 661r (Livre VIII, Chap. 149, Tafel 11) eine im Vergleich zu dem Vorbild in der Cosmographie (Tafel 10) verbesserte Version des Stichs von Quoniambec ${ }^{45}$. Dieser mächtige Indianerführer, der in der Nähe der französischen Festung lebte, wird des öfteren auch von Staden erwähnt (Konyan Bebe $)^{46}$. Es ist im Übrigen sehr selten, dass ein Indianer der damaligen Zeit, selbst wenn es sich um einen Häuptling handelt, in den Texten namentlich fassbar wird und dies noch dazu in verschiedenen Quellen. In den meisten Reiseberichten treten uns die Indianer als amorphe Masse und nicht als Individuen entgegen, da die Beziehungen zwischen den Indianern und Kolonisten oft nicht eng genug waren, um ein persönliches Verhältnis zu ermöglichen. Die Abbildung Thevets zeigt, wie gut das Verhältnis der Indianer zu den Franzosen war und welche Bedeutung Quoniambec unter ihnen hatte, da Thevet ihn immerhin in einem Buch mit den Geistesgrößen und Feldherren der Antike zusammen abbilden lässt, was angesichts des Bildungshorizonts der Zeit eine einmalige Aufwertung dieses Indianers war und nicht allein durch das Interesse Thevets für alles Exotische erklärt werden kann. Quoniambec wird damit als ein bedeutender Vertreter der neuentdeckten Kulturen unbedenklich in die Ahnengalerie der Europäer eingebürgert. Er ist aber nicht der Einzige, dem diese Ehre zuteil wird. In dieser Porträtsammlung finden sich auch

${ }^{44}$ Zitiert nach Sturtevant 1976, 451, Fußnote 40.

${ }^{45}$ Lussagnet (Thevet 1953, 90-92) hat diese beiden Illustrationen publiziert.

${ }^{46} \mathrm{Vgl}$. z. B. Staden 1978 [1557], 1. Buch, Kap. 28ff, Bogensignatur g iii ff "Wie sie mich zu irem obersten Könige Konyan Bebe genant/ führeten/ und wie sie da mit mir umb giengen”. 
Abbilder von einem Potiguara-König ${ }^{47}$ namens Nacolabsov, "Roy du Promontoire des Cannibales" (650r; Tafel 12), von Paraousti Satouriona, dem König von Florida (663r), oder von Paracoussi, dem König der Stämme am Rio de la Plata (656r), die Thevet sicher nicht persönlich gekannt hat und deren Abbilder er der Phantasie seiner Künstler überließ. Dennoch ist auch der Stich von Nacolabsov mit ethnologisch authentischen Elementen ausgestattet. Der König trägt zwei zugespitzte Holzpflöcke an Wangen und Unterlippe, eine Art Schmuck, der sich auch bei den Lippensteinen der anderen verwandten Tupi-Stämme findet. Im Hintergrund sieht man das Vorgebirge, über das der König herrscht und das gleichsam eine lokale Situierung des dargestellten Menschen bewirkt, wie sie in damaligen Stichen als eine Art zitierter Topos häufig ist.

Bei dem Stich von Quoniambec zeigt sich deutlich der qualitative Unterschied zwischen dem frühen Holzschnitt und dem Stich. Die einfachen Schraffuren des Holzschnitts lassen den Körper kaum dreidimensional erscheinen, während die geschickt mit Hell-Dunkel-Kontrasten operierenden Schraffuren des Kupferstichs einen Eindruck von der Körperfülle und der muskulösen Kraft der Gestalt geben. Die Haltung des Kopfes ist dieselbe, auf dem Holzschnitt wirkt die Gestalt jedoch steif und unbeweglich vor eine Landschaftskulisse projiziert. Auf dem Kupferstich ist dagegen der ernsthafte Ausdruck des Gesichts gut eingefangen, die Gestalt blickt nach links oben am Betrachter vorbei, während sie auf dem Holzschnitt vage ins Leere zu schauen scheint. Im Übrigen hat der Stecher die Physiognomie der Gestalt auf dem Kupferstich einigermaßen beibehalten, er hat den Einsatz in die Unterlippe übernommen und noch ethnologisch korrekt zwei Wangensteine eingezeichnet. Der Hals- und Ohrenschmuck der sogenannten "vignol"-Muscheln findet sich auf beiden Illustrationen, ebenso der Federschmuck des Kopfes. Auf dem Stich ist zusätzlich durch die leicht gedrehte Haltung des Oberkörpers der enduape-Federschmuck der Hüften zu sehen, der schon bei Staden abgebildet wurde (1. Buch, Kap. 17) und uns dann später auf den Stichen der Brys noch des Öfteren wiederbegegnen wird. Beide Male hält der Indianer als visuelles Zeichen seines Status als Krieger und Stammeschef die Kriegskeule in der Hand. Diese beiden Illustrationen zeigen deutlich, welche qualitativen Verbesserungen das illustrative Material durch die verfeinerte Technik der Kupferstecherei im Vergleich zum Holzschnitt erlangte. Dies entspricht auch der künstlerischen Entwicklung der Buchillustration zwischen 1554 und 1584. Die Holzschnitte der Singularités sind wohl unter Federführung und zumindest teilweise unter persönlicher Beteiligung von Jean Cousin dem Älteren entstanden. Sein Sohn Jean Cousin der Jüngere kannte sicher die durch flandrische Künstler verbesserten Ausdrucksmöglichkeiten des Kupferstichs, insbesondere die Schraffurtechnik, die sich auch anbot, um sich von der in der

${ }^{47}$ Lussagnet (Thevet 1953, 271, Fußnote 1) geht davon aus, dass die Bezeichnung "cannibaliers", die Thevet an einigen Stellen der Cosmographie verwendet, sich auf die Potiguara aus dem Gebiet zwischen Paraíba do Norte und Parnaíba bezieht. 
Zeichenkunst des Vaters dominanten Linienführung abzugrenzen. Obwohl die geschickte Linienführung in den Holzschnitten der Singularités subtile Gestaltung körperlicher Bewegung und räumlicher Kulissen ermöglicht, bleibt die Darstellung doch künstlich und dem Stil der italienischen Renaissance verpflichtet, der auch in seiner Weiterentwicklung zum Manierismus im letzten Drittel des 16. Jahrhunderts in Frankreich als nicht mehr adäquat empfunden wurde. Die Illustrationen der Cosmographie sollten sicherlich nach der Intention von Künstler und Autor auf der künstlerischen Höhe der Zeit sein und zugleich durch einige Zitate der Singularités und Anlehnungen im Bildaufbau ihre Filiation von den ersten Holzschnitten, die auch durch die Werkstatttradition bedingt ist, nicht verleugnen. Der Leser, der sich für die Cosmographie interessierte, kannte zumeist auch Thevets Erstling über Brasilien und erwartete nicht nur neue inhaltliche Informationen (die Thevet in seinen Mythenschilderungen und Ergänzungen zur zeremoniellen Anthropophagie tatsächlich auch geliefert hat), sondern auch eine neue Aufmachung, die ihn zum Kauf des umfangreichen Werks anregen sollte. Den Illustrationen kommen damit neben der Gestaltung der TextBild-Komponente verschiedene Aufgaben zu, die auch auf eine frühe Marktausrichtung hinweisen. Der erstmalige Einsatz des Kupferstichs durch unbekannte flandrische Künstler in den Vrais pourtraicts stellt gegenüber diesen Vorgaben eine weitere Qualitätssteigerung dar.

Nach seiner Porträtsammlung hat Thevet kein weiteres Werk mehr veröffentlicht. Die Brasilienkapitel aus den als Manuskript erhaltenen Werken (Histoire de deux voyages, Le Grand Insulaire) wurden zusammen mit den Brasilienteilen der Cosmographie 1953 von Suzanne Lussagnet veröffentlicht. Der Grand Insulaire sollte ein opulent illustriertes Werk über die Inseln der Welt mit Kartenbeilagen werden, was wiederum die Bedeutung der Illustrationen im Werk Thevets zeigt. Einige der für dieses Kartenwerk erstellten Kupferstiche sind erhalten ${ }^{48}$.

\section{Textillustration und autonome Aussagestruktur in den Holzschnitten Lérys (Histoire d'un voyage faict en la terre du Brésil, ${ }^{2} 1580$ )}

Zur Ikonographie im Werk Lérys liegen bisher nur die Kapitel über die Bildlichkeit in der Edition der Histoire $\left[{ }^{2} 1580\right]$ von Frank Lestringant (Léry 1992) vor ${ }^{49}$. Über die Illustratoren Lérys ist nichts bekannt. Sie werden von ihm weder namentlich erwähnt, noch gibt es Hinweise auf die Herkunft der Holzschnitte aus einer bestimmten Werkstatt oder Schule. Während seines Brasilienaufenthalts hatte Léry einen mitreisenden begabten Zeichner namens Jean Gardien gebeten, vor Ort Skizzen der Tierwelt zu machen. Dieser ließ sich jedoch zu Lérys passim.

${ }^{48}$ Vgl. hierzu die bibliographischen Ausführungen von Lestringant in Pastoureau 1984

${ }^{49}$ Diese Einschübe mit reichem Bildmaterial sind jeweils unpaginiert als Léry 1992, Panoramique + Zahl zitiert. Sie fehlen in der Ausgabe von Lérys Text, die Lestringant 1994 in Paris als Taschenbuch herausgegeben hat. 
Bedauern nicht dazu bewegen, weshalb man davon ausgehen kann, dass der französische Autor keine Illustrationsvorlagen aus der Neuen Welt zurückgebracht hat (vgl. Histoire $\left.1975\left[{ }^{2} 1580\right], 147\right)$. Vielleicht ist hierin auch ein möglicher Grund für den Verzicht auf Tierdarstellungen (mit Ausnahme des von Thevet kopierten Faultiers in der zweiten Auflage) bei Léry zu suchen.

Im Genfer Staatsarchiv ist ein Dokument über die Summe überliefert, die Léry für sein Buch erhalten hat. In den Notariatsakten des Notars Noël Cornillaud (Bd. 1, Bl. 290v) verpflichtet sich der Genfer Kaufmann Claude Juge, der zahlreiche Drucke von Antoine Chuppin vorfinanziert hat, am 16.10.1577 dazu, dem Pastor Léry am 12.04.1578 300 von einer Gesamtschuld von 340 "livres tournois" zu bezahlen und ihm 50 Freiexemplare seines Buchs und 50 Exemplare einer nicht weiter bekannten und wohl nach Vorgaben Lérys angefertigten Karte zu übergeben ${ }^{50}$. Léry verpflichtet sich seinerseits, die Karte (gemeint ist wohl die zeichnerische Vorlage einer Amerika-Karte) und das Manuskript seines Buchs gleich nach Fertigstellung abzuliefern. Die zum Zeitpunkt des Vertragsschlusses bezahlten 40 "livres" waren sicher der Vorschuss für das Buch, während der Rest der Summe am spätestmöglichen Termin, wohl bei Erscheinen anlässlich der Frühjahrsmesse gezahlt werden sollte.

Der Drucker ist auf dem Titelblatt der ersten Auflage nicht genannt. Die erhaltene Notariatsvereinbarung läßt vermuten, dass die erste Auflage in Genf von Antoine Chuppin gedruckt worden ist, auch wenn einige Exemplare, vielleicht zur Irreführung der Zensur in Frankreich, als Druckort La Rochelle nennen. Die Finanzierung von anderen Drucken der Offizin Chuppin durch den im Vertrag von 16.10.1577 als Geldgeber erwähnten Kaufmann Claude Juge ist auch anderweitig bezeugt (vgl. Bremme 1969, 137f). Dieser hat wohl auch im Fall Lérys das Geld für ein von Chuppin verlegtes Buch vorgestreckt. Der Druck der Erstausgabe in Genf ist ferner auch durch eine zeitgenössische Liste im Genfer Staatsarchiv bezeugt, die die Titel der mit Zustimmung des Rats (Conseil) als der obersten Zensurbehörde veröffentlichten Werke belegt. Lérys Buch wird hier unter dem Datum des 11. November 1577 aufgeführt. Vermutlich wurde das Manuskript zu diesem Zeitpunkt bei der Zensur eingereicht ${ }^{51}$. Auf dem Titelblatt der zweiten Auflage von 1580 sind der Drucker Antoine Chuppin und der Druckort Genf genannt. Da der Text vom Autor für den Neudruck ergänzt und überarbeitet wurde, handelt es sich bei dieser zweiten Auflage sicher um eine mit Lérys Einverständnis gedruckte Fassung, was auch für die Bewertung einiger erstmals 1580 hinzugefügter Illustrationen von Bedeutung ist.

50 Das Dokument ist bisher unveröffentlicht. Ich danke dem Genfer Archiv für die freundliche Übermittlung des Textes. Aufmerksam wurde ich auf die Stelle durch Bremme 1969, 137 und 138, Fußnote 10. Dort fehlt die Angabe zur Höhe der Summe.

51 Vgl. Labarthe 1980, 187: “J[ean] de Leri: Histoire de l'Amerique, 11. novembre [1577]". Auch wenn der Titel in leicht geänderter Form erscheint, ist sicher die Histoire d'un voyage gemeint. 
Der von Léry noch mehrmals überarbeitete und ergänzte Text erschien bis zur letzten Auflage zu Lérys Lebzeiten im Jahre 1611 noch einige Male bei verschiedenen Druckern, aber mit demselben Bildmaterial ${ }^{52}$.

Léry war sich als einer der wenigen Autoren seiner Zeit der erkenntnistheoretischen Probleme bei der Wahrnehmung fremder Kulturen bewusst. Die Problematik der Vermittlung gilt auch für die visuelle Darstellung. In Hinblick auf die Gesten und Körperhaltungen der "sauvages" schreibt er:

[...] si est-ce neantmoins, qu'à cause de leurs gestes et contenances du tout dissemblables des nostres, ie confesse qu'il est mal-aisé de les bien representer, ni par escrit, ni mesme par peinture. Parquoy pour en avoir le plaisir il les faut voir et visiter en leur pays. (Histoire, 1975 [21580], 113f)

Trotz dieser Bedenken wollte er nicht auf eine Illustrierung seines Werks verzichten. Vermutlich hat er sich hierfür an auswärtige Künstler gewandt, da sich im kalvinistischen Genf zu dieser Zeit wohl keine Schule von Bildillustratoren halten konnte. In der Stadt bestand kein Bedarf an kostspieligen Prachtausgaben, auch in der religiösen Literatur dominierte in Abgrenzung zum Katholizismus das reine Wort. Vor diesem Hintergrund sind Lérys Illustrationen als einzigartig anzusehen.

\section{Léry und die Trachtenbücher}

Einige künstlerisch auszumachende Einflüsse in Lérys Illustrationen verweisen auf die Tradition der im 16. Jahrhundert wichtigen Trachtenbücher ${ }^{53}$, in denen die verschiedenen Kleidungen der Völker an ganzfigurig gezeichneten Menschengestalten exemplarisch gezeigt wurden. Vielleicht hat deshalb Léry an einer Stelle seinen Leser aufgefordert, sich einen nackt abgebildeten Indianer vollständig oder halbbekleidet vorzustellen (105f).

Ein Vorbild für seine Abbildung eines indianischen Paares (Histoire, 1975 [21580], 107, Tafel 18) findet sich in dem Holzschnitt 181 (Tafel 17) in dem Trachtenbuch des Nürnberger Druckers und Formschneiders Hans Weigel (nachweisbar in Nürnberg von 1549 bis ca. 1578), das dieser 1577 unter dem Titel Habitus praecipuorum populorum [...] in Nürnberg publiziert hat. Die Holzschnitte des Buchs gehen zum Teil auf den aus Zürich stammenden und damals in Nürnberg lebenden Jost Amman (1539-1591) zurück. Dieser hatte 1562 die Werkstatt seines Lehrmeisters Virgil Solis des Älteren übernommen,

\footnotetext{
${ }^{52} \mathrm{Vgl}$. zu den genauen bibliographischen Angaben die kritische Ausgabe Léry 1975 [ $\left.{ }^{2} 1580\right]$, XXXVIIff und ergänzend Lestringant 1984a, 57, Fußnote 17.

${ }^{53} \mathrm{Vgl}$. Colin 1988, 112. Ein zeitgenössisches französisches Trachtenbuch ist die Sammlung Recueil de la diversité des habits qui sont a present en usaige tant es pays d'Europe, Asie, Affrique et Illes sauvages. Paris: Richard Breton, 1562; vgl. hierzu auch Colin 1988, 219 sowie European Americana I, 562/24.
} 
der vor allem für den Frankfurter Verleger Sigmund Feyerabend gearbeitet hatte. Auf dem letzten Holzschnitt des Trachtenbuchs findet sich Jost Ammans Monogramm. Er hat vermutlich die Entwürfe für die Zeichnungen geliefert, während der Drucker selbst die Holzstöcke und kurze Begleittexte angefertigt hat. Der genaue Umfang von Ammans Beteiligung am Trachtenbuch Weigels ist aber nicht festzumachen. Allerdings weist eine von Amman im gleichen Jahr 1577 als Einblattdruck herausgegebene Allegorie der Kontinente deutliche Parallelen zu dem Trachtenbuch auf (vgl. Menninger 1991, 14ff). Der besagte Holzschnitt im Trachtenbuch ist zwar nicht identisch mit dem von Léry, er zeigt aber ebenfalls einen Indianer mit seiner Frau, die ein Kind in einer Tragetasche an ihrer Schulter trägt. Die Frau wendet sich wie bei Léry dem Mann zu, legt ihm aber ihren Arm nicht um die Schulter. Sie trägt im Gegensatz zu der Frau bei Léry, die mit dem Arm ihr Kind hält, in der einen Hand eine Karaffe, während sie mit der anderen Hand in Anlehnung an eine antike Venusstatue ihr Geschlecht bedeckt. Der Mann steht vor ihr und ist anders als die in Frontalansicht ausgeführte Figur Lérys leicht von der Seite gezeichnet. Er wendet sich gerade seiner Frau zu, die ihn ebenfalls anblickt. Der Indianer ist im Gegensatz zu der vollständig nackten Gestalt bei Léry mit einem enduape-Federschmuck um die Hüften bekleidet und trägt einen Federgürtel, der sein Geschlecht bedeckt. Die Gestalten sind bei Léry gänzlich nackt, wobei der Körper der Frau sicher aus moralischen Gründen und um die Genfer Zensur nicht herauszufordern von dem des Mannes verdeckt wird. Die Nacktheit entspricht den ethnologischen Schilderungen bei Léry, der die Unbekleidetheit der Indianer, die für ihn im Übrigen nicht anzüglich wirkte, in seinem Buch ausführlich behandelt hat. Der Federschmuck bei Weigel ist zwar authentisch gezeichnet, gibt aber nur das bei wenigen besonderen Anlässen getragene Festgewand der brasilianischen Indianer wieder. Aber in einem Trachtenbuch lag der Schwerpunkt naturgemäß thematisch bedingt auf der Abbildung der Kleidung. Nur mit ihren Waffen und einigen Schmuckstücken verzierte nackte Gestalten hätten den zeitgenössischen Leser hier nicht zufriedengestellt.

Der Mann auf dem Holzschnitt 181 von Amman hält wie bei Léry in der rechten Hand einen Pfeil, allerdings nicht so gekünstelt in die Höhe gestreckt, wie dies der Indianer Lérys mit seinen drei Pfeilen tut. In der anderen Hand hält Ammans Indianer wie auf dem Léryholzschnitt einen Bogen. Beide Figuren tragen in dem Buch von Weigel einen Federschmuck um die Stirn, die Frau ist ferner mit einem Umhang bekleidet, der wohl die Tragetasche für das Kind enthält. Der Mann trägt als Schmuck einen Steineinsatz an der sichtbaren Wange und einen länglichen, vorn trapezartig zulaufenden, stark hervorstehenden Lippenschmuck. Genauso hatte Staden 1557 den Lippeneinsatz darstellen lassen (2. Buch, Kap. 16). Dieses Detail sowie der ebenfalls bereits bei Staden abgebildete enduape-Federschmuck (2. Buch, Kap. 17) beweisen die Kenntnis von Stadens Werk bei dem Künstler des Trachtenbuchs, vermutlich Jost Amman. Im Gegensatz zu Staden und Weigel zeigt Léry auf seinen Illustrationen immer nur runde Steine als Gesichtsschmuck, und es bleibt unklar, wie diese befestigt sind. 
Besonders deutlich ist dieses Bestreben, verschiedene Kleidungsstücke zu zeigen, auf den beiden folgenden Holzschnitten 182 und 183 bei Weigel zu spüren, die beide Federkleider tragende Indianer abbilden. Auch diese direkt auf den besprochenen Holzschnitt folgenden zwei Xylographien zeigen laut Überschrift brasilianische Indianer. Auf der ersten ist ein Mann im Kriegsornat ("armati habitus") zu sehen, der mit einem übrigens authentischen, allerdings sicher nicht bei den Kämpfen getragenen Federmantel bekleidet ist und eine nach Stadens Vorbild (2. Buch, Kap. 29, 3) gezeichnete Kriegskeule an die Schulter lehnt ${ }^{54}$. Der folgende Holzschnitt bei Weigel zeigt eine mit einem Federrock, einem Feder-Poncho und einem Stirnband aus Federn bekleidete Frau, die in der Hand eine maraca, eine bei religiösen Zeremonien der Indianer verwendete Rassel, hält. Auf diesem Objekt findet sich im übrigen auch die von Staden erwähnte und in seinen Holzschnitten öfter abgebildete mundförmige Öffnung. Diese Frauen- und Männerbekleidung scheint offenkundig auf die von Christoph Weiditz 1529 von aztekischen Indianern in Spanien gezeichneten Skizzen zurückzugehen, die sicherlich als Kopien zirkulierten ${ }^{55}$. Auf einer anderen solchen Skizze findet sich auch - unabhängig von den klassischen Reminiszenzen des Doryphoros-Typs - ein mögliches Vorbild für den Keulenträger bei Weigel in einem aztekischen Edlen, der, nur mit einem Lendenschurz angetan, einen an einem langen Speer befestigten Sonnenschirm an die Schulter gelehnt hat. Amman hat die Figur des mit einem Federmantel bekleideten Indianers mit der des fächertragenden Edlen verschmolzen und durch die Frauendarstellung gleichzeitig ein für die Kostümbücher übliches Paar gezeigt.

Der Holzschnitt 182 mit der Abbildung des Indianers in Kriegstracht hat den Holzschnitt 207 (wiederholt in 222) bei Léry zumindest in der Motivik und im Bildaufbau beeinflusst. Der französische Holzschnitt (Tafel 19) zeigt einen Totschläger noch mit einer Keule in der Hand. Die Körperhaltung entspricht der bei Amman, der Indianer hält die Keule bei Léry nur etwas unrealistisch in der rechten Hand in die Höhe gestreckt und stützt den linken Arm auf seine Hüften. Bei Amman ist der rechte Arm unter dem Federkleid auf die Hüften gestützt, während der linke etwas realistischer als bei Léry die schwere Keule nach dem oft kopierten Vorbild der griechischen Statue des Doryphoros an die Schulter lehnt. Wieder ist bei Amman die Zeichnung der Linien im Holzschnitt feiner, die Gestalt schreitet voran, während der indianische Krieger bei Léry nach dem Vorbild antiker Statuen leicht zwischen Stand- und Spielbein pendelt. Der bei

${ }^{54}$ Zur Rezeption Stadens durch Weigel/Amman vgl. Menninger 1991, 26ff. Ein von Menninger angenommener direkter Rückgriff auf die Illustrationen Thevets wegen der Abbildungen von Messern bei den Indianern oder von Kindern, die am Grill mit Köpfen spielen, ist allerdings weniger zwingend. Das letztgenannte Motiv findet sich auch auf dem Holzschnitt Stadens, 1. Buch, Kap. 40.

${ }^{55}$ Vgl. die Abbildungen 176/177 in Quetsch 1983, Bd. 2 (Illustrationen). 
Léry im Hintergrund noch abgebildete Bogenschütze ist wohl hinzugefügt, um den Bildraum besser auszufüllen.

In den Holzschnitten von Weigels Buch haben wir also einige der wenigen bisher aufgefundenen Vorbilder für die Holzschnitte in Lérys Werk vor uns. Weigels Buch erschien im Jahre 1577, also ein Jahr vor Lérys Histoire, und mußte für die Zeitgenossen damit eine aktuelle Bedeutung haben. Léry hat es vielleicht selbst gekannt und ähnliche Holzschnitte gewünscht, oder sein Künstler hat dieses Vorbild eigenständig gewählt. Der Holzschnitt mit der Darstellung des Paars ist bei Léry allerdings qualitativ nicht so gelungen wie die sehr feine Zeichnung bei Jost Amman. Der Holzschneider Lérys vermag es nicht, die Figuren in einen kommunikativen Zusammenhang zu stellen; sein Indianer blickt in den leeren Raum, seine Frau, die ihm den Arm um die Schulter gelegt hat, teilnahmslos auf den Betrachter. Darüber hinaus muss die Frontalperspektive in der Körperzeichnung für den Schneider leichter zu realisieren gewesen sein. Hier hat der von Léry beauftragte Künstler offenkundig weniger Können gezeigt als sein Vorbild. Die einzelne Frauendarstellung bei Weigel hat Léry wohl deswegen nicht kopieren lassen, weil sie ihm zurecht als nicht authentisch erschien, und er in Anlehnung an Thevets Werk Sitten der Indianer wie das Begrüßungszeremonial oder die Totentrauer darstellen wollte.

\section{Das Verhältnis des Bildmaterials zum Text}

Lérys Holzschnitte sind sicher in Konkurrenz zu seinem auch inhaltlich bekämpften Gegner Thevet entstanden. Man darf annehmen, dass er in der Qualität den Illustrationen in den Singularités und in der Cosmographie nicht nachstehen wollte und deshalb einige den Illustrationen der Cousins ebenbürtige Holzschnitte hinzugefügt hat. Auch inhaltlich behandeln die Holzschnitte analoge Erscheinungen der Fremdkultur, berücksichtigen also schon bei der Auswahl das ikonographische Vorbild.

Ich gehe bei der Analyse von der zweiten Auflage von Lérys Werk von 1580 aus und widme mich dann den Unterschieden zur Erstausgabe von 1578, was auch praktische Gründe hat. Der große Erfolg des Buchs machte bereits 1580 eine zweite Ausgabe notwendig (bei Antoine Chuppin; vgl. Sturtevant 1976, 442), deren Text vom Autor erheblich erweitert wurde. Diese Edition bildet die Grundlage für die zahlreichen weiteren Ausgaben; sie ist in der von Morisot herausgegebenen Faksimile-Ausgabe von 1975 leicht greifbar.

Lérys Buch enthält weniger Bilder als dasjenige Thevets, der seinem Reisebericht eine ganze Serie beigegeben hatte. Künstlerisch ist bei den Holzschnitten deutlich die Hand von mindestens zwei Meistern erkennbar. Die Illustrationen 107, 207, 246, 284 und 301 (Tafel 18-22) zeigen anspruchsvoll geschnittene Ganzkörperfiguren, die den Bildinhalt vollständig ausfüllen und anatomisch exakt gezeichnet sind. Auch die Darstellung einer begrenzten Anzahl von zwei bis fünf Figuren und die geschickte Technik der Schraffierungen weisen auf einen in seinem Metier erfahrenen Künstler hin, der die Perspektive beherrschte. 
Die Holzschnitte 214 (Tafel 14) und 235 (Tafel 41) und derjenige zwischen 230/231 (Tafel 16) dagegen sind von der Qualität deutlich minderwertiger. Sie tauchen erstmals in der zweiten Auflage von Lérys Buch auf. Die jeweils in eine schwach angedeutete Landschaftskulisse gestellten Gestalten sind grob gezeichnet, die Dreidimensionalität der Körper ist nur wenig angedeutet und auch die Perspektive ist nicht eingehalten. Die Anzahl der dargestellten Figuren nimmt $\mathrm{zu}$, in der Kampfszene sind es über ein Dutzend.

Die Gründe für diesen qualitativen Unterschied sind nur hypothetisch zu rekonstruieren. Illustrationen waren natürlich für die Drucker der damaligen Zeit eine teure Angelegenheit und lohnten sich nur bei aufwendig gestalteten Büchern, die gut abgesetzt werden konnten. Die Reiseliteratur war sicherlich ein beliebtes Genre und wurde auch als Unterhaltungsliteratur angesehen. Es ist durchaus möglich, dass der Drucker bei der zweiten Auflage von Lérys Werk neben den fünf hochwertigen Holzschnitten des Erstdrucks noch Bildmaterial hinzufügen wollte, das dann ruhig weniger qualitätsvoll sein konnte. Eventuell wurde der erste Auftrag für die Illustrationen der ersten Auflage einer auswärtigen Werkstatt von geübten Künstlern erteilt, die die schwierigen Ganzkörperdarstellungen beherrschten. Die drei hinzugefügten Holzschnitte könnten dann in Genf von weniger gut ausgebildeten Kollegen geschaffen worden sein. In den hinzugefügten Holzschnitten findet sich eine größere Menge von Figuren, wobei Abweichungen von der Perspektive oder andere Ungeschicklichkeiten nicht derart ins Gewicht fielen wie bei den Ganzkörperdarstellungen. Die Kampfszene enthält beispielsweise im Vordergrund viele Figuren, die überwiegend aus der leichter zu schneidenden Profilansicht dargestellt sind (mit der einzigen Ausnahme des am Boden liegenden Kriegers). Die Figuren im Hintergrund schließlich sind bar jeder Perspektive gezeichnet, was vor allem für ein schreitendes Kind mit Pfeil und Bogen gilt. Ebenso sind die Figuren im Hintergrund des Bildes mit den Teufelserscheinungen ohne Rücksicht auf die Proportionen der Körper abgebildet. Die Landschaftskulisse erfordert im damaligen Verständnis keine genaue Zeichnung der Gestalten, da diese besonders auf Karten in Landschaften hineinprojiziert wurden, weshalb hier angesichts der nur einige Zentimeter großen Figuren die mindere künstlerische Qualität nicht weiter ins Gewicht fällt.

Wahrscheinlich hat das Bildmaterial der qualitätsvollen Holzschnitte dem Drucker für eine zweite erweiterte Auflage nicht gereicht, worauf auch die Wiederholung einiger Abbildungen hindeutet. Er fügte deshalb noch einige einfache Holzschnitte hinzu, um zumindest die wesentlichen Teile von Lérys Bericht abzudecken.

Die Anlehnungen an die Illustrationen in Thevets Büchern sind im Übrigen bei allen Holzschnitten, besonders den weniger qualitätsvollen, offenkundig. Bei der künstlerisch gelungenen Darstellung des Tränengrußes (Tafel 21) analog zu 
Tabelle 2: Die Illustrationen in Lérys Histoire d'un voyage

(Seitenzahlen nach Ausg. 1975 [21580])

$\begin{array}{llll}\text { S. 107: } & \text { Ein Indianer mit Frau und Kind } & \text { Tafel } & 18 \\ \text { S. 207: } & \text { Zwei Männer mit Kriegskeule und Bogen } & \text { Tafel } & 19 \\ \text { S. 214: } & \text { Tötung eines Gefangenen } & \text { Tafel } & 14 \\ \text { S. 222: } & \text { Wiederholung des Holzschnitts S. 207 } & \text { Tafel } & 19 \\ \text { Zwischen S. 230/231: Kampfszene } & \text { Tafel } & 16 \\ \text { S. 235: } & \text { Teufelserscheinungen } & \text { Tafel } & 41 \\ \text { S. 246: } & \text { Zwei tanzende Indianer } & \text { Tafel } & .20 \\ \text { S. 284: } & \text { Der Tränengruß } & \text { Tafel } & 21 \\ \text { S. 301: } & \text { Trauer um einen Verstorbenen } & \text { Tafel } & 22\end{array}$

den Singularités 1982, 85v könnten sie auch auf gleichlautenden Beschreibungen dieser Sitte beruhen. Der Holzschnitt mit den tanzenden Indianern (Tafel 20) erinnert an eine Illustration Thevets, die auch die Herstellung der Fußrasseln aus den Früchten eines ebenfalls abgebildeten Baumes zeigt (Singularités 1982, 66v, Tafel 6). Diese naturkundliche dokumentarische Dimension entfällt bezeichnenderweise bei Léry. Die Haltung der Tänzer, die ihre Hand auf die Hüften stützen, ist bei beiden Holzschnitten analog. Anstelle der Beerdigungsszene bei Thevet (Singularités 1982, 82v; Tafel 8, Abb. 2) hat Léry die Trauer um einen soeben in einer Hängematte Verstorbenen abbilden lassen (Tafel 22). Die kauernden Frauen im Vordergrund finden sich bei ihm wie bei Thevet.

Die weniger qualitätsvollen Illustrationen wie die Tötung eines Gefangenen (214, Tafel 14), die Kampfszene (230f, Tafel 16) und das Faultier auf dem Holzschnitt mit den Teufelserscheinungen (235, Tafel 41) zeigen deutlich, dass der Schöpfer dieser Holzschnitte ein schon vorhandenes Vorbild brauchte, wobei sich die Anlehnung an die Illustrationen Thevets geradezu anbot. Dem Faultier hatte Thevet einen eigenen Holzschnitt gewidmet (Singularités 1982, 99v), bei Léry ist es im Hintergrund des Holzschnitts mit den Teufelserscheinungen (235) $\mathrm{zu}$ sehen. Auf der letztgenannten Illustration begegnen weiterhin einige bei Thevet abgebildete Untiere (Cosmographie 1575, 976v, Léry 1992, Panoramique VI) sowie die Langhäuser, die bereits auf Thevets Faultierabbildung auftauchen.

Nur der Holzschnitt mit den Teufeln findet sich nicht bei Thevet, obwohl er im Text ebenso wie Léry entsprechend der Konzeption der Zeit behauptet, die Indianer seien dem Teufel verfallen. Auch die von Léry berichtete Anekdote, ein Europäer habe im Namen Christi einen Teufel ausgetrieben, findet sich schon 
bei Thevet (Singularités 1982, 64v) und ist sicher von Léry (1975 [ ${ }^{21580], 234)}$ übernommen worden. Die theologischen Implikationen dieses Holzschnitts werden im Vergleich mit der Version Brys eingehender erörtert (s. unten 102ff).

Die übrigen qualitätsvollen Holzschnitte Lérys, die eine Indianerfamilie (1975 [21580], 107; Tafel 18) oder zwei Krieger (ebd., 207, Tafel 19; vgl. auch Staden Tafel 28, Abb. 2) zeigen, gehen nicht direkt auf Thevet zurück. Hier haben sicher die Holzschnitte von Jost Amman in Weigels Trachtenbuch als Vorbild gedient. Sie bewirken im Gegensatz zu den Massenszenen Thevets eine Fokussierung, die auch inhaltlich den Absichten Lérys entspricht, der bezeichnenderweise den brasilianischen Indianern große Teile seines Werks gewidmet hat.

Auch wenn die Illustrationen in Kenntnis des Werks von Thevet und der Holzschnitte von Jost Amman entstanden sind, kommt ihnen doch ihre eigene Originalität zu. Die Holzschnitte von Jean Cousin zeigen immer eine große Anzahl von relativ kleinen Figuren, was zwar eine räumliche Komposition erfordert, aber gleichzeitig ermöglicht, die Hell-Dunkel-Werte der einzelnen Gestalten etwas zu vernachlässigen.

Lérys Illustrator hat dagegen Figuren geschaffen, die eine größere Bildfläche ${ }^{56}$ ganz ausfüllen, was sowohl kompositorisch als auch in der Detailzeichnung der Schraffuren hohe Ansprüche stellte und der künstlerischen Entwicklung der Zeit entsprach. Dies zeigt ein Vergleich mit den neuen Illustrationen der Cosmographie, die ebenfalls stärker auf den Hell-Dunkel-Kontrast Wert legen.

Alle Holzschnitte sind (mit Ausnahme des einen wiederholten) verständlicherweise an der jeweiligen Textstelle, die sie illustrieren, eingefügt. Léry hat im übrigen zumindest einen Teil von ihnen in seinen Text mit einbezogen. Einige Passagen (1975 [21580], 105f, 222f, 245, 285, 300) deuten darauf hin, dass Léry zum Zeitpunkt, als er sein Manuskript verfasste beziehungsweise überarbeitete, schon mit dem Formenreißer, dem Drucker oder dem Vorzeichner das Programm der Illustrationen vereinbart hatte oder diese in Auftrag gegeben waren.

In Bezug auf die Verknüpfung von Bild und Text kommt dem ersten Holzschnitt eine Sonderstellung zu, insofern als der Autor nur hier eine eigene Bildbeschreibung (inscriptio) mit einbezieht:

${ }^{56}$ Die künstlerisch hochwertigen Holzschnitte Jean Cousins messen sowohl in den Singularités als auch in der Cosmographie ca. $105 \mathrm{~mm}$ Breite gegen 80-90 mm Höhe, Lérys qualitätsvolle Illustrationen $80 \mathrm{~mm}$ Breite gegen $135 \mathrm{~mm}$ Höhe. Bei Léry überwiegt dementsprechend das Hochformat, das sich für Personendarstellungen anbietet. Die weniger differenziert ausgeführten Abbildungen bei Thevet und Léry haben eigene Maße, die sich an dieses Maß angleichen können, überwiegend sind sie aber größer ausgeführt, da dies für den Künstler einfacher zu realisieren war. 
[...] vous le verrez comme il est ordinairement en son pays, \& tel, quant au naturel, que vous le voyez pourtrait cy apres, avec seulement son croissant d'os bien poli sur la poictrine, la pierre au pertuy de la levre: \& pour contenance son arc desbandé, \& ses flesches aux mains. Vray est que pour remplir ceste planche, nous avons mis au pres de ce Toüpinambaoults l'une de ses femmes, laquelle suyvant leur coutume, tenant son enfant dans une escharpe de cotton, l'enfant au reciproque, selon la façon aussi qu'elles les portent tient le costé de la mere embrassé avec les deux iambes: \& au pres des trois un lict de cotton, fait comme une rets à pescher, pendu en l'air, ainsi qu'ils couchent en leur pays. Semblablement la figure du fruict qu'ils nomment Ananas, lequel ainsi que ie le descriray cy apres, est des meilleurs que produise ceste terre du Bresil. (Histoire, 1975 [²1580], 105f)

Der Holzschnitt illustriert die voraufgehende ausführliche Beschreibung des Indianers, und der Text erläutert seinerseits den Holzschnitt mit. Auffallend ist weiterhin die künstlerische Überlegung, dass die Frau und das Kind vor allem deshalb abgebildet wurden, um die freie Fläche des Holzschnitts auszufüllen, woran sich ablesen läßt, wie bewusst die damaligen Illustrationen der Reiseberichte in Absprache zwischen Autor und Künstler geschaffen wurden. Die Ananas im Vordergrund, sicher angeregt durch einen ganzseitigen Thevetholzschnitt (Singularités 1982, 89v), ist gleichsam ein ethnologisches Zitat und füllt auch den einzigen noch verbliebenen freien Raum des Bildes aus. Thevet hatte seinem Werk eigene Pflanzendarstellungen beigegeben; Léry wollte wohl auch eine solche Abbildung bringen, stellt aber, auch dies bezeichnend, den Indianer in den Mittelpunkt der Abbildungen seines Werkes und fügt die Ananas als Beigabe am Bildrand hinzu. Analog dazu hat er auf dem Holzschnitt 246 (Tafel 20) neben den Indianern auch einen Affen und einen Papagei abbilden lassen, letzteren nach der Abbildung des Tränengrußes in Thevets Cosmographie $(1953,113 \text {; Tafel 9, Abb. 1) })^{57}$.

Diese Abbildung eines Indianers und seiner Frau wurde bezeichnenderweise noch öfter kopiert, so von Bry auf dem Titelkupfer seines dritten Bandes (Tafel 32), und noch im 18. Jahrhundert findet man sie als Teil einer größeren Abbildung in Lafitaus Mours des sauvages américains (1724, I, 97), die verschiedene Typen von Indianern zeigt. Bei beiden Autoren ist die Kenntnis von Lérys Werk gegeben, so dass ein direkter Rückgriff auf den Holzschnitt von Jost Amman nicht zwingend anzunehmen ist. Der Text-Bild-Bezug ist jedoch bei den etwas schlechteren Holzschnitten nicht mehr explizit im Text nachweisbar. Die Holzschnitte illustrieren zwar Beschreibungen des Textes, Léry erwähnt sie aber dort nicht mehr. Vermutlich wusste er zum Zeitpunkt der Überarbeitung seines Texts

${ }^{57}$ Lestringant hat die Übernahme dieser Details erkannt (Léry 1992, Panoramique VII). 
nichts von diesen geplanten Illustrationen, während er mit dem Drucker über die erste Serie der qualitätsvollen Holzschnitte genaue Vereinbarungen getroffen und diese zumindest als Vorzeichnung vor der Endredaktion seines Manuskripts gesehen hatte. Anscheinend gehen die drei übrigen Holzschnitte auf die Eigeninitiative des Druckers zurück, der einige ihm wichtig erscheinende Stellen zusätzlich mit Bildmaterial veranschaulichen wollte. Auf jeden Fall entsprechen sie inhaltlich der Konzeption Lérys, der ja die von ihm bewunderten Kampfszenen und die Tötung eines Gefangenen beschrieben hatte (Tafel 16, 14). Bei der Motivauswahl für diese beiden Holzschnitte spielt sicher das Vorbild Thevets eine Rolle, der analoge Szenen in seinem Buch hatte abbilden lassen (Tafel 15, 13; vgl. auch Sturtevant 1976, 442).

Sehen wir uns jetzt die innere Semantik der Holzschnitte Lérys im Detail an. Es geht hier vor allem um die Frage, ob sie entsprechend der theoretischen Prämissen, die im Anfangskapitel dieser Arbeit diskutiert wurden, auch als eine homogene Folge von inhaltlich-ikonographischen Aussagen gelesen werden können oder allein eine illustrierende und damit dienende Funktion gegenüber dem Text erfüllen, d.h. ohne den Text eventuell gar nicht verständlich sind ${ }^{58}$. Die textinternen Verweise auf die Holzschnitte mögen den Schluss nahelegen, dass es sich bei ihnen nur um eine Sichtbarmachung von kulturellen Alteritätserscheinungen handelt, die im Text an den jeweiligen Stellen beschrieben wurden und dem Autor und Illustrator vermutlich wegen ihrer Singularität auch als geeignet für eine Illustration erschienen. An diesen Stellen ging es jedoch vor allem um die Verknüpfung auf einer unteren, gleichsam mikroskopischen Ebene. Auf makroskopischer Ebene hingegen können die Holzschnitte auch als eine autonome Bildfolge gelesen werden, die zwar in inhaltlicher Kenntnis des Texts, aber doch gemäß einer weitgehend unabhängigen und damit auch separat vom Text zu verstehenden Intention aufzufassen sind. Eine Lektüre der Illustrationen als "monoseme" Einheiten, die nur auf ein semantisches Element bezogen sind (also beispielsweise den Text, die Folge $F_{1}$ bis $F_{n}$ der anderen Holzschnitte), wird dem weitaus komplizierteren und geschulteren Leseverhalten der damaligen ersten Rezipienten nicht gerecht werden.

Auffallend ist bei den Holzschnitten Lérys die offenkundige Entsprechung zu den Hauptelementen der thematischen Gliederung des Buches und ihrer Progression. Léry schreitet, auch wenn dies vielleicht unbewusst geschieht, von der physis zur psyche fort, d.h. von der äußeren Erscheinungsform des Indianers zu den mentalen Strukturen der fremden Kultur. Dementsprechend bietet der erste Holzschnitt das äußere Erscheinungsbild von Frauen und Männern, der folgende bringt den Übergang von der rein äußeren Beschreibung zu einer inneren Schilderung. Es geht zwar auch um die Visualisierung des Äußeren der Krieger

${ }^{58}$ Colin 1988, 31 bezeichnet diese Illustrationen als sogenannte "Vorführbilder", da sie ohne die "Vorführung" durch den Text nicht verständlich seien und zitiert als Beispiel die Abbildung des enduape-Federschmucks bei Staden (2. Buch, Kap. 17; vgl. Tafel 28, Abb. 2). 
mit dem abrasierten Stirnhaar und den Inzisionen als Ehrenzeichen für die getöteten Feinde, aber zugleich wird auf den psychologischen Aspekt der großen Bedeutung der Kriegsführung in der Tupinamba-Kultur verwiesen. Der nächste Holzschnitt zeigt die Folge dieser Kriege, die Tötung eines Gefangenen vor dem Ritual der Anthropophagie, die von allen Autoren der Zeit als Ausdruck extremer Rache direkt aus dem Streben nach Ehre im Krieg hergeleitet wurde. Die Anthropophagie als nicht auszuräumender Anklagepunkt gegenüber den indianischen Stämmen wird bezeichnenderweise ikonographisch bei Léry nicht direkt gezeigt, ein Holzschnitt stellt jedoch die Tötung des Gefangenen dar. Seine Leiche wird schließlich am linken Bildrand (S. 214; Tafel 14) in den Armen seiner Frau gezeigt, die rituell um ihn trauert. Die andere Anspielung auf die Tötung des Gefangenen findet sich auf dem unmittelbar folgenden Holzschnitt S. 222 (Tafel 19), wo allerdings nur am Bildrand der Kopf eines Menschen zu sehen ist. Im Vergleich zu den Holzschnitten in Thevets oder Stadens Werk, wo auch noch die Zerteilung des Körpers detailliert dargestellt wird, kann diese Art der Darstellung nur als ein zurückhaltender Verweis angesehen werden, der die grausamen Aspekte ausspart; Lestringant hat in Bezug auf den letztgenannten Holzschnitt treffend von einer "visuellen Synekdoche" gesprochen $(1978,593)$. Man könnte diese beiden Holzschnitte auch als serielle Darstellung ansehen. Der sich dem Betrachter direkt zuwendende Indianer, der die Keule in Händen hält, wäre dann der Totschläger, der soeben sein Opfer hingestreckt hat ${ }^{59}$. Der Indianer im Hintergrund mit Pfeil und Bogen müsste dann analog zur Darstellung des indianischen Paares (Tafel 18) als eine Beigabe angesehen werden, um den Holzschnitt auszufüllen und gleichzeitig einen thematisch verwandten Aspekt zu illustrieren. Die Kampfszene (Léry 1975 [21580], 230; Tafel 16) wiederum wiederholt das Moment des Krieges und der Rachsucht und hat damit zumindest im Verständnis des Autors und der Zeit einen konkreten Bezug zu den zwei vorangehenden Abbildungen.

Von diesem Element aus, das man vereinfacht als Illustration des Themenbereichs Kriegswesen, Rachsucht und dadurch bedingte Anthropophagie bezeichnen könnte, gelangen wir zur geistig höheren Ebene der indianischen Religion. Da sich jede Religion im theologischen Verständnis der Zeit auch als Kultus äußern musste, um überhaupt den Status einer Religion erhalten zu können, ist es nicht verwunderlich, dass eben dieser dargestellt wird, und zwar in Form der Tänze, deren religiösen Charakter Léry und seine sprachkundigen Begleiter klar verstanden haben. Das Zögern, den Indianern in diesen Kapiteln überhaupt eine Religion zuzugestehen, muss als offenkundig negative Bewertung der magischen

${ }^{59}$ Diese serielle Interpretation der beiden Holzschnitte ist auch deswegen gerechtfertigt, weil Bry im dritten Teil des dritten Buchs die Szene der klagenden Frau mit der Abbildung des sich nach der Tötung entfernenden Totschlägers auf einem Stich zusammengezogen hat (America, 1990, 145, Stich 2). Die Zeitgenossen haben diese beiden Bilder also als zeitliche
Folge gelesen. 
Strukturen ihrer Religion gesehen werden, die für die Zeitgenossen nur sehr bedingt als religio gelten konnte. Die Magie der Schamanen galt höchstens als Teufelskult und damit als satanische Parodie der einzig wahren christlichen Religion. Dass diese Sicht des Schamanismus auch Lérys Absicht entspricht, zeigen die expliziten Verweise auf die Walpurgisnacht bei der Schilderung der miterlebten religiösen Zeremonien. Auch der Holzschnitt über die Erscheinungen des Teufels - gleich ob er in Kenntnis Lérys veröffentlicht wurde oder nicht - ist konsequenterweise dem Holzschnitt über die Tänze vorgeschaltet als Hinweis, dass diese trotz aller Bewunderung des Erzählers Léry vom religiösen Standpunkt aus zu verurteilen sind. Vermutlich wollte der Drucker mit diesem Holzschnitt (der zu den geringerwertigen Illustrationen gehört) dem Leser einen deutlichen Hinweis geben, wie die Schilderungen Lérys zu deuten sind, da die verbalen Aussagen ambivalent sind und Lérys Bewunderung der fremden Gebräuche auch von modernen Interpreten als Zeichen einer Offenheit für die Fremdkultur ernstgenommen wurde ${ }^{60}$.

Der Tränengruß (Tafel 21) und die Trauer um einen Verstorbenen (Tafel 22) illustrieren schließlich den ethnologisch und semantisch wichtigen Bereich der sozialen Umgangsformen und Begräbnisriten, der schon in der antiken Literatur, etwa in Herodots Skythenschilderungen, thematisiert wurde und auch bei Thevet abgebildet worden war (Singularités, 1982, 85v; Cosmographie, 1953, 929v).

Als Ergebnis dieser Analyse zeigt sich, dass die Holzschnitte durchaus auch als eine autonome Folge gelesen werden können und Aspekten, die im Text noch ansatzweise ambivalent gestaltet sind, Eindeutigkeit verleihen. Die Auswahl der Illustrationen erscheint bei Léry im ersten Augenblick etwas willkürlich und kann vielleicht als Konkurrenz zu den reich illustrierten Singularités von Thevet gesehen werden. Bei einer genaueren Analyse zeigt sich jedoch eine klare theologische Aussage, die auch der inhaltlichen Intention des Werks entspricht. Die rein ethnographischen Beschreibungen (Äußeres der Indianer, Tränengruß und Bestattungssitten) fungieren gleichsam wieder als Rahmen, der den wichtigeren theologischen Aspekt einschließt. Für die Zeitgenossen und nicht nur für den kalvinistischen Pastor Léry hat in der Tat dieser Aspekt immer den Vorrang gegenüber der kulturgeschichtlichen ethnologischen Analyse und nimmt auch in seinem Werk einen bedeutenden Raum ein, so in der Schilderung der frühen vergeblichen Missionierung der Indianer durch einen Magier, den Léry mit einem Apostel gleichsetzt (s. unten 59).

Die Darstellung des Augenblicks vor der Tötung des Gefangenen und des in der typischen Pose des selbstbewussten, auf seine Taten stolzen Helden auf-

${ }^{60}$ Elias Canetti hat diese Lérystelle als Beispiel für die Schaffung einer Doppelmasse durch Trennung von Männern und Frauen geschildert. Vgl. Masse und Macht, 1980, 66ff. 
tretenden Totschlägers auf dem folgenden Holzschnitt ${ }^{61}$ bilden eine Einheit. Hierzu gehört auch die Kampfszene, die ebenfalls das Streben der Indianer nach Ehre durch den Kampf illustriert. Da diese Sitten eklatant gegen christlichmoralische Vorstellungen verstoßen, fordern sie die moralische Verurteilung geradezu heraus und bilden eine Art Übergang zu der prompt folgenden theologischen Bewertung der Indianerreligion.

Die Holzschnitte bringen damit die Hauptaspekte des Buchs auf einen bildlichen Nenner und geben so wie heutige Bebilderung dem flüchtigen Leser, der nicht alle Kapitel gelesen hat, eine klare Richtlinie an die Hand, wie die Informationen in dem Buch zu verstehen sind. Bei dem Holzschnitt über die Teufelserscheinungen kann man sogar sagen, dass die Aussage der Illustrationen expliziter und eindeutiger ist als die Semantik des Textes, obwohl sich keine prinzipiell andere Richtung ergibt, höchstens eine graduelle Verstärkung der im Text angelegten Aussage.

Das Bildmaterial in Lérys Buch erfährt nach der zweiten Auflage keine größeren Wandlungen mehr. Angemerkt sei noch, dass der Holzschnitt, der die Kampfszene zeigt und erstmals in der zweiten Auflage von 1580 in das Buch aufgenommen wurde, in der kritischen Ausgabe der Histoire (Léry 1975) nur halb abgebildet beziehungsweise nur der Teil einer größeren Platte ist. Der linken Gruppe der kämpfenden Indianer steht hier rechts eine Gruppe von Angreifern spiegelbildlich gegenüber (Tafel 16). Der vollständige Holzschnitt des Originals findet sich in der späteren Ausgabe von 1611 (Reverdin 1957, 89), die Reverdin für seine Auswahl aus Lérys Buch zu Rate gezogen hat. Direktes Vorbild ist ein entsprechender Holzschnitt Thevets in den Singularités (1982, 71v; Tafel 15, Abb. 1) und die Replik hierauf in der Cosmographie (1953, 184; Tafel 15, Abb. 2). In der Illustration bei Thevet finden sich ebenfalls einige am Boden liegende verwundete Indianer, von denen der im linken Bildteil sehr an denjenigen auf dem Holzschnitt in Lérys Werk erinnert.

\section{Die Holzschnitte in Lérys Buch und Thevets Illustrationen}

Bleibt noch der wichtige Aspekt der Omissionen des ikonographischen Materials gegenüber dem Vorbild Thevet. Léry hat offensichtlich die Werke Thevets (der immerhin "cosmographe du roi" und Leiter der königlichen Kunst- und Kuriositätensammlungen war) beim Leser als bekannt vorausgesetzt, wie man aus den zahlreichen Angriffen auf den illustren Gegner in seinem Text schließen kann. Auf die Illustrationen Thevets geht er an keiner Stelle ein und würdigt auch nicht ihre Qualität, die ihm sicher bewusst war. In dem Bemühen, ähnlich

${ }^{61}$ Man vergleiche etwa die Darstellung des Herkules in dem allerdings parodistisch übertriebenen Stich von Goltzius aus dem Jahre 1589 in Eros und Gewalt 1983, 81. Montaigne beginnt nicht umsonst seinen berühmten Essai “Des cannibales" mit der Reflexion über deren uneigennütziges Streben nach Ehre; er hat also die Informationen Thevets und Lérys direkt zum Ausgangspunkt seiner Reflexion genommen. 
qualitätsvolle Holzschnitte zu liefern, was ihm zumindest für einen Teil der Serie gelungen ist, zeigt sich aber deutlich der emulative Charakter von Lérys Vorgehen. Auffallend ist jedoch, dass die bei Thevet auf mehreren Holzschnitten und in allen verschiedenen Phasen gezeigte Anthropophagie in denjenigen Lérys nur angedeutet wird. Nur die Tötung des Gefangenen wird in einer Abbildung festgehalten, die noch dazu erst in der zweiten Auflage als einer der weniger qualitätsvollen Holzschnitte auftaucht. Die Brutalität dieser Illustration wird auch dadurch gemildert, dass nicht wie bei Thevet der zerteilte Körper des Opfers abgebildet wird, sondern der Moment im Zeremoniell vor der Tötung, wo das Opfer bereitwillig seine durch die Stammessitten vorgegebene Rolle übernimmt und den zur Ausführung der Exekution bestimmten Indianer durch Gesten und Worte herausfordert. Der Holzschnitt ist wiederum als synchrone Folge eines Ablaufs aufzufassen, da der Totschläger erst nach dieser zeremoniellen Rede zum tödlichen Schlag mit der erhobenen Keule ausholen wird. Am linken Bildrand schließlich werden die für die europäischen Beobachter unaufrichtigen Tränen der Frau des Getöteten gezeigt, die den Toten beweint, der in ihrem Schoß liegt.

Warum hat Léry oder der Drucker nun die Anthropophagie nicht direkt gezeigt, obwohl er sie in gleichem Maße wie Thevet oder die späteren französischen Reisenden verurteilt? Man darf dies sicher auf die Intention des Autors zurückführen. Léry hat in seinem Buch die Anthropophagie mit verurteilungswürdigen europäischen Sitten wie dem Wucher oder anthropophagen Grausamkeiten der Religionskriege verglichen. Damit soll der Kannibalismus natürlich nicht gerechtfertigt werden, aber er wird mit ähnlich grausamen Sitten in Europa in Bezug gesetzt, wodurch die Gleichsetzung der Indianer mit Tieren relativiert wird, die Thevet im Wesentlichen mit ihrer Menschenfresserei begründet hatte. Bei Léry verlagert sich der Schwerpunkt auf die theologische Ebene, was bei einem Kalvinisten, der nach seiner Rückkehr aus Brasilien Pastor wurde, auch verständlich ist. Er interpretiert den in ganz Amerika bezeugten Mythos eines Fremden, der in grauer Urzeit die Indianer besucht haben soll, als Erinnerung an eine frühe Apostelmission, die die Indianer abgelehnt hätten (Léry 1975 [21580], 254f). Damit beseitigt Léry zugleich das theologische Problem, dass den neuentdeckten Völkern Amerikas ihr Unglaube nicht vorgeworfen werden konnte, da sie ja vor dem Kontakt mit den Europäern keine Kenntnis vom Christentum haben konnten. Ihr Unglaube erklärt ihre Verfallenheit an teuflische Sitten wie die Kriege und die Anthropophagie, die der niedrigsten, nicht durch das Christentum geläuterten Kulturstufe entspricht, die aber Begleiterscheinungen des Unglaubens und nicht wie bei Thevet den primären Grund für die Verurteilung der Indianer abgeben. Lérys differenziertes Menschenbild stellt damit die Theologie in den Mittelpunkt. Entsprechend dieser Aussageintention kommt dem Holzschnitt über die Teufelserscheinungen zentrale Bedeutung im Bildgefüge des Textes zu. Die Indianer sind im theologischen Sinne Verworfene, weil sie die christliche Religion nicht angenommen haben, und angesichts dieser primären Schuld fällt für Léry die Anthropophagie als zu- 
sätzlicher Anklagepunkt nicht mehr wesentlich ins Gewicht, zumal ja auch christliche Europäer zu ähnlich bestialischen Taten fähig waren. Dass Léry trotz alledem von einer undifferenzierten Verurteilung Abstand genommen hat, zeigt sich darin, dass er den Indianern auch positive Charaktereigenschaften wie ihre Gastfreundschaft und ihre natürliche Nächstenliebe ("charité naturelle") zugute gehalten hat.

Dieses Beispiel zeigt, wie subtil die Bildauswahl die Argumentation des Buches widerspiegelt und dem Leser damit eine bestimmte Rezeptionshaltung vermittelt. Die Holzschnitte in Lérys Werk können damit sowohl als den Text erklärende semantische Folge als auch als eigene bedeutungstragende Einheit aufgefasst werden. Auf jeden Fall sind sie keine beliebigen Illustrationen, die mehr oder weniger willkürlich einzelne Textelemente in Szene setzen und verdeutlichen. Sie stehen in vielfachen semantischen Querverbindungen zum Text und untereinander, was bei der bisherigen Analyse der inhaltlich vielbeachteten Reiseberichte kaum in Betracht gezogen worden ist. Die genaue Übereinstimmung von Bild- und Textaussage deutet auf die bewusste Anfertigung des gesamten illustrativen Materials auf Anregungen von Seiten Lérys hin.

Im später von Bry erworbenen und zum Teil bis heute im British Museum erhaltenen Nachlass von John White, dem für seine Virginia-Illustrationen berühmten Künstler, haben sich auch einige Aquarelle erhalten, die bis auf wenige Details exakt den fünf qualitätsvollen Illustrationen in Lérys Buch entsprechen (abgebildet in Hulton 1984, 137-141). Hulton stellt die These auf (ebd., 194), dass diese Skizzen nicht aus Lérys Werk kopiert sind, sondern dass sie und die Holzschnitte Lérys aus einer gemeinsamen, vermutlich gedruckten Quelle stammen. Die Holzschnitte Ammans, deren Vorbildcharakter für Léry deutlich erkennbar ist, waren Hulton nicht bekannt. Dennoch ist die Ähnlichkeit der Bilder Whites zu Lérys Versionen zu groß, um einen alleinigen Rückgriff auf das Trachtenbuch annehmen zu dürfen. Zudem finden sich ja Kopien aller fünf qualitätsvollen Stiche bei Léry, von denen nur zwei von Ammans Holzschnitten beeinflusst werden konnten. Die Unterschiede zwischen den Aquarellen Whites zu den Illustrationen Lérys sind gering, aber nicht zu vernachlässigen. Die Trauerszene und die Begrüßung eines Fremden sind selbst in den Details identisch. Auf der Abbildung eines Totschlägers mit Kriegskeule fehlt allerdings der Indianer im Hintergrund, der einen Pfeil abschießt. Dies entspricht wiederum einem Holzschnitt Ammans, der ebenfalls nur einen Krieger zeigt (Weigel 1969, Abb. 182). Der Kopf des Getöteten ist bei White nicht wie bei Léry diskret am Bildrand plaziert, sondern liegt abgeschnitten vor den Füßen des Indianers, der sich wie bei Léry den Körper mit Ehrennarben verziert hat. Die Körperhaltung und die Keule sind identisch. Der zweite Unterschied besteht allerdings nur darin, daß der Papagei am linken oberen Bildrand auf dem Aquarell mit den beiden Tänzern die Flügel ausbreitet, während er bei Léry still dasitzt. Ansonsten stimmen die Bilder vollständig überein. Der Papagei auf dem Bild der Sammlung White scheint aber erst nachträglich geändert worden zu sein, da sich hier selbst auf der Reproduktion Spuren einer Ausradierung oder Überklebung 
erkennen lassen und ein Rest der Schwanzfedern eines Tieres mit der Haltung des Léryschen Papageis erkennbar ist. Auf einem weiteren Aquarell, der Darstellung der indianischen Familie, ist schließlich die Hängematte auf Lérys Holzschnitt im Hintergrund weggelassen. Auch dies entspricht der Darstellung bei Jost Amman in Weigels Trachtenbuch von 1577 (1969, Abb. 181).

Die geringen Unterschiede in der Darstellung zwischen den Holzschnitten Lérys und den Aquarellen der Sammlung White können als künstlerische Freiheiten des Kopisten White angesehen werden, der auch das Trachtenbuch kannte und in einigen Fällen dessen Version den Abbildungen bei Léry vorzog. Natürlich ist die Möglichkeit nicht auszuschließen, dass White die Vorzeichnungen der Léryschen Holzschnitte mit geringfügigen Änderungen in Händen gehabt hat. Sehr wahrscheinlich hat White die Holzschnitte von Jost Amman aus dem Trachtenbuch gekannt und beide Bücher zum Vorbild seiner Kopien genommen. Die These Hultons von einer gemeinsamen Quelle für Léry und White kann aber nur für die zwei aus dem Trachtenbuch kopierten Holzschnitte zutreffen, während sich die anderen nur in Lérys Buch finden. Eine von Hulton angenommene gedruckte Quelle für alle fünf Holzschnitte scheidet wohl aus. White hat neben seinen eigenen Werken eine Sammlung von Illustrationen mit verschiedenen Indianertypen angelegt, die er vielleicht als Grundlage für die Illustrationen eines Trachtenbuchs sammelte, das nie erschien. Dies würde sein Interesse an den Illustrationen in Lérys Buch bzw. dem Trachtenbuch von Weigel und Amman hinreichend erklären. Das Fehlen der drei einfachen Illustrationen der Ausgabe von 1580 erklärt sich aus der Benutzung der editio princeps von 1578, die nur die qualitätsvollen Holzschnitte enthält. Bry kannte sicher bei seiner Ausgabe von Lérys Text dessen spätere Editionen, da er sich ja auch an den weniger qualitätsvollen Holzschnitten ab der zweiten Ausgabe 1580 inspiriert und im Hinblick auf den Text die späteren Ausgaben zugrunde gelegt hat.

\section{Zwischen Historiographie und Ethnologie: die Illustrationen in Stadens Warhafftige Historia (1557)}

Die zeitgenössischen deutschen Berichte über Südamerika sind im Gegensatz zu den französischen Texten mit Ausnahme des Berichts von Nikolaus Federmann über das Engagement der Welser in Venezuela und der Briefe von Philipp Hutten nicht in Zusammenhang mit deutschen Kolonialgründungen entstanden. Dennoch haben einige wenige Deutsche sich als Soldaten oder Handwerker auf portugiesischen und spanischen Schiffen verdingt und nach ihrer Rückkehr Berichte über die neuentdeckten Länder verfasst. An erster Stelle zu nennen ist der in vielen Auflagen weitverbreitete Bericht von Hans Staden aus Homberg Warhafftige Historia und beschreibung eyner Landtschaft der Wilden, Nackten, Grimmigen Menschenfresser Leuthen, in der Newenwelt America gelegen [...], ([1557] 1978). Ein weiterer bekannter Bericht stammt von dem Straubinger Ulrich Schmidel (1500/1510-1580/81), der als Landsknecht in spanischen Diensten von Buenos Aires aus das Innere des Gran Chaco erkundete. Schmidel 
blieb von 1534 bis 1554 in Südamerika und verfasste nach seiner Rückkehr eine Warhaftige Historia einer wunderbaren schiffart ${ }^{62}$ (erstmals Frankfurt, bei Sigmund Feyerabend 1567), die Bry 1597 im 7. Buch seiner Kollektion veröffentlichte. Dieser Text enthält in der Fassung der Brys jedoch nur drei eigens gefertigte Illustrationen (America 1990, 249-251). Schmidels Text war sicherlich bei den Zeitgenossen weniger bekannt als Stadens Werk, was sich an der geringen Zahl der Auflagen im 16. Jahrhundert im Gegensatz zu den zahlreichen Ausgaben Stadens ablesen lässt. Eine der drei Illustrationen der Bry'schen Fassung zeigt Spanier als Kannibalen, die während einer Hungersnot das Fleisch dreier am Galgen hingerichteter Kameraden abschneiden und verzehren. Diese Episode ist vermutlich deshalb von Bry illustriert worden, weil sie an einen Gedankengang Lérys erinnert, der während der Religionskriege in Frankreich ähnliche Fälle von Kannibalismus erlebt hatte und dies in seiner Histoire als Argument heranzieht, um zu zeigen, dass nicht allein den Indianern der Kannibalismus zum Vorwurf gemacht werden kann. Die anderen beiden Stiche zeigen die Bestrafung von Indianern, die Christen getötet haben, durch den Tod auf dem Scheiterhaufen sowie den Empfang bei einem Indianerhäuptling. Erst eine neue Auflage von Schmidels Werk, die 1599 bei dem Nürnberger Levinus Hulsius erschien, ist mit zahlreichen Illustrationen versehen.

\section{Stadens Reiseerlebnisse und das Authentizitätsproblem}

Hans Staden (1526?-1576?) stammte aus Homberg (Efze) in Nordhessen. Die Stadt war 1526 Tagungsort der Homberger Synode, die die Einführung der Reformation in Hessen beschloss. Dieser protestantische Hintergrund sollte auch im Werk von Staden eine Rolle spielen. Vermutlich erlernte Staden in dem nahegelegenen Erzbau- und Gießereiort Fischbach ein Handwerk, das ihn befähigte, auf seinen späteren Reisen als Kanonier tätig zu sein.

Hans Staden verließ erstmals im Jahre 1547 seine hessische Heimat, die vom Schmalkaldischen Krieg, an dem er wahrscheinlich persönlich teilgenommen hat, verwüstet worden war. Vielleicht war auch die angeordnete Rückkehr zum katholischen Bekenntnis ein Grund für Staden, sich außer Landes zu begeben. Er reiste über Bremen, Holland und Lissabon auf einem portugiesischen Schiff als Büchsenschütze nach Recife, von wo aus er schon 1549 nach Europa zurückkehrte. Über diese erste Brasilienreise berichten die Kapitel 1-5 der Warhafftige(n) Historia. Bei seiner zweiten Brasilienreise verpflichtete er sich 1550 als Kanonier bei einer Expedition, die von dem zum Statthalter des La Plata-Gebiets ernannten Spanier Diego de Sanabria ausgerüstet wurde und unter dem Kommando des Juan de Salazar im Auftrag des spanischen Königs den Rio de la Plata und die Gegend des heutigen Paraguay erforschen und besiedeln sollte. Die Expedition brach mit drei Schiffen von dem spanischen Hafen San Lucar de Barameda auf. An der brasilianischen Küste, in der Nähe

${ }^{62}$ So der Titel ab der Ausgabe von Hulsius 1599 (Schmidel 1599b). 
des heutigen Florianópolis (Bundesstaat Santa Catarina), auf der Höhe des 28. südlichen Breitengrades, trafen sich die zwei übriggebliebenen Schiffe der Expedition, das dritte blieb verschollen. Da eines der Schiffe in der Bucht von Santa Catarina sank, konnte die Fahrt mit dem einzigen verbliebenen, das nicht alle Reisenden aufnehmen konnte, nur von einem Teil der Mannschaft fortgesetzt werden. Ein anderer Teil schlug sich auf dem Landweg nach Asunción durch. Die Europäer mussten zwei Jahre von Indianern unterstützt in der Wildnis verbringen. Staden blieb bei der Hauptgruppe an der Küste, die sich später an einen nahegelegenen Hafen namens Viaçá begab. Er nahm an dem Versuch des Kapitäns Juan de Salazar teil, aus dem nahegelegenen portugiesischen Hafen São Vicente Hilfe zu holen. Das Unternehmen endete mit einem Schiffbruch südlich der Mündung des Rio São Lorenço. Staden konnte sich mit seinen Mitreisenden retten und gelangte nach São Vicente. Der Rest der in der Bucht von Viaçá verbliebenen Expeditionsteilnehmer wurde mit einem gecharterten Schiff nach São Vicente gebracht. Staden schied aus dem spanischen Unternehmen aus, blieb in São Vicente und verdingte sich für zwei Jahre bei dem portugiesischen Gouverneur Tomé de Souza. Er wurde Kommandant eines befestigten Außenpostens auf einer Insel namens Santo Amaro in der Bucht von Santos. Zusammen mit der auf dem Festland gegenüberliegenden Festung Bertioga sollte dieser Außenposten die Zufahrt zur Stadt São Vicente vor Indianerangriffen schützen.

In der Nähe dieses Stützpunkts auf der Insel wurde Staden Ende 1553 oder Anfang 1554 von mit den Portugiesen verfeindeten Tupinamba-Indianern gefangengenommen und verschleppt. Bei den Indianern lebte er in ständiger Furcht, Opfer der Menschenfresserei zu werden und überstand diese Situation nur durch seine Fähigkeit, sich unbewusst an die Rolle eines indianischen Magiers anzugleichen und Regen sowie andere Ereignisse vorauszusagen. Im Oktober des Jahres 1554 wurde er von Seeleuten eines französischen Schiffs, die gute Beziehungen zu den ansässigen Indianern hatten, freigekauft und segelte auf diesem Schiff über Rio de Janeiro nach Honfleur zurück. Wohl im Sommer 1555 gelangte er in seine hessische Heimat und ließ sich in Wolfhagen nieder, wo er das Salpetersieden, Grundlage der Pulverherstellung, ausübte ${ }^{63}$. Im März 1557 erschien Stadens Bericht über seine Gefangenschaft bei den Tupinamba erstmals bei dem Drucker Andreas Kolbe in Marburg. Vermutlich im Jahre 1576 starb Staden in Wolfhagen während einer Pestepidemie.

Die Bedeutung von Stadens Buch kann hier nicht im Einzelnen gewürdigt werden $^{64}$. Sein Bericht ist nach überwiegender Meinung der Forschung neben

${ }^{63}$ Vgl. hierzu das Vorwort der Ausgabe Staden 1964, 5-25.

${ }^{64}$ Den besten Überblick über den historischen Forschungsstand bietet immer noch die Einleitung von Maack und Fouquet (Staden 1964, 1-25). Literaturwissenschaftliche Aspekte des Werks behandeln Wenzel 1991 und Neuber 1991, 1992. Zur Kannibalismusschilderung ist die Arbeit von Wendt 1989 einschlägig. 
Lérys und Thevets Büchern, dem Ende des 16. Jahrhunderts geschriebenen Bericht des Engländers Anthony Knivet ${ }^{65}$ und den Werken des portugiesischen Jesuiten Joseph de Anchieta ${ }^{66}$ eines der wichtigsten Dokumente über das Leben der Küstentupi. Sein für die Reiseliteratur der Zeit in einem außerordentlich persönlichen Ton gehaltener Reisebericht, geprägt durch den heilsgeschichtlichen Bezug auf protestantische Gläubigkeit, besticht durch seine genaue Beobachtungsgabe und wurde bis heute in zahlreichen Neuauflagen und Neubearbeitungen wiederaufgelegt ${ }^{67}$. Sicher hatten sich dieser schon an den Auflagen des 16. Jahrhunderts abzulesende große Erfolg und die Ähnlichkeit der Berichte mit Lérys Beobachtungen die Brys zu einer Zusammenfassung beider Texte im dritten Band ihrer Kollektion veranlasst.

Die Authentizität von Stadens Buch, insbesondere seine Schilderung des rituellen Kannibalismus, wurde immer wieder in Zweifel gezogen. Die Anthropophagie der brasilianischen Ureinwohner ist von Arens (1979) besonders in Bezug auf Stadens und Lérys Darstellung geleugnet worden. Arens' Thesen wurden, was Stadens Werk betrifft, schon von Forsyth (1985) überzeugend widerlegt. Arens' Leugnung des Kannibalismus der Tupinamba wurde jüngst von Heidi Peter-Röcher (1994) wiederaufgegriffen. Die Autorin glaubt, Léry und die portugiesischen Jesuiten widerlegen zu können, indem sie behauptet, dass diese nirgends vom Essen des Fleisches Getöteter berichten, was im eklatanten Gegensatz zu expliziten Textstellen steht. Stadens Bericht wird wegen der Widersprüche in den Schilderungen zwischen dem erzählenden ersten Buch und dem ethnologischen zweiten Buch als unglaubwürdig hingestellt. Staden habe zwar tatsächlich geglaubt, kannibalistische Akte zu sehen, seine Wahrnehmung sei allerdings durch sein Vorwissen über den brasilianischen Kannibalismus beeinflußt worden, das ihn zu einer falschen Interpretation der Realität gebracht habe.

Auch wenn man diesen Kritikern Stadens und anderer zeitgenössischer Reiseschriftsteller zugestehen muss, dass Aussagen über die Bedeutung des Kannibalismus und die Anzahl der Tötungen schwierig zu machen und sicherlich viele Werke mehr von einer Darstellungstradition geprägt sind als von eigener Wahrnehmung der Schreibenden, kann angesichts der Quellenlage an der Existenz des Kannibalismus unter südamerikanischen Indianern kein Zweifel bestehen. Astrid

${ }^{65}$ Knivets Bericht über seine Brasilienreise ca. 1591-1601, die ihn mit Potiguara der Gegend des Rio Grande und Tamoio (=Tupi) von São Paulo in Verbindung brachte, erschien in der von Samuel Purchas 1625 herausgegebenen englischen Reisesammlung Hakluytus posthumus or Purchas his pilgrimage in Bd. 16; im selben Band findet sich auch ein Léryexzerpt (518-79).

${ }^{66} \mathrm{Vgl}$. Anchieta: Obras completas, Bd. 11. 1984ff. Vgl. bes. die Doutrina cristã auf Tupi (Bd. 10,1 und 10,2, 1992), die Lírica portuguesa e tupi, (Bd. 5, 1984) und den Dialogo da fe, (Bd. 8, 1988).

${ }^{67}$ Die Ausgabe 1964, 214-231 verzeichnet insgesamt 83 verschiedene Ausgaben in zahlreichen Sprachen, von denen einige allerdings apokryph sind, so eine angeblich in Cherbourg erschienene französische Ausgabe von 1559. 
Wendt (1989) hat das reichhaltige zeitgenössische Quellenkorpus über den Kannibalismus in Südamerika in einer ethnologisch ausgerichteten Arbeit analysiert, in der sie zu dem Ergebnis kommt, dass - selbst bei berechtigten Zweifeln an dem Wahrheitsgehalt der Kannibalismusschilderungen der ersten Dokumente über Südamerika wie den Vespuccibriefen - die späteren Berichte von Staden, Thevet, Léry, von portugiesischen Autoren wie Soarez de Souza, Magalhães de Gândavo oder die Briefe portugiesischer Jesuiten, die alle den Kannibalismus brasilianischer Indianer bezeugen, aufgrund ihrer einheitlichen Wahrnehmung trotz einzelner Unrichtigkeiten glaubwürdig sind (Wendt 1989, 214). Ungeachtet der negativen Bewertung des Kannibalismus bei den genannten Autoren dienen die Schilderungen nicht in allen Fällen als Vorwand zur Diskriminierung des Indianers und gewinnen damit an Wert. Selbst wenn Stadens im Übrigen recht sachlicher und trotz eindeutiger Verurteilung nicht polemischer Bericht über die Anthropophagie der Sensationslust des Publikums entgegenkommt (so auch die Bewertung von Wendt 1989, 79ff) und stellenweise zeitgenössische Vorbilder verarbeitet, wie Annerose Menningers rezeptionsgeschichtliche Studien (1992, 1995) konstatieren, ist dies noch kein Grund, den Wahrheitsgehalt der Kannibalismusschilderungen von Stadens Bericht ganz in Frage zu stellen, wie dies Menninger getan hat. Die Leugnung des Kannibalismus der Tupi beruht zumeist auf der unbewussten Absicht, in einer nachträglichen Ehrenrettung der autochthonen Bevölkerung die Alterität fremder Kulturen, die sich im Kannibalismus in besonders krasser Weise zeigt, auf ein Minimum zu reduzieren. Menningers Versuch, Stadens Kannibalismusschilderungen ausschließlich als Kompilation zeitgenössischer Quellen hinzustellen und dem Autor eine an den Publikumserwartungen und am Markterfolg orientierte sowie mit Hilfe des Professors Dryander professionell produzierte Fälschung großen Stils nachzuweisen, erweist nicht nur der Bildung und dem Scharfsinn eines einfachen Landsknechts zuviel Ehre, sondern verkennt auch die Authentizität vieler Details seiner Schilderungen, die von französischen und portugiesischen Quellen bestätigt werden. Die Autorin erklärt diese Übereinstimmungen mit der nur zum Teil glaubwürdigen Hypothese, Staden habe von deutschen Übersetzungen der bei weitem nicht so ausführlichen Vespucci-Briefe oder einigen in Italienisch veröffentlichten und deshalb Staden oder selbst Dryander wohl kaum bekannten Jesuitenbriefen Nóbregas abgeschrieben. Die Ähnlichkeiten in Thevets und Lérys Berichten werden dann durch die Abhängigkeit Thevets (und folglich Lérys) von Staden erklärt, eine These, die, wie schon in Bezug auf die Ikonographie der Bücher oben dargelegt, aus zeitlichen Gründen nicht zu halten ist. Übereinstimmungen zwischen Büchern können im Übrigen auch auf gleiche Wahrnehmung zurückgehen, die dann durch ähnlichlautende Quellen bestätigt werden (siehe die trotz einiger eher marginaler Differenzen zahlreichen $\mathrm{Pa}$ rallelen Lérys $\mathrm{zu}$ Thevet) und erklären sich nicht zwangsläufig durch Kompilation, selbst wenn dies in vielen Reiseberichten oder Kosmographien der Zeit der Fall ist. Allein der Nachweis einer Rezeption anderer Autoren erlaubt kein erkenntnistheoretisch relevantes Urteil über die Wahrheit des Berichteten. 
Staden hat sein Buch, wie wir aus seiner Vorrede wissen, auf Anregung des Landgrafen Philipp von Hessen geschrieben, dem es auch gewidmet ist. Der Marburger Professor Johannes Dryander hat das Werk durchgesehen und eine eigene Vorrede hinzugefügt, die insbesondere Stadens Glaubwürdigkeit und sein Gottvertrauen lobend hervorhebt. Dryander hat wohl auch die für die Genreentwicklung des Reiseberichts richtungsweisende Aufteilung der narratio und descriptio in zwei Bücher angeregt. Das erste Buch enthält in insgesamt 54 Kapiteln die Geschichte von Stadens zwei Brasilienreisen, seiner Gefangenschaft bei den Indianern bis zu seiner Rückkehr nach Europa. In einem zweiten Buch bringt der Autor einige ethnologisch ungemein wichtige Beobachtungen über das Leben und die Sitten der Indianer. Dieser Teil entspricht den auch bei Léry separaten descriptio-Teilen. Beide Bücher sind mit einer großen Anzahl von wohl auf Stadens genaue Vorgaben zurückgehenden Holzschnitten eines unbekannten Künstlers versehen. Das Buch ist offensichtlich in großer Eile erstellt worden ${ }^{68}$, um der Neugierde des Publikums gerecht zu werden. Darauf deutet auch das Erscheinen nur eineinhalb Jahre nach Stadens Rückkehr hin. In Marburg standen keine großen Künstler vom Format eines Jean Cousin zur Bebilderung des Buchs zur Verfügung, umso bemerkenswerter ist es, dass der Erstdruck eine große Anzahl von thematisch pertinenten Illustrationen enthält. Diese sollten sicher die Verkäuflichkeit des Buchs besonders bei den im Lesen weniger geübten Zeitgenossen fördern (vgl. auch Wendt 1989, 80f).

Die Bedeutung der Stadenschen Illustrationen liegt weniger in ihrem künstlerischen Wert als in der Geschlossenheit einer erzählenden Sequenz, die Bry dann später übernehmen konnte. Besonders die Illustrationen des zweiten Teils haben zudem durch ihre dokumentarische Qualität einen erheblichen ethnologischen Wert und werden bis heute als weitgehend korrekte Darstellungen des indianischen Lebens geschätzt ${ }^{69}$.

${ }^{68}$ So sind die Holzschnitte der Kapitel 3, 9, 12, 18, 47 vom Formschneider seitenverkehrt geschnitten worden, wie Staden in den Errata ohne Nennung der Holzschnitte auch angibt; bei zahlreichen Kapiteln fehlt zudem die Numerierung oder ist fehlerhaft.

${ }^{69} \mathrm{Vgl}$. auch Wendt 1989, 81, die Stadens Illustrationen im Vergleich zu Thevets Bildern zurecht als authentischer ansieht. Abreu Campanário (1980) hat den Holzschnitten Stadens ein Kapitel seines mehr paraphrasierenden als analysierenden Staden-Buchs gewidmet. Er beschreibt einige ausgewählte Holzschnitte, versucht besonders die dargestellten Fische und Bäume zu identifizieren, bringt aber keinen strukturellen oder kunstgeschichtlichen Ansatz zum Verständnis der Illustrationen. 


\section{Staden und die deutsche Bildtradition}

Die Illustrationen in Stadens Warhafftige Historia fügen sich in die deutsche Tradition der Indianerabbildungen seit Vespucci ein (Wendt 1989, 81), wie am Beispiel des Münchner Holzschnitts von 1505 schon aufgezeigt wurde. Dennoch sind sie in ihrem Versuch, eine fremde Kultur umfassend zu schildern, für ihre Zeit singulär. Toscano del Banner (1992) hat der Herkunft der Illustrationen eine eigene Analyse gewidmet, die trotz der Übernahme von Einzelelementen zeitgenössischer Holzschnitte den eigenständigen Charakter der Bildlichkeit bei Staden betont. Die Schiffsdarstellungen lehnen sich beispielsweise an eine ähnliche Darstellung in Hans Sebald Behaims 1538 und 1539 erschienener Apokalypse an (ebd., 63), während andere an Stadtillustrationen der Cosmographia Sebastian Münsters (besonders in der Ausgabe Basel 1552 und öfter) erinnern, wo sich auch einzelne Tierdarstellungen ähnlich denen bei Staden als Vignetten finden. Auch die Orientierung an zeitgenössischen Flugblättern mit Schlachtendarstellungen, etwa einer der Schlachten von Mühlberg an der Elbe 1547 während des Schmalkaldischen Kriegs, ist wahrscheinlich. Interessanter als diese inhaltlich wenig aussagekräftigen Übereinstimmungen ist Toscano del Banners Analyse, der in den Darstellungen Stadens in der Kannibalismusszene Anklänge an religiöse Darstellungen des Menschen unter dem Kreuz sieht, auch wenn diese Übereinstimmung wohl eher auf die sich anbietende Illustration der in der Tat lebensbedrohlichen Situation Stadens als auf eine bewusste Gestaltungsabsicht des Künstlers zurückgeführt werden kann. Toscano del Banner erkennt allerdings sehr gut die spannungssteigernde Funktion der Wiederholung der Stiche aus Kapitel 22 und 24 in der Kannibalismussequenz. Erst auf dem letzten Holzschnitt des Kapitels wird die Spannung aufgelöst: Staden erscheint hier - durch sein Monogramm gekennzeichnet - noch lebend als Betender. Der Illustrationszyklus erzeugt damit bei einer bloßen Betrachtung der Holzschnitte ein textunabhängiges Spannungsmoment. Diese Analyse ist sicher zutreffend; da die Existenz dieses Buches Stadens Überleben jedoch voraussetzt, dient diese Anordnung der Holzschnitte wesentlich dazu, den Leser auf den Text neugierig zu machen und das Interesse von der Tatsache des Überlebens auf die Schilderung, wie es Staden gelang, sich aus den ihn bedrohenden Gefahren zu retten, und damit auf die Lektüre des Texts selber zu lenken. Die Kannibalismusdarstellungen sind neben der ikonographischen Funktion textunabhängig zu lesen und dienen auch als Anreiz, um dem Leser den Kauf und die Lektüre des Buchs nahezulegen.

Stadens Holzschnitte hier im Einzelnen inhaltlich zu analysieren, würde in eine Nacherzählung der Episoden des Buches münden. Die wichtigsten inhaltlichen Elemente sind in einer Liste im Anhang behandelt (138f), einige wesentliche Aspekte sollen im Kapitel mit den Übernahmen der Brys herausgearbeitet $w^{2} e^{7}{ }^{70}$. Allgemein kann der szenische und sequentielle Charakter eines Groß-

${ }^{70}$ Vgl. hierzu z. B. Colin 1988, 207-212; zur Rezeption Stadens durch Bry ebd., 257-264. 
teils der Holzschnitte festgestellt werden. Da Stadens Buch seiner eigenen Geschichte einen bedeutenden Platz zuweist, liegt ein Schwerpunkt auf den "historiographischen" Abbildungen (z. B. den Kämpfen zwischen Indianern und Europäern). Stadens Reisebericht war im Gegensatz zu den Büchern von Thevet und Léry, die zumindest von ihrem Anspruch und der Bildung ihrer Verfasser her wissenschaftliche Erkenntnisse bieten wollten, für ein breites Publikum geschrieben. Zudem dürfte Staden, was selbst angesichts der Hilfestellung des Professors Dryander bei der Abfassung des Buchs an seiner unbeholfenen Schreibweise abzulesen ist, nicht über die Bildung des Geistlichen Thevet oder des Pastors Léry verfügt haben. Stadens Bildmaterial sollte die Beschreibungen des Buches visualisieren, während bei den französischen Autoren der ästhetische und wissenschaftliche Anspruch des Textes und der Illustrationen fühlbar ist.

Neuber $(1990,253)$ hat die Bedeutung der Illustrationen des Buchs im Kontext der Reiseliteratur der Zeit gesehen, die stilistisch dem genus humile oder medium angehört. Die sich an die Historiographie angleichende Reiseliteratur muss im Sinne der Objektivität das Gebot der Affektlosigkeit befolgen. Dieser Affekt, der sich im Text nicht äußern darf, kann sich aber im Bild zeigen. Diese These ist für die Gattung des Reiseberichts allgemein sicher überzeugend; im Falle Stadens bietet die von Neuber erkannte Theologisierung des Reiseberichts die Möglichkeit, einen gleichsam religiös motivierten Affekt, etwa das Mitleiden des Lesers mit dem Erzähler, dessen Leben bedroht ist, in den Text zu integrieren. Dennoch ist es sicher zutreffend, dass die deskriptiven Passagen besonders im ethnologischen zweiten Teil des Buchs eine überraschende Sachlichkeit an den Tag legen, während im Gegensatz dazu die hilflosen und entsetzten Gesten des abgebildeten Staden auf einigen der Holzschnitte des zweiten Buchs eine deutliche moralische Wertung ausdrücken.

Staden hat sich selbst auf einigen der Holzschnitte abbilden lassen. Er führt damit gleichsam seine Geschichte in Bildern vor. In Kapitel 18 wird beispielsweise der an seinem Bart leicht erkennbare Staden gefesselt vor den Indianerhäuptling Konyan Bebe (der oben 43 f erwähnte und von Thevet auch porträtierte Quoniambec, s. Tafel 10, 11) geführt, in Kapitel 30 inmitten einer Gruppe sitzender Indianer mit Tabakrauch angeblasen. An dieser Stelle bringt im Übrigen die Illustration über das Rauchen eine zusätzliche Information, die im eigentlichen Text fehlt (vgl. Toscano del Banner 1991, 70). Dies zeigt deutlich, dass die im Bildmaterial verarbeiteten ethnologischen Fakten mit Sicherheit von Staden selbst herrühren.

Meist wird der Erzähler auf den Bildern des Buchs betend dargestellt, was neben den Schilderungen, wo er von Gebeten während seiner Todesangst spricht, natürlich auch der mehrfach betonten protestantischen Frömmigkeit Stadens entspricht (vgl. auch Wendt 1989, 82, und 82, Fußnote 1). Der Autor hat laut Vorwort (1978 [1557], unpag., Blatt A2v) sein Buch explizit als Dank an Gott für die Erlösung aus der lebensbedrohlichen Gefangenschaft der Indianer geschrieben. 
Wichtig ist auch der Holzschnitt im 2. Buch, Kap. 29, 11, wo Stadens vor der Brust verschränkte Hände seine Hilflosigkeit ausdrücken, die Anthropophagie zu verhindern. Dass auf den ersten beiden Illustrationen der Anthropophagiesequenz im Kapitel 29 des zweiten Buchs das Opfer der Gestalt Stadens ähnelt, liegt daran, dass diese beiden Holzschnitte schon im ersten Buch (Kap. 22 und 24) verwandt wurden. Das getötete Opfer der folgenden Holzschnitte dieser Sequenz ist ein Indianer. Nur auf der letzten Illustration (Kap. 29, 11) ist noch einmal Staden abgebildet (durch sein Monogramm H. S. auch benannt), der mit hilflos vor der Brust gekreuzten Händen die Riten des Kannibalismus beobachtet. Die Holzschnitte Kap. 29, 3-11 bilden stilistisch eine Serie, selbst wenn der Unterschied zu den anderen Illustrationen nicht sehr stark ins Auge fällt. Auf jeden Fall sind die Figuren geringfügig größer gezeichnet als in den Gruppenbildern der anderen Holzschnitte und stehen im Mittelpunkt der Darstellung, während die Landschaftskulisse nur noch im Hintergrund angedeutet ist. Dies liegt natürlich an der inhaltlichen Vorgabe des Autors, die Zeremonien der Anthropophagie genau zu schildern. Vermutlich wurden diese Holzschnitte in einer Serie erstellt. Die Unterschiede sind aber nicht groß genug, um die Zuordnung zu einem anderen Künstler zu rechtfertigen.

Der im ersten Buch überwiegende Typus zeigt Darstellungen von Kampfszenen oder Fahrten der Indianer auf ihren Booten. Ganze Indianerstämme und Gruppen von Europäern werden in Form von zahlreichen kleinen Gestalten in Figurengruppen miteinander konfrontiert. Überwiegend zeigen die Holzschnitte eine sicherlich von der Tradition der illustrierten Karten abgeleitete Draufsicht, oft ist zudem eine den Küstenverlauf genau nachzeichnende Landschaftskulisse im Hintergrund angedeutet, die ebenso wie einige in die Umrisskarte projizierte Ortsbezeichnungen direkt auf die Karten als künstlerisches Vorbild verweist. Einzig aus der Reihe fallen einige Passe-partout-Abbildungen von Schiffen, die Anfang und Ende der Reise symbolisieren.

Auch die Titelblätter des ersten und zweiten Buchs verdienen eine eigene Würdigung. Das erste zeigt einen nackten, in einer Hängematte liegenden Indianer, der ein menschliches Bein von einem Holzrost nimmt und sich anschickt, es zu verzehren. Neben ihm liegt eine Axt, ganz in Anlehnung an die nur an dieser Stelle bei Staden zitierte Tradition herkömmlicher Menschenfresser-Bilder. Das Bild soll als "Kondensat der ethnographischen Erfahrungen Stadens" (Neuber 1992, 49) den Inhalt des Buchs zusammenfassen. Der Schriftzug mit den indianischen Worten dient der Wahrheitsbeteuerung des Inhalts, während einige Objekte wie die Hängematte, die fremden Tiere, Hausrat oder eine Landkarte auf den ethnologischen Teil verweisen (ebd., 48f). Dies gilt auch für das Titelblatt des zweiten Buchs. Die mit etwas mehr Sorgfalt geschnittenen zwei geschmückten Indianer mit Kriegskeule bzw. Pfeil und Bogen, die den Bildraum in Ganzkörperdarstellung einnehmen, verweisen auf die exakten ethnographischen Informationen dieses der descriptio gewidmeten Buchs (Tafel 28, Abb. 2). Neuber $(1992,50)$ betont, dass diese Alteritätszeichen bei der Abbildung der Indianer dem Betrachter, der den Text nicht kennt, zuerst be- 
fremdlich vorkommen und, so könnte man hinzufügen, ihn auf den Inhalt des Buchs neugierig machen sollen. Er sieht den Holzschnitt etwas überzogen als eine Art negativer Kopie der Darstellung des Sündenfalls an, bei der Adam und Eva durch zwei männliche Gestalten ersetzt worden sind (ebd.).

In diesem zweiten Buch entfällt verständlicherweise bei einigen Holzschnitten, die Objekte abbilden, der sequentielle Charakter, außer bei den zahlreichen Abbildungen des Anthropophagie-Rituals in Kapitel 29 des zweiten Buchs (Tafel 24-28, Abb. 1), die auch einige Kleinszenen enthalten, die jeweils einen Teil des Rituals, z. B. die Bemalung der Keule oder des Gefangenen zeigen. Die Darstellung der Kriegskeule (Kap. 29, 3; Tafel 24, Abb. 1) ist als Teil des Rituals der Anthropophagie zu verstehen, da diese Keule während der Zeremonien bemalt und schließlich bei der Tötung des Gefangenen verwendet wurde.

\section{Staden und die französischen Reiseberichte von Thevet und Léry}

Die künstlerische Qualität der Holzschnitte Stadens bewegt sich ungefähr auf dem Niveau der erstmals bei Léry 1580 eingefügten drei zusätzlichen Holzschnitte. Die Gestalten sind grob in ihren Umrissen gezeichnet und in eine Landschaft ohne Perspektive gestellt. Dennoch enthalten die Szenen eine Fülle korrekter Details wie die Darstellung des boucan, der von Palisadenzäunen umgebenen Langhäuser der Indianer und ihrer Einbäume, die sicherlich auf die exakten Vorgaben Stadens für seine Illustratoren zurückgehen.

Modern wirkt im Vergleich zum Bildmaterial Thevets und Lérys der historiographische Charakter der überwiegenden Anzahl der Holzschnitte im ersten Buch $^{71}$, der auch auf ikonographischer Ebene auf die innovative Bedeutung von Stadens Buch verweist. Stadens Holzschnitte bebildern den Text, sie versuchen nicht primär eine eigene ikonographische Sprache zu entwickeln und wirken vielleicht deshalb auf den heutigen Leser zugänglicher als die Illustrationen von Thevet und Léry, die ein größeres Vorwissen über zeitgenössische Darstellungstraditionen erfordern. Bry betont den historiographischen Aspekt der Bildsprache bei seiner Neubearbeitung der Stadenillustrationen, wenn er beispielsweise die Gestalt des entsetzten Staden in den Mittelpunkt seiner Konstruktionen stellt, auch wenn er dabei auf Holzschnitte aus dessen Werk zurückgreift, die Staden nicht immer direkt zeigen.

Wie Thevet bringt Staden im 2. Buch einige rein dokumentarische Holzschnitte, aber nur zwei Tierdarstellungen und keine explizite Pflanzendarstellung. Anders als bei Léry und Thevet nehmen bei Staden die Beschreibungen exotischer Tiere und Pflanzen nur geringen Raum ein, vermutlich weil er nicht wie die beiden französischen Autoren das Wissen langjährig in Brasilien ansässi-

${ }^{71}$ Einzige Ausnahme bilden im 1. Buch die Passe-partout-Holzschnitte der Schiffe. Selbst die wenigen Illustrationen, die beispielsweise die Behandlung portugiesischer Gefangener zeigen, wie in Kapitel 43 und 44, sind dort eingeschaltet, wo Staden über diese Ereignisse berichtet. 
ger Übersetzer in seinem Werk verarbeiten konnte. Deshalb waren auch keine weitergehenden Illustrationen dieses Themenbereichs notwendig.

Ein direkter Einfluss von Stadens Illustrationen auf die Werke von Thevet und Léry ist m. E. nicht nachweisbar. Thevet hat Staden an keiner Stelle seiner Werke erwähnt und sein Werk wohl auch gar nicht gekannt. Aus einem Zusatz in einer späteren Auflage der Histoire Lérys (1599/1600) wissen wir, dass dieser 1586, also nach Erscheinen der ersten drei Auflagen seines Buchs (1578, 1580, 1585) mit Hilfe eines deutschsprachigen Freundes Auszüge aus Stadens Werk gelesen und das Buch positiv beurteilt hatte ${ }^{72}$. Die These von Palencia-Roth $(1985,17)$, nach der Thevets Darstellung der Tötungsszene des Gefangenen aus Staden kopiert worden ist, kann durch einen Vergleich beider Abbildungen widerlegt werden, die nur geringe kompositionelle Parallelen aufweisen und sich auch qualitativ unterscheiden. Sturtevant $(1976,435)$ trägt dieselbe These vor, die m. E. auch in Hinblick auf die Erscheinungsjahre der Bücher und erhaltene buchgeschichtliche Quellen nicht zu halten ist. Menninger (1995, 266ff) wiederholt diese Behauptung, immer bedacht, durch den Nachweis von direkter Abhängigkeit bei den zeitgenössischen Autoren die Glaubwürdigkeit ihrer Kannibalismusschilderungen in Abrede zu stellen. Stadens Buch erschien erstmals 1557 in Marburg, Thevets Buch 1557/58; bei Thevet finden sich beide Jahresangaben auf den Titelblättern der ersten Auflage. Die These, dass ein deutsches Buch in so kurzer Zeit in Frankreich rezipiert wurde und dann gleich auch noch als Vorbild für die Illustration des Buchs von Thevet genommen wurde, übersieht, dass sowohl Buchdistribution und Verbreitung als auch Sprachkenntnisse in der damaligen Zeit nicht an heutigen Maßstäben gemessen werden dürfen. Stadens Text wurde erstmals im 19. Jahrhundert in französischer Übersetzung herausgebracht ${ }^{73}$. Zudem stammt der schon erwähnte Vertrag zwischen dem Drucker und Thevet vom 29.11.1556, das Druckprivileg vom 18.12.1556. Es ist wahrscheinlich, dass das Buch damals schon im Manuskript vorlag, während Stadens Werk laut Kolophon des Erstdrucks "uff Fastnacht 1557" erschien. Dies entzieht auch den Thesen Menningers (1995, 74ff) von einer inhaltlichen Abhängigkeit Thevets von Staden die Grundlage. Der Druck von Thevets Buch hat sich nur durch den Tod seines Druckers Ambroise de La Porte bis Ende 1557/1558 verzögert. Die Koinzidenzen zwischen den Holzschnitten beruhen mit hoher Wahrscheinlichkeit allein auf der Gemeinsamkeit der Fakten. Staden und Thevet haben unabhängig voneinander - der eine als Augenzeuge und genauer Beobachter, der andere als Verarbeiter von fremden Informationen von Seiten der sogenannten "truchements" (Übersetzer, die lange Zeit bei den brasilianischen Stämmen gelebt haben) - genaue Angaben über das hochkomplizierte

${ }^{72}$ Dieses Dokument wurde erstmals zitiert in Léry 1880 [21580], 191f. Ein Auszug des Urteils von Léry über Staden in Foltys 1992, 21.

${ }^{73}$ Eine in der Bibliographie der Stadenausgabe von 1964 (216, Nr. 6) unter Vorbehalt aufgeführte französische Ausgabe, Cherbourg 1559, ist nicht nachweisbar. 
und sich über mehrere Jahre erstreckende Zeremoniell der Anthropophagie gehabt und diese für europäische Augen fremdeste Sitte natürlich auch abgebildet. Da Staden seine Gefangenschaft bei Stämmen verbrachte, die, wie er öfters betont, mit den Franzosen in der französischen Kolonie in der Bucht von Guanabara (heute Rio de Janeiro) freundschaftliche Beziehungen pflegten, haben Thevet, Léry und er dieselben Informationen über nah verwandte, oft sogar identische Stämme verarbeitet. Da das indianische Zeremoniell die Fesselung des Gefangenen mit Stricken durch zwei Stammesmitglieder und die Tötung durch einen Dritten mittels eines Keulenschlags auf den Kopf vorsah, ist es auch nicht weiter verwunderlich, dass die beiden Szenen sich jeweils ähneln.

In diesem Kontext muß die symbolische Interpretation des Wahlspruchs Verbum domini manet in aeternum in der Vignette erwähnt werden, mit der in der Erstveröffentlichung von 1557 der Erlebnisteil schließt. Menninger (1996, 524, Fußnote 86) sieht hier eine Anspielung auf den Landgrafen Philipp von Hessen und ein Bekenntnis zu dessen protestantischem Glauben durch eine Art reformatorisches Erkennungszeichen. Schon die zweite Auflage (Marburg 1558) hat dieses Motiv durch eine andere Passe-partout-Vignette ersetzt, einen Geier mit sieben Männergestalten, angeblich um diese Anspielung zu entschärfen. Menninger $(1996,524)$ nimmt dies in Verbindung mit den zahlreichen Anspielungen des Buchs auf die Frömmigkeit Stadens und den Landgrafen Philipp zum Anlass, den Text als Propagandaschrift für den deutschen Protestantismus zu lesen, dessen Schauplatz unverfänglich in der Neuen Welt angesiedelt ist. Die Gefangenschaft Stadens würde damit symbolhaft für die Gefangenschaft des Landesherren (1547-1552) bei Karl V. nach der Niederlage der Protestanten im Schmalkaldischen Krieg stehen.

Diese Interpretation scheint jedoch weit hergeholt und übersieht, dass es im Zeitkontext wohl keiner verschlüsselten Reisebeschreibung bedurfte, um politische oder religiöse Propagandaliteratur zu verbreiten. Dies hätten die im 16. Jahrhundert so häufigen Traktate, Flugschriften oder im protestantischen Einflussgebiet gedruckten Werke genauso gut bewirkt. Hier liegt wieder ein Versuch vor, die Gefangenschaft Stadens nicht referentiell als reales Faktum zu lesen, sondern durch eine Interpretation auf symbolischer Ebene die Angaben des Reiseberichts zu entkonkretisieren, was aber vom Text wegführt. Um eine Allegorie über die Gefangenschaft des Landesherrn zu schreiben, hätte Staden kein Buch über die Indianer Südamerikas und keinen Reisebericht verfassen müssen; hier hätte ein Pamphlet oder ein polemisches Werk diesen Zweck weit besser erfüllt. 


\section{Kap. 3: Brys America (1590-1634) oder die Sprache der Bilder}

\section{Theodor de Bry: vom verfolgten Hugenotten zum erfolgreichen Verleger}

Theodor de Brys Werk gehört trotz der Herkunft des Künstlers aus dem flämischen Lüttich im Wesentlichen zur deutschen Geschichte der Buchillustration. Seine Sammlung von Reiseberichten hat jedoch europäische Bedeutung, was für das Werk selbst wie auch seine Rezeption gilt. Bry hat die ikonographischen Traditionen der frühen deutschen und französischen Reiseberichte aus Brasilien übernommen und einem gebildeten europäischen Publikum bekannt gemacht. Der erste Band wurde ins Englische und Französische, die ganze Sammlung ins Lateinische übersetzt. Die Bedeutung der Familie Bry für die Entwicklung des Kupferstichs wird in der Forschung heute erkannt. So bezeichnet Kunze (1993, I, 477) ihr Werk, das wesentlich zur Verbreitung dieser Technik beigetragen hat, als einen "Markstein in der Geschichte der Kupferstichillustration". Als Kupferstecher haben die Brys nicht eigenschöpferisch gewirkt, sondern zeitgenössische Vorlagen reproduziert und damit einem breiten Publikum durch ihre Buchillustration bekannt gemacht. Die Auswahl von Text- und Bildmaterial in ihren Werken sowie die interpretative Verarbeitung der ikonographischen Vorbilder haben eine große inhaltliche Bedeutung für die Leserlenkung, die bisher trotz der Arbeiten von Bucher (1977) und Duchet (1987) kaum erforscht worden ist.

Theodor de Bry wurde 1528 in Lüttich geboren. Um 1570 musste er als Kalvinist seine damals von Spanien regierte Heimat verlassen. Er floh nach Straßburg, wo er als Goldschmied und Kupferstecher tätig war. In dieser Zeit wurde er vermutlich zum Schüler des anlässlich der Bartholomäusnacht von 1572 aus Paris geflohenen kalvinistischen Kupferstechers Etienne Delaune (1519-1583; vgl. auch Duportal 1914, 127). Dies ist insofern von Bedeutung, als Delaune auch nach Vorlagen von Jean Cousin gearbeitet hat ${ }^{74}$ und wohl die künstlerischen Errungenschaften der Illustrationen Cousins, insbesondere in den Thevetbüchern, an Bry vermittelt hat. Ein Kupferstich Delaunes mit kämpfenden Kriegern mit dem Hüftschmuck der Tupinamba in der Serie "Combats et triomphes" 75 von 1576 kopiert direkt Thevets Kampfszenen in den Singularités $(1982,71 v)$ bzw. die Replik hierauf in der Cosmographie (1953, 184; abgebildet auch bei Léry 1992, Panoramique III). Dieser Einfluss Delaunes auf Bry ist auch

${ }^{74}$ Dies ist bezeugt für einen "Moses, der dem Volk die eherne Schlange zeigt". Vgl. Thieme-Becker, 1912, VII, 597, Artikel "Jean Cousin". Die Information stammt aus FirminDidot 1863, 175, wo auch andere Werke Delaunes nach Cousin erwähnt werden.

${ }^{75}$ Nr. 7 der Serie, die im Cabinet des Estampes in der Bibliothèque Nationale, Paris, erhalten ist. 
bei der Ornamentik etwa der Bordüren seiner Stiche bezeugt ${ }^{76}$. Bry arbeitete in Straßburg vermutlich als Goldschmied. Die Ausbildung in diesem Beruf war wegen der technischen Nähe für einen Kupferstecher sicher von Vorteil, und die Arbeit als Goldschmied ermöglichte zudem eine problemlose Einschreibung in eine der traditionell angesehenen Zünfte.

In Straßburg heiratete Theodor de Bry um 1560 Katharina Eßlinger, von der er zwei Söhne hatte: Johann Theodor (1561-1623) und Johann Israel (15651609). Der erste Sohn Johann Theodor ist 1561 in Lüttich geboren, woraus man schließen kann, daß Theodor de Bry sich noch nicht auf Dauer in Straßburg niedergelassen hatte (vgl. Zülch 1935, 365). Seine Frau starb vor 1570, er heiratete 1570 in Frankfurt die Tochter eines Frankfurter Goldschmieds, Katharina Rölinger (1542-1610). Im Jahre 1588 erwarb er in Frankfurt das Bürgerrecht und übersiedelte 1590 endgültig dorthin. Ausschlaggebend für die Entscheidung, in Frankfurt eine eigene Werkstatt zu gründen, mag neben der Stellung Frankfurts als Messezentrum auch der Tod des Verlegers Sigmund Feyerabend (ca. 1527-1590) gewesen sein, für den Theodor de Bry schon während seiner Straßburger Zeit lange Jahre tätig gewesen war (vgl. Lübbecke 1948, 76).

Der aus Heidelberg stammende Sigmund Feyerabend hatte 1559 in Frankfurt eine prachtvoll illustrierte Vergilausgabe und im folgenden Jahr eine von dem Nürnberger Virgil Solis (1514-1562) illustrierte Lutherbibel publiziert und beherrschte bis zu seinem Tod 1590 als wichtigster Verleger den damaligen Frankfurter Buchdruck und Buchhandel. Er veröffentlichte besonders beliebte Volksbücher wie das 1587 gedruckte Buch der Liebe. Die Verwendung der Neudörffer-Andreae Fraktur in diesen Volksbüchern machte diese Schrift populär. Nach 1590 wurde der von Feyerabend gepflegte Holzschnitt in Frankfurt auch dank der Brys langsam durch den Kupferstich abgelöst (zu Feyerabend vgl. auch Zülch 1935, 307). Das Vakuum, das Feyerabends Tod in der Frankfurter Buchlandschaft hinterließ, bildete sicher eine günstige Gelegenheit für die Gründung einer eigenen Werkstatt durch Theodor de Bry.

Brys Idee, eine deutsche und lateinische ${ }^{77}$ Reiseberichtsammlung herauszugeben, ging vermutlich auf seine Begegnung mit Richard Hakluyt (ca. 15531616) in London um das Jahr 1587 zurück. Sein Aufenthalt in England ist durch eine signierte und datierte Londonansicht bezeugt (Zülch 1935, 367). Hakluyt bereitete damals die erste englische Reiseberichtsammlung unter dem Titel The principal navigations, voiages and discoveries of the English nation (1589-1600)

${ }^{76}$ Vgl. Thieme-Becker, 1913, IX, 3, Artikel "Etienne Delaune". Ein bekanntes ornamentales Werk der Brys sind die Alphabeta et characteres und das Nejw kunstliches Alphabet von 1595 bzw. 1596.

${ }^{77}$ Die lateinische Fassung wird u.d.T. Collectiones peregrinationum in indiam orientalem et indiam occidentalem zitiert. In der französischen Sekundärliteratur hat sich die Bezeichnung "Grands voyages" in Abgrenzung zu den später erscheinenden "Petits voyages" mit Afrika- und Asienreiseberichten durchgesetzt, obwohl der Formatunterschied nur 2,7 cm beträgt. 
$\operatorname{vor}^{78}$. Samuel Purchas hat eine vierbändige posthume Ausgabe, die um zahlreiche auch von Nicht-Engländern geschriebene Berichte erweitert worden war, unter dem Titel (Hakluytus posthumus or) Purchas his pilgrimes 1625 herausgegeben. Über die Vermittlung von Hakluyt erhielt Bry auch Aquarelle von John White, einem frühen Pionier in Virginia; ferner konnte er die Skizzen von Le Moyne de Morgues über die Indianer in Florida bei dessen Witwe erwerben, um den Floridareisebericht Laudonnières zu illustrieren.

Theodor de Bry besaß in Frankfurt keine Buchdruckerei, sondern nur eine Kupferstichdruckerei. Der Buchdruck war während seiner Straßburger Zeit von Sigmund Feyerabend in Frankfurt besorgt worden, später von Feyerabends Erben oder anderen Frankfurter Druckern wie dem ebenfalls aus den Niederlanden stammenden Nikolaus Bassé oder der Offizin von Andreas Wechel. Theodor de Brys Söhne kamen 1593/94 nach Frankfurt, sicher um ihren gichtkranken Vater bei der Herausgabe seiner seit 1590 erscheinenden Reiseberichtkollektion zu unterstützen ${ }^{79}$. Beide heirateten 1594 zwei Töchter des reichen Kaufmanns Marsilius von der Haiden und baten um Aufnahme in die Bürgerschaft. 1598 starb Theodor de Bry, die Söhne und die Stiefmutter führten die Herausgabe der Reiseberichtsammlung mit den Bänden 7 bis 12 weiter. Nach Meinung von Duchet $(1987,10)^{80}$ sinkt die Qualität der Illustrationen nach dem Tod von Theodor de Bry, was vielleicht auch daran liegt, dass für die nun veröffentlichten Berichte keine Vorlagen mehr vorhanden waren. Der dreizehnte Band der lateinischen Ausgabe der "Großen Reisen" wurde dann schließlich von Matthäus Merian 1634 herausgegeben.

Der erste Sohn Johann Theodor (1561-1623) war, bevor er nach Frankfurt zog, einige Zeit in der Türkei als Büchsenmacher tätig. Johann Theodor zog 1609 ins damals pfälzische und den Kalvinisten wohlgesonnene Oppenheim und bat um Entlassung aus der Frankfurter Bürgerschaft, da er seine kalvinistische Religion in Frankfurt nicht ohne Behinderung ausüben konnte. Der Verlag und die Kupferstichdruckerei blieben jedoch in Frankfurt. Kurz vor seinem Tod nahm Johann Theodor aus gesundheitlichen Gründen 1619 erneut seinen Wohnsitz in Frankfurt (vgl. Zülch 1935, 144). Im Jahr 1618 verheiratete er seine Tochter Magdalena an den aus Basel stammenden Matthäus Merian (1593-1650),

${ }^{78}$ Die erste große Reiseberichtskollektion ist die schon erwähnte von Giovanni Battista Ramusio, die er unter dem Titel Delle navigationi e viaggi 1550-1565 veröffentlicht hat.

${ }^{79}$ Wenn in dieser Arbeit von "Bry" oder den "Brys" die Rede ist, soll damit implizit der Werkstattcharakter ihrer Arbeiten eingeschlossen sein, auch wenn Theodor de Bry bis zu seinem Tod 1598 sicher künstlerisch und inhaltlich die Gestaltung der Sammlung bestimmte.

${ }^{80}$ Zur gegenteiligen Meinung in älterer Literatur vgl. Thieme-Becker, Artikel “Theodor de Bry”, 1911, V, 162; Zülch 1935, 441. Auch wenn bei einer Gemeinschaftsproduktion wie den "Großen Reisen" der Anteil einzelner Künstler schwerlich auszumachen ist und Brys Söhne erst 1593/94 nach Frankfurt kamen, zeigt sich doch nach dem Tod von Theodor de Bry in Aufbau und Konstruktion m. E. eine leichte Qualitätsabnahme, was der eigenständigen Bedeutung anderer später von Johann Theodor illustrierten Werke keinen Abbruch tut. 
der seit 1617 in seiner Werkstatt tätig war und nach dem Tod des Schwiegervaters dessen Werk gemeinsam mit dem Engländer Wilhelm Fitzer weiterführen sollte, der 1625 Susanna, eine andere Tochter von Johann Theodor, heiratete. Die dritte Tochter Margarete Elisabeth heiratete 1623 den Buchhändler Johann Ammon aus Amberg, der sich in seiner Buchhandlung in Heidelberg vor allem um den Vertrieb der zahlreichen Werke der Brys kümmerte (vgl. Bouyer 1983, 64). Wilhelm Fitzer übernahm 1625 mit Merian die Kupferstichdruckerei des verstorbenen Johann Theodor, schied aber schon im folgenden Jahr aus. Er blieb als Beisasse 1625-1632 in Frankfurt und veröffentlichte dort unter anderem 1628 das bekannte Buch von Harvey über den Blutkreislauf (Exercitatio anatomica de motu cordis et sanguinis in animalibus). Im Jahr 1632 ging er als Buchhändler nach Heidelberg, machte dort aber 1639 Konkurs. Fitzer nahm zahlreiche Kupferplatten nach Heidelberg mit, von denen nach seinem Konkurs laut einem erhaltenen Inventar 115 von dem schon erwähnten Johann Ammon übernommen und 1638 bei einem Brand größtenteils zerstört wurden. Fitzer wurde später Postverwalter in Heidelberg und starb dort 1671 (vgl. Zülch 1935, 519, zu Fitzer besonders Sondheim 1933).

Der zweite Sohn Theodor de Brys, Johann Israel, vermutlich um 1565 in Lüttich geboren, starb bereits 1609 , nachdem er einige Zeit in der Werkstatt von Vater und Bruder tätig gewesen war. Matthäus Merian setzte die Reiseberichtkompilation schließlich bis 1628 (östliches Indien) und 1634 (westliches Indien) fort.

Diese familiären Hintergründe sind wichtig, um die Kontinuität der Ikonographie der Reiseberichte von Bry und ihren ideologischen Bezug zum Kalvinismus zu verstehen. Durch die Einheirat Merians in die Familie Bry blieb die Tradition der Werkstatt der Brys ungebrochen; die Stiche konnten bis in die Mitte des 17. Jahrhunderts wiederverwendet werden und beherrschten damit das Bild des Indianers noch in der ersten Hälfte des 17. Jahrhunderts.

Maria Sybilla Merian (1647-1717), die Tochter von Matthäus Merian aus zweiter Ehe mit Johanna Sybille Heim, wurde schließlich zu einer bedeutenden Insektenforscherin, die ihre entomologischen Beobachtungen aus ihrem Aufenthalt in Surinam in prachtvoll illustrierten Bänden publizierte. Sie vereint in ihrer Person gleichsam das Interesse ihres Vaters und der Brys für Reisen und deren künstlerische Begabung für den Kupferstich.

Brys Kupferstichdruckerei in Frankfurt war in einem der damaligen Zentren der Buchproduktion und des Buchvertriebs angesiedelt. Es standen in Frankfurt genügend geschulte Drucker und Typographen zur Verfügung, die den Druck der Texte übernehmen konnten. Zudem konnte Theodor de Bry für die Herstellung der Kupfer auch seine Söhne heranziehen, die nach seinem Tod sein Werk fortsetzten. Matthäus Merian führte die Tradition seines Schwiegervaters Johann Theodor de Bry bruchlos fort, und der Name Bry findet sich noch auf Büchern um die Mitte des 17. Jahrhunderts gleichsam als Qualitätssiegel auf dem Frontispiz. 
Die Kupferstichproduktion der Brys ist ein frühes Beispiel für ein breit diversifiziertes Programm, das den Ansprüchen des Publikums in exemplarischer Weise gerecht zu werden versuchte. Ikonographiegeschichtlich wichtig sind die von Theodor de Bry illustrierten Emblemata saecularia (1593), ein für die Literatur und Kunst des Barock schulemachendes Emblembuch. Das Programm reicht von Themen aus der Kunstgeschichte, so u. a. der Topographia Romae von Jean Jacques Boissard (erstmals Frankfurt 1597-1602, noch 1681 von Merians Erben wiederaufgelegt!), über den Bereich der Magie mit dem damals ungemein beliebten Buch Boissards De divinatione \& magicis praestigiis ([0.J.] ca. 1616) bis hin zu einer Porträtsammlung berühmter Zeitgenossen ${ }^{81}$.

Die Brys, die ihr ganzes Vermögen bei der Flucht aus Lüttich verloren hatten, gelangten, nach zeitgenössischen Dokumenten zu urteilen, in Frankfurt zu beträchtlichem Wohlstand, was sicherlich am guten Absatz ihrer Bücher lag. Die Beliebtheit der Reiseliteratur ist ein oft bezeugtes Faktum. Sie bildete damals einen Schwerpunkt der Sammeltätigkeit von Bibliotheken. Zudem muss man die heute leicht vergessene Tatsache in Betracht ziehen, dass vor Ausprägung der einzelnen naturwissenschaftlichen oder anthropologischen Teilfächer gegen Ende des 18. Jahrhunderts in erster Linie die Reiseliteratur Informationen über die neuentdeckten Kontinente lieferte und damit die Neugier des Publikums befriedigte.

Die Brys waren zwar nicht die ersten, bei denen die Auswahl der Texte von einem festen verlegerischen und inhaltlichen Programm bestimmt wurde, aber sie taten es mit bewundernswerter Konsequenz. Der erste Band der Reiseberichtkollektion erschien gleichzeitig in einer deutschen, französischen, englischen und lateinischen Version, sollte also von Anfang an einer auf bestimmte Zielgruppen gerichteten Strategie gerecht werden. Dieses Ziel war sicher zu hoch gegriffen, weshalb die französische und englische Ausgabe eingestellt und nur die deutsche und lateinische beibehalten wurden. Sie erschienen in vierzehn Teilen, die deutsche zwischen 1590 und 1630, die lateinische im Zeitraum von 1590 bis 1634. Die lateinische Ausgabe war ohnehin dem gebildeten Leser in ganz Europa zugänglich, und nur dieser kam als potentieller Käufer der teuren illustrierten Ausgaben in Großfolio in Frage. Latein war trotz der Förderung der Volkssprachen immer noch die alleinige Wissenschaftssprache. Die Publikation eines Werks auf Latein sicherte die Verbreitung der Bücher auch außerhalb des deutschen Sprachraums. Benzonis Historia wurde ebenfalls eher in der lateinischen Bearbeitung Chauvetons (Venedig, 1565) rezipiert, die später in Brys Kol-

${ }^{81}$ Bibliotheca chalcographica illustrium virorum virtute atque eruditione in tota Europa [...]. Frankfurt/M.: Theodor de Bry, 1650. Das erstmals 1595 unter demselben Titel erschienene Buch ist sicher, was die Auswahl der Berühmtheiten und den ideologischen Hintergrund betrifft, eine kalvinistische Antwort auf Thevets Pourtraicts et vies des hommes illustres von 1584. Es finden sich allerdings im Gegensatz zu Thevets Werk keine Darstellungen von Indianern. 
lektion einging, als in der schon zuvor veröffentlichten italienischen Version. Bei den Holzschnitten griff Bry allerdings wieder auf das sehr anspruchslose Bildmaterial der italienischen Originalausgabe zurück.

Erwähnt sei noch eine weitere Kollektion von Reiseberichten der Brys, die der Asien- und Afrikareisen. Die deutsche Ausgabe dieser sogenannten "Kleinen Reisen" erschien in insgesamt 13 Teilen 1597-1628, die lateinische in 12 Teilen 1598-1628. Nachdrucke der älteren Teile der Großen und Kleinen Reisen werden noch bis in die Mitte des 17. Jahrhunderts wiederaufgelegt ${ }^{82}$.

In der ersten Hälfte des 17. Jahrhunderts erschienen außerdem Zusammenfassungen dieser beiden Reisesammlungen, die für einen breiteren Leserkreis erschwinglich waren. Bereits im Jahre 1617 war bei Johann Theodor de Bry eine stark verkürzte Kompilation der ersten Teile der "Großen Reisen" (Amerika) in einer Bearbeitung von Philipp Ziegler unter dem Titel America, das ist Erfindung und Offenbahrung der Newen Welt veröffentlicht worden. 1619 erschien sodann eine Zusammenfassung der "Kleinen Reisen" (nach Asien und Afrika) bei Wilhelm Fitzer, dem späteren Schwiegersohn von Johann Theodor de Bry ${ }^{83}$. Im Jahr 1631 (und 1655) folgte bei Matthäus Merian eine weitere von Johann Ludwig Gottfried besorgte Überarbeitung und Zusammenfassung der AmericaSammlung unter dem Titel [Historia Antipodum oder] Newe Welt und Americanische Historien unter teilweiser Verwendung von originalen, noch von der Werkstatt Bry gestochenen Kupfern ${ }^{84}$.

\section{Die Selbstporträts von Theodor und Johann Theodor de Bry}

Zeugnisse über die Motivation der Brys für die Herausgabe dieser umfangreichen Amerika-Sammlung sind nicht erhalten. Die Vorworte der Kollektion gehen nicht über die allgemeinen Floskeln des "prodesse et delectare" derartiger Textsorten hinaus. Im Vorwort des dritten Bandes (America, 1990, 113) betont Theodor de Bry die religiöse Verstocktheit der brasilianischen Indianer und verweist auf die wundersame Rettung Stadens aus indianischer Gefangenschaft durch göttliche Gnade. Auch Merian betont in der Leseransprache des 13. Buchs

${ }^{82}$ Für eine genaue bibliographische Beschreibung des Inhalts von Brys Reisesammlungen sei auf die Forschungsliteratur verwiesen. Vgl. die detaillierten Angaben in Camus 1802, Weigel 1845, Brunet ${ }^{5} 1860$, I, Spalte 1310-1363 (Sabin 1870, III, 20-62 ist nur eine Übersetzung von Brunet) und Church 1951 [1907]; s. auch die kurze Zusammenfassung in Bry, America, 1990, 438ff. Die Bry-Sammlung der New York Public Library wird beschrieben in einem Catalogue of the De Bry collection in: Bulletin of the New York Public Library 1904, 230-243; hier auch Angaben zu älterer bibliographischer Literatur zum Thema (230). Für eine vollständige bibliographische Erfassung von Brys Amerikasammlung vgl. auch neuerdings European Americana (1980ff) I, II.

${ }^{83}$ Extract der orientalischen Indien beschrieben durch Caesarem Longinum Historicum, Gedruckt zu Franckfurt am Mayn, Bey Caspar Rötell, In Verlegung Wilhelm Fitzers.

${ }^{84} \mathrm{Vgl}$. zu diesen Angaben das Nachwort von Sievernich zur Neuedition der Kupferstiche (America, 1990, 436ff). 
den religiösen Hintergrund der Reiseberichte. Alles Wissen komme von Gott, der Herr über die menschliche Geschichte sei. Die Reisesammlung dokumentiere diese Ereignisse und bewahre ihre Erinnerung (vgl. Duchet 1987, 45). Indirekt lässt sich die Bedeutung der Reiseberichtsammlung für Johann Theodor de Bry gut an einem Selbstporträt ablesen, das er einer Ausgabe von Boissards Werk über die Magie beigegeben hat ${ }^{85}$. Vorbild war sicherlich ein Porträt seines Vaters, das dieser im Jahre 1597 kurz vor seinem Tod gestochen hatte ${ }^{86}$. Dieses Bild zeigt den damals 69jährigen Greis mit Kurzhaar und Pelzkragen sowie einem Zirkel in der einen Hand und einem Totenschädel in der anderen, darunter auf einem Brett eine erbauliche Inschrift, die auf den emblematischen Charakter des Totenschädels verweist, der nicht nur den von Krankheit gezeichneten Bry, sondern alle Menschen zum Gedanken an Gott bringen soll. Das Selbstporträt soll als eine Art Erinnerungsbild die Züge des Menschen bewahren, aber zugleich in kalvinistischer Bescheidenheit seine Sterblichkeit vor Augen führen. Eine weitere Version dieses Porträts, die sicher auf die gleiche Bildnisaufnahme zurückgeht, ist in der Kupferstichsammlung von Dresden erhalten ${ }^{87}$. Der Kupferstich ist rechteckig und in einen architektonischen Rahmen eingepaßt und zeigt ein Brustbild von Theodor de Bry ebenfalls mit Kurzhaar und Pelzkragen, jedoch ohne Zirkel und Totenkopf (Tafel 29).

Im Vergleich dazu drückt das Selbstporträt von Johann Theodor (Tafel 30) trotz der beibehaltenen Memento-mori-Elemente ein gesteigertes Selbstbewusstsein aus, das ihn als Herausgeber seiner vom Vater begonnenen Reiseberichtsammlung auszeichnete. Porträts von Kupferstechern sind in der damaligen Zeit selten und deshalb an sich schon ungewöhnlich. In Ermangelung aussagekräftiger autobiographischer Dokumente und angesichts der Tatsache, dass die Stiche der Brys immer symbolische Aussagen enthalten, ist es legitim, dieses Porträt auch in Hinblick auf Johann Theodor de Brys Selbstdarstellung als öffentliche Persönlichkeit zu interpretieren.

Ähnlich wie bei den damals üblichen Porträtstichen, etwa in einer ebenfalls von der Werkstatt Bry herausgegebenen Porträtsammlung bekannter Zeitgenossen, tritt uns Johann Theodor de Bry hier stehend als Halbfigur hinter einem Brett entgegen, das als Ablage zugleich den Vordergrund bildet und auf dem einige symbolhafte Gegenstände liegen. Die Gestalt des damals über 50jährigen blickt den Betrachter streng an und strahlt eine zurückhaltende Würde aus. Der Grabstichel spielt auf den Beruf des Abgebildeten an. Der linke Arm des Künstlers liegt auf einem Stapel Bücher, eben seiner Reiseberichtsammlung, deren Titel angegeben ist. In der linken Hand hält er einen Stich mit der Aufschrift (Joh. 8, 51; in der Übersetzung Martin Luthers)"Wahrlich, wahrlich, ich sage

${ }^{85}$ In der posthumen Ausgabe Boissard, Jean Jacob: De divinatione \& magicis praestigiis [...]. Oppenheim, o. J. [= ca. 1616].

${ }^{86} \mathrm{Vgl}$. die Abbildung dieses Porträts in Lorant 1965, 266.

${ }^{87}$ Vgl. Singer, Allgemeiner Bildniskatalog 1967 [1930], I, 88 (Dresden B. 1554, 2, S. 6). 
Euch: So jemand mein Wort wird halten, der wird den Tod nicht sehen ewiglich", darüber ein Kind auf einem Totenschädel, das Seifenblasen in die Luft bläst und das Motto Quis evadet? Die Kombination von Kindheit und Tod ist ein typisch emblematisches Motiv. Zudem wird damit diskret auf die ikonographiegeschichtlich bedeutenden Emblembücher angespielt, die Bry senior veröffentlicht hatte ${ }^{88}$. Auf dem Tisch liegt im Vordergrund ein Blatt mit einem Zitat aus Psalm 139, das auch für den Betrachter lesbar ist. Die Psalmen hatten in protestantischen Kreisen einen großen Stellenwert in der täglichen Bibellektüre. Vor diesem zeitgenössischen Hintergrund darf dieser kurze Text nicht nur als symbolhaftes Bekenntnis zum Glauben im Sinne der üblichen Lobsprüche über die pietas des Abgebildeten interpretiert werden, sondern auch als ein subtiles Bekenntnis zum Protestantismus, was angesichts des persönlichen Schicksals der Brys, die Vertreibung und Not kannten, nicht weiter verwundern mag. Auch der Wahlspruch der Brys ist angegeben: "Nul sans soucy".

Das Porträt Johann Theodor de Brys verfolgt hochgradig symbolische Intentionen. Das Selbstverständnis und der Stolz des Stechers und Verlegers, der sich erst durch sein Werk Ansehen als Künstler erobern musste, wird hier auf den Punkt gebracht. Dieses Selbstbewusstsein gründet nicht zuletzt auf der Reiseberichtkollektion, die der Vater begonnen hatte und die der Sohn auf diesem Stich dem Zuschauer vor Augen führte. Johann Theodor war sich wohl zu Recht bewusst, dass neben den zahlreichen anderen Werken, die sicher ihre Bedeutung hatten und ein breites Publikum erreichten, der Nachruhm seiner Familie sich vor allem auf die Veröffentlichung der "Grands voyages" stützen würde. In der Tat übertrifft die Rezeption von Brys Kollektion bei weitem die seiner anderen Werke, die nur noch in Spezialistenkreisen, unter Buchliebhabern oder Emblematikforschern, bekannt sind. Die Reiseberichtkollektion erfreut sich hingegen zunehmenden Interesses in der Forschung und wurde jüngst durch die Edition einer prachtvoll kolorierten Ausgabe der Stiche einem breiten Publikum wieder zugänglich gemacht (America, 1990) ${ }^{89}$.

\section{Theologie und leyenda negra}

Der ideologische Gehalt der Reiseberichte von Bry hat schon früh Beachtung gefunden. Insbesondere die Rezeption von Benzonis Historia del mondo nuovo durch Urbain Chauvetons Übersetzung ins Lateinische, deren kritische Tendenz

${ }^{88} 1592$ publizierte Theodor de Bry die Emblemata erstmals in Frankfurt unter dem Titel Emblemata nobilitati et vulgo scitu digna. Sein Sohn Johann Theodor ließ 1596 und 1611 wesentlich erweiterte Neuauflagen unter dem Titel Emblemata secularia folgen; ein Nachdruck der Ausgabe 1611 erschien 1994.

${ }^{89}$ Viele Kupferstiche sind in dieser Ausgabe in einer altkolorierten Fassung abgebildet. Über die Künstler und den genauen Zeitpunkt dieser Kolorierungen finden sich bei Sievernich keine Angaben. 
in der französischen Fassung ${ }^{90}$ verschärft wurde, hat entscheidend zu der später als leyenda negra bezeichneten spanienkritischen Sicht des Kolonialismus beigetragen. In protestantisch-kalvinistischen Kreisen war diese Bewertung ein beliebtes Vehikel der Kritik an der katholischen Religion. Nicht umsonst hat die Werkstatt der Brys auch die Übersetzung von Las Casas' Brevissima relacion de la destruycion de las Indias (Sevilla 1552), dem zentralen Text der spanischen Kolonialismuskritik, illustriert ${ }^{91}$. Sabine Horl (1985/86) hat anhand einiger ausgewählter Stiche ${ }^{92}$ aus der America-Sammlung subtil die ideologischen Hintergründe der Illustrationen analysiert. Analog zu den Thesen von Duchet (1987) gelangt sie zu dem Ergebnis, dass das Bild bei Bry weniger eine wahrheitsgemäße Wiedergabe einer konkreten Realität sei, sondern diese vielmehr deuten solle (ebd., 49). Trotz der stellenweise idyllischen Zeichnung der Natur enthalten die Stiche ein eindeutiges moralisches Werturteil. Das indianische Idol ist beispielsweise mit allen tradierten Attributen des Teuflischen und Monstruösen gezeichnet, die Indianerin von Cumaná wird - entsprechend der von Bucher aufgezeigten Darstellungstradition - als Hexe mit Hängebusen gezeichnet. Auch bei der Szene, in der die Spanier homosexuelle Indianer betrachten, die sie von ihren Hunden zerfleischen lassen, ist die moralische Absicht eindeutig. Selbst wenn das grausame Schauspiel auf den ersten Blick Mitleid erwecken mag und die Perversion der Indianer anprangert ${ }^{93}$, zeigt sich doch die Überlegenheit der von ihrem moralischen Standpunkt aus strafenden Europäer in deren edlen Gebärden des Schreckens, während sich die Indianer in qualvollen und manieristisch ungezügelten Gesten im Todeskampf winden. An diesen Beispielen wird die von Horl zurecht erkannte Emotionalisierung der Bildinhalte bei Bry deutlich, der vom Zuschauer eine moralische Verurteilung sowohl der indianischen Frevel und ihres Unglaubens als auch der Brutalität der spanischen Konquistadoren fordert. Dem stehen laut Horl idyllisch anmutende Stiche gegenüber wie z. B. eine Marktszene, die den Exotismus der Früchte und der Landschaft in den

${ }^{90}$ Histoire nouvelle du nouveau monde, Genf: Eustache Vignon, 1579.

${ }^{91}$ Die Bry-Ausgabe erschien unter dem Titel: Narratio regionum indicarum per hispanos quosdam devastatarum verissima [...]. Frankfurt 1598. Der Text war zuvor schon mehrere Male (1578, 1579, 1596, Titel bei Sabin 1961, III, 393f) in einer niederländischen Version bei anderen Druckern ohne die Illustrationen der Brys erschienen. Die Ausgabe der Brys erschien auch auf deutsch: Warhaftiger und grundlicher Bericht der Hispanier grewlich und abschewlichen Tyranney. Oppenheim: Johann Theodor de Bry, 1613. Vgl. zu den frühen Ausgaben von Las Casas: Sabin 1961, III, 388-403.

92 So u. a. der Besuch der Indianerin von Cumaná (America, 1990, 4. Buch, Stich 3, S. 156), die Zerfleischung von Homosexuellen durch die Hunde der Spanier (ebd., 4. Buch, Stich 22, S. 177), der Götzendienst der Indianer (ebd., 4. Buch, Stich 24, S. 179).

${ }^{93}$ Frübis 1995, 125 sieht in ihrer Interpretation dieses Stichs nur diesen Aspekt, berücksichtigt aber nicht die gleichzeitige moralische Verurteilung der von sexuellen Normen
abweichenden Indianer. 
Vordergrund stellt. In allen Illustrationen herrscht die an das Schönheitsideal der Antike erinnernde Körperzeichnung der Indianer vor.

Trotz der etwas willkürlichen Auswahl der analysierten Kupferstiche sind die Ergebnisse von Horls Analyse zutreffend. Sie erkennt die Eigenwertigkeit der Ikonographie, berücksichtigt aber den Textbezug der einzelnen Illustrationen zu wenig. Ihre Schlussfolgerung, derzufolge die Illustrationen intellektuelle und emotionale Prozesse symbolisieren (ebd., 53), bringt eine wichtige Tendenz der Stiche der Brys auf den Punkt. So übersetzt der Stich über die Hinrichtung der Homosexuellen die Kolonialismuskritik im Sinne der leyenda negra und überträgt gleichzeitig die Verurteilung der indianischen Kultur ins Bildliche. Diese Integrierung eines moralischen Werturteils wird dann auch bei den Stichen feststellbar sein, die die Anthropophagie der brasilianischen Indianer im Stadenteil illustrieren. Besonders deutlich sieht man dies an den von Horl nur teilweise behandelten Stichen 23 und 24 des Benzoniberichts (America, 1990, 4. Buch, 178f). Auf Stich 23 verüben zahlreiche Indianer Selbstmord, weil sie "der Spanier Tyrannei nicht länger leiden" wollen. Auf der darauffolgenden Illustration wird die Verehrung des oben erwähnten indianischen Idols gezeigt, also aus der Sicht der Zeitgenossen die Teufelsanbetung der Indianer.

Mit der Anklage der katholischen Gewalt in den Kolonien wollte Bry sicher auch katholischer Propaganda gegen die Grausamkeiten der Protestanten insbesondere in den Religionskriegen entgegentreten. Viele der damaligen katholischen Kampfschriften enthalten drastisch realistische Illustrationen, die die Anklage des Texts visualisieren sollten. Duviols $(1985,201)$ verweist auf ein illustriertes Theatre des cruautez des heretiques von Richard Verstegen ${ }^{94}$ und erkennt den ideologischen Wettstreit der Illustrationen bei Bry mit diesen Werken. Richard Verstegen (auch Verstegan, ca. 1550-1641), mit richtigem Namen Richard Rowlands, war ein aus England vertriebener Katholik, der als Agitator in Frankreich und Flandern im Auftrag von Philipp II. in seinen Werken Front gegen die Protestanten bezog. Die anonymen Illustrationen des von Lestringant 1995 wiederaufgelegten Buchs wurden früher den Brüdern Wierix zugeschrieben, vielleicht stammen sie jedoch von Verstegen selbst, der auch als Graveur und Antikensammler tätig war (vgl. Verstegan [sic!] 1995, 8, Fußnote 1).

In dem hier behandelten 3. Band der Reisekollektion geht es jedoch weniger um die Brutalitäten der Europäer als um die Bewertung der Indianer und ihrer ursprünglichen Sitten. Dies liegt daran, dass die von Staden und Léry erlebte indianische Kultur noch intakt war, da die Europäer gerade erst mit der Erschließung Brasiliens begonnen hatten, während weite Teile Spanisch-Amerikas schon erobert waren, was in den Texten und Bildern der anderen Bände be-

${ }^{94}$ Lateinische Ausgabe Antwerpen 1587 und öfter, französische ebenda erstmals 1588. Zu Verstegen vgl. den Beitrag von Lestringant 1984b sowie die Einleitung zu seiner Neuausgabe des Théâtre des cruautés (Verstegan 1995); s. auch die Abbildung einer Illustration bei Duviols 1985, 201. 
handelt wird. Um so größer ist die Bedeutung dieser Illustrationen innerhalb der Kollektion, da hier gleichsam die später durch die Europäer zerstörte Indianerkultur Südamerikas im Urzustand präsentiert wird, und diese Abbildungen auch ein moralisches Urteil über die anthropophagen Indianer bei den Betrachtern provozieren mussten. Der Indianer Südamerikas erscheint einerseits als das vom Teufel verblendete Naturkind, das aber Gott im Sinne kalvinistischer Theologie aus der Schöpfung erkennen könnte ${ }^{95}$, andererseits - trotz aller Kritik an der menschenverachtenden spanischen Kolonialisationspolitik - als ein im religiösen und moralischen Sinne Verworfener.

Für unsere Fragestellung gilt es aufzuzeigen, wie die Brys ihre aus der französischen Tradition und dem Stadenbuch übernommenen Buchillustrationen zum Träger eines moralisch-theologischen Urteils im Sinne der gängigen und zeittypischen Verurteilung der dem Teufel verfallenen Indianer machten. Diese abstrakte theologische Verurteilung wird subtil visuell in den Illustrationen umgesetzt, was beispielhaft an den Stichen über die Anthropophagie und an den von Lérys Bildmaterial kopierten Stichen aufgezeigt werden soll.

Vor einer Analyse des Bildinhalts der einzelnen Stiche muss die Illustration des Frontispizes des dritten Bandes gewürdigt werden (Tafel 32). Wie bei anderen Titelkupfern von Bry ist hier der ikonographische Topos der Scheinarchitektur verwendet. Zur Linken befindet sich in einer Nische ein nackter Indianer, der durch den Federschmuck auf dem Kopf und um die Hüften deutlich als Tupinamba gezeichnet ist. Er beißt mit den Zähnen in ein abgeschnittenes Bein und hält eine Kriegskeule in der Hand. In der rechten Scheinarchitektur steht eine indianische Frau, die in einen abgeschnittenen Unterarm beißt und auf dem Rücken ein kleines Kind trägt. Die Figur ähnelt vom Aufbau her sehr stark der Frauengestalt auf einem Holzschnitt in Lérys Histoire (1975 [21580], 107; Tafel 18), die ebenfalls ein Kind in einem Tragetuch auf dem Rücken trägt. Neu ist im Vergleich zu Léry die Hinzufügung der abgeschnittenen Körperteile sowie der grimmige Gesichtsausdruck der Gestalten, der die Wildheit der Kannibalen versinnbildlichen soll. Die Indianer Südamerikas, die in diesem Band behandelt werden, sind damit schon auf der Titelseite als Kannibalen gekennzeichnet. Dies entsprach neben den beim Leser als bekannt vorausgesetzten ethnologischen Informationen sicher auch den Erwartungshaltungen der Zeitgenossen. Auffallend ist aber, dass an einer derart zentralen Stelle und trotz des ikonographischen Bezugs auf Léry ${ }^{96}$ doch wieder die alte Bildtradition der wilden Indianer, die menschliche Körperteile verzehren, zum Vorbild gewählt wurde. Diese findet sich schon auf den ersten Darstellungen zu Beginn des 16. Jahrhunderts, so auf dem bereits besprochenen in München erhaltenen Holz-

${ }^{95} \mathrm{Vgl}$. Frübis 1995, 126. Zur Erkenntnis Gottes aus der Natur und der Ablehnung der Predigt eines vermeintlichen Apostels durch die Indianer vgl. Léry, Histoire 1975 [ ${ }^{21580], ~} 257 \mathrm{ff}$.

96 Ein direkter Rückgriff auf die für Léry vorbildhafte Illustration von Ammans Trachtenbuch muss hier nicht angenommen werden. 
schnitt, der - um 1505 entstanden - vermutlich brasilianische Küstenbewohner zeigt (Tafel 3). Diese Art der Darstellung der wild in Körperteile beißenden Indianer zieht sich als Konstante durch die Illustrationsgeschichte des 16. Jahrhunderts und taucht auch bei den Darstellungen des AnthropophagieZeremoniells von Bry im selben Band auf (America, 1990, 3. Buch, 3. Teil, Stich 1, S. 144).

Auf der Spitze der Scheinarchitektur von Brys Frontispiz sieht man zwei kniende Indianer, die eine Art Kugel auf einem Schaft anzubeten scheinen. Es handelt sich, wie bei entsprechenden Textkenntnissen unschwer entzifferbar, um eine maraca, eine mit Körnern gefüllte hohle kastanienähnliche Frucht, die bei den religiösen Zeremonien und Tänzen der Indianerkultur eine große Rolle spielte und von Bry auch an anderen Stellen, z. B. im Gefolge eines Léryholzschnitts (1975 [ ${ }^{21580], ~ 246 ; ~ T a f e l ~ 20), ~ a b g e b i l d e t ~ w u r d e ~(A m e r i c a, ~ 1990, ~} 3$. Buch, 3. Teil, Stich 4, S. 147). Da die Indianer in ihren Zeremonien keine göttliche Gestalt anbeteten ${ }^{97}$, musste Bry im Bild auf die maraca zurückgreifen. Es war den Zeitgenossen natürlich nicht klar, dass diese Frucht an sich kein heiliges Objekt war, sondern erst durch ihre Rolle im religiösen Zeremoniell als Wohnort der magischen Geister sekundär eine solche Bedeutung erhielt ${ }^{98}$. Für die magischen Strukturen des Schamanismus konnte kein Reiseschriftsteller der damaligen Zeit ein Verständnis zeigen, das über eine mehr oder weniger drastische Verurteilung hinausgelangt wäre. Bei Bry ist auf der Außenschale der maraca zusätzlich eine halbmondförmige Öffnung abgebildet, die auch auf den Holzschnitten der Originalausgabe Stadens belegt ist (2. Buch, Kapitel 23).

Ganz zu unterst gibt die Scheinarchitektur des Titelkupfers einen Blick auf Indianer frei, die um einen boucan stehen, eine Art Grillrost, auf dem Fleisch durch Feuer haltbar gemacht wurde, und die ebenfalls menschliche Körperteile verzehren.

Die Bedeutung des Frontispizes liegt auf der Hand. Die Indianer werden schon auf dem ersten Blatt des Buchs als Menschenfresser (untere und mittlere Ebene) und symbolisch auf der obersten Ebene des Stichs auch als Götzendiener hingestellt. Damit wird gleichsam das moralische Thema der Texte und der Illustrationen angeschlagen. Das illustrative Material vermittelt dem Leser ein Werturteil, das im Text auch auf verbaler Ebene ausgedrückt wird. Die religiöse Ebene, also der Götzendienst, entspricht dem obersten Teil des Frontispizes, was im Bildaufbau die Bewertung der Epoche widerspiegelt und an die Tradition

${ }^{97}$ Bezeichnenderweise zeigt das Frontispiz des 4. Buchs von Brys Sammlung aus dem Jahr 1594 in der Spitze anstelle der Anbetung eines göttlichen Wesens durch die Indianer ihren Kult für ein teuflisches Idol (America, 1990, 149).

${ }^{98}$ Die maraca erscheint im Zusammenhang mit religiösen Tänzen, Tötungszeremonien und Begräbnisriten bei Thevet (so u. a. Tafel 6, 8, Abb. 2), Léry (s. Tafel 20, 22), bei Staden (2. Buch, Kap. 23) und mehrfach bei de Bry (so z. B. Tafel 32, 33). 
religiöser Ikonographie anknüpft, wo die oberste Ebene, etwa im Gesprenge mittelalterlicher Altäre, Gott vorbehalten ist.

Ikonographiegeschichtlich liegt die Bedeutung der Titelblattkupfer von Brys Werk im Übrigen auch darin, dass sie die traditionelle, geometrisch geprägte Scheinarchitektur auf einen abgebildeten wirklichen Raum hin erweitern. Während das hier besprochene Kupfer des dritten Bands noch tradierte Strukturen aufgreift und allenfalls einige "Durchblicke" im konkreten Sinn auf Landschaft und Szenen des Indianerlebens enthält, wird diese Gliederung in einigen der späteren Titelkupfer, so in dem des 4. Buchs (America, 1990, 149), auf ein Landschaftsbild erweitert, dessen Scheincharakter nur durch die Mittelkartusche mit dem Titel und die darunterliegende Durchfahrt eines Schiffs in Erinnerung gebracht wird. Die zahlreichen Indianer zur Rechten und Linken bewegen sich ganz natürlich, sind von hinten gezeichnet und begeben sich zu dem Idol am oberen Bildrand. Nur in den beiden frontal und wesentlich größer gezeichneten Indianern am unteren Bildrand lebt die Tradition der statuarisch auf beiden Seiten der Scheinarchitektur gesetzten Indianer - etwa des Titelkupfers von Bd. 3 - fort (vgl. zu dieser Bedeutung der Titelkupfer auch Duchet 1987, 20).

\section{Das Korpus der Brasilienreiseberichte: das Emblem der verkehrten Welt oder die Illustration der Anthropophagie}

Bry hat im dritten Band seiner Kollektion den schon im ersten Band 1590 veröffentlichten Stich mit der Darstellung des Sündenfalls wiederholt ${ }^{99}$ (Tafel 31). Die Darstellung dieses Themas in einer Reiseberichtsammlung mag den heutigen Leser zwar befremden, ist aber vor dem Horizont der Zeit von eminent theologischer Bedeutung. In vielen der von Bry veröffentlichten Texte wird die Frage nach dem Ursprung der Indianer diskutiert, z. B. bei Léry, der an eine Abstammung von den Kanaanitern glaubt (Histoire, 1975 [21580], 259ff). Léry wendet sich damit gegen die Präadamitenthese, nach der die Indianer von einem vor Adam lebenden Urvater abstammen würden und damit auch dem Sündenfall nicht unterworfen wären. Diese im Widerspruch zum Bericht in der Genesis (Kap. 9, Vers 18/19) stehende Idee, in dem von der Abstammung aller Menschen von den Söhnen Noahs berichtet wird, würde in der Tat die Indianer als Menschen ansehen, für die die Erlösungstat Christi unnötig gewesen wäre. Damit kommt dem Stich über den Sündenfall gleichsam eine argumentativ gegen die Präadamitenthese gerichtete theologische Funktion zu. Er ruft den Genesisbericht in Erinnerung und soll jeder nicht orthodoxen Ansicht gleich zu Beginn des Buches plakativ die Grundlage entziehen. Zugleich wird dem Leser auch die theologische Dimension des ikonographischen Materials verdeutlicht,

99 Übrigens ist dieser mit großer Sorgfalt ausgeführte Stich als einziger in dem Buch vom Stecher "Iodocus a Winghe in[cisit], Theodore de Bry fe[cit]" signiert. 
die im dritten Teil insbesondere bei dem Stich über die Teufelserscheinungen eine Rolle spielen wird.

\section{Bry und Staden}

Im dritten Buch seiner Sammlung, das 1592 zuerst lateinisch und 1593 deutsch erschien, hat Bry die thematisch zusammengehörigen Berichte von Hans Staden und Jean de Léry in einem Band vereinigt ${ }^{100}$. Die Stiche in diesem Band greifen auf die einfachen Holzschnitte bei Staden als Vorlage zurück, ersetzen sie jedoch durch prachtvolle Illustrationen, die fast jede wichtige Episode in Stadens Buch bebildern. Dem deutschen Leser war sicher Stadens überaus populäres Buch besser bekannt als Lérys Reisebericht, der erstmals in der Sammlung von Bry in deutscher Übersetzung greifbar wurde. So erklärt sich auch die große Sorgfalt, die auf die Herausgabe von Stadens Buch verwandt wurde, das von den Zeitgenossen trotz seines Anspruchs auf Authentizität sicher mehr als Volksbuch gelesen wurde. Es erhielt durch die Aufnahme in eine anspruchsvolle Edition und besonders durch die erstmalige Veröffentlichung einer lateinischen Version einen wissenschaftlichen Anspruch. Dazu trug sicher auch das umfangreiche Bildmaterial bei ${ }^{101}$. Der erste Teil des dritten Buchs behandelt die Geschichte von Stadens Einschiffung bis zu seiner Gefangennahme durch die Tupinamba und lehnt sich genau an seine Holzschnitte an, von denen hochwertige neue Versionen geschaffen wurden. Auffallend ist die große Bedeutung dieses narrativen Teils sowohl bei Staden selbst als auch bei den Illustrationen der Brys. Dies liegt wohl an der generellen Tendenz, die narrativen Strukturen im Reisebericht gegen Ende des 16. Jahrhunderts immer mehr zu verstärken. Damit fanden auch die älteren Texte, die wie Stadens und Lérys Berichte diese Elemente enthielten, großes Interesse, im Gegensatz zu den zwar ethnologisch ebenso interessanten, aber stilistisch veralteten Büchern Thevets.

Auffallend bei der Synopse der beiden Werke ist, wie eng Bry sowohl im Aufbau als auch in der Abfolge der Stiche den Modellen bei Staden trotz ihrer geringen künstlerischen Qualität folgt. Allerdings verzichtet er auf die Holzschnitte mit Schiffen zu Beginn und Ende des ersten Buchs, vermutlich weil es sich um wenig aussagekräftige Passe-partout-Holzschnitte handelt. Auch wer-

${ }^{100}$ Die nach dem Text von Staden und Léry in der lateinischen Ausgabe (1592, 285-295) noch hinzugefügten zwei Briefe des Protestanten Nicolas Barré, der Lotse von Villegagnon in der Kolonie von Rio de Janeiro (1555-1560) war, erschienen erstmals unter dem Titel Copie de quelques lettres sur la navigation du chevalier de Villegaignon, Paris 1557. Sie sind als kurze historiographische Dokumente weder im Original noch bei Bry illustriert und können hier außer Acht gelassen werden. In der deutschen Ausgabe fehlen sie, wohl weil sie als reine Faktenberichte eher den wissenschaftlich gebildeten Leser der lateinischen Ausgabe interessierten.

${ }^{101}$ Vgl. hierzu im Anhang unten 145f den Vergleich zwischen dem Bildmaterial des lateinischen und des deutschen Teils. Die deutsche Version der ersten fünf Bände liegt auch in einem Faksimile vor ([Americae $]$ 1970). 
den einige der Kupferstiche Brys in verschiedenen Bänden seiner Sammlung wiederholt, wobei auch zuerst bei Staden auftauchende Stiche im Léryteil wiederkehren können. So z. B. zeigt der erste Stich des Buchs, den Bry hinzugefügt hat, um gleichsam einen Auftakt zum narrativen Teil zu bieten, die Abfahrt Stadens und er taucht entsprechend zu Beginn des Léryteils wieder auf. Auch einige der Szenen mit Indianern werden willkürlich wiederholt. Um so bezeichnender sind die wenigen Auslassungen von Stadenillustrationen. Es handelt sich um die Holzschnitte der Kapitel 20, 1; 20, 2; 28; 30; 47 und 48 des ersten Buchs der Originalausgabe. Mit Ausnahme des Holzschnitts 28, der eigentlich nur die Unterredung des gefangenen Staden mit einem Indianerhäuptling illustriert, vollbringt Staden auf sämtlichen Abbildungen durch die Anrufung Gottes kleine Wunder. Holzschnitt 20, 1 zeigt die Landung der Indianer und des Gefangenen auf einer Insel; beim Verlassen der Insel fordern die Indianer Staden auf, durch Anrufung seines Gottes einen Sturm zu besänftigen, was auf dem Holzschnitt Kap. 20, 2 dargestellt wird. Bei Bry entfällt die ganze Episode in den Illustrationen. Auf Holzschnitt 30 erklärt Staden den Indianern, dass er den Mond anblicke und dieser zornig auf sie sei. In Kapitel 34 (ohne Illustration) beschreibt Staden, wie einer der Indianerhäuptlinge glaubt, aufgrund dieser Drohung krank geworden zu sein und ihn bittet, seinen Gott zu besänftigen. Auch auf den Holzschnitten in den Kapiteln 47 und 48 zeigt Staden, wie Gott auf sein Gebet hin den Regen enden bzw. beginnen lässt. Die Auslassung dieser Holzschnitte bei Bry hat sicher inhaltliche, in der Theologie begründete Ursachen. Staden hatte eine naive Gottesgläubigkeit, die sich besonders in diesen Episoden zeigt, die ein direktes Eingreifen Gottes auf die Bitte des Gläubigen hin illustrieren. Dies entspricht aber eher katholischer Wundergläubigkeit, die im Zuge der Neudefinition des Protestantismus und des Kalvinismus in der zweiten Hälfte des 16. Jahrhunderts immer mehr zurückgedrängt wurde. Dieser theologische Wandel erklärt, weshalb diese Schilderungen von erhörten Gebeten in Stadens Bericht Ende des 16. Jahrhunderts Bry nicht mehr genehm waren und dementsprechend auch die Illustrationen entfielen. Die Brys ließen sich sicher bei der Erstellung des Bildprogramms auch von fachkundigen Theologen beraten oder kannten als gläubige Kalvinisten die Theologie der Zeit gut genug, um die theologische Dimension dieser Episoden beurteilen zu können.

Die zahlreichen Auslassungen, die die Illustrationen von Stadens zweitem Buch betreffen, haben folgende Gründe: In den Bry-Drucken sind im Gegensatz $\mathrm{zu}$ Thevets Werken fast keine rein naturkundlichen oder sich auf die materielle Kultur der Indianer beziehenden Illustrationen enthalten, weshalb auch die entsprechenden Stadenholzschnitte entfallen. Der Holzschnitt bei Staden, 2. Buch, Kap. 6 zeigt beispielsweise das Feuermachen, das auch Thevet hatte illustrieren lassen, Kap. 7 die Hängematte, die ohnehin auf zahlreichen anderen Stichen bei Bry auftaucht, Kap. 8 das Fischen mit Pfeilen, Kap. 11 den Gartenbau, Kap. 16 die Lippenpflöcke und Kap. 17 den Federschmuck. Die maraca aus dem 2. Buch, Kapitel 23 findet sich zudem auf zahlreichen anderen Stichen. Von den Anthropophagie-Illustrationen wurden bei Bry der Holzschnitt 2. Buch, 
29, 1 weggelassen, der zeigt, wie der im Dorf ankommende Gefangene verspottet wird und ihm die Augenbrauen rasiert werden, sowie die Abbildung 2. Buch, Kap. 29, 2, die den erzwungenen Tanz des Todgeweihten zeigt. Beide Holzschnitte sind ohnehin Wiederholungen der Abbildungen im 1. Buch, Kap. 22 und 24, welche schon als Vorbild für die Stiche 10 und 11 bei Bry (America, 1990, 126, 127) aufgegriffen worden waren. Der Holzschnitt 29, 3, der die mussurana - den Strick, mit dem der Gefangene gefesselt wurde - und die Tötungskeule als Detail zeigt, entfällt ebenfalls. Beide Objekte finden sich bereits auf den Darstellungen des Tötungszeremoniells. Der Tanz der Indianer um die in einer Hütte aufgestellte Tötungskeule auf dem Holzschnitt 2. Buch, 29, 6 erschien Bry wohl als unwesentliches Detail; das Fest wurde zusammen mit der Herstellung des cahouin auf einem einzigen Stich zusammengezogen. Die Illustrationen des 2. Stadenbuchs, Kap. 31 und 32 zeigen schließlich Tiere und wurden als rein naturkundliche Illustrationen nicht mehr aufgegriffen.

Die Stiche im Stadenteil sind vom Bildaufbau her in der Regel nicht von den französischen Reiseautoren beeinflusst, da diese prinzipiell keine Illustrationen von Erlebnissen der Autoren lieferten, mit Ausnahme eines Holzschnitts in der Cosmographie von Thevet, auf dem der Endkampf um die Festung Coligny dargestellt wird. Einflüsse finden sich dennoch in einigen Details, so in dem Motiv der Tanzdarstellungen (America, 1990, 3. Buch, 1. Teil, Stich 17, S. 133). Bei der Zeichnung des mit seinem Arm zu Boden fassenden Indianers (der fünfte von rechts) aus der Gruppe der Tanzenden ist deutlich das Vorbild von Lérys Stich (Histoire, 1975 [21580], 146) spürbar, der seinerseits wieder einen Thevetholzschnitt aufgreift (Singularités 1982, 66v). Bry hat nur noch den Federschmuck des Kopfs hinzugefügt. Dasselbe Motiv des sich im Tanz gleichzeitig mit anderen rhythmisch zu Boden neigenden Indianers wird später noch auf Stich 4 des 3. Buchs, 3. Teil (America, 1990, 147; Tafel 40) bei der Figurengruppe aufgegriffen. Es handelt sich um den Kupferstich zu Lérys Beschreibung eines religiösen Fests der Tupinamba. Andere Übereinstimmungen in den Motiven, etwa die an Thevet erinnernde Zeichnung eines winzigen boucan auf dem Stich 19 (ebd., 3. Buch, 1. Teil, 135), gehen sicher eher auf analoge Beobachtungen und die in der Tat sehr ähnlichen Schilderungen der Autoren zurück als auf einen fassbaren ikonographischen Einfluss.

Bry hat auch die Abbildungen des Autors Hans Staden, die in der damaligen Reiseliteratur eine Ausnahme bilden ${ }^{102}$, aus den ursprünglichen Holzschnitten übernommen und generalisiert. Staden ist an seinem Bart zu erkennen (vgl. Tafel 36, 37, 39). Von Thevet sind zwar Bildnisse erhalten, aber nicht in den

${ }^{102}$ Ein von Hans Just Winckelmann in seiner Der americanischen Neuen Welt Beschreibung [...] (Oldenburg 1664) erstmals veröffentlichtes Porträt des Reisenden ist sicher nicht authentisch. Es lehnt sich an die Abbildungen Stadens auf den Originalholzschnitten an, vgl. Staden 1964, Abb. 55. Winckelmann standen auch die Platten einiger Holzschnitte der editio princeps Stadens zur Verfügung, die er in seinem Text an beliebigen Stellen eingefügt hat. 
Illustrationen seines Reiseberichts, sondern z. B. als Vorblatt seiner Cosmographie. Diese Übernahme ist bei den Brys sicher nicht absichtslos. Duchet $(1987,27)$ hat darauf hingewiesen, dass mit der Aufnahme des Autors in einige Stiche die Perspektive gleichsam gedoppelt wird, indem der Autor Staden, der seine persönlichen Erlebnisse in dem Buch beschreibt, zugleich auf den Stichen als Teilnehmer des Geschehens erscheint. Die Figur Stadens wird damit zu einer selbstreflexiven Gestalt, in der nicht nur die Authentizität des Dargestellten und Beschriebenen, sondern auch der Akt des Sehens thematisiert wird, also die Problematik der Fremdwahrnehmung absolut ungewohnter und vom europäischen Standpunkt verurteilungswürdiger Sitten auf jedem Bild dem Betrachter durch sein europäisches Spiegelbild, den beobachtenden und durch seine Gesten wertenden Staden, ins Gedächtnis gerufen wird.

Der im narrativen Teil nur sporadisch feststellbare Einfluss der französischen Illustrationen zeigt sich dann jedoch in den im engeren Sinne deskriptiven Teilen der Stadenillustrationen bei Bry, vor allem bei der Darstellung der Anthropophagie. Während Thevet auch Szenen aus dem Alltagsleben der Indianer illustriert, entfallen diese bei den Brys - vermutlich setzten sie bei ihren Lesern die Kenntnis dieses alten Bildmaterials voraus - zumal sie angesichts der hochwertigen Holzschnitte der Cousinschule in den Singularités und der Cosmographie wohl nur eine weitere Version von bekanntem Material hätten liefern können. Dagegen zeigt sich bei den Brys eine Fokussierung auf die Anthropophagie, die sicherlich in extremer Form den Unterschied der Kulturstufen sichtbar macht.

Die einzige Ausnahme einer Abbildung mit "ethnologischem" Inhalt ist bei den Stichen der Brys die Darstellung der Totentrauer und der Begräbnissitten (3. Buch, 1.Teil, Stich 14, America, 1990, 130) im Stadenteil in Anlehnung an eine Illustration der deutschen Vorlage (1. Buch, Kap. 35) ${ }^{103}$. Da das Thema typisch für die Bebilderung der Werke Thevets ist, könnte man hier vermuten, dass der entsprechende Holzschnitt (Singularités 1982, 82v, übernommen in der Cosmographie 1953, 98) Vorbild war. Dennoch ist der Bildaufbau unterschiedlich. Cousin zeigt den Augenblick, in dem die Verwandten und Freunde trauernd um einen aufrecht sitzenden, mit Stricken verschnürten Leichnam versammelt sind, während Bry einen sequentiellen Stich bringt. Der Bildaufbau verweist wiederum auf das entsprechende Vorbild von Léry (1975 [21580], 301). Am linken Bildrand des Kupferstichs liegt der Tote wie in dem Holzschnitt bei Léry in einer Hängematte (hamac), um die ein Schamane mit einer maraca tanzt, deren mundförmige Öffnung auch in der Darstellung auf dem oben analysierten Frontispiz von Bry zu sehen ist (Tafel 32). Diese Öffnung verweist auf die Stadenillustrationen, da sie bei Léry weder erwähnt noch abgebildet ist.

${ }^{103}$ Die Darstellung, wie die Frauen Maniok zerkauen und damit cahouin herstellen (3. Buch, 2. Teil, Stich 2; America, 1990, 138) gehört eigentlich schon zu den Vorbereitungszeremonien für das Fest, das der Anthropophagie vorangeht. 
Rechts im Bild senken zwei Indianer den in einen hamac verschnürten Leichnam in eine offene Grube. Dieses Motiv ist direkt von dem Stadenholzschnitt im 1. Buch, Kap. 35 kopiert. Im Vordergrund ist wie bei Staden eine Gruppe von kauernden Frauen, die ihr Gesicht mit den Händen bedecken, in Rückenansicht zu sehen. Diese drei Frauen erinnern an den Thevetholzschnitt, wo am rechten Rand zwei Frauen und am linken Rand eine einzelne Frau in derselben Körperhaltung trauern (Tafel 8, Abb. 2). Aber auch Lérys FormenreiBer, der sicher die Version Thevets kannte, zeigt zwei hockende Frauen im Vordergrund mit bedecktem Gesicht und zusätzlich hinter der Hängematte zwei kauernde Frauen, die sich trauernd umarmen (Tafel 22). Diese Parallelen können natürlich auf den analogen Beschreibungen beruhen, dennoch ist die Kombination der Darstellung von trauernden Frauen und dem Toten in der Hängematte, um die ein Schamane tanzt, ein deutlicher Verweis auf den Holzschnitt bei Léry. Bry hat den Leichnam aus dem Zentrum des Bildes gerückt. Im Gegensatz zu den homogeneren Stichen über die Anthropophagie ist also diese Illustration durch eine Verschmelzung von verschiedenen ikonographischen Vorbildern aus Staden und Léry geprägt.

Die Illustrationen zur Religion und zur Anthropophagie, die Bry aus dem zweiten Stadenbuch und aus Léry übernommen hat, sind nachfolgend zusammengestellt (Tabelle 3). Bei allen ist die Tendenz zur seriellen Darstellung klar erkennbar. Nur der gleichsam auf den Hauptteil hindeutende titelblattartige erste Stich mit einer winzigen Tötungsszene stellt in dieser Hinsicht eine Ausnahme dar. Auf dem Holzschnitt 1. Buch, Kap. 22, wiederholt im 2. Buch, Kap. 23, 1 in der Originalausgabe von Stadens Warhafftige(r) Historia, ist in synchroner Darstellung die Misshandlung des gefesselten Gefangenen durch die Frauen und schließlich das Rasieren der Augenbrauen beim sitzenden Gefangenen abgebildet. Einige der Frauen beißen sich vor lauter Gier in die Arme, ein Element, das sich auch bei Bry findet (America, 1990, 3. Buch, 2. Teil, Stich 4 und 5, S. 140f). Die im Text erwähnte Bemalung der Kriegskeule findet sich bei Staden auf dem Holzschnitt des 2. Buchs, Kap. 29, 5. Der Illustrator bildet die Kriegskeule selbst im Übrigen kurz zuvor ab im 2. Buch, Kap. 29, 3. Die Inspirierung an den Staden-Holzschnitten ist also offenkundig. 
Tabelle 3: Illustrationen zur Religion und zur Anthropophagie in Brys America, Bd. 3

America, 1990

3. Buch [2. Teil - Staden, Buch 2]

Stich 1, S.137: Die um einen Dorfplatz gruppierten Hütten der Indianer mit einer kleinen Tötungsszene

Stich 2, S.138: Trinkgelage der Indianer: cahouin (Tafel 33)

Stich 3, S.139: Bemalung des Gefangenen, im Vordergrund Bemalung der Tötungskeule (Tafel 34)

Stich 4, S.140: Die Tötung eines Gefangenen (Tafel 35)

Stich 5, S.141: Zerhacken und Ausweiden des toten Körpers (Tafel 37)

Stich 6, S.142: Frauen und Kinder verspeisen den Sud und die Eingeweide (Tafel 38)

\section{[3. Teil - Léry]}

Stich 1, S.144: Verzehr der auf dem boucan im Vordergrund liegenden Körperteile des Opfers durch die Indianer; Gier der alten Frauen (Tafel 39)

Stich 2, S.145: Der Erschlagene liegt am Boden, seine Frau trauert um ihn; der Totschläger, noch mit der Keule in der Hand, entfernt sich; im Vordergrund schneidet eine Frau den auf dem Rücken liegenden Körper längs der Wirbelsäule auf, eine andere stopft ein Stück Holz in den Anus des Toten (Tafel 36) $^{104}$.

Stich 3, S.146: Teufel quälen Indianer (Tafel 42)

Stich 4, S.147: Die religiösen Tänze der Indianer (Tafel 40)

${ }^{104}$ Hier ist allerdings Sievernich in seiner Ausgabe (America, 1990) eine Ungenauigkeit in der Anordnung der von ihm aufgenommenen Illustrationen unterlaufen. Dieser Stich taucht in der lateinischen und deutschen Originalausgabe nicht erstmalig an dieser Passage des Léryteils auf, sondern bereits im zweiten Teil des Stadenberichts. In Sievernichs Bry-Edition fehlt er im Stadenbericht Teil 2 zwischen Bild 4 und 5. In der lat. und dt. Erstausgabe von Bd. 3 der America-Sammlung wird er im Léryteil nur wiederholt. Für die Interpretation des Stichs ist dieses Detail nicht unwesentlich; vgl. hierzu auch Anhang, 144, Fußnote 129. 


\section{Bry und Léry}

Die Lérysequenz bei Bry erscheint auf den ersten Blick weniger homogen als der Stadenteil. Der innere Zusammenhang erschließt sich erst durch eine genauere Analyse der Bilder. Auffallend ist, dass es zu einigen Stichen in der Lérysequenz zumindest themengleiche Entsprechungen bei Thevet gibt. Die Darstellung des boucan, also des Grills, auf dem ersten Stich (America, 1990, 3. Buch, 3. Teil, Stich 1, S. 144; Tafel 39) entspricht thematisch dem Holzschnitt in den Singularités (1982, 77r, Tafel 8, Abb. 1) und in der Cosmographie (1953, 202). Léry, der die Darstellung der Zerteilung des Getöteten und des Röstens ausspart, hat den boucan nur ganz winzig im Hintergrund der Kampfszene (1975 [21580], 230f; Tafel 16) sicher unter Rückgriff auf Thevet abbilden lassen. Hat nun Bry hier bei Thevet, Léry oder nur bei Staden, der ja den Grill mehrmals abbildet, Anleihen gemacht?

Bei Bry ist der Grill im Vergleich zu Thevet etwas in den Vordergrund gerückt und bildet nur einen Teil des in der üblichen Simultantechnik in mehreren Kleinszenen geschilderten Zeremoniells der Anthropophagie.

Der Holzschnitt bei Thevet (Tafel 8, Abb. 1) sei hier als synchrone Schilderung eines Ablaufs genauer beschrieben: Zuerst wird ganz rechts das Zerhacken des toten Körpers gezeigt. Ein Indianer trennt mit einem Beil Kopf, Arme und Beine vom Rumpf. Einzig die Übernahme des Beils findet sich nicht bei Staden und deutet auf eine Kenntnis dieses Thevetholzschnitts durch Bry hin ${ }^{105}$. Staden hatte nur die steinernen Schabwerkzeuge der Indianer abbilden lassen. Lestringant (1987, 83ff) hat bei der Analyse dieses Beilmotivs bei Bry allerdings darauf verwiesen, dass es sich schon auf Abbildungen von Münsters Cosmographie aus dem Jahre 1544 oder den Karten des französischen Geographen Le Testu von 1555 findet, also auch in der genuin französischen Bildlichkeit einen ikonographischen Topos bildet ${ }^{106}$. Lestringant sieht die Rekurrenz dieses Motivs in Zusammenhang mit der Diskussion über die Gefahr von eisernen Waffen in Indianerhand in zeitgenössischen Reiseberichten und verweist auf das interessante Detail, dass bei dem Beil Brys die indianische Machart des mit Schnüren am Stil festgebundenen steinernen Beils als ethnologisches Zitat die absolute Fremdheit der dargestellten Anthropophagie symbolisch ausdrücken soll (ebd., 1987, 89). Diese Feststellungen zeigen in nuce die Tendenz Brys auf, sich an die bildliche Tradition der frühen Kannibalismusdarstellungen anzugleichen und damit zugleich den brasilianischen Indianer als absolutes Gegenbild zur europäischen Kultur zu zeichnen.

${ }^{105}$ So bereits Lestringant 1978, 585. Bei Staden findet sich ein kaum erkennbares europäisches Beil auf dem vignettenartigen Titelholzschnitt des 1 . Buchs neben einem Grill mit Menschenfleisch. Es handelt sich um eine typische Anspielung auf die Abbildungstradition der Kannibalen schon bei den deutschen Übersetzungen der Vespucci-Briefe.

${ }^{106}$ Zahlreiche weitere Belege für den Topos in der deutschen Tradition bei Menninger 1995, 147 und Kügelgen 1996, $201 \mathrm{ff}$ (mit Abbildungen). 
Eine vor dem boucan kniende Frau entfernt bei Thevet aus einem schon teilweise zerhackten Körper die Eingeweide. Einige Kinder spielen mit den Köpfen der Toten ${ }^{107}$. Ein kauernder Indianer facht das Feuer an, während ein anderer einen abgehackten Arm auf die Roststäbe legt oder ihn wendet. Links davon tragen zwei Indianer ein Bein zum boucan. Der entsprechende Holzschnitt bei Staden (2. Buch, Kap. 29, 4; Tafel 24, Abb. 2) enthält ganz ähnliche Motive. Der Grill befindet sich ebenfalls rechts im Vordergrund. Neben ihm kniet wie bei Thevet ein Indianer, der das Feuer mit einer Art Wedel anfacht. Auf dem Grill liegen menschliche Gliedmaße, dahinter stehen drei männliche Gestalten, von denen die mittlere ein Stück Fleisch zu ergreifen scheint. Es finden sich keine Gestalten, die demonstrativ diese menschlichen Gliedmaßen in die Höhe recken. Da dieses Motiv sich aber auf anderen Stadenholzschnitten findet, beispielsweise auf dem Holzschnitt 2. Buch, Kap. 29, 9, wo wie bei Bry zwei Frauen abgetrennte Beine in die Höhe halten, kann Bry auch hier bei Staden ein direktes Vorbild gefunden haben. Diese in die Höhe gehaltenen Gliedmaßen erscheinen mehrfach bei Bry, unter anderem auf dem Frontispiz (Tafel 32) als Allegorie für kannibalistische Wildheit, dort gleichsam auf eine aus Lérys Holzschnitten übernommene Indianerabbildung überblendet. Sie finden sich aber auch schon auf den ältesten Kannibalismusdarstellungen wie z. B. auf einer Illustration der bereits erwähnten Mandeville-Ausgabe von 1484 (s. oben 25). Die Geste ist - ähnlich wie das auch in dem eben erwähnten Stadenholzschnitt vorkommende "Sich in die Arme Beißen" der Frauen bei Ankunft eines neuen Gefangenen - als Zeichen der Vorfreude auf das kannibalistische Mahl zu interpretieren. Es handelt sich beide Male um eine Art visueller Synekdoche, die auf die gesamte Anthropophagie verweist.

Auf dem Stadenholzschnitt (2. Buch, Kap. 29, 4; Tafel 24, Abb. 2) finden sich noch andere Details, die Bry nicht kopiert hat, so z. B. die kauernden Frauen, die kleine Fleischteile, etwa menschliche Hände, in ein Feuer halten, und andere Frauen, die gemeinsam die in einem Topf gekochten Eingeweide verspeisen. Da letzteres Thema aber von Bry auf dem Stich 6 des zweiten Stadenteils (Tafel 38) eigens abgebildet wurde, ist hier kein Verlust von ikonographischer Information im Vergleich zu Staden gegeben, der diese hier nur im Hintergrund abgebildete Szene auch auf einem eigenen Holzschnitt bildfüllend gezeigt hat (2. Buch, Kap. 29, 10; Tafel 27, Abb. 2). Trotz der Ähnlichkeiten der Darstellung mit Thevet ist also auch hier das Vorbild Stadens für Bry entscheidend.

${ }^{107}$ Ein typisches Vanitas-Motiv, das sich in den Emblemata secularia (Kind mit Totenkopf) wiederfindet und auch von Bry auf seinen Illustrationen gern aufgegriffen wird (vgl. America, 1990,3 . Buch, 2. Teil, Stich 5, S. 141). Eventuell ist diese Illustration auch ein Nachklang der Abbildung bei Staden, 1. Buch, Kap. 40, wo eine kleine Gestalt den Kopf eines getöteten Sklaven in den Fluss wirft. 
Auf dem fünften Stich der Anthropophagiesequenz bei Staden hat Bry im übrigen noch einzelne bisher nicht illustrierte Details hinzugefügt, so das Kochen des Suds aus den Eingeweiden und das Sieden des Kopfes in einem großen Topf. Dies entspricht ziemlich genau der von Staden eigens auf dem Holzschnitt im 2. Buch, Kap. 29, 11 (Tafel 28, Abb. 1) dargestellten Szene. Der folgende sechste Stich (Tafel 38) illustriert schließlich den gemeinsamen Verzehr dieses Suds und der gekochten Körperteile durch Frauen und Kinder und entspricht dem Stadenholzschnitt 2. Buch, Kap. 29,10 (Tafel 27, Abb. 2).

Es gibt aber auch deutliche Hinweise auf Bewertungen, die nur in Lérys Text begegnen. So stehen auf dem ersten Stich des Léryteils (America, 1990, 144; Tafel 39) drei ältere Frauen in der von Bucher analysierten typischen Darstellungsweise mit Hängebusen am boucan und beißen gierig in abgetrennte Körperteile des Toten. Nur eine Frau im Vordergrund ist jünger gezeichnet. Léry hatte in seinem Reisebericht (1975 [ [21580], 218f) erzählt, dass besonders die älteren Frauen gierig nach Menschenfleisch seien, was wohl an der Lebenskraft verleihenden Bedeutung dieses Verzehrs liegt und darüber hinaus gut zum europäischen Klischee von der Hexe passt. Eine alte Frau mit Hängebusen, die einen Matrosen hinterrücks erschlägt, findet sich schon auf einer HolzschnittIllustration zu Vespuccis Soderini-Brief in der deutschen Ausgabe unter dem Titel Diß Büchlin saget (Straßburg, Grüninger 1509; vgl. die Abbildung bei Kohl 1985, 320). Wieder zeigt sich, wie vielfältig die Sinnbezüge einer Abbildung sein können: Brys Stich steht ikonographisch in der Tradition von Staden, verweist jedoch auch eindeutig auf Léry und enthält zugleich Elemente eines zeittypischen Topos aus einer älteren ikonographischen Tradition.

Die Vorliebe der alten Frauen für das flüssige Fett des Toten kann in Anlehnung an Bucher wieder als Zeichen der Degradation gelesen werden, da dieses Fett ja in den Bereich des pourri fällt. Aber auch die Kritik von Duchet $(1987,29)$ an dieser Interpretation ist berechtigt, die bei den Anthropophagiestichen besonders betont, dass alle Indianer, auch die alten Frauen, den Körper des Getöteten gesamt verspeisen.

Der folgende zweite Stich des Léryteils (America, 1990, 145; Tafel 36, vgl. auch oben Fußnote 104) illustriert schließlich den Augenblick nach der Tötung des Gefangenen und greift zumindest teilweise auf den Holzschnitt von Lérys Histoire (1975 [21580], 214; Tafel 14) zurück. Dieser zeigt in Anlehnung an Thevet (Tafel 13) den Augenblick kurz vor der Tötung und am linken Rand die am Körper des Getöteten trauernde Frau, der alle zeitgenössischen Autoren eine heuchlerische Trauer vorgeworfen haben, da sie sich nach dieser rituellen Trauer am Festmahl beteiligt. Die Tötung selbst erscheint bei Bry an anderer Stelle, er braucht sie deshalb hier nicht zu wiederholen. Der Stich stammt allerdings aus der Staden-Sequenz, wo er auch erstmalig in der Anthropophagiedarstellung vor der dem Stadenholzschnitt 2. Buch, Kap. 29, 9 nachempfun- 
denen Szenerie auftaucht ${ }^{108}$. Bry stellt den Augenblick dar, in dem sich der Totschläger noch mit der Keule in der Hand vom Ort der Tötung entfernt. Hier hat er sicher die Abbildung dieser Gestalt auf dem Holzschnitt von Léry (1975 [21580], 222; Tafel 19) mit der Trauerszene (ebd., 214, Tafel 14) zu einer Einheit verschmolzen. Im rechten Hintergrund sieht man wieder eine Gruppe Indianer und den vor Entsetzen die Hände ringenden Staden, der eine Gruppe Frauen betrachtet, von denen eine den nun auf dem Bauch liegenden Körper des Toten längs der Wirbelsäule aufschneidet. Eine Frau steckt dem Toten einen Holzpflock in den Anus. Dieses Detail findet sich bei den möglichen Vorbildern nur in Stadens Text ${ }^{109}$. In der Erstausgabe hat es keine eigene Illustration erhal$\operatorname{ten}^{110}$. Stadens Holzschnitt zeigt nur die Zerteilung des Rumpfes, ein Motiv, das bei ihm auf zahlreichen Stichen begegnet (so u. a. in Buch 1, Kap. $40^{111}$ oder Buch 2, Kap. 29, 9; Tafel 27, Abb. 1), bei Léry jedoch fehlt. Bry hat wohl aus ästhetischen Gründen den Körper nicht wie bei Staden als zerstückelten Rumpf gezeichnet. Warum genau das Detail des Holzpflocks als Verschluss des Anus übernommen wurde, ist schwierig zu sagen. Möglicherweise wollte Bry damit auf tabuisierte sexuelle Bereiche anspielen, entsprechend der Interpretation der homosexuellen bzw. autoerotischen Gesten einiger Frauen bei der Vorführung des Gefangenen (America, 1990, 3. Buch, 1. Teil, Stich 10, S. 126) bei Bucher. Dieser Stich ist also trotz der teilweisen Inspiration an Léry eine Verarbeitung inhaltlicher Angaben und ikonographischer Vorgaben von Staden.

Die sexuellen Gesten der Frauen auf diesem Stich sind bei den Brys im übrigen ebenso wie der Kannibalismus als Zeichen einer im Vergleich zu Europa verkehrten Welt zu deuten und als sexuelle Freizügigkeit zudem ein typisches Attribut der "Wilden Familie" und der Hexe. Ikonographisch finden sich im Kontext der Reiseberichte Vorläufer hierzu schon bei den frühesten Illustrationen über die Neue Welt, so in der autoerotischen Geste einer Frau, die ihre Brüste streichelt, in einem Holzschnitt der lateinischen Ausgabe des Vespucci-

${ }^{108}$ Zur Auslassung dieses Stichs im Stadenteil bei Bry in Sievernichs Ausgabe (America, 1990) s. oben Fußnote 104.

${ }^{109}$ Staden 1978, Kap. 29, unter Holzschnitt 9: "[die Indianer] stopfen im den hindersten mit eynem holze zu, auff das ihm nichts entgehet”. Kügelgen 1996, 214 geht irrtümlich davon aus, dass Staden dieses "Pfählmotiv" im Text nicht erwähnt hat. Thevet $(1953,281)$ bezieht sich auf diese Praxis in seinem Manuskript "Les deux voyages". Dieses in der Bibliothèque Nationale, Paris erhaltene Manuskript, entstanden kurz vor Thevets Tod 1592, war den Zeitgenossen allerdings nicht bekannt und scheidet als Quelle aus.

${ }^{110}$ Kügelgen $(1996,214)$ verweist in diesem Kontext auf das in der Tat sehr ähnliche Motiv des "Über ein Seil Ziehen" in Verstegans Werk 1588 (1995, Abb. 24).

${ }^{111}$ Konsequenterweise hat Bry dann bei seiner Neubearbeitung dieses Staden-Holzschnitts (America, 1990, 3. Buch, 1. Teil, Stich 15, S. 131) den Rumpf anders positioniert. Er liegt bereits auf dem boucan und wird von vorne geöffnet. 
Briefs an Piero Francesco di Medici über seine dritte Reise in die Neue Welt ${ }^{112}$. Diese Geste des Streichelns ist wiederaufgenommen in der schon erwähnten Textillustration des Soderini-Briefs in der Straßburger Ausgabe unter dem Titel Diß Büchlin saget von 1509 (Tafel 4). Hier betrachtet die Frau einen Mann, der menschliche Gliedmaßen auf einem Block wie auf einer Schlachtbank zerteilt. Es findet sich hier erstmals eine Verbindung von Kannibalismus und autoerotischem Motiv, die im Text Vespuccis, trotz des Verweises auf die sexuelle Freizügigkeit unter den Indianern, nicht gegeben ist und intentional aus Sicht des Illustrators das hexenhafte Wesen der Indianerinnen unterstreichen soll (Kohl 1985, 325). Bry hat dieses Motiv als sexuelle Geste zwischen Frauen aufgegriffen, um damit in der Homosexualität eine im Zeitkontext ideale Illustration der "verkehrten Welt" der neuentdeckten Kontinente im Sinne seiner Textintention zu erhalten.

Warum hat Bry überhaupt die Anthropophagie noch durch zumindest eine neue Illustration im Léryteil abbilden lassen und sich nicht mit den Abbildungen im Stadenteil, die ja detailliert genug waren, zufrieden gegeben? Auch auf der erstmals im Léryteil aufgeführten Anthropophagie-Abbildung (Tafel 39) sieht man im Hintergrund eine Gestalt, die Gesten der Hilflosigkeit zeigt. Sie entspricht mit ihrem langen Bart exakt der Stadenfigur auf den Illustrationen zu seinem Bericht. Der andere Kannibalismus-Stich (Tafel 36) wiederholt eine Abbildung aus dem Stadenteil. Dass Staden im Léryteil auftaucht, ist an sich nicht befremdlich, da er hier als eine Art Passe-partout-Figur durch seine Gesten des Entsetzens sehr wohl den für alle Europäer geltenden Abscheu vor den abgebildeten Handlungen versinnbildlichen kann, ohne dass dies den Leser irgendwie befremden würde. Staden visualisiert damit als Teil der Darstellung das europäische Werturteil, das in den Texten verbalisiert wird.

Hier dürfte aber auch eine andere entstehungsgeschichtliche Ursache mitspielen. Diese beiden Stiche im Léryteil fügen sich exakt in die Anthropophagiesequenz bei Bry im Stadenteil (3. Buch, 2. Teil) zwischen den Stichen 4 und 5 (America, 1990, 140f) ein, wobei bei dieser Einordnung Stich 2 des Léryteils (Tafel 36) Stich 1 (Tafel 39) vorangehen müsste, da er ja die Zerteilung des Körpers zeigt, während auf Stich 1 die Einzelteile schon geröstet werden. In der lateinischen Originalausgabe (nicht im Nachdruck der Stiche von Sievernich, der hier eine Illustration unterschlägt) findet sich zumindest der zweite Stich der Lérysequenz an der passenden Stelle des Stadenteils. Welche Funktion hat dann die Kollokation eines offenkundig für den Stadenteil gefertigten Stichs mit dem boucan im Léryteil? Wozu dient die Wiederholung des Stichs mit der Zerteilung des toten Körpers?

${ }^{112}$ Epistola Albericii, De novo mundo, Rostock [um 1504/05]. Die Szene ist abgebildet bei Kohl 1985, 317, der auch die Filiationen des Motivs aufgezeigt hat. Es handelt sich um einen Reflex der Darstellungstradition “Wilder Mann und Frau”, deren Einfluss auf die Illustrationen der Vespucci-Ausgabe, Straßburg 1509 oben schon aufgezeigt wurde (vgl. oben 24f). 
Die Kollokation eines Stichs ist natürlich auch eine Art Leserlenkung. Das Auftauchen Stadens im Léryteil verweist den Leser auf die inhaltlich sehr ähnlichen Beschreibungen und Beobachtungen der beiden Reiseschriftsteller, die in der Tat mit nah verwandten Indianerkulturen konfrontiert waren.

Zudem wollten die Brys ihr Bildmaterial sicher gleichmäßig verteilen, und bei dem Übergewicht der Illustrationen des Stadenteils wäre der Léryteil ohne Darstellung der Anthropophagie aus dem Rahmen gefallen. Ein einziger diesbezüglicher Stich im inhaltlich wichtigen Léryteil wäre zu wenig gewesen, weshalb sich wie auch bei anderen Stellen des Buchs die Wiederholung einer Stadenillustration anbot. Die einzige für den Leser des Stadenteils neue Anthropophagieabbildung im Léryteil enthält im Übrigen auch klare inhaltliche Verweise auf Léryschilderungen in den Stichen (die Gier der alten Frauen). Das erstmalige Auftauchen dieses Stichs im Léryteil ist damit inhaltlich gerechtfertigt, auch wenn er vielleicht anfangs im Rahmen der Stadensequenz angefertigt wurde und deshalb die Abbildung Stadens enthält. Der andere Stich mit der Zerteilung des Körpers ist zwar nur sekundär von Léry inspiriert, was die Abbildung des Totschlägers betrifft, aber er ist zumindest an dieser Stelle als Wiederholung inhaltlich passend. Auf Stich 4 des Léryteils (Tafel 40) tauchen dann auch Figuren einer von Léry erzählten Episode auf: Der Autor selbst und zwei Übersetzer, mit denen er am rechten oberen Bildrand ein Indianerfest betrachtet, entsprechen genau den detaillierten Schilderungen Lérys und stellen damit wie die Abbildung der alten Frauen auf Stich 1 (Tafel 39) eine direkte Verbindung zwischen Bild und Text her, auch wenn zuerst die künstlerisch hochwertige Darstellung des indianischen Tanzes die Aufmerksamkeit des Betrachters auf sich zieht.

Ein weiterer Grund für die Kollokation der an Stadens Bericht angelehnten Stiche im Léryteil ist sicherlich, dass Léry im Bildmaterial seines Buchs das Zeremoniell der Tötung des Gefangenen nicht gezeigt hatte. Bry wollte aber die für den zeitgenössischen Leser und seine Bewertung des Indianers hochgradig wichtige Anthropophagie auch visualisieren und musste damit mangels ikonographischer Vorbilder bei Léry auf Staden und eventuell auf Thevet zurückgreifen. Dass sich damit auch die Bewertung von Lérys Text etwas zugunsten einer undifferenzierten Anklage der Anthropophagie verschiebt, entspricht sicher Brys Absicht. Die eigentliche theologische Aussage ist aber in den beiden folgenden Stichen 3 und 4 (Tafel 42, 40) der Lérysequenz zu erkennen. Bevor die Lérystiche Brys abschließend gewürdigt werden können, müssen deshalb die beiden letzten Stiche der Serie genau analysiert werden. Diese zeigen mustergültig, wie man Theologie in einen Kupferstich umsetzen kann.

Die beiden auf Léry zurückgehenden Stiche im 3. Teil des dritten Buchs der Reiseberichtkompilation von Bry finden sich nach den schon besprochenen Darstellungen der Tötung und Verspeisung des Gefangenen, die Stadens Illustrationen aufgreifen. Sowohl diese Stellung in einer Folge von Stichen als auch ihre inhaltliche Aussage müssen gleichsam als conclusio der vorherigen Bilderfolge gelesen werden. 
Der erste Stich (Tafel 42) nach dem Vorbild von Lérys Holzschnitt (1975 [21580], 235; Tafel 41) illustriert ein Lieblingsthema der religiösen Bewertung der Indianerreligion und greift zugleich auf eine bei Léry erzählte Episode zurück. Nach der theologischen Sicht der Zeit, die von katholischen Missionstheoretikern wie dem Jesuiten José de Acosta ebenso wie von Protestanten oder Kalvinisten vertreten wurde, sind die ungläubigen Indianer Opfer des Teufels. Léry hatte dies anhand der von ihm im Text berichteten Erlebnisse illustrieren lassen. Indianer, die während eines Gesprächs mit Europäern plötzlich Schmerzen empfinden, machen dafür einen bösen Geist verantwortlich. Ein Europäer hat angeblich diesen Teufel durch den Namen Christi gebannt, wie Léry erzählt wurde. Diese Szene ist im Mittelgrund des Stichs dargestellt, die zum Himmel erhobenen Arme des Europäers und die Gestik des Indianers sollen dem Leser diese Episode in Erinnerung rufen.

Der Holzschnitt zeigt die damals übliche geographische Kulisse mit einer stilisierten Küste. Diese dient aber nicht nur wie auf den Kartendarstellungen etwa von Ramusio oder Le Testu dazu, eine Schau aus der Vogelperspektive auf einige Gestalten des Kontinents zu ermöglichen, sondern hat auch eine symbolische Bedeutung: die Teufel herrschen nämlich über alle Elemente. Im Meer befinden sich ein Ungeheuer und einige Fische, vermutlich einige unbeholfene Darstellungen der auch von Léry beschriebenen fliegenden Fische, die auch auf einem anderen Holzschnitt des Léryteils und später im Benzonitext auftauchen (vgl. unten Anhang, 146, Fußnote 131). Darüber schwebt ein geflügelter Teufel in den Lüften. Im Vordergrund quälen Teufel auf der Erde die nackten Indianer. Einer fasst einem schlafenden Indianer von hinten an den Hals, um ihn zu würgen, ein anderer prügelt mit einem Stock auf einen laufenden Indianer ein, der seinen Kopf schützend mit den Händen bedeckt, während ein danebenstehender die Hände vor Entsetzen in die Höhe reckt. Vermutlich symbolisiert diese dreifache Darstellung von Teufeln bzw. Ungeheuern, dass alle Elemente in der Neuen Welt von ihnen beherrscht werden. Die Illustration drückt gleichzeitig den Glauben an ihre Erscheinungen in der Neuen Welt aus. Auch ein kleiner Indianer im Hintergrund deutet auf eine der fliegenden Gestalten hin. Dieser Glaube an die Sichtbarkeit von Teufeln ist zeittypisch.

Im Hintergrund des Holzschnitts befinden sich einige malocas (indianische Langhäuser), im Vordergrund Palmen und im Zentrum ein sogenanntes haut. Dieses Tier, auf Tupi hai, ist nichts anderes als ein Faultier. Bereits Thevet hatte es als eine seiner singularités beschrieben: als ein Tier, das sich angeblich von Wind ernährt. Léry erwähnt es ebenfalls, äußert aber vorsichtiger dazu, dass es nach Meinung einiger von Wind lebe. Thevet hatte dieses Tier auch auf einem seiner Holzschnitte dargestellt $(1982,99 \mathrm{v})$, den Lérys Illustrator hier direkt kopiert hat. Das menschliche Antlitz und die Größe des Tieres, das so hoch wie die menschlichen Gestalten auf derselben Ebene ist, geben ihm ein monströses Aussehen, das sicher auch dem nur mäßigen Können des Künstlers zuzuschreiben ist, der keine Perspektive kannte und selbst die Palmen im Vordergrund mannshoch zeichnete. 
Dieser Holzschnitt bei Léry stammt vermutlich von demselben Illustrator wie der Holzschnitt mit der Kampfszene und zeigt einen deutlichen Qualitätsunterschied zu den Darstellungen einzelner Indianer; von der technischen Kunstfertigkeit her kann man ihn sogar als den schlechtesten bezeichnen. Unabhängig davon hat die Teufelsszene eine eminent theologische Bedeutung. Jeder apologetischen oder gar präadamitischen These über den Ursprung der Indianer, die damit nicht der Erbsünde unterworfen wären, soll auf diese Weise ein Riegel vorgeschoben werden. Léry betont auch explizit an einer Stelle (1975 [ ${ }^{21580]}$, 259ff), dass die Indianer nach seiner Ansicht von Adam abstammen würden, ohne Rücksicht auf die Frage, wie sie nach Amerika gelangen konnten.

Der Holzschnitt Lérys illustriert damit die Bewertung der Indianer von Seiten der zeitgenössischen Theologen an einer der wenigen Episoden, die sich für eine visuelle Darstellung überhaupt eigneten. Léry hatte zwar auch von einer angeblichen Missionierung durch einen geheimnisvollen Fremden berichtet, aber diese Legende, die sich bei mehreren spanischen Chronisten des 16. Jahrhunderts findet ${ }^{113}$, wäre wohl schwerer darzustellen gewesen und hätte nicht der protestantischen Ablehnung von Heiligendarstellungen entsprochen.

Sehen wir uns jetzt die Version Brys von diesem Holzschnitt an (Tafel 42). Die Landschaftsperspektive ist spiegelbildlich übernommen. Die Gestalten sind vergrößert auf das in der Kollektion für Personendarstellungen übliche Format. Dieselben Personengruppen tauchen auf: Die Europäer, die mit den Indianern sprechen, sind in den Vordergrund des Stichs gerückt. Daneben liegt der Schlafende, den ein bockshäuptiges Monstrum quält, im Hintergrund der von einem Teufel geprügelte und andere Indianer, die auf die Fabelwesen in der Luft zeigen. Der Europäer hat die rechte Hand zur Teufelsaustreibung erhoben. Im Hintergrund findet sich wieder das Faultier, das wie bei Léry und Thevet gezeichnet ist. Die Hütten der Indianer sind dieses Mal als echte Langhäuser dargestellt wie auf den Stichen, mit denen Bry Stadens Reisebericht illustriert hat.

Forge (1987, 117ff) hat in seiner Analyse der eben besprochenen Abbildung darauf verwiesen, dass die Teufelsgestalten ziemlich genau zeitgenössische, in der Literatur beschriebene Muster aufgreifen. Auch die fliegenden Fische werden in dieser Abbildung zu Monstern, die sich zu den anderen teuflischen Lebewesen gesellen. Das bockshäuptige Ungetüm verweist beispielsweise auf die Wollust und den Stolz. Alle Versionen zoomorpher und anthropomorpher Teufelsdarstellungen sind auf dem Bild vertreten. Forge hat auch auf die subtile Konstruktion der Fluchtlinien in dem Bild verwiesen (vgl. ebd. die Abb., S. 121). Die vertikale Mittelachse und die horizontale Achse des Horizonts schneiden sich genau in der längsstehenden Hütte. Alle Gestalten sind in einem Dreieck angeordnet, dessen oberster Winkel auf diesen Fluchtpunkt zuläuft, wobei kleiner werdende Gestalten die räumliche Tiefe ausdrücken. Die Bildmitte und den Schnitt-

${ }^{113}$ Der Legende nach soll der Apostel Thomas den Glauben in Amerika verkündet haben. 
punkt der Diagonalen von einer Bildecke zur andern füllt die Gruppe aus, in der ein Teufel auf den Rücken eines Kauernden einschlägt, die Gruppe im Vordergrund bildet ein kleineres Dreieck, das ebenfalls auf diese zentrale Gruppe ausgerichtet ist (vgl. die Haltung des Europäers, der dem Betrachter den Rücken zuwendet und die Gesten des prügelnden Teufels). Dies zeigt, wie subtil der Bildaufbau von Bry bedacht wurde. Auch das Faultier (haut), das Lérys Künstler von Thevet kopiert hatte, findet sich rechts von der Bildmitte wieder, und passt mit seinem menschengesichtigen Kopf gut zu den anderen Monstern. Forge (ebd., 119) verweist ferner darauf, dass sich eine Abbildung des Faultiers bei dem renommierten französischen Arzt Ambroise Paré (1509-1590) findet, der als einer der ersten über medizinische Themen nicht mehr in Latein, sondern auf Französisch schrieb und deshalb eine große Bedeutung für die Entwicklung des Französischen als Wissenschaftssprache hat. In einem Teil seines Werks, das auch Monster und Wunderzeichen behandelt ${ }^{114}$, hat er einige der Illustrationen direkt aus Thevets Cosmographie übernommen, was wohl auf die damals übliche Gewohnheit der Drucker hinweist, einmal gebrauchte Bildstöcke für die Illustration eines neuen Buchs wiederzuverwenden, selbst wenn diese thematisch nicht genau passten ${ }^{115}$. Dieses Beispiel des angeblich vom Wind lebenden Faultiers zeigt deutlich, dass nach wie vor die mittelalterlichen Vorstellungen von Wundern weiterlebten, denen Thevet in seinen Singularités Vorschub geleistet hatte. Im übrigen ist die Abbildung des Faultiers eine der wenigen naturkundlichen Abbildungen Thevets, der ein Weiterleben in anderen Büchern beschieden sein sollte. Obwohl Bry diese Aspekte in der Ikonographie seiner Vorbilder sonst gänzlich ausspart, hat er an dieser Stelle im Gefolge Lérys nicht auf eine Anspielung auf das haut verzichtet. Das Faultier und ein anderes bei Thevet (1982, 109r; 1575, 1002r) unter dem Namen su abgebildetes Tier tauchen auch in Konrad Gesners Thierbuoch auf, das 1563 in Zürich bei Froschauer erschienen war $^{116}$. In der deutschen Bearbeitung des Reiseberichts von Walter Raleigh über seinen Guyanaaufenthalt, die der auf Reiseliteratur spezialisierte Levinus Hulsius 1599 unter dem Titel Kurtze wunderbare Beschreibung deß goldreichen Königreichs Guianae in America oder newen Welt in Nürnberg veröffentlicht hat, findet sich eine Skizze, die im Gefolge Thevets das Faultier (hier haute) und einige andere exotische Tiere wie den Leopard und das Gürteltier zeigt ${ }^{117}$. Das menschenähnliche Faultier findet sich ferner mit anderen Tieren zusammen auf

${ }^{114}$ Des oevvres de M. Ambroise Paré ... auec les figures \& portraicts tant de l'anatomie que des instruments de chirurgie, \& de plusieurs monstres. Le tout diuisé en vingt six liures [...]. Paris: G. Buon, 1575.

${ }^{115}$ Vgl. Thevet 1985, LXVII, dort auch die Liste der Übernahmen bei Paré (1575).

116 Vgl. Blatt LXXIVr, CXLVIIIr. Aufmerksam wurde ich auf diese Abbildungen durch Menninger 1991, 37, Fußnote 55.

117 Vgl. die Abbildung in America, Das frühe Bild der Neuen Welt, 1992, 40. Die pfeilschießenden Indianer verweisen direkt auf Abbildungen von Amazonen in den Singularités Thevets, die an Bäumen hängende Männer töten (Thevet 1982, 126v). 
einem Stich in dem Werk De nieuwe en onbekende Weereld von Arnoldus Montanus 1671 (abgebildet bei Honour 1982, 38). Auch andere Tierdarstellungen Thevets leben in den "Grands voyages" fort. Das schon erwähnte in Kanada lebende Tier su, das in den Singularités beschrieben und abgebildet wurde, taucht auf einem Stich bei Bry im 14. Buch auf (America, 1990, 427), das 1630 von Matthäus Merian herausgegeben wurde. Vielleicht liegt hier die Abbildung in Gesners Tierbuoch zugrunde.

Die Überlieferung dieser in der Tradition der Monster- und Mirabilia-Ikonographie stehenden Abbildungen, die als naturkundliche Bilder eine absolute Ausnahme in der Sammlung der Brys darstellen, zeigt deutlich, dass eben die phantastischen Erzählungen mancher Reiseberichte noch auf reges Publikumsinteresse stießen, wohl weil sich der epistemologische Bruch zwischen mittelalterlich phantastischen Vorstellungen und neuzeitlich kritischer Berichterstattung in der damaligen Reiseliteratur erst allmählich vollzog.

Diese Illustration bei Bry muss auch im Gesamtzusammenhang der Stiche im Léryteil seines dritten Bands gesehen werden. Die nachfolgende Abbildung 4 (America, 1990, 147; Tafel 40) zeigt die religiösen Tänze der Indianer nach einer berühmten Schilderung Lérys (1975 [ $\left.{ }^{2} 1580\right], 244 \mathrm{ff}$ ), die immer wieder als Beispiel für seine indianerfreundliche Haltung herangezogen wurde. Diese Stelle muss im Vergleich zum Kontext allerdings noch kritisch beleuchtet werden. Der in diesem Kapitel expressis verbis vorgetragene Bezug auf den Hexensabbat, der in den späteren Fassungen der Histoire durch weitere Digressionen verstärkt wurde, ist mit Sicherheit eine von Léry oder seinen möglichen theologischen Beratern gewollte Leserlenkung im Sinne einer scharfen Verurteilung der indianischen Religion als Teufelszeug. Léry befindet sich in einem Dilemma. Selbst wenn seine Bewunderung für die fremden Zeremonien durchaus glaubwürdig ist und die Beschreibung, wie er langsam die Angst vor dem Fremden in diesen Riten verliert, doch eine mentale Öffnung gegenüber dem fremden Kultus zeigt, muss er den zugrundeliegenden Glauben verurteilen, den er als einer der ersten wohl deutlich gespürt hat, so wie der Kapuzinermissionar Claude < d'Abbeville > mit Entsetzen den zeremoniellen und damit letztlich religiösen Charakter der Anthropophagie in seinem Buch hervorhob (Histoire, 1615, 287r). Léry kann als gläubiger Kalvinist nicht umhin, jede nichtchristliche Religion zu verdammen, denn die Bewunderung für religiös-mentale Strukturen anderer Religionen ist neuzeitlich und ohne das Werk der Aufklärung nicht denkbar. Die Strukturen des Totemismus oder gar die Anthropophagie als religiöse Zeremonie und nicht nur als Werk des Teufels anzuerkennen, war den damaligen Reisenden im zeitgenössischen epistemologischen und theologischen Kontext naturgemäß unmöglich.

Wichtig ist für Léry auch der Verweis auf den Sündenfall und die seither verderbte Natur des Menschen. Bezeichnenderweise wiederholt auch Bry im dritten Teil der "Grands voyages" den ersten Stich des ersten Bandes, der Adam und Eva beim Apfelpflücken im Paradies zeigt (Tafel 31). Für den damaligen Leser war dies ein deutlicher Hinweis darauf, dass die Indianer, über deren Ursprung 
in der damaligen Zeit heftig diskutiert wurde, von Adam abstammen mussten und damit der Erbsünde unterworfen waren. Damit ist für den Leser ein Kontext gegeben, in dem auch die Stiche über die Anthropophagie und den Götzendienst der Indianer auf die Verderbtheit aller Menschen und insbesondere der Heiden seit dem Sündenfall hinweisen.

Dieser Gedankengang bietet eine Erklärung dafür, warum der Stich über die Teufelserscheinungen gezielt an dieser Stelle der Sequenz untergebracht wurde. Selbst wenn dies der Gliederung von Lérys Buch entspricht, ist doch eine darüber hinaus gehende Absicht erkennbar. Er gibt gleichsam retrospektiv eine theologische Beleuchtung für die Anthropophagiesequenz (die Herkunft dieser Abbildungen des Kannibalismus aus dem Bildmaterial Stadens ist hier irrelevant, da auch Léry die Anthropophagie schildert und sie trotz der Parallelen, die er zum europäischen Wucher und den Grausamkeiten der Religionskriege zieht, ebenfalls verurteilt). Die bei Bry hervorgehobene Grausamkeit der Anthropophagie, die nach den Interpretationen Buchers zu recht als eine hochgradig allegorische Darstellung der verkehrten Welt angesehen werden kann, wird hier nach der Erwartung des zeitgenössischen Lesers theologisch gedeutet. Die Anthropophagie in Brasilien und andere damit verbundene Grausamkeiten oder sexuelle Normüberschreitungen sind für Christen ein Zeichen der Herrschaft des Teufels. Also ist es konsequent, dies auch in die Bildfolge zu übersetzen, und dazu bot sich eben der Holzschnitt Lérys als ikonographisches und theologisches Vorbild an.

Auffallend ist, dass dieser Holzschnitt Lérys mit den Teufelserscheinungen in der inzwischen sehr umfangreichen Forschungsliteratur zu diesem Autor keine detaillierte Würdigung erfahren hat. Erst Forge (1987) hat in seiner umfassenden Analyse vor allem die ikonographischen Bezüge zur zeitgenössischen Vorstellungswelt über die Teufel aufgezeigt und zudem einen stilistischen Vergleich mit den späteren Versionen des Holzschnitts bei Bry und Gottfried (als Kupferstich bzw. geätzte Kupferplatte) durchgeführt, die im Folgenden ebenfalls berücksichtigt werden sollen.

Dieser geringen Beachtung der Ikonographie Lérys und seiner Anspielungen auf das Teufelswesen unter den Indianern liegt wohl die Absicht zugrunde, ihn bewusst oder unbewusst einseitig zu einem Vertreter des positiven Indianerbildes zu stempeln und damit alle anderen Aspekte, wie seine unmissverständliche theologische Verurteilung der Indianer, wenn auch nicht ganz zu übergehen (dazu ist sie zu evident), so doch nicht dem Zeitkontext gemäß zu gewichten. Diese apologetische Funktion entspricht vermutlich der verbreiteten Auffassung, literarische Wertung einzig nach den derzeit geltenden Kriterien der Modernität oder Antizipation heutiger Toleranzvorstellungen auszusprechen. Dies ist bei den frühen Reiseberichten des 16. und 17. Jahrhunderts nicht angemessen, da sie trotz ihrer Bedeutung für die Anthropologie der Aufklärung doch immer dem theologisch geprägten Menschenbild der Zeit verhaftet bleiben.

Bei der Interpretation dieses von Léry inspirierten Stichs tritt dieser Aspekt deutlich zutage. Weder die Texte noch das Bildmaterial des 16./17. Jahrhunderts 
kennen eine (postmodernistische) Ambiguität, sondern Autor und Künstler geben dem Leser eine klare Interpretation an die Hand, die er - sofern er die Art des Lesens insbesondere bei den Emblemen oder den Stichen versteht - auch ohne weiteres entschlüsseln kann. Für die heutigen Leser ist dies angesichts des zeitlichen Abstands und des unterschiedlichen epistemologischen Hintergrunds, der für unsere Kultur wesentlich durch die Aufklärung geprägt ist, schwieriger, da er erst die Aussageintentionen des ikonographischen Materials rekonstruieren muss, so wie dies anhand eines begrenzten Korpus in diesem Buch versucht wird.

Der bereits erwähnte Stich bei Bry mit der Darstellung der Tänze der Indianer (America, 1990, 3. Buch, 3. Teil, 4. Stich, S. 147; Tafel 40) greift wiederum eine Lérystelle und eine seiner Abbildungen (1975 [21580], 246; Tafel 20) auf. Bei Léry waren auf den qualitätsvollen Stichen üblicherweise nur zwei Ganzkörperfiguren abgebildet, davon eine als nach vorne gebeugter Tänzer mit einer Hand am Rücken und dem Federschmuck enduape um die Hüften. Im Hintergrund ist ein Tänzer mit einer maraca dargestellt. Bry hat die Körperhaltung dieser Gestalten zwar übernommen, bildet aber in Anlehnung an eine Szene, die Staden in der Mitte eines Kreises von rauchenden Indianern zeigt (Tafel 26, Abb. 1), - der Holzschnitt in Staden, 1. Buch, Kap. 30 wird deshalb in der Stadensequenz bei Bry auch nicht wieder aufgegriffen - eine Gruppe von tanzenden, bis auf die aufgeklebten Federn und ihren enduape-Federschmuck nackten Indianern im Kreis ab. Sicherlich hat Bry sich hier durch die Beschreibungen Lérys anregen lassen. In der Mitte stehen die drei Zauberer, deren Körperhaltung derjenigen der Indianer im Hintergrund von Lérys Holzschnitt entspricht. Die Schamanen halten wie bei Léry eine maraca in Händen und wie die auf dem Stadenholzschnitt (1. Buch, Kap. 30) im Kreis Sitzenden Röhrchen zum Rauchen, mit denen sie entsprechend der Beschreibung Lérys die Tanzenden mit Tabakrauch anblasen. Wie auf dem vorangehenden Stich finden sich auch hier Verschmelzungen von Einzelelementen aus Lérys und Stadens Vorbildern, wobei der künstlerisch gelungene Stich sich in diesem Fall in erster Linie eng an die Beschreibungen Lérys hält und ethnologisch korrekt gezeichnet ist. Bry hat die Darstellung eines Rundtanzes sicher auch deshalb gewählt, weil diese räumliche Ausdehnung eher dem von ihm bevorzugten Bildaufbau in Form von kleineren Menschengruppen entsprach als die Beschränkung auf die bildfüllende Darstellung von nur zwei Indianern bei Léry. Die zwei Europäer, mit denen Léry nach seinem Bericht diese Zeremonien beobachtet hat, sind mit ihm im rechten oberen Hintergrund des Stichs angedeutet, wodurch der Textbezug explizit gemacht wird. Ihre abwehrenden Gesten schwanken zwischen Verwunderung und Verurteilung und sind damit als Pendant zu den Gesten der Stadengestalt auf den Stichen mit der Anthropophagiedarstellung zu sehen.

Der Stich über die Teufelsaustreibung wird in seiner Aussage nicht nur von dem vorhergehenden Anthropophagiezyklus bestimmt, den er retrospektiv beleuchtet, sondern auch von dem folgenden Bild. Eine dem Teufel verfallene Kultur 
wie die der Indianer musste nach dem Glauben der Zeit notwendigerweise auch einen Kultus schaffen, der die wahre christliche Religion parodiert, weil auch der Geist des Bösen eine Art göttliche Verehrung wünschte. Dieser Kultus äußert sich in Form der religiösen Tänze. Der letzte Stich im Léryteil steht damit in einem klaren semantischen Bezug zu dem vorhergehenden und führt diesen gleichsam theologisch weiter. Der Teufel beherrscht die Indianer, folglich ist ihre Religion teuflisch.

Dabei ist zu bedenken, dass Bry seiner Reiseberichtkollektion die späteren überarbeiteten Ausgaben von Lérys Histoire zugrunde gelegt hat, in denen der Bezug auf den Hexensabbat nach der Beschreibung des religiösen Festes und der Tänze durch eingefügte Digressionen expliziter ist als in den ersten beiden Auflagen, auch wenn die religiöse Verurteilung dort in demselben Maße erkennbar ist. Das entspricht sicherlich der Absicht Lérys, diesen theologischen Aspekt, der angesichts der geschilderten Faszination für die fremden Zeremonien leicht in den Hintergrund geraten konnte, noch einmal explizit zu betonen, um keinesfalls mit orthodox kalvinistischen Gedanken in Konflikt zu geraten. Der schreibende Léry war sich als ausgebildeter kalvinistischer Pastor der theologischen Implikationen von Reiseberichten klar bewusst und betont seine Orthodoxie an allen potentiell gefährlichen Stellen expressis verbis, so wenn er über die Abstammung der Indianer von Adam nach der Vorgabe des Bibelberichts schreibt. Bry hat sicherlich als Grundlage für seine Übersetzungen die damals aktuellste lateinische oder französische Ausgabe Lérys herangezogen ${ }^{118}$.

An diesen Stichen zeigt sich deutlich, wieviele Implikationen und Textbezüge ein einziges Bildelement aufweisen kann. Der Stich mit den Teufelserscheinungen hat seinen semantischen Stellenwert als Mittelteil der Léryillustrationen, so wie auch die theologischen Kapitel im Mittelpunkt des Textes stehen. Analog dazu wird die für die Zeit zentrale theologische Bewertung in das Zentrum des Bildaufbaus gerückt. Der Stich ist aber im selben Maße durch die Bezüge zu den Textstellen und, was noch wichtiger ist, vor dem epistemologischen Hintergrund der Zeit zu verstehen.

\section{Das Fortleben von Brys Bildmaterial}

Welche Bedeutung der Stich mit der Darstellung der Teufelsaustreibung hatte, zeigt sich auch darin, dass er noch 1631 von Matthäus Merian, dem Schwieger-

${ }^{118}$ Lérys Bericht war bereits 1578,1580 und 1585 in französischer Sprache in La Rochelle [fingierter Druckort] und Genf (bei Antoine Chuppin), in lateinischer Übersetzung erstmals im Jahre 1586 in Genf bei Eustache Vignon erschienen, ein Nachdruck 1594 bei demselben Drucker. Bry hat in seiner lateinischen Version, die sicher die weiteste Verbreitung gefunden hat und den Originaltext durch zahlreiche Querverweise auf andere Reiseberichte erweitert, die historischen Teile über die Geschichte der Kolonie Villegagnons und die Vertreibung der Kalvinisten gestrichen, da diese im Jahre 1592, als Brys dritter Band der Kollektion erschien, nicht mehr aktuell waren (vgl. zur Editionsgeschichte Léry 1975 [21580], XXXVIII). 
sohn von Johann Theodor de Bry, in der komprimierten Bearbeitung der AmericaSammlung von Johann Ludwig Gottfried (Historia Antipodum oder Newe Welt und Amerikanische Historien) aufgegriffen wurde (abgebildet bei Forge, 1987, 122, vgl. Tafel 43).

Der Stich ist von einer geätzten Kupferplatte ("eau-forte") abgezogen und greift in abgewandelter Form Elemente des Léry-Holzschnitts auf. Der Stil entspricht dem gewandelten Geschmack der barocken Illustration. Die gequälten Indianer sind nun endgültig in den Vordergrund der Szene gerückt und nehmen den ganzen Bildraum ein. Die Landschaft ist auf eine bloße Kulisse ohne ethnologische Elemente wie die Langhäuser der Indianer in Brys Version reduziert. Der barocke Geschmack und der Einfluss der niederländischen Stecher hat aus den Figuren muskulöse nackte Athleten mit manieristischen und betont perspektivisch verkürzten Körpern gemacht. Das Zentrum des Stiches wird von der Gestalt des Teufels beherrscht, der wie in den Vorbildern auf einen am Boden liegenden Indianer mit einer Art Geißel einschlägt. Dieser Indianer ist elegant in Rückenansicht gezeichnet. Rechts befindet sich ein hilflos am Boden liegender Nackter, den ein ochsenköpfiges Zwitterwesen am Arm packt. Am linken Bildrand hält sich ein stehender Indianer die Ohren zu, wohl um sich vor dem Lärm der Ungeheuer zu schützen. Ein anderer vogelgesichtiger Teufel sticht mit einem Messer auf einen vor ihm am Boden kauernden Indianer ein. Im rechten Mittelgrund wenden sich zwei Indianer einer fliegenden Schlange und einem fliegenden Teufel mit Menschenkörper und Froschgesicht zu, die perspektivisch stark verzerrt gezeichnet zum linken oberen Bildrand zu fliegen scheinen. Die Bewegung dieser Gestalten und die Diagonale, die von dem Indianer, der sich die Ohren zuhält, nach oben führt, verleihen dem Bild eine Dynamik des Schreckens, die sich auf den Betrachter übertragen soll.

Im Hintergrund finden wir die Szene, die bei Bry bezeichnenderweise ganz in den Vordergrund verlagert war: Zwei Europäer, von denen einer die Hand erhoben hat und auf den Himmel deutet, wo sich die Hand Gottes zeigt, reden mit einigen Indianern. Es handelt sich wieder um die Illustration der Stelle, wo Léry auf einen Bericht anspielt, dass einige Europäer durch die Anrufung Christi den Teufel bei den Indianern austreiben konnten (s. oben 53). Bei Merian ist diese Szene im Hintergrund nur angedeutet. Sie dient aber nicht nur zur Illustration der im Text geschilderten Episode, sondern drückt im Vergleich zu den dynamischen Szenen im Vordergrund die Ruhe aus, die die Christen durch die Teufelsaustreibung errungen haben.

An diesem Stich lässt sich sehr gut die Entwicklung der Zeichenkunst von den manieristischen Stichen Brys zu der barocken Version der Historia Antipodum aufzeigen. Bei Bry steht die Teufelsaustreibung als Zeichen für die Macht der christlichen Religion auch ikonographisch im Vordergrund, in Merians Stich wird sie nur noch im Hintergrund kurz angedeutet. Hier gewinnen stattdessen die gequälten Gestalten der Indianer ein Eigenleben, da sich an ihnen extreme Positionen zeigen ließen. Die schwebenden Teufel schließlich erinnern an die schwebenden Engel mancher Heiligendarstellungen, die Märtyrern die Sieges- 
palme in die Hand drücken. Bei den nackten Körpern der Indianer ist es eindeutig die Freude an der Zeichnung der Körper in ungewöhnlichen Positionen und extremen Verkürzungen, die den Vorzeichner hier bewegt hat. Die theologische Aussage gerät ganz in den Hintergrund und auch die an Hieronymus Bosch erinnernde Darstellung der Teufel bildet einen Vorwand, der Phantasie des Künstlers freien Lauf zu lassen. Die Körper selbst sind in barocker Manier mit zahlreichen Schraffierungen und extremen Hell-Dunkelkontrasten gezeichnet und damit im Gegensatz zu der durch die Dominanz der Linie geprägten Stiche bei Bry auf den ersten Blick als barock erkennbar, was natürlich auch in der Technik dieses Stichs begründet ist.

Merian hat den Stich wohl nicht nur als Zitat eines bekannten ikonographischen Korpus übernommen, sondern wollte auch seine künstlerischen Fähigkeiten bei der Personenzeichnung in Kombination mit der Perspektive in Szene setzen. Die Zeichnung gewinnt ein Eigengewicht gegenüber der inhaltlichen Aussage; der Manierismus der Körper gerät zum Selbstzweck. An diesem Stich ist erkennbar, dass sich die bei Bry immer noch gegebene Balance zwischen inhaltlich-illustrativer Funktion der Stiche und Freude an der ethnologisch weitgehend korrekten und künstlerisch anspruchsvollen Zeichnung zugunsten letzterer verschoben hat. Die theologische Aussage, also die Überlegenheit der christlichen Religion und die Herrschaft des Teufels über die Ungläubigen, gerät zum Vorwand, um in barocker Pracht der Darstellung zu schwelgen. Interessanterweise entfallen in der Historia Antipodum die Anthropophagiedarstellungen der Brys (vgl. auch Wendt 1989, 87), mit Ausnahme einer Darstellung des Kannibalismus hungerleidender Spanier im Rückgriff auf eine Schmidel-Illustration. Das Fortleben des Stichs mit den Teufelserscheinungen zeigt in diesem Kontext eine Verlagerung des inhaltlichen Interesses von der Darstellung fremder Sitten hin $\mathrm{zu}$ barocker Heiligen- und Teufelsdarstellung. In einem fast zeitgenössischen Werk, der Nova typis transacta navigatio (Linz 1621) des unter dem Pseudonym Honorius Philoponus schreibenden österreichischen Benediktiners Caspar Plautius finden sich allerdings wieder Stiche von Kilian, die die Anthropophagie zeigen, gleichsam als Rechtfertigung der benediktinischen Missionsbemühungen an den anthropophagen Völkern ${ }^{119}$.

Forge $(1987,123)$ verweist auf eine weitere mögliche Interpretation dieses Stichs. Das Fehlen jeglicher ethnologischer Zitate, etwa auch der Hütten, die den Ort näher differenzieren, zeigt, dass die Darstellung bei Merian nicht mehr nur die Indianer Südamerikas, sondern gleichzeitig alle Heiden als Opfer des Teufels hinstellt und damit durchaus im Sinne von Léry ist. Forge (ebd.) hat auf

$119 \mathrm{Vgl}$. Wendt 1989, 87/88. Eine Anthropophagie-Abbildung aus Plautius (1621) bei Duviols 1985, 100 steht mit der Darstellung eines am Spieß gerösteten enthaupteten Körpers und eines Mannes, der mit einem Beil auf einem Schlachttisch einen Menschenleib zerteilt, deutlich in der Tradition der Münsterschen Cosmographie und ihrer ikonographischen
Vorläufer. 
eine weitere Replik dieses Werks von Merian verwiesen, und zwar im 15. Band der von dem Drucker Van der Aa herausgegebenen Reisesammlung Naaukeurige Versameling der gedenkwaardigste see en land reysen na Oost en West Indien [...] (Leyden, 29 Bde.; Tafel 44). Die Illustrationen dieses Werks kopieren die Vorlagen von Bry, nur bei der Replik auf den Stich mit dem Teufel wird in Anlehnung an die Abbildung bei Merian ein neuer Stich eingefügt (abgebildet in Forge 1987, 124), was darauf hindeutet, dass der Künstler die Ausgabe der Historia Antipodum zum Vorbild genommen hat. Die verzerrten Gestalten der Indianer werden diesmal vom Donner heimgesucht, was zwar auch mit einigen Schilderungen Lérys konform geht, der von ihrer Angst vor dem Donner berichtet hatte, aber nun den Schwerpunkt entsprechend dem aufklärerischen Zeithorizont auf ein anderes Element legt, die Angst vor Naturkatastrophen ${ }^{120}$. Die Gruppe der Europäer und Indianer ist wie bei dem Vorbild Merian im Hintergrund angedeutet. Die Erscheinung von Teufeln ist für die Zeitgenossen der Aufklärung nicht mehr glaubwürdig, sie werden auch nicht mehr dargestellt, und so verlagert sich das für den Menschen nicht zu beherrschende Böse auf die Naturgewalten, denen er wie die Gestalten auf dem Stich schutzlos und nackt ausgeliefert ist.

An der Folge dieses immer wieder kopierten Holzschnitts bzw. Stichs kann man mustergültig die Bezüge der Illustrationen eines Texts zum zeitgenössischen ideengeschichtlichen Hintergrund und zur Kunstentwicklung aufzeigen. Erstaunlich ist, dass dieser Stich noch zu Beginn des 18. Jahrhunderts wieder aufgegriffen wird. In den ersten Versionen dominiert die theologische Bedeutung. Sie dokumentieren zugleich den damals noch allgemein verbreiteten Glauben an Monster und Teufel. Bei Merian steht dann die Darstellung des gequälten Menschen im Zentrum, bis die Teufel schließlich in der niederländischen Reisesammlung von 1706/07 ganz entfallen und die entfesselten Naturgewalten an deren Stelle treten.

\section{Aussageintention und Bildlichkeit: die Bedeutung der Stiche in Brys Reiseberichtkollektion}

Die Anlehnung an die Vorbilder, gleich welcher künstlerischen Qualität sie sein mochten, ist ein wesentliches Merkmal der Ikonographie von Brys Reiseberichtkollektion. Bei der Analyse des Brasilienkorpus im 3. Buch sind wir in der glücklichen Lage, durch die Vielzahl der erhaltenen Dokumente die Filiationen und damit die darstellerischen Absichten der Brys rekonstruieren zu können, im Gegensatz zu anderen Teilen der Kollektion, in denen die Vorbilder nur schwer

${ }^{120}$ Man denke an die ideengeschichtliche Bedeutung, die das Erdbeben von Lissabon (1755) für das Denken der Aufklärung hatte. 
zu ermitteln oder nicht erhalten sind. Die Aquarelle von John White ${ }^{121}$ existieren nur noch zum Teil, von den Skizzen Le Moyne de Morgues' ist eine einzige erhalten $^{122}$. Die Bücher der französischen Reisenden und die Originalausgabe von Stadens Reisebericht ermöglichen uns hingegen eine detaillierte Analyse der durch die Auswahl und die Veränderungen in den Illustrationen deutlich werdenden Aussageintentionen.

Angesichts der hohen Qualität der Stiche von Bry mag diese enge Anlehnung an bestehende Holzschnitte verwundern; man darf aber nicht die heutige Konzeption künstlerischer Originalität zugrunde legen und kann als Vergleich etwa die Rezeption der Dürerholzschnitte heranziehen, die immer wieder kopiert wurden. Im 17. Jahrhundert bestand die Originalität eines Vorzeichners für Kupferstiche nicht in neuen Kompositionen oder gewagten Infragestellungen der Tradition, sondern in der ansprechenden Verarbeitung vorgegebener Modelle. Viele Stecher arbeiteten nur nach Entwürfen von anderen Künstlern. Erst bei dem oben besprochenen Stich Merians aus dem 17. Jahrhundert ist, selbst wenn der Traditionsbezug auf das thematische Vorbild Bry/Léry und die Illustrationsgeschichte gegeben ist, doch die Originalität in der Behandlung eines schon bekannten Themas von wesentlicher Bedeutung. Dieser Traditionsbezug soll dabei nicht nur Hommage an ältere Vorbilder sein, sondern vielmehr für den Leser bewusst den künstlerischen und inhaltlichen Wandel in der Betrachtungsweise verdeutlichen. Wenn man so will, ist Traditionalität nicht nur Beharren, sondern auch selbstreflexives Erneuern, das durch kleinste Unterschiede in der künstlerischen Technik dem Betrachter die Differenz der künstlerischen und moralischen Sehweise stärker als ein gänzlicher Traditionsbruch zu Bewusstsein bringt. Der Merianstich der Teufelserscheinungen muss unter diesem Gesichtspunkt als eine höchst bewusst erfolgte Neubearbeitung der Tradition betrachtet werden.

Die Analyse hat dabei gezeigt, dass der ethnologische Gehalt der Stiche zwar ohne Zweifel vorhanden ist, aber durch Vertauschungen (Stadenbilder in der Lérysequenz) und Zusammenziehung ikonographischer Elemente aus verschiedenen Quellen beispielsweise in den Lérystichen und einigen Stadenillustrationen keine primäre Bedeutung hat. Diese Feststellung sollte eine primär ethnologisch orientierte Analyse der Stiche ausschließen.

Mit den Worten Duchets $(1987,42)$ sollte man lieber von einer "homologie des codes" sprechen und die Aussageintention der Stiche sowohl in ihrem Bezug aufeinander als in ihrem Verhältnis zum Text sehen bzw. zu der Version des Texts, den die Brys aufgenommen haben, was bei Léry ja nicht der Erstfassung

${ }^{121}$ Zum Verhältnis von Whites Illustrationen zu den Repliken bei Bry vgl. Hulton 1990 passim.

${ }^{122}$ Vgl. Duchet 1987, 19. Das Bildmaterial dieser Künstler, das Bry bei seinem Englandaufenthalt durch Vermittlung von Samuel Purchas erhielt, ist in den Büchern von Lorant 1965 und Hulton 1984 abgebildet und zeigt wiederum die enge Anlehnung der Stecher an die Vorbilder. 
des Buchs entspricht. Bry hat beispielsweise in seiner Textversion die zahlreichen historischen Angaben Lérys über die längst nicht mehr existierende Kolonie der "France antarctique" und die dortigen religiösen Konflikte zwischen Katholiken und Kalvinisten weggelassen, da sie selbst für kalvinistische Leser 1592 nicht mehr aktuell waren.

Ein wesentliches Verdienst von Léry im Vergleich zu seinem Vorgänger und Antagonisten Thevet besteht in einer einheitlich thematischen Gliederung des Texts, die die mittelalterliche enumeratio von einzelnen singularités überwindet. Die Holzschnitte Thevets bilden im Gegensatz zum Inhalt seiner Kapitel eine weitgehend homogene Folge und sind damit der modernste Teil seines Werks. Vor diesem Hintergrund ist es nicht verwunderlich, dass ihnen in Brys Kompilationen eine vielleicht aus zweiter Hand vermittelte Rezeption beschieden sein sollte. In den Holzschnitten hat sich die enumeratio heterogener Elemente, die den heutigen Leser am Stil Thevets stört, nicht negativ bemerkbar gemacht, weil ihnen eine tradierte Bildsprache zugrunde lag. Die Kunst kennt seit frühesten Zeiten eine Darstellung von zeitlicher Folge in parallel geschalteten Elementen (man denke z. B. an die Zyklen religiöser Illustrationen im mittelalterlichen Bildschmuck der Tympana von der Schöpfung bis zur Passion oder an die Illustrationen des Florentiner Baptisteriums von Brunelleschi, die auch im Hintergrund - und damit semantisch abgetrennt - verschiedene Episoden einer biblischen Geschichte zeigen können). Deshalb konnten Cousin oder seine Schüler einzelne semantisch verwandte Elemente kombinieren. Am homogensten wirkt die Folge dort, wo sich der zeitliche Ablauf eines Geschehens, also etwa die subtil differenzierten Zeremonien der Anthropophagie, für eine serielle Darstellung anbot. Diese Verwendung von Bildfolgen ist im übrigen in der damaligen Reiseliteratur selten, auch wenn die Bildsequenz durchaus eine tradierte Form der Illustrationsgeschichte darstellt. In diesen eng zusammenhängenden Teilen liegt die große Neuerung der Illustrationen in Stadens und in geringerem Maße auch in Thevets Buch (vgl. zu den Bildfolgen Colin 1988, 51). Die Holzschnitte Stadens sind fast vollständig von Bry übernommen worden, auch wenn dieser die sieben Holzschnitte des Anthropophagierituals bei Staden in sechs Stichen (einschließlich des erstmals im Léryteil auftauchenden) zusammengefasst hat. Es geht ihm aber nicht um eine ethnologisch korrekte Darstellung, die alle Details der Schilderungen enthält, sondern eher darum, ein zusammenhängendes Korpus zu schaffen. Der semantisch kohärente Charakter dieser Holzschnitte, der hieraus trotz der Kollokation nur eines Stichs im Léryteil resultiert, sollte aber nicht über die von Bucher aufgezeigte, ebenfalls vorhandene symbolische Aussageintention hinwegtäuschen.

Was die Filiation des ikonographischen Materials bei Bry und sein Verhältnis zu der französischen Tradition angeht, so hat die Analyse gezeigt, dass die Übernahmen aus Léry eindeutig sind, sowohl was die Motivik und den Aufbau einzelner Stiche (die Teufelsaustreibung) als auch einzelne Motive mehrerer Stiche (die Tanzenden, die Totenklage) im Stadenteil angeht. Der Einfluss von Thevets Bildmaterial ist vermutlich über Léry vermittelt; ein direkter Einfluss 
des französischen Kosmographen ist m. E. nicht mit absoluter Sicherheit nachweisbar, da sämtliche Parallelen - z. B. bei den zahlreichen Anthropophagie-Illustrationen - ebensogut auf die Holzschnitte Stadens zurückgehen können und nicht wie bei Léry die Veröffentlichung des Textes auch die Kenntnis der Ikonographie der Vorlage voraussetzt. Selbst einzelne Übernahmen aus Thevets Holzschnitten wie die Abbildung eines Indianers, der mit einem Beil die Extremitäten vom Körper eines Getöteten abtrennt, können sowohl Reminiszenzen an Thevet als auch an die ältere Bildtradition der Kannibalismusdarstellungen sein. Lérys Werk stand den Brys durch den eindeutigen Bezug zum Kalvinismus sicher ideologisch näher als dasjenige des Franziskanermönchs Thevet. Dessen Singularités waren ferner zum Zeitpunkt der Publikation ihrer Reisesammlung bereits über 30 Jahre alt, seine Cosmographie datiert von 1575 und erschien in Aufbau und Konzeption schon den Zeitgenossen trotz ihrer heute erkannten ethnologischen Bedeutung als veraltet. Dennoch ist meines Erachtens von einer Kenntnis der Holzschnitte Thevets durch die Brys auszugehen, auch wenn deren Einfluss auf die eigene Bildwelt der Brys nur in Reminiszenzen besteht. Was bei den Werken der Cousinwerkstatt sehr viel wichtiger ist und für Bry sicher vorbildhaft war, ist der sequentielle, dramatisch szenische Aufbau der Holzschnitte und die idealisierende Zeichnung der nackten Indianer. Léry bringt rein statische Holzschnitte, von der einen nicht sonderlich gelungenen Kampfszene oder der anspruchslos geschnittenen Tötung des Gefangenen einmal abgesehen, die beide ohnehin auf das Vorbild Thevets zurückgehen. Bei Thevet finden sich dagegen in den Anthropophagie-Illustrationen sequentielle Szenen von der Tötung des Gefangenen bis zur Trauer der Frau, der Zerlegung des Körpers, der Zubereitung auf dem Grill und der Verspeisung der Körperteile. Bei Staden ist zwar auch eine zeitlich logische Sequenz in den Anthropophagieszenen zu beobachten, diese sind allerdings bei ihm reine Szenen zwischen Kleingruppen und damit als Vorbild sicherlich weniger überzeugend als Cousins Holzschnitte. Wesentlicher ist der Vorbildcharakter Cousins für die Brys deshalb vor allem beim Gesamtaufbau der Stiche. Die Beschränkung auf wenige hervorgehobene Personen, die mit unterschiedlichen Tätigkeiten beschäftigt sind und sich von der amorphen Masse der Indianer im Hintergrund durch Größe und aktives Handeln abheben, ist mit Ausnahme einzelner Holzschnitte bei Staden so nur in den Holzschnitten Cousins überzeugend verwirklicht, deren szenenhafter Charakter für viele der Stiche der Brys maßgebend wurde. Auf den qualitätsvollen Holzschnitten Lérys wird immer nur ein Ausschnitt gezeigt, eine Fokussierung auf einige gleichsam symbolisch dargestellte Indianer, was besonders bei dem Holzschnitt mit einem indianischen Paar deutlich wird (Tafel 18). Die Figuren füllen den Bildinhalt fast komplett aus, selbst die Tanzszene, die doch laut Text eine Gruppendarstellung erfordert, zeigt nur zwei Tänzer (Tafel 20).

Auch der mit Liebe zum Detail gezeichnete Landschaftshintergrund, die perspektivisch exakte Zeichnung der im Sinne der Renaissance-Zeichenkunst idealisierten nackten Körper der Indianer und die zahlreichen ethnologischen Zitate 
gehen sicher mehr auf das künstlerisch hochstehende Vorbild Cousins als auf die anspruchslosen Skizzen Stadens zurück.

Dieser Vorbildcharakter von Thevets Illustrationen ist also eher struktureller Natur und könnte auch über andere zeitgenössische Kupferstiche vermittelt sein. Von zentraler Bedeutung in diesem Zusammenhang ist der bereits erwähnte Etienne Delaune, der Theodor de Brys Lehrer in Straßburg war, seinerseits das Werk Cousins gut kannte und Stiche nach dessen Vorbildern ausgeführt hat. Man sollte statt von einem direkten Einfluss eher von einer Weiterentwicklung und konsequenten Anwendung der von Cousin entwickelten künstlerischen Verfahren sprechen. Dennoch ist bei den genauen Recherchen der Brys, die immerhin das zeichnerische Vorbild für ihr Bildmaterial in den Virginia- und Floridareiseberichten eigens in England erworben haben, zumindest von einer Kenntnis der Holzschnitte Thevets auszugehen.

Thevets Illustrationen haben möglicherweise auch inhaltliche Anregungen für die Auswahl von Bildmotiven geliefert; so entspricht z. B. die Festszene (America, 1990, 3. Buch, Stich 2, S. 138) zumindest thematisch einem Holzschnitt in den Singularités (1982 [1557/58], 46v). Dass Bry die bei Thevet und in Stadens zweitem Buch vorhandenen zahlreichen ethnologischen und naturkundlichen Holzschnitte einfach beiseite gelassen hat, mag mit der historischen Ausrichtung seiner Reiseberichtkollektion zusammenhängen, liegt aber sicher auch an der allgemeinen Genreentwicklung. Bei den Virginiaillustrationen hat Bry ebenfalls die zahlreichen naturkundlichen Aquarelle von John White, die er mit Sicherheit besaß, einfach unterschlagen ${ }^{123}$. Die narrativen Elemente des Reiseberichts gewinnen seit Léry an Bedeutung und drängen die ethnologisch dokumentarische Funktion der Texte sowie der Abbildungen zurück. Im 17. Jahrhundert entstehen dann eigene Werke, die sich zunehmend auch der Flora und Fauna der Neuen Welt widmen, wie z. B. Joannes de Laets bedeutende mit zahlreichen Illustrationen versehene Amerikadarstellung (Americae utriusque descriptio, 1633). $\mathrm{Zu}$ dem wussten die zeitgenössischen Leser durch Thevets, Lérys und Stadens Bücher schon so viel über die Tupi, dass sich Bry in seinen Illustrationen auf spektakuläre Elemente beschränken konnte. Natürlich stellt die sicher u. a. durch Thevets Illustrationen angeregte Ikonographie der Anthropophagie und die theologisch bedeutende Darstellung der Teufelserscheinungen im Gefolge Lérys eine für den Leser klare Bewertung dar, auch wenn diese die ikonographische Aussage und die Anklage von Lérys Buch erheblich verschärft. Wendt $(1989,87)$ geht jedoch mit ihrer Behauptung zu weit, dass Brys Illustrationen durch die Fokussierung auf den Kannibalismus im Gegensatz zu Lérys überwiegend positivem Indianerbild ein "Auseinanderklaffen von Wort und Bild" (ebd.) erkennen lassen. Lérys differenzierte Bewertung des Kannibalismus und sein offener Blick auf die fremde Kultur, seine positive Schilderung der Gastfreundschaft und des india-

${ }^{123} \mathrm{Vgl}$. Campbell 1988, 181. Einige dieser naturkundlichen Aquarelle haben sich erhalten, vgl. Campbell 1988, 192-193 oder Hulton 1984 passim. 
nischen Charakters dürfen nicht dazu verleiten, sein Werk einseitig als Begründung einer "indianerfreundlicheren" protestantischen Tradition zu verstehen. Die katholischen Berichte aus Iberoamerika, insbesondere die als Rechtfertigung missionarischer Anstrengungen geschriebene Literatur beruhen laut Wendt (ebd., 215) auf einem kritischeren Indianerbild, wobei das Fehlen einer missionarischen Tradition von protestantischer Seite im 16. Jahrhundert auch zum Teil Ursache dieser indianerfreundlicheren Haltung protestantischer Autoren gewesen sein mag. Dennoch differieren m. E. protestantische und katholische Autoren nicht grundsätzlich in ihrer einhelligen Verurteilung indianischer Kulturen. Zwar bemühen sich Staden und Léry in ihren Werken mehr als der katholische Geistliche Thevet um eine sachliche Schilderung der kannibalistischen Zeremonien, verurteilen sie aber genauso eindeutig, wenn auch ohne die übliche zeitgenössische Polemik. Auch Lérys Bewertung der angeblichen Religionslosigkeit der Tupinamba ist ohne Einschränkung negativ, was besonders die schon erwähnte Schilderung eines religiösen Fests als Hexensabbat in späteren Ausgaben seines Werkes zeigt. Léry unterscheidet sich von seinem Zeitgenossen Thevet allenfalls dadurch, dass er entsprechend der protestantisch-kalvinistischen Rechtfertigung des Menschen allein durch den Glauben die Verurteilung der Indianer ausschließlich auf ihren Unglauben gründet, und nicht wie Thevet auf die Anthropophagie oder andere kulturelle Differenzen. Das Bildmaterial Stadens bemüht sich um eine klare Verurteilung des Kannibalismus durch die Gesten der abgebildeten Figur des beobachtenden Staden. Léry bringt in seinen Abbildungen nur diskrete Verweise auf die Anthropophagie, wohl um ein zu einfaches Urteil über die Indianer bei seinem Leser zu vermeiden und weil für ihn der Unglaube mehr als alle noch so verurteilungswürdigen sozialen Praktiken ins Gewicht fiel. Theodor de Bry hat diese verstreuten Urteile in den von ihm bearbeiteten Quellen nur in ein zusammenhängendes ikonographisches Programm umgesetzt, das der Bewertung dieser Autoren entsprach, auch wenn es ihre Argumentation vereinfacht und zeitgenössischen Erwartenshaltungen seiner Leser entgegenkommt. Die Rezeption des Bildmaterials von Léry und Staden durch die Brys verstärkt damit die ideologische Komponente der Vorbilder, es erfolgt aber keine prinzipiell unterschiedliche Bewertung. Der zusammenhängende Charakter der Illustrationen der Brys verleiht ihnen im Hinblick auf den Leser eine eindeutigere Aussageintention als dies bei dem Bildmaterial Thevets, Lérys und Stadens der Fall ist.

Die plakative Funktion als Kaufanreiz für den Leser darf bei diesen bis heute oft abgebildeten Szenen nicht vergessen werden, selbst wenn Bry sicher mehr an eine klar formulierte theologische Aussage als an die Sensationslust seines Publikums gedacht hat. Im Gesamtgefüge der "Grands voyages" dienen die Illustrationen der Brasilienreiseberichte im dritten Teil der Sammlung vor allem dazu, stellvertretend am brasilianischen Tupinamba eine eindeutige moralische und theologische Verurteilung der Indianerkulturen der Neuen Welt zu veranschaulichen und damit gleichsam den argumentativen Gegenpol zu den Anklagen der Greueltaten katholischer Eroberer in Spanisch-Amerika an den 
Indianern zu bilden. Selbst wenn Theodor de Bry wie Las Casas oder die zeitgenössische protestantische Literatur der Zeit, etwa Urbain Chauveton in seiner Benzonibearbeitung, die Grausamkeiten der spanischen Eroberer an den Indianern zutiefst anklagt, ist dies auch für die protestantischen Vertreter der leyenda negra kein Grund, eine Bewahrung der ursprünglichen Kultur der Indianer zu fordern. Diese Haltung findet ihre moralische Rechtfertigung in den kulturellen Sitten der Indianer wie der Anthropophagie oder im Schamanismus, der als Teufelskult angesehen wurde. Unter diesem Gesichtspunkt ist es verständlich, dass auch die Illustrationen der Brys schwerpunktmäßig diese Bereiche behandeln. Der Indianer wird damit funktionalisiert als Träger der Kritik an den Katholiken, aber seine Kultur wird nicht als eigenständiger Wert aufgefasst, was vor dem epistemologischen Hintergrund der Zeit auch nicht zu erwarten ist. Die weitgehend um Objektivität und Sachlichkeit bemühten Berichte von Staden und Léry werden damit in ihrer Rezeption durch Theodor de Bry Teil einer umfassenden protestantischen Welterklärung, die bei Staden nur als heilsgeschichtlicher Bezug eines bedrängten Individuums auf Gottes Schutz und bei Léry in Ansätzen als moralische Beurteilung eines gebildeten, schreibenden Pastors spürbar war. Die Rezeption durch die Brys verstärkt diese ideologische Komponente. In diesem Sinne tragen die Illustrationen des dritten Teils und die dortige negative Bewertung einer ursprünglichen Indianerkultur, wie sie im Brasilien des 16. Jahrhunderts vorlag, wesentlich zum inneren Zusammenhang der gesamten Reisesammlung bei.

Brys Illustrationen zeigen künstlerisch die Entwicklung der Buchillustration mustergültig auf. Die Illustrationen Jean Cousins für die Singularités waren noch stark der liniengeprägten Zeichenkunst der italienischen Renaissance verpflichtet. Die für die Cosmographie neugefertigten Bilder legen ähnlich wie die etwas später entstandenen Holzschnitte Lérys den Wert auf Tiefenwirkung durch Schraffuren und Hell-Dunkel-Kontraste. Bry konnte von dieser Entwicklung profitieren und auch die bei seinen Vorgängern nur staffageartige Landschaft sehr viel realistischer zeichnen. Selbst dort, wo die Indianer gleichsam in den Vordergrund eingeblendet werden und die Landschaft im Hintergrund nur eine Kulisse zur räumlichen Situierung des Geschehens nach dem Vorbild der Holzschnitte bei Staden bildet, wirken die Stiche nicht unnatürlich oder bar jeder Perspektive wie bei Staden. Der Einfluss des Manierismus zeigt sich schließlich in der Expressivität der Gesten, insbesondere bei den Kampfszenen, den Tötungsszenen, der Erscheinung der Teufel, oder vielen anderen Stichen, wo die Gruppen von Indianern nicht nur einen bloßen Hintergrund für die wenigen Hauptfiguren bilden, sondern durch Gesten, Mimik und Körperhaltung vielfach aufeinander bezogen sind.

Der Manierismus wird vor allem in einer gestischen Sprache der Gestalten sichtbar und in einer "Dramatisierung des Geschehens" (vgl. Colin 1988, 285), die sich auch im Bildaufbau widerspiegelt. Diese Gesten sind aber nicht nur reiner künstlerischer Selbstzweck, sondern zugleich bedeutungstragend. Sie können zum Beispiel für den Leser eine verbindliche moralische Verurteilung aus- 
drücken, wie etwa die hilflose Gestik Stadens bei der Betrachtung des Kannibalismus. Das abgebildete Geschehen wird damit dramatisiert. Lérys qualitätsvolle Holzschnitte wirken dagegen wie viele der Indianerdarstellungen im 16. Jahrhundert statisch. Auch viele der sequentiellen Holzschnitte Thevets erscheinen wie einzelne, beinahe unverbunden nebeneinander gestellte Episoden, während die Bilder Brys eine gestische und - wie die Analyse des Stichs mit den Teufelsaustreibungen gezeigt hat - gleichzeitig eine kompositorische Einheit vermitteln. Diese Dramatisierung ist sicher nicht nur, wie schon Colin (1988, 258) erkannte, ein Zugeständnis an die Sensationslust des Publikums, sondern bedeutet vor allem eine erhebliche Steigerung der künstlerischen Qualität im Vergleich zu zahlreichen statisch wirkenden Reiseberichtillustrationen des 16. Jahrhunderts.

Das Werk der Brys ist früher oft wegen ihres etwas "trockenen Stils" kritisiert worden (Kristeller 1922, 257; vgl. auch Bouyer 1983, 65). Dieses Urteil liegt sicher darin begründet, dass die Brys Formenreißer und Stecher waren, die nach Vorbildern arbeiteten und damit nicht dem tradierten Kunstbegriff der Moderne entsprachen. Heute kann man ihrem Werk eher gerecht werden. Nach dem Urteil von Wendland (Lexikon des gesamten Buchwesens, ${ }^{2} 1987, \mathrm{I}, 567$ ) gehören die Brys zu den bedeutendsten manieristischen Künstlern in Deutschland und zu den Wegbereitern des Kupferstichs als Buchillustration.

Die Zeichnung der edlen nackten Indianer wurde als unrealistisch kritisiert. Aber diese Anlehnung an Vorbilder bei der Personenzeichnung in der zeitgenössischen europäischen Kunst dient einer gleichsam allegorischen Schilderung des Fremden als "Verfremdung des Bekannten", die Nähe und Distanz zugleich ausdrückt, wie Luchesi $(1982,74)$ zurecht bemerkte.

Eben die damit verbundene möglicherweise unbeabsichtigte Idealisierung des Äußeren, die im übrigen auch den Beschreibungen vieler Reiseberichte entspricht und sich dort gegen die mittelalterlichen Vorstellungen von monströs gewachsenen und von Haaren bedeckten Fremden richtet, ist ideengeschichtlich wirksam geworden. Die körperlich wohlgewachsenen Indianer auf den Stichen der Brys haben das europäische Indianerbild lange Zeit geprägt und stehen ikonographisch am Anfang der Entwicklung zum bon sauvage des Aufklärungszeitalters. Besonders die zahlreichen Neuauflagen von Brys Reiseberichtkollektion in der ersten Hälfte des 17. Jahrhunderts und die vielen nach dem Vorbild von Bry kopierten Illustrationen vermitteln die Kunst dieser Drucker- und Stecherfamilie bis ins 18. Jahrhundert.

Vor allem die Geschlossenheit ihrer Gesamtkonzeption und schließlich der große Umfang des Bildmaterials von ca. 340 Stichen in der Kollektion sind singulär in der gesamten Geschichte des Reiseberichts. Der trotz unterschiedlichster Vorbilder einheitliche Stil der Bry-Illustrationen verleiht zumindest den Bänden, die zu Lebzeiten von Theodor de Bry erschienen sind, eine für damalige bebilderte Werke äußerst seltene ikonographische Einheitlichkeit. Bei Thevets oder Lérys Werken hingegen finden sich immer Spuren verschiedener Künstler von höchst unterschiedlicher Qualität. Auch der ideengeschichtliche Hintergrund des 
Kalvinismus in den bearbeiteten Texten und dem Bildmaterial stellt eine innere Geschlossenheit dar, die für die Zeit exzeptionell ist.

Nach dem Werk der Brys wurden zwar noch andere illustrierte Bücher über Amerika veröffentlicht; ihre prunkvoll bebilderte Reiseberichtkollektion blieb jedoch ein Maßstab, an dem sich alle späteren Werke zu messen hatten. Das umfangreiche ikonographische Brasilienkorpus des dritten Buchs von 1592 war zu seiner Zeit einmalig. Erst mit den niederländischen Künstlern, die in dem zeitweise von den Niederländern beherrschten Nordbrasilien vor Ort zeichneten, setzte gegen Mitte des 17. Jahrhunderts ein weiteres bedeutendes SüdamerikaKorpus ein ${ }^{124}$. Die Gemälde von Albert Eckhout oder Frans Post fanden jedoch kein breites Nachleben in illustrierten Werken; so finden sich z. B. in den Bildern der Amerikadarstellung des Naturforschers Joannes de Laet (Americae utriusque descriptio, Lüttich, 1633) überwiegend naturkundliche Abbildungen. Umfangreiche Brasiliendarstellungen enthalten erst wieder die Werke von Caspar Barlaeus (Rerum per octennium in Brasilia [...] Historia, Amsterdam, 1647), Georg Marggraf (Historiae rerum naturalium Brasiliae, Leyden, $1648^{125}$ ), Willem Piso (De Indiae utriusque re naturali et medica, Amsterdam, 1658), und die umfangreichen polyhistorischen Kompilationen des späten 17. Jahrhunderts, so vor allem zwei Werke von Erasmus Francisci (Ost- und WestIndischer wie auch Sinesischer Lust- und Stats-Garten, Nürnberg, 1668 und Neu-polirter Geschicht- Kunst- und Sittenspiegel ausländischer Völcker, Nürnberg, 1670), Arnoldus Montanus (De Nieuwe en Onbekende Weereld, Amsterdam, 1671) und die reich bebilderte vierbändige Kompilation von Simon de Vries (Curieuse Aenmerckingen der bysonderste Oost en West-Indische verwondernswaerdige dingen, Utrecht, 1682).

Die Stiche der Brys wurden wegen ihrer Qualität und der Begründung einer langandauernden Tradition zu einem Markstein in der Ikonographie des Reiseberichts. Kein heutiges historisches Buch über Amerika, das altes Bildmaterial über die Neue Welt bringt, verzichtet auf den Abdruck einiger Stiche aus der Kupferstichwerkstatt der Brys, die damit unser Bild vom Amerika der Entdeckungsreisen bis in die Gegenwart prägen.

${ }^{124}$ Vgl. hierzu den Aufsatz von Boogaart 1990.

${ }^{125}$ Erschienen als Bd. 2 von Willem Piso, Historia naturalis Brasiliae [...], Leyden: Haack; Amsterdam: Elsevier, 1648. 


\section{Bibliographie}

\section{Quellen}

Aa, Pieter van der, siehe: Naaukeurige Versameling [...].

Abbeville, Claude d', s. Claude <d'Abbeville >

America [dt.]. 1590-1630. 14 Tle. Frankfurt/M.: de Bry.

-. [lat.]. 1590-1634. 14 Tle. Frankfurt/M.: de Bry.

[America, dt.]. 1590. Wunderbarliche, doch warhafftige Erklärung, von der Gelegenheit und Sitten der Wilden in Virginia [...]. 3 Tle. Frankfurt/M.: J. Wechel für Theodor de Bry.

[America, lat.]. 1592. America tertia pars Memorabilem provinciae Brasiliae historiam continens, Germanico primùm sermone scriptam a Ioanne Stadio. Nunc autem latinitate donatam a Teucrio Annaeo Privato Colcante Po: \& Med. (Adamo Leonicero, poeta et medico), ... Addita est Narratio profectionis Joannis Lerii in eamdem provinciam, quam ille initio gallicè conscripsit... His accessit Descriptio morum \& ferocitatis incolarum illius regionis... Omnia recens evulgata et iconibus... illustrata... studio et diligentia Theodori de Bry... Frankfurt/M.: J. Wechel für Theodor de Bry.

[America, dt.]. 1593. Dritte Buch Americae, darinn Brasilia durch Johann Staden von Homberg ausz eigener Erfahrung in Teutsch beschrieben. Item Historia der Schiffart Ioannis Lerij in Brasilien, welche er selbst publiciert hat, jetzt von newem verteutscht durch Teucrium Annaeum Privatum C. [i.e. J. A. Lonicer]. Frankfurt/M.: Theodor de Bry.

[Americae]. 1970 [1591-1600]. Wunderbarliche, doch wahrhafftige Erklärung von der Gelegenheit und Sitten der Wilden in Virginia, erstlich in engelländischer Sprach beschrieben durch Thomam Hariot [...]. Faksimile-Nachdruck der Teile 1-5 der Reiseberichtkollektion von Theodor de Bry, Frankfurt 1591-1600. München: Kölbl-Verlag.

America, de Bry, 1590-1624. 1990. Amerika oder die Neue Welt. Die "Entdeckung" eines neuen Kontinents in 346 Kupferstichen. (Materialien zur Geschichte der europäischen Expansion). I: Bry, Reisen in das östliche und westliche Indien in zwei Teilen. Teil I: Reisen in das westliche Indien (America). Bearb. und hg. von Gereon Sievernich. Berlin (u. a.): Casablanca.

Anchieta, Joseph de (S.I.). 1984ff. Obras completas. Ed. Armando Cardoso. 11 Bde. São Paulo: Ed. Loyola.

Barlaeus, Caspar. 1647. Rerum per octennium in Brasilia et alibi nuper gestarum [...] Historia. Amsterdam: J. Blaeu. 
Barré, Nicolas. 1592. [N. Barré: Copie de quelques lettres, Paris 1557, lat.]. Exemplar duarum litterarum quibus [...] explicantur et navigatio Nicolai Villagagnonis in illam Americae provinciam ... Scriptae.. a quodam e Villagagnonis domesticis. In: [America tertia pars Memorabilem provinciam Brasiliae historiam continens...J. 1592. Frankfurt/M.: Theodor de Bry, 285-295.

-. 1840/41. Copie de quelques lettres sur la navigation du chevalier de Villegagnon es terres de l'Amérique. Paris 1557. In: Archives des voyages ou collection d'anciennes relations inédites ou très rares. Éd. Henri TernauxCompans. Paris: Arthus-Bertrand, I, 102-116.

Belon, Pierre. 1997 [1555]. Histoire de la nature des oyseaux. Éd. Philippe Glardon. Genève: Droz (Travaux d'humanisme et Renaissance, 306).

Benzoni, Girolamo. 1969 [1565]. La Historia del Mondo Nuovo. Venedig. Graz: Adeva (Nachdruck Frühe Reisen und Seefahrten, 2).

Boissard, Jean Jacques. [o.J.] [ca.1616]. De divinatione \& magicis praestigiis, [...] iam modo eleganter aeri incisis per Joh[ann] Theodor de Bry. Oppenheim: Hieronymus Galleri.

-. 1650-54. Bibliotheca chalcographica illustrium virtute atque eruditione in tota Europa clarissimorum virorum [...] Sculptore Joano Theod. de Bry, Sebast. Furckio et Jo. Ammonio. 3 Bde. Frankfurt/M.: J. Ammon.

-. 1681 [1597-1602]. Topographia Romae, Durch Dieterich De Bry. Frankfurt/M.: Matthäus Merians Erben.

Bry, Theodor de (Vater)/Johann Theodor de (Sohn):

s. [America dt.]. 1593

s. [Americae lat.]. 1590. 1593

s. [Americae]. 1970

s. Boissard, Jean Jacques. [o.J.; ca. 1616] und 1650-54

s. Emblemata secularia. 1994

s. Gottfried, Joh. Ludwig. 1631. 1655

s. Hariot, Thomas. 1590

s. Las Casas, Bartolomé de. 1598 (lat.). 1613 (dt.)

s. Léry, Jean. 1592 (lat.). 1593 (dt.)

s. Schmidel, Ulrich. 1597 (dt.)

s. Staden, Hans. 1592 (lat.). 1593 (dt.)

C'est la deduction du somptueux ordre plaisantz spectacles [...]. Rouen 1551. s. Denis, Ferdinand und Mac Gowan, Margaret

Claude <d'Abbeville >. 1963 [1614]. Histoire de la mission des peres capucins en l'isle de Maragnon et terres circonvoisines. Paris. Hg. Alfred Métraux und Jacques Lafarge. Graz: Adeva (Frühe Reisen und Seefahrten in Originaltexten, 4). 
Cousin, Jean. 1560. Livre de perspective. Paris: Le Royer.

Dati, Giuliano. 1493. La lettera dell isole che ha trovate novamente il Re di Spagna. Florenz: [L. de'Morgiani \& J. Petri].

Denis, Ferdinand. 1944. [Une fête brésilienne célébrée à Rouen en 1550. Paris 1850, portug.]. Uma festa brasileira, com os poemas brasílicos de P. Cristovâo Valente (S.I.). Trad. de Plínio Ayrosa, Rio de Janeiro. [Das Buch war mir nur in der portugiesischen Übersetzung zugänglich.]

Dise Figur anzaigt [...]. 1504/1505. [Einblattholzschnitt] s. Vespucci, Amerigo. $1504 / 1505$

Emblemata secularia. 1994 [1611] von Johann Theodor de Bry. Nachdruck der Ausgabe 1611. Hg. mit einem Nachwort von Cornelia Kemp. Hildesheim: Olms.

L'entrée de Henri II à Rouen 1550, s. Mac Gowan, Margaret

Extract der Orientalischen Indien beschrieben durch Caeserem Longinum Historicum. 1619. Frankfurt/M.: Caspar Rötell, In Verlegung Wilhelm Fitzers.

Une fête brésilienne célébrée à Rouen en 1550, s. Denis, Ferdinand

Francisci, Erasmus. 1668. Ost- und West-Indischer wie auch Sinesischer Lustund Stats-Garten [...]. Nürnberg: Endter.

-. 1670. Neu-polirter Geschicht-, Kunst- und Sittenspiegel... ausländischer Völcker. Nürnberg: Endter.

Fries, Lorenz. 1525 [u.ö.]. Uslegung der Mercarthen. Straßburg: Grüninger.

Gândavo, Pero de Magalhães. 1969. [Historia da provincia sancta Cruz, Lisboa 1576, engl.]. The histories of Brazil, now translated into English for the first time and annotated by John B. Stetson, Jr., with a facsimile of the Portuguese original, [1576]. New York 1922. Nachdruck New York: Kraus (Documents and narratives concerning the discovery and conquest of Latin America, 5).

Goltzius, Hendrik [1558-1617]. 1983. Eros und Gewalt. Hg. von Eva Magnaguagno-Korazija. Dortmund: Harenberg. [Slg. der wichtigsten Einzelstiche].

Gottfried, Johann Ludwig. 1631. [Historia Antipodum oder] Newe Welt und Amerikanische Historien, inhaltende Warhafftige und vollkommene Beschreibung aller West-Indianischen Landschaften [...]; Item Historische und Außführliche Relation 36. Fürnembster Schiffarten unterschiedlicher Völcker in West-Indien [...] mit Landtafeln und Kupfferstücken gezieret von Matthaeo Merian. Frankfurt/M.: Matthäus Merian. 2 Tle. [Extrakt aus T. 1-12 von de Bry's America.] 
-. 1655. [Historia Antipodum oder] Newe Welt und Amerikanische Historien [...]. Frankfurt/M.: Merian. [Erw. 2. Auflage].

Grynaeus, Simon (Hg.). 1532. Novus orbis regionum ac insularum veteribus incognitarum. Basel: J. Herwagen.

Hariot, Thomas. 1590. Wunderbarliche, doch wahrhafftige Erklärung von der Gelegenheit und Sitten der Wilden in Virginia [...]. 3 Tle. Frankfurt/M.: Theod. de Bry. s. [America, dt.] 1590.

—. 1970. s. [Americae, dt.]

Hakluyt, Richard. 1589, 1598, 1600. The principal navigations, voiages and discoveries of the English nation, made by sea or over land. 3 vols. London: G. Bishop, R. Newberry, R. Barker.

Hulsius s. Raleigh, Walter

Laet, Joannes de. 1633. Americae utriusque descriptio; Novus Orbis seu Descriptio Indiae occidentalis Libri XVIII. Leyden: Elzevier.

Lafitau, François. 1724. Mours des sauvages américains comparées à ceux des premiers temps. Paris: Saugrain.

Las Casas, Bartolomé de. 1598. [Brevissima relacion de la destruycion de las Indias, Sevilla 1552, lat.]. Narratio regionum indicarum per hispanos quosdam devastatarum verissima [...]. Frankfurt/M.: Theodor de Bry.

-. 1613. [Brevissima relacion de la destruycion de las Indias, Sevilla 1552, dt.]. Warhafftiger und gründlicher Bericht der Hispanier grewlich und abschewlichen Tyranney [...]. Oppenheim: Johann Theodor de Bry.

Léry, Jean de. 1880 [21580]. Histoire d'un voyage faict en la terre du Brésil. Éd. Paul Gaffarel. Paris: Lemerre.

-. 1975 [ $\left.{ }^{2} 1580\right]$. Histoire d'un voyage fait en la terre du Brésil. [Faksimile]. Édition, présentation et notes par Jean Claude Morisot. Genève: Droz.

-. 1992 [ $\left.{ }^{2} 1580\right]$. Histoire d'un voyage fait en la terre du Brésil, 1557. Édition de Frank Lestringant. Paris: Chaleil.

-. $1994\left[{ }^{2} 1580\right]$. Histoire d'un voyage faict en la terre du Brésil. Texte établi, présenté et annoté par Frank Lestringant. Paris: Livre de poche.

-. ${ }^{3} 1585$. Histoire d'un voyage faict en la terre du Bresil autrement dite Amerique [...], bien augmenté de discours notables en ceste troisiesme edition. Genève: Chuppin.

-. 1592. Navigatio in Brasiliam Americae a Joanne Lerio Burgundo [...]. s. [Americae, lat.], Americae tertia pars [...] 
-. 1593. ...Historia der Schiffart Ioannis Lerii in Brasilien... s. [America, dt.]. 1593. Dritte Buch Americae [...]

-. s. auch [Americae]. 1970 [1591-1600]. Bd. 3

-. 1706. De seer aanmerklijke en vermaarde reys... In: Naaukeurige Versameling der gedenkwaardigste see en land reysen na Oost en West Indien [...], door P. van der Aa. Leyden, Bd. XV.

-. 1975 [1574]. [Histoire mémorable de la ville de Sancerre, contenant les entreprinses, siege, assaux \& autres efforts des assiegeans, La Rochelle (i.e. Genf)]. Au lendemain de la Saint Barthélemy. Histoire mémorable du siège de Sancerre. Éd. Géralde Nakam. Paris: Éd. Anthropos.

La Lettera dell'Isole. 1493. s. Dati, Giuliano

Mac Gowan (Hg.). 1974. L'entrée de Henri II à Rouen 1550, a facsimile of the edition Rouen 1551. Amsterdam (Renaissance triumphs): Theatrum orbis terrarum.

Mandeville s. Montevilla

Marggraf, Georg. 1648. Historiae rerum naturalium Brasiliae s. Piso, Willem

[Memorabilis provinciae Brasiliae historia]. 1592. s. [America, lat.]. 1592. Americae tertia pars [...]

Montaigne, Michel de. 1976. Euvres complètes. Éd. Maurice Rat. Paris: Gallimard (Bibliothèque de la Pléiade, 14).

Montanus, Arnoldus. 1671. De Nieuwe en Onbekende Weereld of Beschryving van America en t' Zuidland. Amsterdam: Meurs.

Montevilla [ = Mandeville], John. 1484. Johannes von Montuilla Ritter. Das erste buich/ Do ich Johan von Monteuilla Ritter Geborn usz Engeland von einer stat genant Sant alban [...] ich obgenanter Otto von Demeringen Thümherre von latyn vnnd/ frantzoyscher sprach zů tútsch gebracht han. Straßburg: Johannes Prüß d. Ä.

Münster, Sebastian. 1544. Cosmographia. Beschreibung aller Lender. Basel: Heinrich Petri.

-. 1550. Cosmographiae universalis Lib. VI: in quibus iuxta certioris fidei scriptorum traditionem describuntur, Omnium habitabilis orbis partium situs [...] Omnium gentium mores, leges, religio, res gestae, mutationes [...]. Basel: Heinrich Petri.

Naaukeurige Versameling der gedenkwaardigste see en land reysen na Oost en West Indien [..] 1706/07, door P. van der Aa. 29 Bde. Leyden: P. van der Aa. 
[Navigationi e viaggi]. 1556. Terzo volume delle navigationi et viaggi nel quale si contengono le navigationi al Mondo Novo [...], raccolto già da M. Giovanni Battista Ramusio. Venezia: Nella stamperia de Giunti.

Paré, Francois. 1575. Des oevvres de M. Ambroise Paré [...] auec les figures \& portraicts tant de l'anatomie que des instruments de chirurgie, \& de plusieurs monstres. Le tout diuisé en vingt six liures comme il est contenu en la page suyuante. Paris: G. Buon.

Piso, Willem. 1648. Historia naturalis Brasiliae [...] in qua non tantum plantae et animalia, sed et indigenarum morbi, ingenia et mores describuntur et iconibus [...] illustrantur. T. I, II. Leyden: F. Haack \& L. Elsevier in Amsterdam. [T. II enthält: Marggraf, Georg: Historia rerum naturalium Brasiliae libri octo].

-. 1658. De Indiae utriusque re naturali et medica libri quatuordecim [...]. 3 Tle. Amsterdam: Elsevier. [Enthält u. a.: Marggraf, Georg, Tractatus topographicus \& meteorologicus Brasiliae].

Plautius, Caspar [Pseud. Honorius Philoponus]. 1621. Nova typis transacta navigatio. Novi orbis India Occidentalis [...]. [Linz].

Portugaliae monumenta cartographica. 1987. Ed. Armando Cortesão e Avelino Teixeirada da Mota. 5 Bde. Lisboa, 1960. Nachdruck Lisboa: Imp. Nacional Casa de Moeda.

Prévost d'Exiles, Antoine-François. 1747. Histoire générale des voyages ou nouvelle collection de toutes les relations de voyages par mer et par terre. Nouvelle edition. 19 vols. La Haye: Chez Pierre de Hondt.

Purchas, Samuel. 1965 [1625]. (Hakluytus Posthumus or) Purchas His Pilgrimes [...]. London: Fetherstone. Neuauflage in 20 Bänden, Glasgow 1906. Nachdruck New York: Ams Press 1965.

Raleigh, Sir Walter. 1599. [The discoverie of Guiana, London 1596, dt.]. Kurtze wunderbare Beschreibung deß goldreichen Königreichs Guianae in America oder newen Welt. Nürnberg: C. Lochner für Levin Hulsius.

Ramusio, Giovanni s. [Navigationi e viaggi]

Recueil de la diversité des habits qui sont a present en usaige tant es pays d'Europe, Asie, Affrique et Illes sauvages. 1562. Paris: Richard Breton.

Schmidel, Ulrich. 1567. Neuwe Welt: Das ist, Warhafftige Beschreibung aller schönen Historien von Erfindung viler vnbekanten Königreichen, Landschafften, Insulen vnnd Stedten, von derselbigen gelegenheit, wesen, bräuchen [...]; Auch von allerley gefahr, streitt vnd scharmützeln [...] Jtem von erschrecklicher, seltzamer natur und Eygenschafft der Leuthfresser/ Durch Ulrich von Schmid von Straubingen und andern mehr, so in eigner Person gegenwertig gewesen. Frankfurt/M.: Lechler für Sigmund Feyerabend \& S. 
Hüter. [Ersch. als Bd. 2 von Sebastian Franck, Erster theil dieses Weltbuchs, von Newen erfundnen Landtschafften: Warhafftige Beschreibunge aller theil der welt [...]. Frankfurt/M.: M. Lechler für Sigmund Feyerabend \& S. Hüter 1567].

-. 1597. Warhafftige unnd liebliche Beschreibung etlicher fürnemmen Indianischen Landschaften und Insulen: die [...] erstlich in der Schiffart Ulrici Schmidts von Straubingen [...] von ihm selber auffs fleissigst beschrieben und dargethan/ Und an Tag gebracht durch Dieterich von Bry. [Frankfurt/M.]: T. de Bry [= America, dt., Bd. 7].

-. 1599a. Vera historia admirandae cuiusdam navigationis, quam Huldericus Schmidel. Straubingensis, ab Anno 1534. usque ad anum 1554. in Americam vel novum Mundum, iuxta Brasiliam \& Rio della Plata, confecit. Nürnberg: [C. Lochner für] Levinus Hulsius.

-. 1599b. Warhafftige Historien einer wunderbaren Schiffart welche [...] von Anno 1534 bis Anno 1554 in Americam oder Newenwelt, bey Brasilia und Rio della Plata gethan [...] durch erwelten Schmidel selbs beschrieben [...]. Nürnberg: [C. Lochner für] Levin Hulsius (Hulsius Levinus: [Sechsundzwanzig Schiffahrten]; 4).

Staden, Hans. 1978 [1557]. Wahrhaftige Historia und Beschreibung einer Landschaft der wilden, nackten, grimmigen Menschenfresser, in der Neuen Welt Amerika gelegen [...].Marburg: [Andreas Kolbe]. Faksimile, hg. von G. Bezzenberger. Kassel: Thiele und Schwarz.

-. 1592. America tertia pars memorabilem provinciae Brasiliae historiam continens [...] s. [ America, lat.]. Bd. 3

-. 1593. s. [America, dt.]. Bd. 3

-. 1964. Hans Stadens wahrhaftige Historia. Hg. und übersetzt von R. Maack und K. Fouquet. Marburg: Trautvetter und Fischer.

Thevet, André. 1985 [1556]. Cosmographie de Levant. Éd. Frank Lestringant. Genève: Droz.

-.1997 [1557]. Le Brésil d'André Thevet. Les Singularités de la France Antarctique (1557). Édition intégrale, présentée \& annotée par Frank Lestringant. Paris: Chandeigne.

-. 1558. Les Singularités de la France antarctique. Paris: Ambroise de La Porte.

-. 1982 [1558]. Les Singularités de la France antarctique. Facsimilé de l'édition de 1558. Éd. Pierre Gasnault, introd. Jean Baudry. Paris: Le Temps.

-. 1878. Les Singularités de la France antarctique. Éd. P. Gaffarel, Paris. 
-. 1983. Les Singularités de la France antarctique. Choix de textes. Éd. Frank Lestringant. Paris: Maspero (La découverte, 68).

-. 1575. Cosmographie universelle. 2 vols. Paris: Guillaume Chaudiere.

-. 1953. Les Français en Amérique pendant la deuxième moitié du XVI siècle. Le Brésil et les Brésiliens par A. Thevet. Éd. Suzanne Lussagnet. Introduction par Ch. A. Julien. Paris: PUF (Pays d'outre mer. Deuxième série, Les classiques de la colonisation, 2). [Enthält nur die Brasilienkapitel der Cosmographie und das Manuscrit de deux voyages].

-. 1973 [1584]. Les vrais pourtraicts et vies des hommes illustres. Paris 1584. Éd. R. C. Cholakian. New York: Scholar's Facs. and Repr.

Verstegan, Richard [auch Verstegen, Richard, i.e. Richard Rowlands]. 1995 [1588]. Théâtre des cruautés des hérétiques de notre temps. Texte établi, présenté \& annoté par Frank Lestringant. Paris: Chandeigne.

Vespucci, Amerigo. 1504/1505. Epistola Albericii. De novo mundo. [Rostock: H. Barkhusen].

-. 1505. Dise Figur anzaigt uns das volck und insel. [Einblattholzschnitt; vermutlich Augsburg: Froschauer].

—. 1902 [1509]. Diß Büchlin saget [...]. Strassburg, Grüninger. [Nachdruck unter dem Titel: The first four voyages of Americus Vespuccius, a reprint in exact facsimile of the german edition printed at Strassburg by John Grüninger, New York: Dodd, Mead].

Vries, Simon de. 1682. Curieuse Aenmerckingen der bysonderste Oost en WestIndische verwondernswaerdige dingen. T. I-IV. Utrecht.

Weiditz, Christoph. 1927. Das Trachtenbuch des Christoph Weiditz, von seinen Reisen nach Spanien (1529) und den Niederlanden (1531/32). Nach der in der Bibliothek des Germanischen Nationalmuseums zu Nürnberg aufbewahrten Handschrift. Hg. von Theodor Hampe. Berlin: Christoph de Gruyter (Historische Waffen und Kostüme, 2).

Weigel, Hans. 1969 [1577]. Habitus praecipuorum populorum, tam virorum, quam foeminarum, singulari arte depicti. Nürnberg: H. Weigel. Nachdruck Unterschneidheim: Uhl, 1969.

Winckelmann, Hans Just. 1664. Der americanischen Neuen Welt Beschreibung [...] Beneben einer wunderbaren Schifffart und Reise Beschreibung [...] Hans von Staden. Oldenburg: Heinrich Conrad Zimmer.

Yves <d'Evreux>. 1615. Suitte de l'Histoire de la mission des choses plus memorables advenues en Maragnan és annees 1613 \& 1614. [...]. Paris: Huby. [Mikrofilm des Exemplars der Public Library New York]. 


\section{Forschungsliteratur}

Abreu Campanário, Manoel de. 1980. Hans Staden: o homem e a obra. São Paulo: Editora Parma.

Alegría, Ricardo E. 1978. Las primeras representaciones gráficas del Indio Americano (1493-1523). Barcelona: Instituto de Cultura Puertoriqueña.

America, das frühe Bild der neuen Welt. 1992. [Anläßlich der Ausstellung in der Bayrischen Staatsbibliothek München vom 10. April bis 27. Juni 1992]. Hg. von Hans Wolff. München: Prestel (Ausstellungskataloge Bayerische Staatsbibliothek, 58).

L'Amérique de Théodore de Bry. Une collection de voyages protestante du XVI siècle. Quatre études d'iconographie. 1987. Sous la direction de Michèle Duchet. Paris: CNRS.

L'Amérique vue par l'Europe. 1976. s. Honour

Arens, William. 1979. The man-eating myth. New York: Oxford Univ. Press.

Baudry, Jean. 1983. Documents inédits sur André Thevet, cosmographe du roi. Paris: Musée Galerie de la Seita.

Berg, Eberhard. 1987. "Wie ich in der tyrannischen Völcker Gewalt kommen bin". Hans Stadens Reisen in die Neue Welt. In: Der Reisebericht, die Entwicklung einer Gattung in der deutschen Literatur. Hg. von Peter J. Brenner. Frankfurt: Suhrkamp, 178-198.

Bild der Welt. 1996. Landkarten aus fünf Jahrhunderten; Kommentar zu einer Sammlung alter gedruckter Karten, Druckschrift anläßlich einer Ausstellung im Museum der Stadt Regensburg, von Hans Dachs. Regensburg: Museen der Stadt Regensburg.

Böhme, Max. 1904. Die großen Reisesammlungen des 16. Jahrhunderts und ihre Bedeutung. Straßburg: Heitz.

Boogaart, Ernst van den. 1990. The slow progress of colonial civilty indians in the pictorial record of dutch Brazil, 1637-1644. In: La imagen del Indio en la Europa moderna, 389-403.

Bouyer, Marc. 1983. Le spectacle de la Floride ou les beaux "sauvages" de Théodore de Bry. In: Etudes sur l'impact culturel du nouveau monde. Séminaire interuniversitaire sur l'Amérique espagnole coloniale. Éd. Marc Bouyer. 3 vols. Paris: L'Harmattan, III, 63-80.

Brasiliana. Vom Amazonenland zum Kaiserreich. 1989. Katalog zur Ausstellung mit Beständen der Brasilien-Bibliothek der Robert Bosch-GmbH in der Universitätsbibliothek Heidelberg, 29.04.-29.07.1989. Hg. von Josef Stumpf u. Ulrich Knefelkamp. Heidelberg: Univ. Bibliothek (Heidelberger Bibliotheksschriften, 35). 
Bremme, Hans Joachim. 1969. Buchdrucker und Buchhändler zur Zeit der Glaubenskämpfe. Studien zur Genfer Druckgeschichte 1565-1580. Genève: Droz (Travaux d'humanisme et Renaissance, 104).

Brun, Robert. 1969. Le livre français illustré de la Renaissance. Étude suivie du catalogue des principaux livres à figures du $\mathrm{XVI}^{\mathrm{e}}$ siècle. Paris: Picard.

Brunet, Jacques Charles. ${ }^{5} 1860-1865$. Manuel du libraire et de l'amateur des livres. 6 vols. Paris: Didot.

Bucher, Bernadette. 1977. La sauvage aux seins pendants. Paris: Hermann.

-. 1982. Die Phantasien der Eroberer, zur graphischen Repräsentation des Kannibalismus in de Brys America. In: Mythen der Neuen Welt, 75-91.

-. 1990. Al oeste del Edén. La semiótica de la conquista, deconstrucción del ícono y política estructural. In: Mercedes López-Baralt u. Bernadette Bucher (Hg.), La iconografía política del Nuevo Mundo. Puerto Rico: Ed. de la Universidad de Puerto Rico, 3-26.

Campbell, Mary B. 1988. The illustrated travel book and the birth of ethnography: part I of De Bry's America. In: David Allen u. a. (Hg.), The work of dissimilitude. Essays from the sixth citadel conference on Medieval and Renaissance literature. Charleston: Univ. of Delaware Press, 177-195.

Camus, Armand. 1802. Mémoire sur la Collection des Grands et Petits voyages et sur le voyage de Thevenot. Paris: Baudouin.

Canetti, Elias. 1980. Masse und Macht. Frankfurt am Main: Fischer.

Catalogue of the De Bry collection of voyages. 1904. In: Bulletin of the New York Public Library VIII, 230-243.

Church, Elihu Dwight. 1951 [1907]. A catalogue of books relating to the discovery and early history of North and South America, forming a part of the Library of E.D. Church [1482-1884]. New York: Dodd, Mead \& Co. (Repr., Gloucester, Mass.: P. Smith, 1951).

Circa 1492. Art in the age of exploration. 1991. National Gallery of Art, Washington, 21.10.91-12.01.92. [Ausstellungskatalog]. Ed. Jay A. Levenson. New Haven: Yale Univ. Press.

Colin, Susi. 1988. Das Bild des Indianers im 16. Jahrhundert. Idstein: SchulzKirchner (Wissenschaftliche Schriften im Wissenschaftlichen Verlag Dr, Schulz-Kirchner, 102).

Courboin, François. 1923. La gravure en France des origines à 1900. Paris: Delagrave.

Defert, Daniel. 1987. Collections et nations au XVIe siècle. In: L'Amérique de Théodore de Bry, 47-67. 
Delgado-Gómez, Angel. 1993. The earliest european views of the New world Natives. In: Jerry M. William und Robert E. Lewis (Hg.), Early images of the Americas. Tucson u. a.: Univ. of Arizona Press, 3-20.

Dickason, Olive Patricia. 1984. The Myth of the Savage and the Beginnings of French Colonialism in the Americas. Alberta: The University of Alberta Press.

Duchet, Michèle. 1984. Les gravures des "Grands voyages" de Théodore de Bry. In: Bernard Beugnot (Hg.), Voyages: récits et imaginaire. Actes de Montréal. Paris: PFSCL (Biblio 17), 41-45.

-. 1987. Le texte gravé de Théodore de Bry. In: L'Amérique de Théodore de Bry, 9-46.

Duportal, Jeanne. 1914. Etude sur les livres à figures, édités en France de 1601 à 1660. In: Revue des bibliothèques, Supplément XIII, Paris, 1-388.

Duviols, Jean Paul. 1978. Voyageurs français en Amérique (colonies espagnoles et portugaises). Paris: Bordas.

-. 1985. L'Amérique espagnole vue et rêvée. Les livres de voyage de Christophe Colomb à Bougainville. Paris: Éd. Promodis.

-. 1998. Les < sauvages brésiliens > dans le miroir européen (XVI ${ }^{\mathrm{e}}$ siècle). In: Naissance du Brésil moderne, 33-65.

Eames, Wilberforce. 1922. Description of a wood engraving illustrating the south american indians (1505). In: Bulletin of the New York Public Library XXVI, Nr. 9, 755-760.

Enders, Angela. 1993a. Fremde Menschen in fremder Natur. Formen der Verein nahmung einer Neuen Welt in romanischen Reiseberichten des 16. Jahrhunderts. In: Günter Berger u. Stephan Kohl (Hg.), Fremderfahrung in Texten des Spätmittelalters und der frühen Neuzeit. Trier: Wiss. Verlag, 103-150.

-. 1993b. Die Legende von der "Neuen Welt". Montaigne und die "littérature géographique” im Frankreich des 16. Jahrhunderts. Tübingen: Niemeyer (Mimesis, 21; zugleich Phil. Diss., Regensburg 1992).

European Americana. A Chronological Guide to Works Printed in Europe Relating to the Americas, 1493-1776. 1980-1997. Ed. John Alden and Dennis C. Landis. 6 vols. New York: Readex.

Falk, Tilman. 1987. Frühe Rezeption der Neuen Welt in der graphischen Kunst. In: Wolfgang Reinhard (Hg.), Humanismus und Neue Welt. Weinheim: VCH (Acta humaniora, Mitteilung XV der Kommission für Humanismusforschung), 37-64. 
Firmin-Didot, Ambroise. 1863. Essai typographique sur l'histoire de la gravure sur bois, faisant suite aux Costumes anciens et modernes de César Vercellio. Paris: Firmin-Didot.

-. 1870. Etude sur Jean Cousin. In: Gazette des Beaux Arts II, 406-413 und: Un tableau inconnu de Jean Cousin, ebd., 457-465. [Der Artikel erschien auch in einer Monographie des Autors: Etude sur Jean Cousin, suivie de notices sur Jean Leclerc et Pierre Woeiriot, Paris 1872. Nachdruck Genf: Slatkine, 1971. Ich zitiere nach der Originalausgabe von 1870].

Foltys, Christian. 1992. Colloque de l'entree ou arrivee en la terre du Bresil entre les gens du pays nommez Toupinambaoults, \& Toupinenkins en langage sauvage \& françois. In: Neue Romania 13, 17-103.

Forge, Jacques. 1987. Naissance d'une image. In: L'Amérique de Théodore de Bry, 105-125.

Forsyth, Donald W. 1983. The Beginnings of Brazilian Anthropology: Jesuits and Tupinamba Cannibalism. In: Journal of Anthropological Research 39, 147-178.

- 1985. Three cheers for Hans Staden, the case for brazilian cannibalism. In: Ethnohistory 32, 17-36.

Frübis, Hildegard. 1995. Die Wirklichkeit des Fremden. Die Darstellung der Neuen Welt im 16. Jahrhundert. Berlin: Reimer [zugleich Phil. Diss., Tübingen 1992/93].

Gagnon, François M. 1978. Figures dans le texte. A propos de deux gravures dans Thevet. In: Etudes Françaises 14, 183-198.

Giuseppi, Montague Spencer. 1916. The work of Theodore de Bry and his sons, engravers. In: Proceedings of the Huguenot Society of London, II, 204-226.

Hamy, Ernest Theodor. 1907. Le bas-relief de l'hôtel du Brésil au Musée départemental d'antiquités de Rouen. In: Journal de la société des américanistes, Nouvelle série, IV, Paris, 1-6.

-. 1908. Les indiens de Rasilly peint par Du Viert et gravés par Firens et Gaultier (1613). Étude iconographique et ethnographique. In: Journal de la société des américanistes, Nouvelle série, V, Paris, 21-52.

Harms, Wolfgang. 1985ff. Deutsche illustrierte Flugblätter des 16. und 17. Jahrhunderts. 4 Bde. erschienen. Tübingen: Niemeyer. Vgl. bes. Bd. 3: Die Sammlung der Herzog August Bibliothek in Wolfenbüttel, Teil 3: Theologica, Quodlibetica. Bibliographie, Personen- und Sachregister. Tübingen: Niemeyer, 1989.

Harrisse, Henry. 1958-60. Bibliotheca Americana vetustissima: a description of works relating to America published between the years 1492 and 1551. Ed. Carlos Sanz. 7 vols. Madrid: Suarez. [Bd. 1 und 2 dieser Ausgabe sind ein 
Nachdruck der Originalausgabe von Harrisse, Bd. 1, New York 1866 und Bd. 2, Paris 1872].

Harthan, John. 1981. The History of the Illustrated Book, the Western Tradition. London: Thames and Hudson.

Honour, Hugh (Hg.). 1976. L'Amérique vue par l'Europe. [Exposition au Grand Palais, 17.09.76-03.01.77]. Paris: Editions des musées nationaux.

-. 1982. Wissenschaft und Exotismus, die europäischen Künstler und die außereuropäische Welt. In: Mythen der Neuen Welt, 22-47.

Horl, Sabine. 1985/86. Aspectos ideológicos en la "America" de Theodor de Bry. In: Palinure 1, 42-54.

Hulton, Paul. 1984. America 1585. The Complete Drawings of John White. Chapel Hill: Univ. of North Carolina.

-. 1990. The persistance of White-De Bry image of the north american indian. In: La imagen del Indio en la Europa moderna, 405-415.

Hunnewell, James F. 1889. Illustrated Americana (1493-1624). In: Proceedings of the American Antiquarian Society, N.S., April, 66-77.

La imagen del Indio en la Europa moderna. 1990. Ed. Consejo Superior de Investigaciones Científicas, Fundación Europea de la Ciencia. Sevilla: Escuela de Estudios hispano-americanos.

Julien, Charles André (u. a.) (Hg.). 1948. Les voyages de découverte et les premiers établissements, $X V^{e}-X V I^{e}$ siècles. Paris: PUF.

Kohl, Karl-Heinz. 1985. Über einige frühe Darstellungen der Bewohner der Neuen Welt in der europäischen Kunst. In: Hermann Sturm (Hg.), Das Fremde. Ästhetische Erfahrung beim Graben, Reisen, Messen, Sterben. Aachen: Rader (Jahrbuch für Ästhetik, 1), 307-334.

Kristeller, Paul. ${ }^{4} 1922$. Kupferstich und Holzschnitt in vier Jahrhunderten. Berlin: Cassirer.

Kügelgen, Helga von. 1996. Die Austauschbarkeit der Bilder: Frühe Darstellungen der Neuen Welt. In: Karl Kohut u. a. (Hg.), Deutsche in Lateinamerika - Lateinamerika in Deutschland. Frankfurt/M.: Vervuert (Americana Eystettensia, Ser. B, 7), 199-222.

Kunze, Horst. 1993. Geschichte der Buchillustration in Deutschland. Das 16. und 17. Jahrhundert. 2 Bde. Frankfurt/M.: Insel.

Labarthe, Olivier. 1980. Une liste genevoise des livres imprimés 1567-1586. In: Cinq siècles d'imprimerie genevoise. Actes du Colloque international sur l'histoire de l'imprimerie et du livre à Genève, 27-30 avril 1978. Éd. Jean Daniel Candaux et Bernard Lescaze. Genève: Société d'Histoire et d'Archéologie, I, 171-197. 
Leidinger, Georg. 1925. Die älteste bekannte Abbildung südamerikanischer Indianer. In: Gutenberg-Festschrift zur Feier des 25jährigen Bestehens des Gutenberg-Museums in Mainz. Hg. von A. Ruppel. Mainz: Verlag der Gutenberg-Gesellschaft, 179-181 [und unpag. Abbildung im Anhang].

Lestringant, Frank. 1978. Les représentations du sauvage dans l'iconographie relative aux œuvres du cosmographe Thevet. In: Bibliothèque d'Humanisme et Renaissance, XL, 583-595.

—. 1984a. L'excursion brésilienne. Note sur les trois premières éditions de l'Histoire d'un voyage de J. de Léry. In: Pierre Georges Castex (Hg.), Mélanges sur la littérature de la Renaissance à la mémoire de V. L. Saulnier. Genève: Droz, 53-72.

—. 1984b. Un théâtre des cruautés. In: Jean-Renée Béguin (Hg.), La Renaissance et le nouveau monde. [Exposition, présentée au Québec du 6 juin au 12 août 1984]. Québec: Musée du Québec, 204-207.

-. 1987. L'automne des cannibales ou les outils de la conquête. In: L'Amérique de Théodore de Bry, 69-104.

-. 1990. Le Huguenot et le sauvage. L'Amérique et la controverse coloniale en France, au temps des guerres de religion (1555-1589). Paris: Aux amateurs du livre (Littérature des voyages, 5).

-. 1991. André Thevet. Genève: Droz (Travaux d'humanisme et Renaissance, 251; teilweise zugleich Phil. Diss., Paris).

-. 1994. Le cannibale. Grandeur et décadence. Paris: Perrin.

Lévi-Strauss, Claude. 1964. Le cru et le cuit. Paris: Plon (Mythologies, 1).

Lexikon des gesamten Buchwesens. 1987ff. Zweite, völlig neu bearbeitete Auflage $\left({ }^{2} \mathrm{LGB}\right)$. Hg. von Severin Corsten u. a. Stuttgart: Hiersemann.

Lieure, Jeanne. 1927. La gravure dans le livre et l'ornement. Paris: Vanoest.

Lorant, Stefan. ${ }^{2} 1965$. The New World. The First Pictures of America, Made by John White and Jacques Le Moyne and Engraved by Theodore de Bry. New York: Duell, Sloan and Pearce.

Lübbecke, Friedrich. 1948. Fünfhundert Jahre Buch und Druck in Frankfurt am Main. Frankfurt/M.: Cobet.

Luchesi, Elisabeth. 1982. Von den "Wilden/Nackten/Grimmigen Menschen fresser Leuthen/ in der Newenwelt America gelegen"; Hans Staden und die Popularität der "Kannibalen" im 16. Jahrhundert. In: Mythen der Neuen Welt, 71-74.

Lussagnet, Suzanne (Hg.). 1953. s. Thevet, André 
Mac Gowan, Margaret M. 1968. Forms and Themes in Henri II's entry to Rouen. In: Renaissance Drama, N. S., 1, 199-251.

- (Hg.) 1974. s. L'entrée de Henri II à Rouen 1550 [...]

Massa, J. M. 1975. Le monde luso-brésilien dans la joyeuse entrée de Rouen. In: Jean Jacquot (Hg.), Les fêtes de la Renaissance. 3 vols. Paris: CNRS (Quinzième colloque d'études humanistes, Tours 10.-20.07.1972) III, 105-116.

Massing, Jean Michel. 1991. Early European Images of America. The Ethnographic Approach. In: Circa 1492. Art in the Age of Exploration, 514-520.

Menninger, Annerose. 1988. Die Vermarktung des Indianers. In: Ulrich Knefelkamp und Hans-Joachim König (Hg.), Die neuen Welten in alten Büchern. [Ausstellung der Staatsbibliothek Bamberg]. Bamberg: Staatsbibliothek, 92-117.

-. 1991. Die Kannibalin Amerika. Zur Rezeption eines Bild-Topos in den Erdteilallegorien Jost Ammans und Hans Weigels (1577). Bamberg: Forschungsstiftung für vergleichende europäische Überseegeschichte (Kleine Beiträge zur europäischen Überseegeschichte, 11).

-. 1992. Unter "Menschenfressern". Das Indianerbild der Südamerikareisenden Hans Staden und Ulrich Schmidl zwischen Dichtung und Wahrheit. In: Thomas Beck u. a. (Hg.), Kolumbus' Erben. Europäische Expansion und überseeische Ethnien im ersten Kolonialzeitalter, 1415-1815. Darmstadt: Wiss. Buchgesellschaft, 63-98.

-. 1995. Die Macht der Augenzeugen. Neue Welt und Kannibalen-Mythos; 1492-1600. Stuttgart: Steiner (Beiträge zur Kolonial- und Überseegeschichte 64; zugleich Phil. Diss., Bamberg 1993).

-. 1996. Hans Stadens "Wahrhaftige Historia". Zur Genese eines Bestsellers der Reiseliteratur. In: Geschichte in Wissenschaft und Unterricht 47, 509-525.

Métraux, Alfred. 1932. A propos de deux objets tupinambas du Musée d'Éthnographie du Trocadero. In: Bulletin du Musée du Trocadero 2, 3-13.

Mundus novus. 1992. [America oder die Entdeckung des Bekannten (...). Ausstellung des Instituts für Zeitungsforschung 21.02.-26.04.1992. Dortmunder Ausstellung "Mundus novus"]. Hg. von Peter Mesenhöller. Essen: KlartextVerlag.

Mythen der Neuen Welt. 1982. Zur Entdeckungsgeschichte Lateinamerikas. [Berliner Festspiele, Horizonte]. Hg. von Karl-Heinz Kohl. Berlin: Frölich und Kaufmann.

Naissance du Brésil moderne: 1500-1800. 1998. XX Colloque de l'Institut de Recherches sur les civilisations de l'Occident Moderne les 4 et 5 mars 1997 en Sorbonne/ Centre d'Etudes sur le Brésil. Sous la dir. de Katia de Queiros Mattoso. Paris: Presses de l’Univ. de Paris-Sorbonne (Civilisations, 22). 
Die Neue Welt in den Schätzen einer alten Bibliothek. 1976. Ausstellung der Herzog August Bibliothek, Wolfenbüttel (30.06.-22. 08.1976). Braunschweig (Ausstellungskataloge der Herzog August Bibliothek, 17).

Neuber, Wolfgang. 1990. Imago und Pictura. Zur Topik des Sinn-Bilds im Spannungsverhältnis von Ars Memorativa und Emblematik. In: Text und Bild, Bild und Text, DFG-Symposion 1988. Stuttgart: Metzler (Germanistische Symposien Berichtbände, 11), 245-261.

-. 1991. Fremde Welt im europäischen Horizont. Zur Topik der deutschen Amerika-Reiseberichte der Frühen Neuzeit. Berlin: Schmidt (Philologische Studien und Quellen. Hg. von H. Steger und H. Steinecke, Heft 121).

- 1992. Amerika in deutschen Reiseberichten des 16. und 17. Jahrhunderts. In: Hans-Joachim König und Gustav Siebenmann (Hg.), Das Bild Lateinamerikas im deutschen Sprachraum. Ein Arbeitsgespräch an der Herzog August Bibliothek Wolfenbüttel, 15.-17.03.89. Tübingen: Niemeyer (Beihefte zur Iberoromania, 8), 37-54.

Nissen, Claus. 1969/1978. Die zoologische Buchillustration, ihre Bibliographie und Geschichte. I: Bibliographie, Stuttgart: Hiersemann, 1969. II: Geschichte. Stuttgart: Hiersemann, 1978.

Obermeier, Franz. 1995. Französische Brasilienreiseberichte im 17. Jahrhundert, Claude d'Abbeville: Histoire de la mission; Yves d'Evreux: Suitte de l'histoire. Bonn: Romanist. Verlag [zugleich Phil. Diss., Regensburg, 1994].

—. 1998. Katechismen in der "língua geral" der brasilianischen Tupiindianer und ihre Überlieferung in zeitgenössischen französischen und portugiesischen Dokumenten des 16. und 17. Jahrhunderts. In: Bibliotheksforum Bayern 26, 1, 48-69.

Palencia-Roth, Michael. 1985. Cannibalism and the New Man of Latin America in the 15th and 16th Century European Imagination. In: Comparative Civilizations Review 12, 1-12.

Parent, Annie. 1974. Les Métiers du livre à Paris au XVIe siècle (1535-1560). Genève: Droz.

Pastoureau, Mireille. 1984. Les atlas français XVI et XVII siècles. Répertoire bibliographique et étude par M. Pastoureau avec la collaboration de F. Lestringant pour l'Insulaire d'André Thevet. Paris: Bibliothèque Nationale, Département des cartes et plans.

Peter-Röcher, Heidi. 1994. Kannibalismus in der prähistorischen Forschung. Studien zu einer paradigmatischen Deutung und ihren Grundlagen. Bonn: Habelt (Universitätsforschungen zur prähistorischen Archäologie. Aus dem Seminar für Ur- und Frühgeschichte der Freien Universität Berlin, XX). 
-. 1998. Mythos Menschenfresser. Ein Blick in die Kochtöpfe der Kannibalen. München: Beck (Beck'sche Reihe, 1262).

Poeschel, Sabine. 1985. Studien zur Ikonographie der Erdteile in der Kunst des 16.-18. Jahrhunderts. München: Klein (Beiträge zur Kunstwissenschaft, 3).

Putscher, Marielene. 1983. Das Bild der Welt zu Beginn des 17. Jhs. Alchemie und Kosmographie in den Bildern von Johann Theodor de Bry (1561-1623) und Matthäus Merian (1593-1650). In: Bernhard Fabian u. Paul Raabe (Hg.), Gelehrte Bücher vom Humanismus bis zur Gegenwart. Referate des 5. Jahrestreffens des Wolfenbüttler Arbeitskreises für Geschichte des Buchwesens vom 6.-9. Mai 1981 in der HAB. Wiesbaden: Harrassowitz (Wolfenbütteler Schriften zur Geschichte des Buchwesens, 9), 7-50.

Quetsch, Cäcilie. 1983. Die "Entdeckung der Welt" in der deutschen Graphik der beginnenden Neuzeit (Wende 15.- bis Wende 16./17. Jahrhundert). 2 Bde. I: Text. II: Abbildungen. Erlangen [zugleich Phil. Diss, Erlangen, 1983].

Reverdin, Olivier. 1957. Quatorze calvinistes chez les Topinambous. Histoire d'une mission genevoise au Brésil (1556-1558). Genève: Droz.

Sabin, Joseph. 1961 [1869-92]. Bibliotheca Americana. A Dictionary of Books Relating to America from its Discovery to the Present Time. New York: Sabin. 29 Bde. Nachdruck Amsterdam: Israel, 1961.

Schuller, Rudolf. 1925. Die älteste bekannte Abbildung südamerikanischer Indianer. In: Dr. A. Petermanns geographische Mitteilungen aus Justus Perthes geographischer Anstalt 71, 21-24.

-. 1930. The oldest known illustration of south american indians. In: Indian Notes, 484-497.

Sebastián López, Santiago. 1992. Iconografia del Indio americano. Siglos XVI, XVII. Madrid: Ed. Tuero (Collección Investigación y crítica, 9).

Singer, Hans Wolfgang. 1967 [1930]. Allgemeiner Bildniskatalog. Leipzig. Nachdruck Stuttgart u. a.: Hiersemann 1967.

Sondheim, Moritz. 1933. Die De Bry, Matthäus Merian und Wilhelm Fitzer, eine Frankfurter Verlegerfamilie des 17. Jahrhunderts. In: Philobiblon 6, 9-34.

Sturtevant, C. 1976. First Visual Images of Native America. In: F. Chiappelli (Hg.), First Images of America: the Impact of the New World on the Old. Berkeley-Los Angeles: Univ. of Calif. Press, 417-454.

Le théâtre du nouveau monde. Les grands voyages de Théodore de Bry. 1992. Éd. Jean-Paul Duviols et Marc Bouyer. Paris: CNRS (Découvertes Gallimard Albums). 
Thieme, Ulrich. 1911ff. Allgemeines Lexikon der bildenden Künstler von der Antike bis zur Gegenwart. Begründet von Ulrich Thieme und Felix Becker. Leipzig: Seemann.

Thomsen, Christian W. 1983. Menschenfresser in der Kunst, der Literatur, in fernen Ländern, Mythen, Märchen und Satiren, in Dramen, Liedern, Epen und Romanen; eine kannibalistische Text-Bild Dokumentation. Wien: Brandstätter.

Toscano del Banner, Andreas. 1992. Frühe Darstellungen Amerikas, Hans Stadens "Wahrhaftige Historia". In: Staden Jahrbuch 37/38, 1989/90, $50-73$.

Wegener, Richard N. 1925. Frankfurts Anteil an der Verbreitung anatomischer Kenntnisse im XVI. bis XVIII. Jahrhundert. Ein Beitrag zur Urgeschichte der Frankfurter Hochschule. Frankfurt/M.: Englert und Schlosser (Frankfurter gelehrte Reden und Abhandlungen, Heft 5).

Weigel, Theodor Oswald. 1845. Bibliographische Mitteilungen über die deutschen Ausgaben von De Brys Sammlung der Reisen nach dem abend- und morgenländischen Indien. In: Serapeum 6, 65-78, 81-92, 97-110.

Wendt, Astrid. 1989. Kannibalismus in Brasilien. Eine Analyse europäischer Reiseberichte und Amerika-Darstellungen für die Zeit zwischen 1500 und 1654. Frankfurt/M.: Lang (Europäische Hochschulschriften Reihe "Ethnologie et anthropologie sociale", XV).

Wenzel, Horst. 1991. Deutsche Conquistadoren: Hans Staden in der Neuen Welt. Vorträge des XI. Anglo-deutschen Colloquiums, 11.-15.09.89, Univ. Liverpool. In: Dietrich Huschenbett u. a. (Hg.), Reisen und Welterfahrung in der deutschen Literatur des Mittelalters. Würzburg: Könighausen und Neumann (Würzburger Beiträge zur dt. Philologie, 7), 290-305.

Zerner, Henri. 1969. Die Schule von Fontainebleau. Das graphische Werk. Wien: Schroll.

Zülch, Walter Karl. 1935. Frankfurter Künstler, 1223-1700. Frankfurt: Diesterweg (Veröffentlichung der historischen Kommission der Stadt Frankfurt am Main, X).

\section{Unveröffentlichte Dokumente}

Genfer Staatsarchiv (Archives d'Etat de Genève): Notariatsakten Noël Cornillaud, Bd. I, Blatt 290v., Schuldverschreibung des Kaufmanns Claude Juge für Jean de Léry vom 16.10.1577. 




\section{Anhang:}

\section{Verzeichnisse der Illustrationen und Konkordanzen}

\section{Vorbemerkung zu den zitierten Ausgaben}

Staden: Die Originalausgabe der Historia von 1557 (Faksimile 1978) ist nicht paginiert. Sie besteht aus zwei "Büchern", i.e. eigentlich Teilen, der zweite mit eigenem Titelblatt. Ich ordne die Holzschnitte den Büchern und Kapiteln zu und zähle sie in den Kapiteln der Reihe nach durch.

Léry: Ich zitiere die Histoire i.d.R. nach der Faksimileausgabe $1975\left[{ }^{2} 1580\right]$. Der Stich mit der Kampfszene ist in diesem Faksimile fälschlicherweise nur zur Hälfte abgebildet. Vorlage für die Tafeln im Bildteil waren die Illustrationen der dritten Ausgabe von 1585 (UB Erlangen).

Thevet: Die Illustrationen von Thevets Singularités zitiere ich nach der Faksimileausgabe von 1982 [1558], diejenigen der Cosmographie nach der Auswahlausgabe von 1953 und der dort auch angegebenen Originalpaginierung. Bei dort nicht enthaltenem Bildmaterial zitiere ich nach der in der Bibliographie angeführten Originalausgabe, erschienen bei Chaudière, 1575 (Stadtbibliothek Augsburg).

Bry: Die Texte Stadens, Lérys sowie Brys dazugehörige Stiche befinden sich im 3. Band der America-Kollektion, lat. 1592, dt. 1593. Der Text von Staden bildet jeweils den ersten, Léry den zweiten Teil; in der lateinischen Ausgabe folgt noch eine Übersetzung der Briefe von Barré (franz. Original, Paris 1556) ohne Illustrationen und ein unpaginierter Index.

Um den Text der Analyse nicht mit komplizierten Nachweisen zu belasten und um der Tatsache Rechnung zu tragen, dass die Ausgabe von Sievernich (1990) für die meisten Leser am ehesten greifbar ist, folge ich bei der Zitierung im Text den Seitenzahlen von Sievernich in der Form: America, 1990, Seitenzahl.

In den Konkordanzlisten ist ebenfalls die Anordnung der Illustrationen bei Sievernich aufgeführt, auch wenn sich bei ihm einige kleinere Fehler in der Reihenfolge der Stiche im Vergleich zu den lat. und dt. Originalen finden (vgl. die Hinweise in den Fußnoten zu den Konkordanztabellen) und er für den dritten Band der America-Sammlung in Abweichung von den Originalausgaben eine eher verwirrende explizite Einteilung (der Stiche) in 3 Teile vornimmt, die Stadens 1. Buch, seinem deskriptiven 2. Buch und Lérys Text entsprechen. Bei Sievernich entfallen zudem einige Wiederholungen von Stichen. Die Zählung von Sievernich ist in den Tabellen kursiv angegeben.

Die Angaben der beigefügten Tabellen beziehen sich - sofern nicht eigens vermerkt immer auf den dritten Band der America-Sammlung von Bry in der lateinischen oder deutschen Fassung. Der Anhang enthält ferner einen Vergleich des Bildmaterials des lateinischen und deutschen Originals von Brys drittem Band. In dieser Zusammenstellung sind auch die Wiederholungen von Stichen genau aufgeführt. Teilübernahmen von einzelnen Elementen der Vorbilder werden durch $v g l$. $x y$ bezeichnet. 


\section{Die Illustrationen in Stadens Warhafftige Historia}

$\mathrm{Da}$ die Originalausgabe nicht paginiert ist, ordne ich die Holzschnitte den Kapiteln zu.

\section{Inhaltliche Analyse}

(Titelblatt)

1. Buch

Schiff 1

Karte

Kap. 2, Schiff 2

Kap. 2, Schiff 3

Karte

Kap. 3

Kap. 4

Kap. 5

Kap. 6

Kap 7

Kap. 9

Kap. 12

Kap. 14

Kap. 18

Kap. 20, 1

Kap. 20, 2

Kap. 22

Kap. 24

Kap. 28

Kap. 29

Kap. 30

Kap. 35

Kap. 39

Kap. 40

Kap. 41

Kap. 42,1

Kap. 42,2

Kap. 43

Kap. 44

Kap. 47
Indianer in Hängematte, daneben ein Grill mit Menschenfleisch, davor eine europäische Axt

\author{
Halt der Schiffe in Afrika \\ Küstenlandschaft mit Kampfszene \\ Küste mit Schiffen \\ Schiff $2^{126}$ \\ Küste von Superagui \\ der Hafen von Santa Catarina \\ Schiffbruch Stadens bei Itanhaem \\ kämpfende Indianer \\ Gefangennahme Stadens \\ Zwischenhalt auf einer Insel \\ Staden sagt ein Gewitter voraus \\ Ankunft Stadens im Dorf \\ ritueller Tanz Stadens
}

Staden vor dem Häuptling Konyan Bebe

Angriff von Indianern auf ein Indianerdorf

Staden inmitten einer Gruppe Rauchender

Begräbnisszene, Staden als Heilkundiger

Ankunft eines portugiesischen Schiffs

Staden als Heilkundiger, Hinrichtung

des kranken Carijó-Sklaven, Zerteilung des Körpers

Staden versucht auf ein Schiff zu

fliehen und wird abgewiesen

Kriegszug der Indianer, Zwischenhalt

Kriegszug der Indianer, Kampfszene

Behandlung gefangener Feinde

die Gefangenen müssen tanzen

Staden sagt Ende des Regens voraus

${ }^{126}$ Der Holzschnitt des Schiffs 2 ist ebenso wie bei der zweiten Wiederholung (1. Buch nach Kap. 53) leicht nachgeschnitten, das Maul des Fisches oben links ist besser erkennbar, vgl. Abreu Campanário 1980, 116. 
Kap. 48

Kap. 53

Schiff 2

Schlussvignette

\section{Buch}

Titelholzschnitt

Kap. 5

Kap. 6

Kap. 7

Kap. 8

Kap. 11

Kap. 15

Kap. 16

Kap. 17

Kap. 23

Kap. 29, 1

Kap. 29, 2

Kap. 29, 3

Kap. 29, 4

Kap. 29, 5

Kap. 29, 6

Kap. 29, 7

Kap. 29, 8

Kap. 29, 9

Kap. 29, 10

Kap. 29, 11

Kap. 31

Kap. 32
Staden erbittet von Gott Regen während eines

Fischfangs

Abfahrt der Schiffe
Zwei Indianer mit Waffen

Indianerdorf

Feuermachen

Hängematte

Fischen mit Pfeilen

wie 1. Buch, Kap. 47

Bereitung des cahouin-Getränks

Lippenschmuck

enduape (Federschmuck)

maraca (religiöses Instrument)

wie 1. Buch, Kap. 22, Staden wird ins Dorf geführt

wie 1. Buch, Kap. 24, Staden tanzt

die Kriegskeule und der Strick zum Fesseln (mussurana)

boucan (Grill) mit Menschenfleisch ${ }^{127}$

die Keule und der Gefangene werden bemalt

ritueller Tanz um die Keule

Festmahl (cahouin) und ritueller Tanz

Tötung des Gefangenen

Zerteilung des Körpers

Frauen verspeisen Eingeweide

der Sud wird gekocht

Tierdarstellung (Gürteltier)

Tierdarstellung (Beutelratte)

127 Eigentlich müßte dieser Holzschnitt in der synchronen Folge der Anthropophagiedarstellungen zwischen Holzschnitt 29, 10 und 29, 11 oder ganz am Ende der Folge stehen. Er zeigt links oben auch eine Gruppe essender Frauen wie der Holzschnitt 29, 11. Vielleicht wollte der Drucker die thematische Übereinstimmung mit diesem Holzschnitt vermeiden und nahm ihn deshalb aus seinem Platz in der Folge. 


\section{Ikonographische Konkordanzen}

\section{Staden und Bry (America, 1990)}

Die Nummern der zweiten Spalte entsprechen der Zählung von Sievernich (America, 1990). Verweise auf Teilübernahmen werden durch $v g l$. ... angezeigt.

\section{Staden}

Titelblatt

1. Buch

Schiff 1

Karte

Kap. 2, Schiff 2

Kap. 2, Schiff 3

Karte

Kap. 3

Kap. 4

Kap. 5

Kap. 7

Kap. 9

Kap. 12

Kap. 14

Kap. 18

Kap. 20, 1

Kap. 20, 2

Kap. 22

Kap. 24

Kap. 28

Kap. 29

Kap. 30

Kap. 35

Kap. 39

Kap. 40

Kap. 41

Kap. 42,1

Kap. 42,2

Kap. 43

Kap. 44

Kap. 47

Kap. 48

Kap. 53 (Abfahrt der Schiffe)

Schiff 2
Bry

Titelkupfer

3. Buch, 1. Teil [=Staden, 1. Buch]

vgl. die Karte nach Stich 1

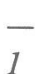

Karte

2

3

4

5

6

7

8

9

$-$

10

11

12

$\overline{14}$

13

15

16

17

18

vgl. 3. Teil, Stich 2 (Léry)

vgl. 3. Teil, Stich 4 (Léry)

-

- 
2. Buch

Titelholzschnitt

Kap. 5

Kap. 6

Kap. 7

Kap. 8

Kap. 11

Kap. 15

Kap. 16

Kap. 17

Kap. 23

Kap. 29, 1 (ähnlich 29, 5)

Kap. 29, 2

Kap. 29, 3

Kap. 29, 4

Kap. 29, 5

Kap. 29, 6

Kap. 29, 7

Kap. 29, 8

Kap. 29, 9

Kap. 29, 10

Kap. 29, 11

Kap. 31

Kap. 32

\section{[Léry]}

vgl. Staden, 2. Buch, Kap. 29, 4

vgl. Léry, S. 214 und 222 und

Staden, 1. Buch, Kap. 40

vgl. Léry, S. 235

vgl. Léry, S. 246 und Staden, 2. Buch, Kap. 29, 7
3. Buch, 2. Teil [=Staden, 2. Buch]

2. Teil, Stich 1

-

$-$

2. Teil, Stich 2

-

ähnlich 2. Teil, Stich 3

vgl. 3. Teil, Stich 1

2. Teil, Stich 3

vgl. 3. Teil, Stich 4

2. Teil, Stich 4

2. Teil, Stich 5

2. Teil, Stich 6

vgl. 2. Teil, Stich 5

3. Buch, 3. Teil [=Léry]

1

2

3

4 


\section{Staden, Léry und Bry (America, 3. Buch, lat. Ausgabe, 1592)}

Die Nummern der zweiten Spalte entsprechen der Zählung bei Sievernich (America, 1990)

3. Spalte: America, lat. Ausgabe, 1592

\section{Staden}

Titelblatt

1. Buch

Schiff 1, vor Kap. 1

Karte, vor Kap. 1

Kap. 2, Schiff 2

Kap. 2, Schiff 3

Kap. 3

Kap. 4

Kap. 5

Kap. 7

Kap. 9

Kap. 12

Kap. 14

Kap. 18

Kap. 20, 1

Kap. 20, 2

Kap. 22

Kap. 24

Kap. 28

Kap. 29

Kap. 30

Kap. 35

Kap. 39

Kap. 40

Kap. 41

Kap. 42,1

Kap. 42,2

Kap. 43

Kap. 44

Kap. 47

Kap. 48

Kap. 53
Bry 1990

Titelkupfer

Bry (lat.), 1592

Frontispiz Staden

Vgl. die Karte nach Stich 1

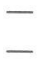

1. Teil
1
Karte
2
3
4
5
6

wie 5

7

wie 7

8

9

$-$

10

11

12

$\overline{14}$

13

15

16

17

wie 13

wie 17

18

vgl. 3. Teil, Stich 2 (Léry)

vgl. 3. Teil, Stich 4 (Léry)
Kap. 1, S. 1

Karte angebunden

Kap. 2,

S. 3

Kap. 4, S. 7

Kap. 5, S. 10

Kap. 7, S. 14

Kap. 9, S. 18

Kap. 10 , S. 21

Kap. 12, S. 24

Kap. 13 , S. 26

Kap. 18 , S. 34

Kap. 19 ， S. 37

Kap. 22, S. 41

Kap. 23, S. 43

Kap. 29, S. 52

Kap. 34 , S. 59

Kap. 32 , S. 56

Kap. 41, S. 74

Kap. 38, S. 66

Kap. 39, S. 68

Kap. 42 , S. 76

Kap. 42 , S. 78
Kap. 40 , S. 71 
Schiff 2

19
wie 19
wie 4

Titelholzschnitt

Kap. 5

Kap. 6

Kap. 7

Kap. 8

Kap. 11

Kap. 15

Kap. 16

Kap. 17

Kap. 23

Kap. 29, 1 (ähnlich 29, 5)

Kap. 29, 2

Kap. 29, 3

Kap. 29, 4

Kap. 29, 5

Kap. 29, 6

Kap. 29, 7

Kap. 29, 8

Kap. 29, 9

Kap. 29, 10

Kap. 29, 11

Kap. 31

Kap. 32
Bry 1990 [=Staden, 2. Teil]

2. Teil

wie 1. Teil, Stich 1

Kap. 43 , S. 80

Kap. 49, S. 89

Kap. 53, S. 96

[lat. 1592]

[neue KapitelZählung]

Kap. 1, S. 102

Kap. 5, S. 106

2. Teil, Stich 1

Kap. 15, S. 112

2. Teil, Stich 2

Kap. 28, S. 122

ähnlich 2. Teil, Stich 3

Kap. 29, S. 124

2. Teil, Stich 3

vgl. 3. Teil, Stich 4

2. Teil, Stich 4

wie 3. Teil, Stich 2

Kap. 29, S. 125

Kap. 29, S. 126

Kap. 29, S. 127

2. Teil, Stich 5

2. Teil, Stich 6

vgl. 2. Teil, Stich 5
Kap. 29, S. 128 
Léry

vgl. Staden, 2. Buch, Kap. 29, 4

vgl. Léry, S. 214, 222, und Staden, 1. Buch, Kap. 40 vgl. Léry, S. 235 vgl. Léry, S. 246 und Staden, 2. Buch, Kap. 29,7
Bry 1990, 3. Buch,

3. Teil [Léry]

$-$

Titelblatt

wie 1. Teil, Stich 1 ,

wie Bry, Buch $4^{128}$

wie 2. Teil, Stich 2, 1

wie 1. Teil, Stich 18

wie 2. Teil, Stich 4

$2^{129}$

3

4

wie 1. Teil, Stich 14
Bry, Bd. 3, lat. 1592 [Léry]

Eigenes

Frontispiz

Titelblatt

S. 144 Sündenfall

Kap. 2, S. 146

Kap. 3, S. 151

Kap. 8, S. 174

Kap. 9, S. 179

Kap. 13 , S. 208

Kap. 14, S. 212

Kap. 14 , S. 213

Kap. 15 , S. 223

Kap. 15 , S. 228

Kap. 18 , S. 248

Briefe von

Barré [o. III.]

Index

${ }^{128}$ Auch hier hat Sievernich eine neue Illustration unterschlagen. Die Abbildung der fliegenden Fische findet sich in seiner Auswahl erstmals in der Benzoniillustration im 4. Buch, Abb. 2 der Kollektion (Sievernich 1990, S. 155).

${ }^{129}$ Bei Sievernich erstmals an dieser Stelle abgebildet. Dieselbe Illustration findet sich bei Bry allerdings schon im 2. Stadenteil in der lat. Ausgabe 1592, Kap. 29, 126. 


\section{Bry, America, Bd. 3: lateinische und deutsche Ausgabe}

Die vorgeschalteten Nummern der ersten Spalte entsprechen denen bei Sievernich (Ameri$c a, 1990)$

1990

lat. Ausgabe 1592

dt. Ausgabe 1593

Nr. d. Abb.

Titelkupfer

Titelkupfer

Wappen

\section{Teil [Staden, 1. Buch] Staden [1. Buch]}

1

Karte

2

3

4

5

6

wie 5

7

wie 7

8

9

10

11

12

14

13

Kap. 1, S. 1,

Karte, angebunden

Kap. 2, S. 3

Kap. 4, S. 7

Kap. 5, S. 10

Kap. 7, S. 14

Kap. 9, S. 18

Kap. 10, S. 21

Kap. 12, S. 24

Kap. 13, S. 26

Kap. 18 , S. 34

Kap. 19, S. 37

Kap. 22, S. 41

Kap. 23, S. 43

Kap. 29, S. 52

Kap. 34, S. 59

Kap. 32 , S. 56

$-$

16

17

wie 13

wie 17

18

19

wie 19

wie 4

Kap. 40, S. 71

Kap. 41, S. 74

Kap. 38, S. 66

Kap. 39 , S. 68

Kap. 42 , S. 76

Kap. 42 , S. 78

Kap. 43 , S. 80

Kap. 49, S. 89

Kap. 53, S. 96
Titelkupfer

Wappen

Staden [1. Buch]

Kap. 1, S. 1

Karte, angeb.

Kap. 2, S. 3

Kap. 4, S. 5

Kap. 5 , S. 7

Kap. 7 , S. 10

Kap. 9, S. 13

Kap. 12 , S. 16

Kap. 18, S. 22

Kap. 19, S. 24

Kap. 22, S. 27

Kap. 23 , S. 29

Kap. 29, S. 35

Kap. 34, S. 39

Kap. 32, S. 37

wie Nr. 13,

Kap. 38, S. 45

Kap. 39, S. 48

Kap. 40, S. 50

Kap. 41, S. 52

-

Kap. 42, S. 54

Kap. 43, S. 56 
2. Teil

\section{Staden [2. Buch]}

wie 1

2. Teil, Stich 1

2. Teil, Stich 2

wie 1. Teil, Stich 3

2. Teil, Stich 3

2. Teil, Stich 4

wie 3. Teil, Stich 2

2. Teil, Stich 5

2. Teil, Stich 6

3. Teil [Léry]

[Frontispiz: vgl. S. 111]

[Sündenfall: 1. Buch, S. 15]

wie 1. Teil, Stich 1

wie Bry 4. Buch ${ }^{131}$

wie 2. Teil, Stich 2

1

wie 1. Teil, Stich 18

wie 2. Teil, Stich 4

2

3

4

wie 1 . Teil, Stich 14 neue Kapitelzählung

Staden [2. Buch]

Kap. 1, S. 102

Kap. 5, S. 106

Kap. 15, S. 112

Kap. 28, S. 122

Kap. 29, S. 124

Kap. 29, S. 125

Kap. 29, S. 126

Kap. 29, S. 127

Kap. 29, S. 128

Léry

eigenes Frontispiz

(Scheinarchtitektur)

S. 144, Sündenfall

Kap. 2, S. 146

Kap. 3, S. 151

Kap. 8, S. 174

Kap. 9, S. 179

Kap. 13, S. 208

Kap. 14, S. 212

Kap 14, S. 213

Kap. 15, S. 223

Kap. 15, S. 228

Kap. 18, S. 248

Briefe von

Barré [ohne Ill.]

Index neue Kapitelzählung

Staden [2. Buch]

Kap. 4, S. 70

Kap. 12, S. 75

Kap. 29, S. 83

Kap. 29, S. 85

Kap. 29, S. 86

Kap. 29, S. 87

\section{Léry}

Titelblatt

ohne/mit Schein-

$\operatorname{architektur}^{130}$ )

nach Vw. unpg.,

Sündenfall

Kap. 2, S. 97

Kap. 3, S. 103

Kap. 9, S. 150

Kap. 10, S. 155

Kap. 14, S. 189

Kap. 15, S. 193

Kap. 15, S. 195

Kap. 16, S. 215

Kap. 16, S. 221

Kap. 19, S. 245

${ }^{130}$ Die dt. Ausgabe von Bd. 3 der Kollektion trägt in der ersten Auflage ein Frontispiz, eine zweite Auflage druckt nur den Titel ohne Frontispiz, vgl. Brunet (1860), Bd. 1, Spalte 1347.

${ }^{131}$ Wie schon erwähnt findet sich diese Abbildung Brys bei Sievernich erstmals bei den Illustrationen der fliegenden Fische im Benzonibericht im 4. Buch der Kollektion, Abb. 2 (America, 1990, S. 155). 


\section{Die Illustrationen von Thevets Singularités und ihr Fortleben in der Cosmographie}

Erklärung der Siglen:

A: Übernahme der alten Illustration der Singularités

N: neu erstellter Holzschnitt in direkter Anlehnung an die Illustration der Singularités

?: nur sehr geringe oder zweifelhafte Anlehnung an einen thematisch ähnlichen Holzschnitt der Singularités (in Tabelle 1 nicht berücksichtigt, s. oben 36f)

Die Paginierung bezieht sich auf die Ausgabe der Cosmographie, Paris bei Guillaume Chaudière, 1575. Die zwei Bände weisen durchgehende Paginierung auf (Bd. I: Bl. 1-469, Bd. 2: B1. 469-1025). Im selben Jahr erschien eine weitere Ausgabe in Paris "Chez Pierre l'Huillier".

\section{Singularités}

$6 \mathrm{v}$

$18 \mathrm{v}$

20v Produktion von Palmwein

28r Landschaft mit Vulkan

31r Bewohner von Guinea beten Götzen an

41r Rhinozeros und Elephant

$45 \mathrm{r} \quad$ Vogeldarstellung $(p a)$

46v Produktion von cahouin

48r Riesenfisch

50r Fisch

53r hetich (Kartoffel)-Wurzeln

57r Essen und Trinken bei den Indianern

61v Bananenbaum

66v Herstellung der Fußschellen zum Tanzen aus Früchten eines Baums

71v Kampfszene

72v Fällen eines Baums

73v Provokationen vor dem Kampf

76v Tötung eines Gefangenen

$77 \mathrm{r} \quad$ Zerteilung des toten Körpers

82v Bestattungsriten

83r Tänze und Bankette

85v Tränengruß der Indianer

88v Heilung Kranker durch Schamanen

89v Ananas

91r Vogeldarstellung (toucan)

98v Tierdarstellung (uhebehasoub)

99v Faultier (haut)

101r Tabakrauchen und Feuermachen

105r Baum (Choine)

109r Tier mit Jungen auf Rücken

114r Pflanzendarstellung (manioc)

$115 \mathrm{v} \quad$ Vogeldarstellung

\section{Cosmographie}

$\mathrm{N} 16 \mathrm{r}$

N 420r?

$\mathrm{N} 74 \mathrm{v}$

N 403v

A $994 \mathrm{r}$

N 917r

N 992r?

A $921 \mathrm{r}$

A $930 \mathrm{v}$

N 942v

A $943 \mathrm{v}$

N $945 \mathrm{v}$

A $946 \mathrm{r}$

A $926 \mathrm{r}$

A $927 \mathrm{v}$

N 929v

A $935 \mathrm{r}$

A $936 \mathrm{r}$

N 938v

A $940 \mathrm{r}$

N 941r

A $938 \mathrm{r}$

A $953 \mathrm{r}$

A $1002 \mathrm{r}$

A $948 \mathrm{v}$

A $962 \mathrm{v}$ 
117r Fällen eines Baums

120v Indianer ernten Früchte von Bäumen

124v Amazonen kämpfen gegen Männer

$126 \mathrm{v}$

$133 \mathrm{v}$

$147 \mathrm{v}$

$151 \mathrm{r}$

$156 \mathrm{r}$

$164 \mathrm{r}$
Amazonen töten Gefangene durch Pfeilschüsse

Fisch

Tierdarstellung (Büffel)

Kanadische Indianer auf der Jagd

Überfall kanadischer Indianer

Musizierende kanadische Indianer tragen

ihren Häuptling
$\mathrm{N} 951 \mathrm{v}$

$\mathrm{N} 420 \mathrm{r}$ ?

A $960 \mathrm{r}$

A $960 v$

N 1007v

N 1011r

A $1012 r$

A $1013 r$

\section{Abbildungsverzeichnis}

\section{Tafel}

1 Brasilienkarte.- Ramusio, Delle Navigationi e viaggi, Bd. 3, 1556.

2 Indianische Darbietungen beim Einzug von Henri II in Rouen 1550 .- Abb. in: C'est la deduction [...], 1551.

3 Brasilianische Indianer.- Einblattholzschnitt "Dise Figur anzaigt ..." von ca. 1505 ("Münchner Holzschnitt").

4 Indianische Familie und Darstellung des Zerhackens des Getöteten.- Vespucci, Diß Büchlin saget, Straßburg, 1509.

5 Indianer und Kokospalme.- Thevet, Singularités, 1558 [Illustrator vermutlich Jean Cousin].

6 Vergleichbare Szene [vgl. den Qualitätsunterschied zu Tafel 5; zur Darstellung der maraca s. auch Tafel 8 (Abb. 2), 20, 22, 32, 33].- Thevet, Singularités, 1558 .

7 Abb. 1: Die Herstellung von cahouin, einem alkoholischen Getränk. Abb. 2: Essensszene mit einer Hängematte.- Beide Abb.: Thevet, Singularités, 1558.

8 Abb. 1: Der boucan (Grill der Indianer) mit Teilen eines getöteten Gefangenen; Abb. 2: Begräbnisszene.- Beide Abb.: Thevet, Singularités, 1558.

9 Abb. 1: Der “Tränengruß”, die rituelle Begrüßung von Neuangekommenen [vgl. auch Tafel 21]; Abb. 2: Eine der ersten Darstellungen des Rauchens; rechts das Feuermachen.- Beide Abb.: Thevet, Singularités, 1558.

10 Der Tupinambahäuptling Quoniambec [vgl. Tafel 11].- Holzschnitt aus Thevet, Cosmographie, 1575.

11 Der Tupinambahäuptling Quoniambec, Kupferstich [vgl. Tafel 10].- Thevet, Les vrais pourtraicts, 1584.

12 Der Häuptling Nacolabsov aus dem Stamm der canibales, Holzschnitt.- Thevet, Cosmographie, 1575.

13 Tötungsszenen [vgl. auch Tafel 14, 26 (Abb. 2)].- Abb. 1: Thevet, Singularités, 1558; Abb. 2: Thevet, Cosmographie, 1575. 
Tötungsszene [vgl. Tafel 13].- Léry, Histoire, 1585.

Kämpfe zwischen verfeindeten brasilianischen Indianern [vgl. Tafel 16].- Abb. 1: Thevet, Singularités, 1558. Abb. 2: Thevet, Cosmographie, 1575.

Kampfszene mit brasilianischen Indianern [vgl. Tafel 15].- Léry, Histoire, 1585.

Indianisches Paar [vgl. Tafel 18].- Weigel, Habitus praecipuorum populorum, 1577, Abb. 181.

Indianisches Paar [vgl. Tafel 17].- Léry, Histoire, 1585.

9 Zwei Krieger mit Pfeil und Tötungskeule.- Léry, Histoire, 1585.

Zwei Tänzer, einer davon mit der maraca [zur maraca vgl. auch Tafel 6, 8 (Abb. 2), 22, 32, 33].- Léry, Histoire, 1585.

1 Der "Tränengruß”, die rituelle Begrüßung von Gästen [s. auch Tafel 9, Abb. 1].Léry, Histoire, 1585.

Die Trauer um einen toten Angehörigen.- Léry, Histoire, 1585.

3 Abb. 1: Der Gefangene wird bei seinem Eintreffen im Dorf von den Indianerfrauen beschimpft. Abb. 2: Der Gefangene führt einen rituellen Tanz aus.- Beide Abb.: Staden, Warhafftige Historia, 1557, 1. Buch, Kap. 22; 24.

4 Abb. 1: Die Tötungskeule und der Strick, mit dem der Gefangene gefesselt wird. Abb. 2: Der Grill und die Verspeisung des Getöteten.- Beide Abb.: Staden, Warhafftige Historia, 1557, 2. Buch, Kap. 29.

Abb. 1: Die Bemalung des Gefangenen und der Tötungskeule. Abb. 2: Der rituelle Tanz um die Tötungskeule.- Beide Abb.: Staden, Warhafftige Historia, 1557, 2. Buch, Kap. 29.

Abb. 1: Der Gefangene nimmt während des Rituals an einem Trinkgelage teil. Abb. 2: Die Tötung des Gefangenen [vgl. Tafel 13, 14, 35].- Beide Abb.: Staden, Warhafftige Historia, 1557, 2. Buch, Kap. 29.

27 Abb. 1: Die Zerteilung seines Körpers. Abb. 2: Die Frauen verspeisen den Sud aus seinen Eingeweiden.- Beide Abb.: Staden, Warhafftige Historia, 1557, 2. Buch, Kap. 29.

28 Abb. 1: Der Kopf wird in einen Topf geworfen; rechts die Gestalt Stadens $[H$. S.].- Staden, Warhafftige Historia, 1557, 2. Buch, Kap. 29. Abb. 2: Zwei Indianer mit Waffen und Kriegsschmuck [Deckblatt des 2. Buchs].

29 Selbstporträt von Theodor de Bry [Kupferstich].- Dresden, Kupferstichkabinett (B 1554, 2, S. 6).

30 Selbstporträt von Johann Theodor de Bry [Kupferstich von 1615].- Boissard, Bibliotheca chalcographica, 1650-54.

1 Darstellung des Sündenfalls [Kupferstich].- America (lat.), Vorblatt zu Bd. 3, Frankfurt, 1592 [u. zu Bd. 1, lat. 1590].

32 Titelkupfer.- America (lat.), Bd. 3, Frankfurt, 1592 [u. Bd. 7, lat. 1599]. 
33 Der Gefangene nimmt an einem Festmahl anläßlich der Zeremonien seiner Tötung teil.- America (lat.), Bd. 3 [Staden, 2. Buch], Frankfurt, 1592.

34 Die Bemalung des Gefangenen und der Tötungskeule.- America (lat.), Bd. 3 [Staden, 2. Buch], Frankfurt, 1592.

35 Tötung des Gefangenen.-America (lat.), Bd. 3 [Staden, 2. Buch], Frankfurt, 1592.

36 Der Totschläger entfernt sich. Frauen weiden den Körper aus.- America (lat.), Bd. 3 [Staden, 2. Buch; Wiederholung im Léryteil], Frankfurt, 1592.

37 Die Zerteilung des toten Körpers.- America (lat.), Bd. 3 [Staden, 2. Buch], Frankfurt, 1592.

38 Frauen und Kinder verspeisen den Sud und die Eingeweide des Toten.- America (lat.), Bd. 3 [Staden, 2. Buch], Frankfurt, 1592.

39 Der Grill und die Verspeisung des Getöteten. Im Hintergrund die Gestalt Stadens.-America (lat.), Bd. 3 [Léryteil], Frankfurt, 1592.

40 Ein ritueller Tanz der Indianer, Schamanen blasen Tabakrauch auf die Tänzer.America (lat.), Bd. 3 [Léryteil], Frankfurt, 1592.

41 Teufelserscheinungen [vgl. Tafel 42-44].- Léry, Histoire, 1585.

42 Teufelserscheinungen [vgl. Tafel 41, 43, 44].- America (lat.), Bd. 3 [Léryteil], Frankfurt, 1592.

43 Replik auf die Abbildung der Teufelserscheinungen bei Léry und Bry [s. auch Tafel 41, 42, 44].- Gottfried, Historia antipodum, 1631.

44 Teufelserscheinungen nach Léry, Bry und Merian [vgl. Tafel 41-43].- P. van der Aa, Naaukeurige versameling, Bd. XV, 1706.

\section{Verzeichnis der Tabellen}

Tab. 1: Die Illustrationen der Singularités und ihre Übernahme in der Cosmographie - Zuordnung zu verschiedenen Künstlern

Tab. 2: Die Illustrationen in Lérys Histoire d'un voyage

Tab. 3: Illustrationen zur Religion und zur Anthropophagie in Brys America, Bd. 3 


\section{Nachweis der Rechte}

\section{Tafel Abbildung}

1 Ramusio, Delle Navigationi e viaggi, Bd. 3, 1556: UB Freiburg.

2 C'est la deduction [...], 1551: Bibliothèque municipale Rouen, photographe: Didier Tragin.

3 [Vespucci:] Dise Figur anzaigt ("Münchner Holzschnitt” von 1505): BSB München.

$4 \quad$ Vespucci, Diß Büchlin saget, Straßburg, 1509: WLB Stuttgart.

5-9 Thevet, Singularités, 1558: Brasilienbibliothek, Bosch AG, Stuttgart (soweit identisch mit der Cosmographie stammen die Abbildungen aus der Cosmographie, Paris, L'Huillier, 1575: Stadtbibliothek Augsburg).

10 Thevet, Cosmographie, L'Huillier, 1575: Stadtbibliothek Augsburg.

11 Thevet, Les vrais pourtraicts, 1584: Stadtbibliothek Nürnberg.

12 Thevet, Cosmographie, L'Huillier, 1575: Stadtbibliothek Augsburg.

13 Tötungsszenen: Thevet, Singularités, 1558: Brasilienbibliothek, Bosch AG, Stuttgart; Thevet, Cosmographie, L'Huillier 1575: Stadtbibliothek Augsburg.

14 Tötungsszene: Léry, Histoire, 1585: UB Erlangen.

15 Kampfszene: Thevet, Singularités, 1558: Brasilienbibliothek, Bosch AG, Stuttgart; Thevet, Cosmographie, L'Huillier, 1575: Stadtbibliothek Augsburg.

16 Kampfszene: Léry, Histoire, 1585: UB Erlangen.

17 Weigel, Habitus praecipuorum populorum, 1577: BSB München.

18-22 Léry, Histoire, 1585: UB Erlangen.

23-28 Staden, Wahrhaftige Historia, 1557. Hg. von Maack und Fouquet, Marburg, 1964, Verlag Trautvetter und Fischer.

29 Theodor de Bry, Portrait, Kupferstichsammlung Dresden (B 1554, 2, S. 6), Fotograf: R. Richter.

30 Johann Theodor de Bry, in: Boissard, Bibliotheca chalcographica, 1650-54: UB Freiburg.

31 Vorblatt zu Bry, America (lat.), Bd. 3, Frankfurt, 1592: UB Erlangen.

32 Titelkupfer.- Bry, America (lat.), Bd. 3, Frankfurt, 1592: UB Erlangen.

33-40 Bry, America (lat.), Bd. 3, Frankfurt, 1592: UB Erlangen.

41 Teufelserscheinungen: Léry, Histoire, 1585: UB Erlangen.

42 Teufelserscheinungen: Bry, America (lat.), Bd. 3, Frankfurt, 1592: UB Erlangen.

43 Replik auf die Abbildung der Teufelserscheinungen: Gottfried, Historia antipodum, 1631: UB Eichstätt.

44 Teufelsdarstellung in: Van der Aa, Naaukeurige versameling, 1706: UB Erlangen. 
Bildtafeln 


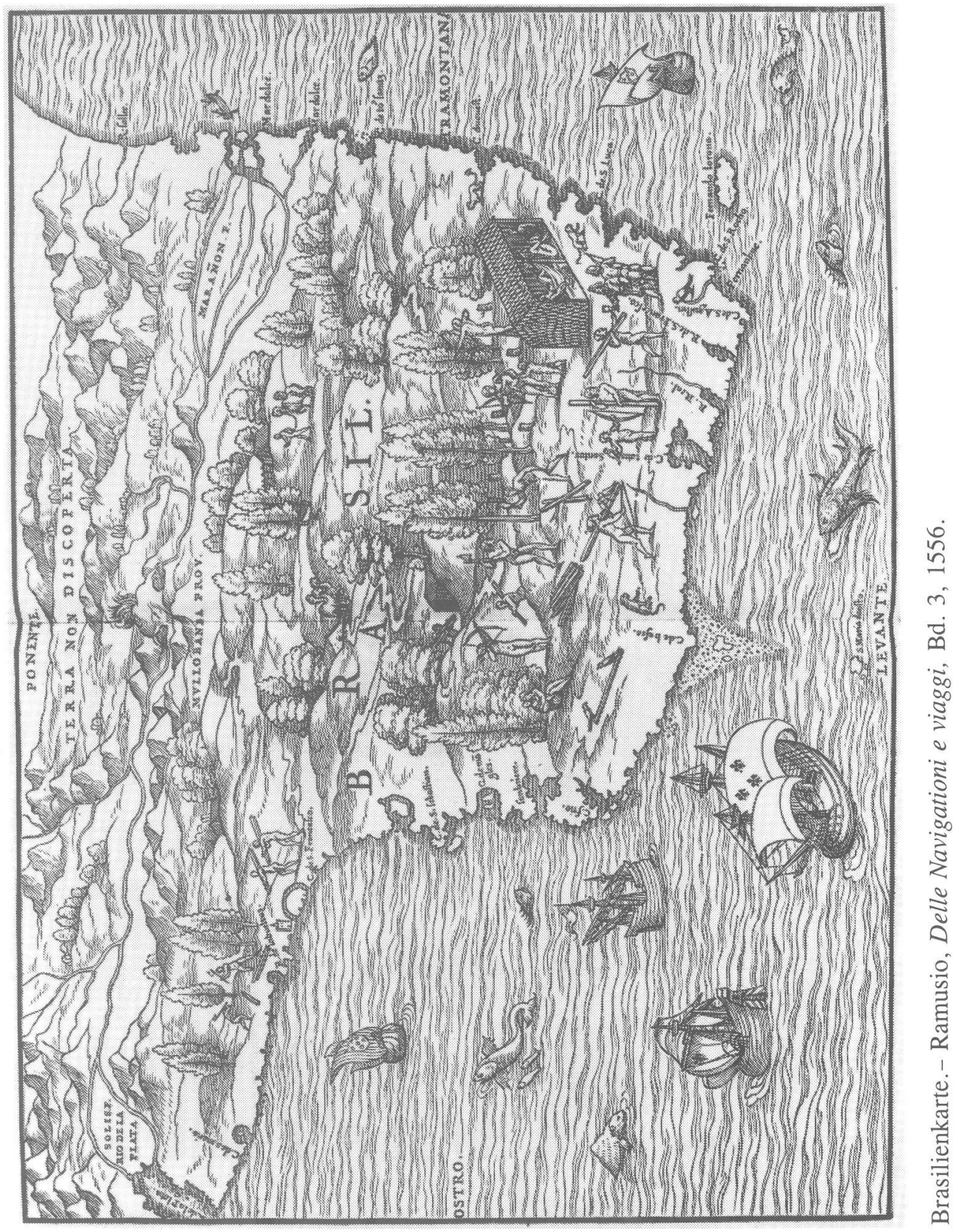




\section{TAFEL 2}

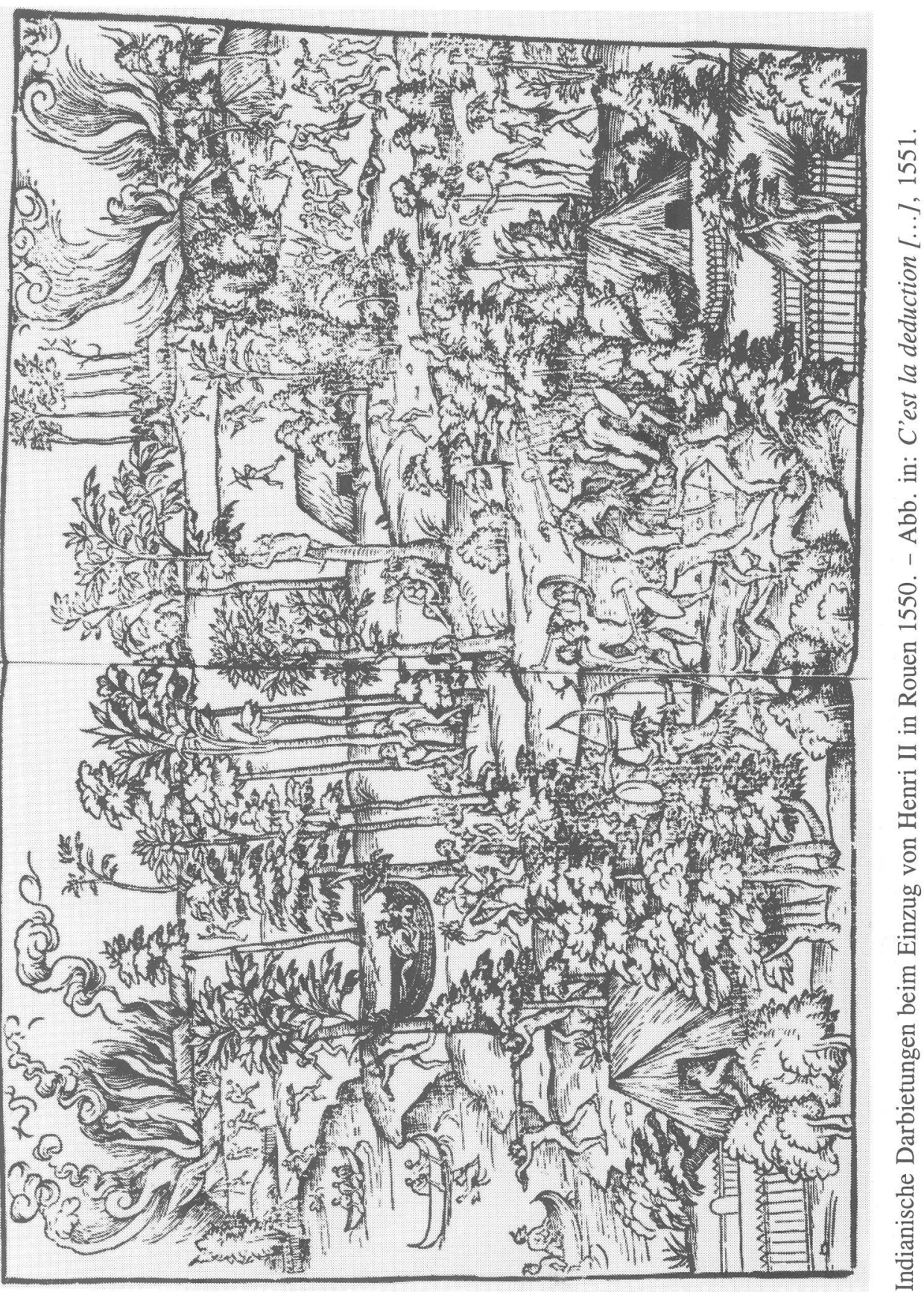




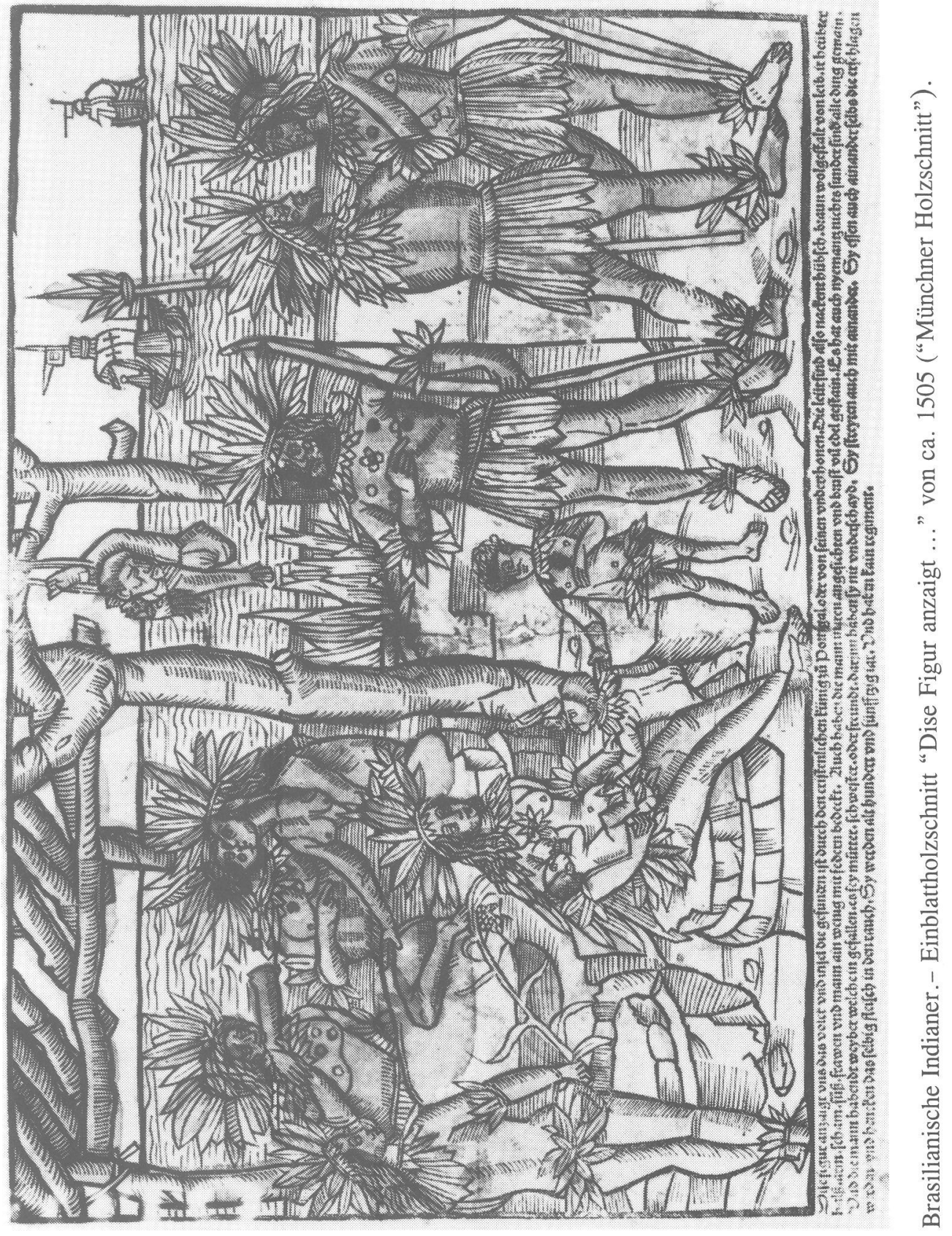




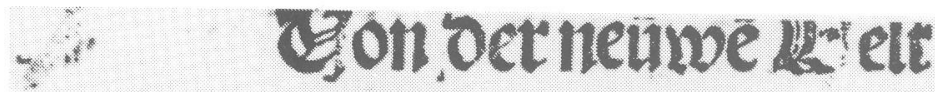

vint6 weld’es wille wir Sanurzemal nit wentig Beluftiget. gewefent, Doit welder leíte fitten ( Da wit fie Baben gefes Ben/ Gond wir die feitmal die Bequemliticiefis begibe/ auró pinderweil ketein wôllen jiefert.

\section{Gon irêlebeniono /atten}

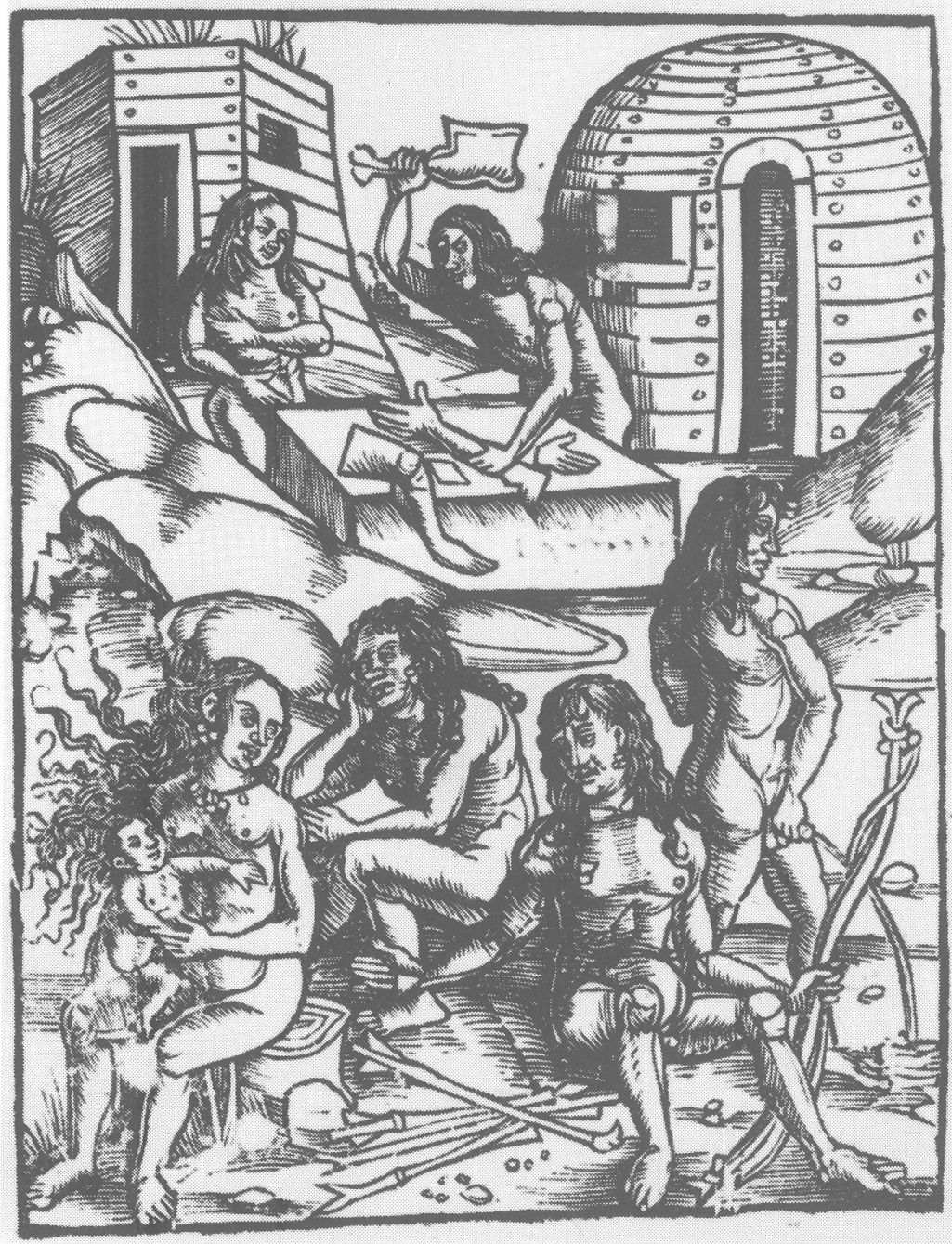

Indianische Familie und Darstellung des Zerhackens des Getöteten.Vespucci, Diß Büchlin saget, Straßburg, 1509. 


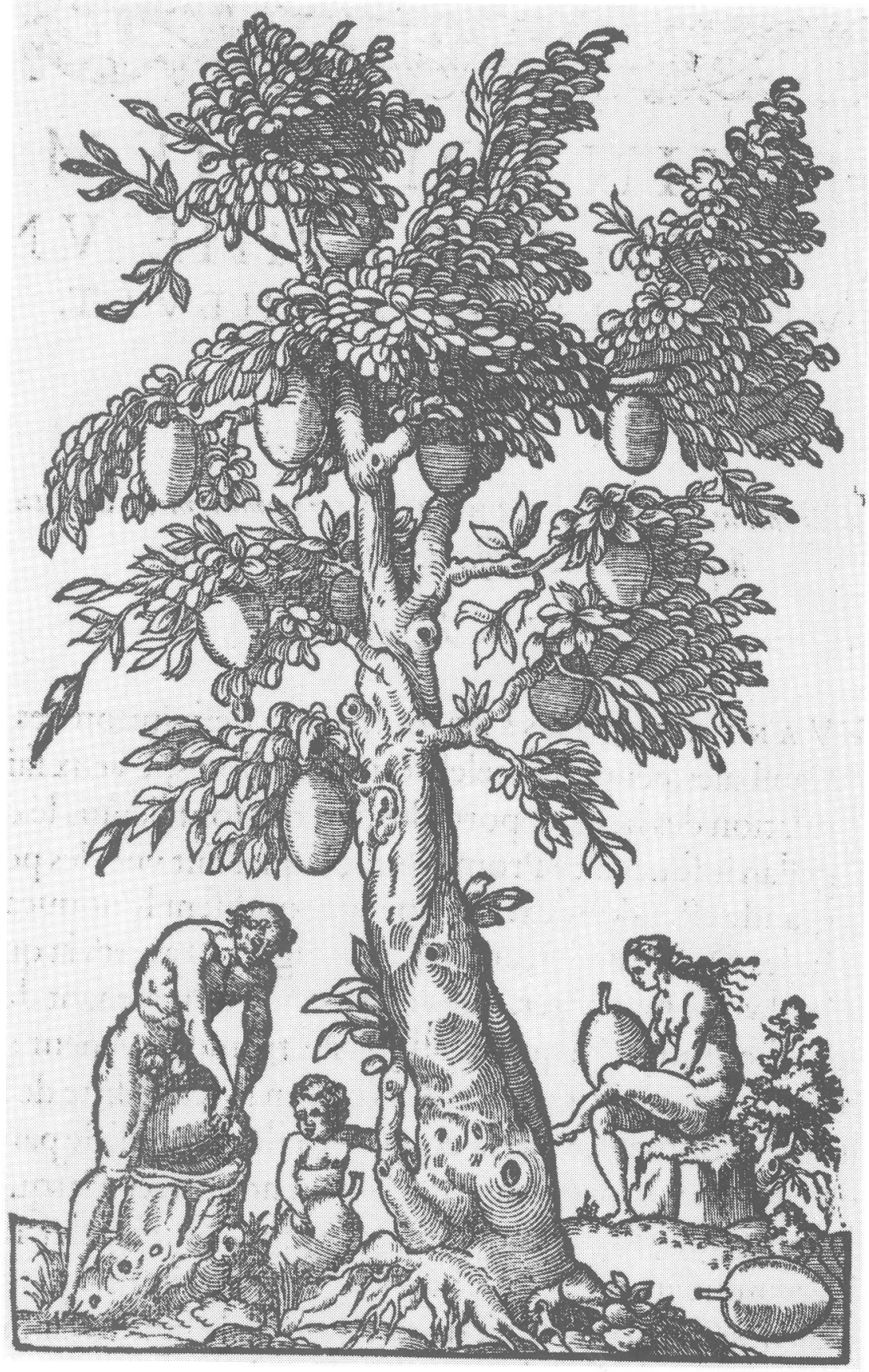

Indianer und Kokospalme.- Thevet, Singularités, 1558 [Illustrator vermutlich Jean Cousin]. 


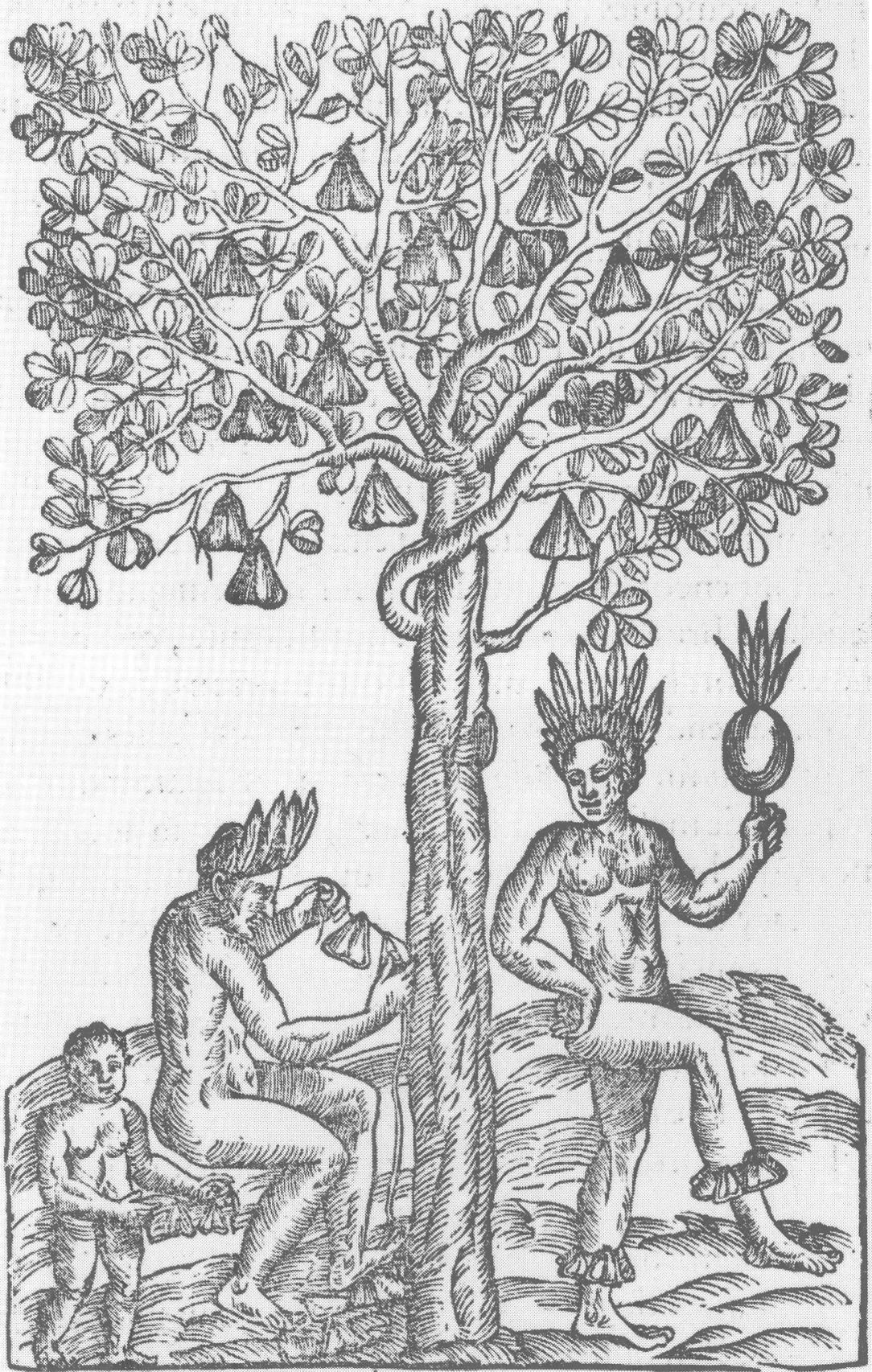

Vergleichbare Szene [vgl. den Qualitätsunterschied zu Tafel 5; zur Darstellung der maraca s. auch Tafel 8 (Abb. 2), 20, 22, 32, 33].- Thevet, Singularités, 1558. 

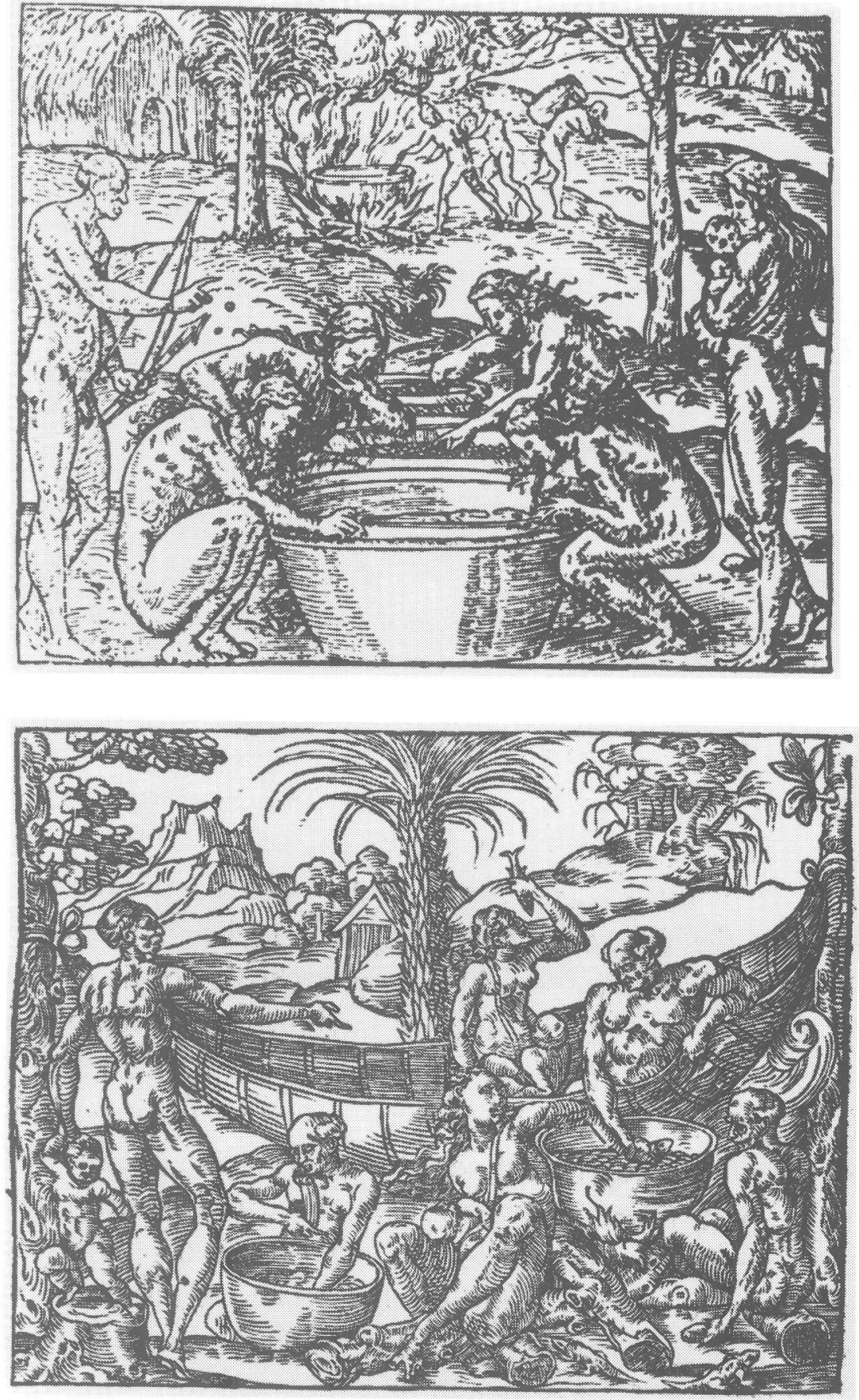

Abb. 1: Die Herstellung von cahouin, einem alkoholischen Getränk.

Abb. 2: Essensszene mit Hängematte.- Beide Abb.: Thevet, Singularités, 1558. 


\section{TAFEL 8}
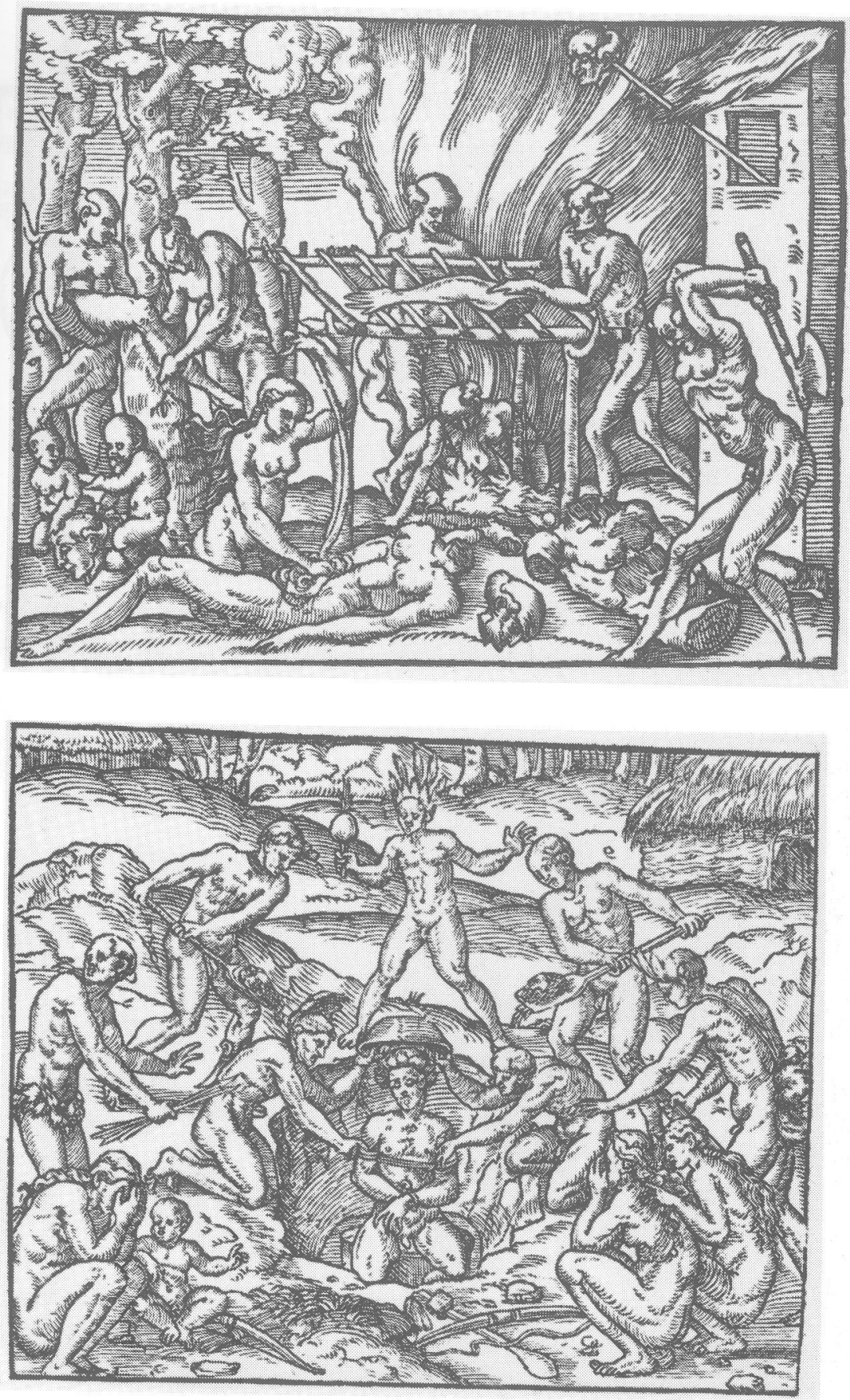

Abb. 1: Der boucan (Grill der Indianer) mit Teilen eines getöteten Gefangenen. Abb. 2: Begräbnisszene.- Beide Abb.: Thevet, Singularités, 1558. 


\section{TAFEL 9}
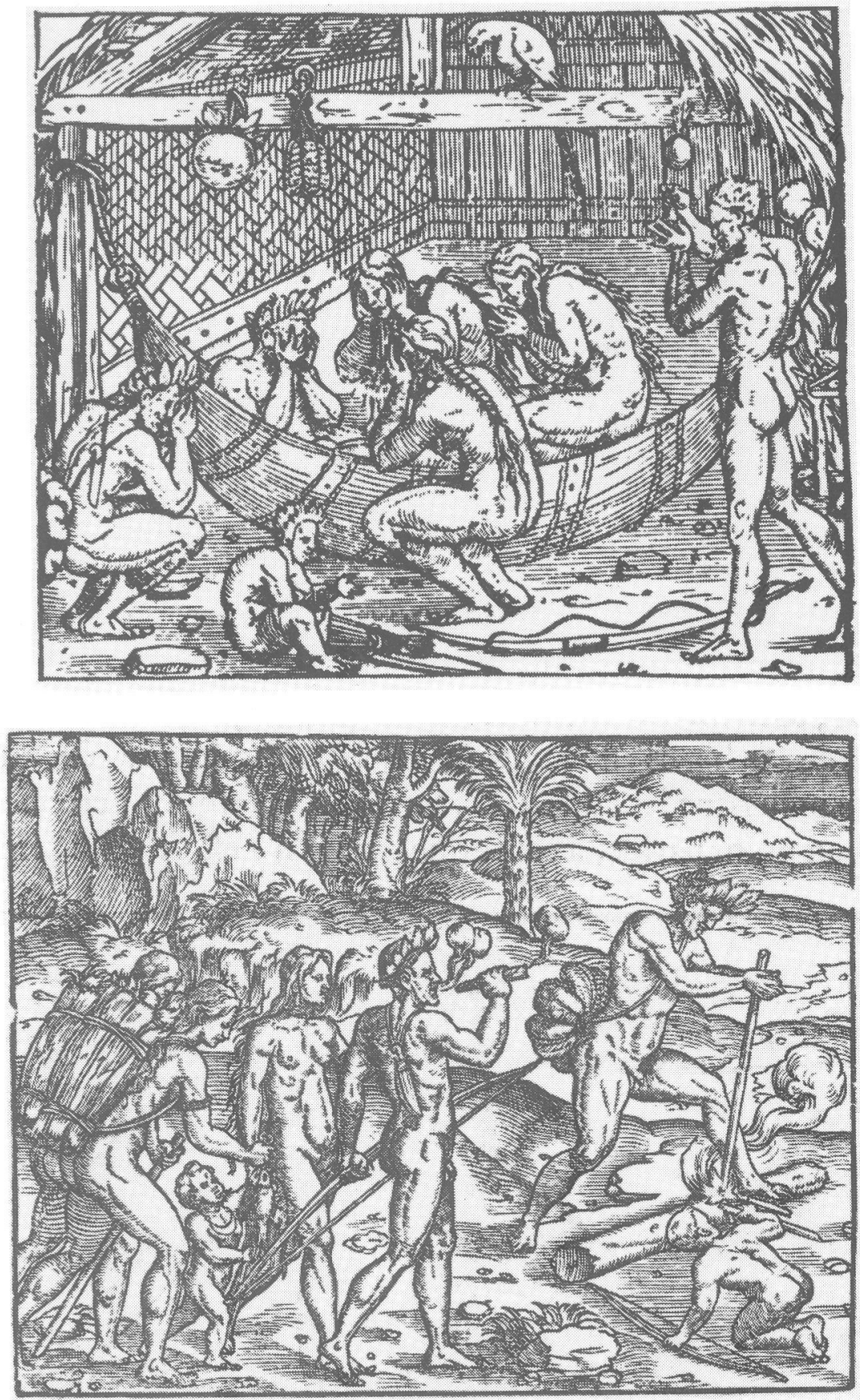

Abb. 1: Der "Tränengruß”, die rituelle Begrüßung von Neuangekommenen [vgl. auch Tafel 21]. Abb. 2: Eine der ersten Darstellungen des Rauchens; rechts das Feuermachen.- Beide Abb.: Thevet, Singularités, 1558. 


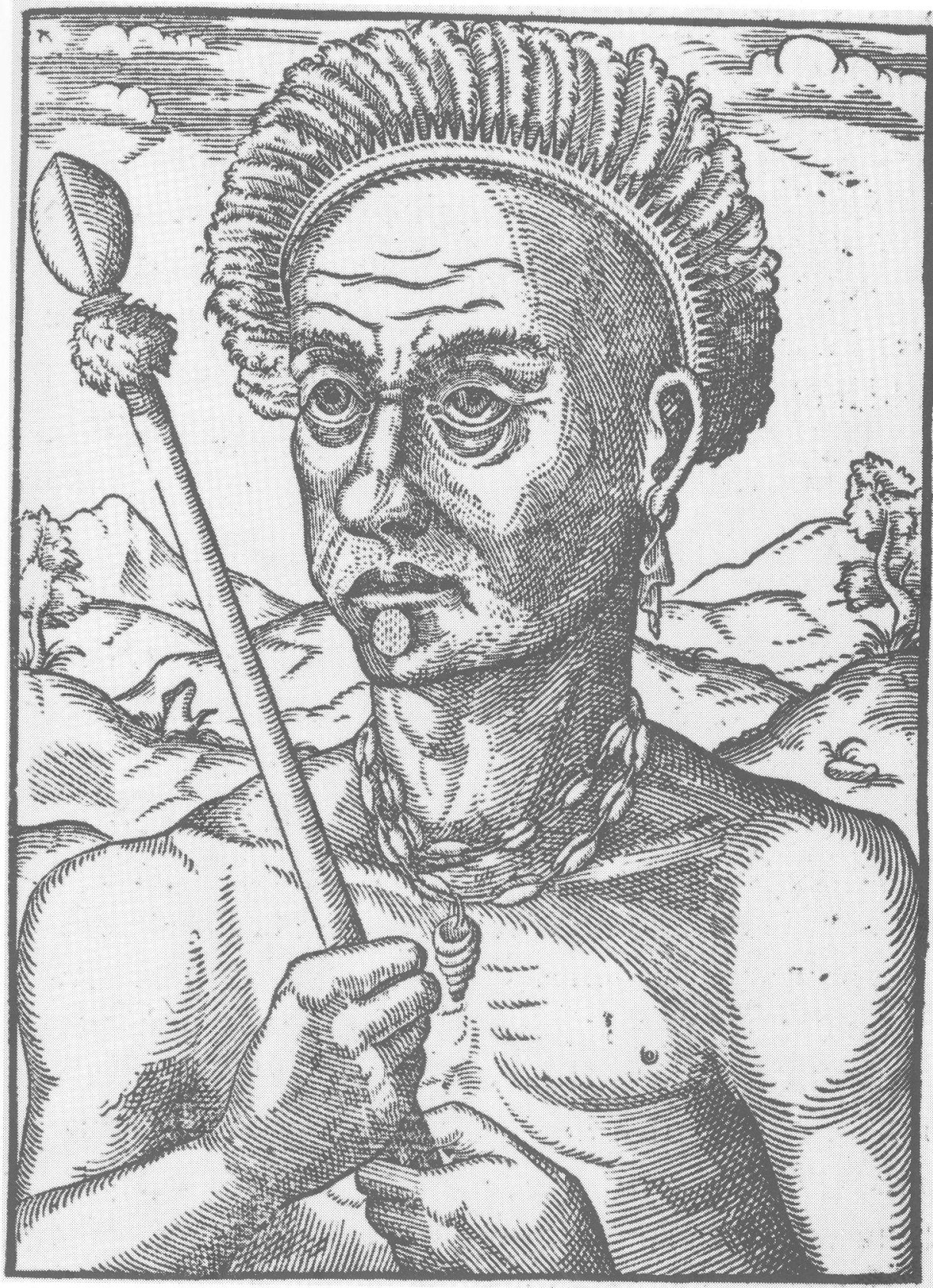

Der Tupinambahäuptling Quoniambec [vgl. Taf. 11].- Holzschnitt aus Thevet, Cosmographie, 1575. 


\section{De A. Theuet, Liure VIIII.}

\section{QVONIAMBEC.}

\section{Chapitre. 149.}

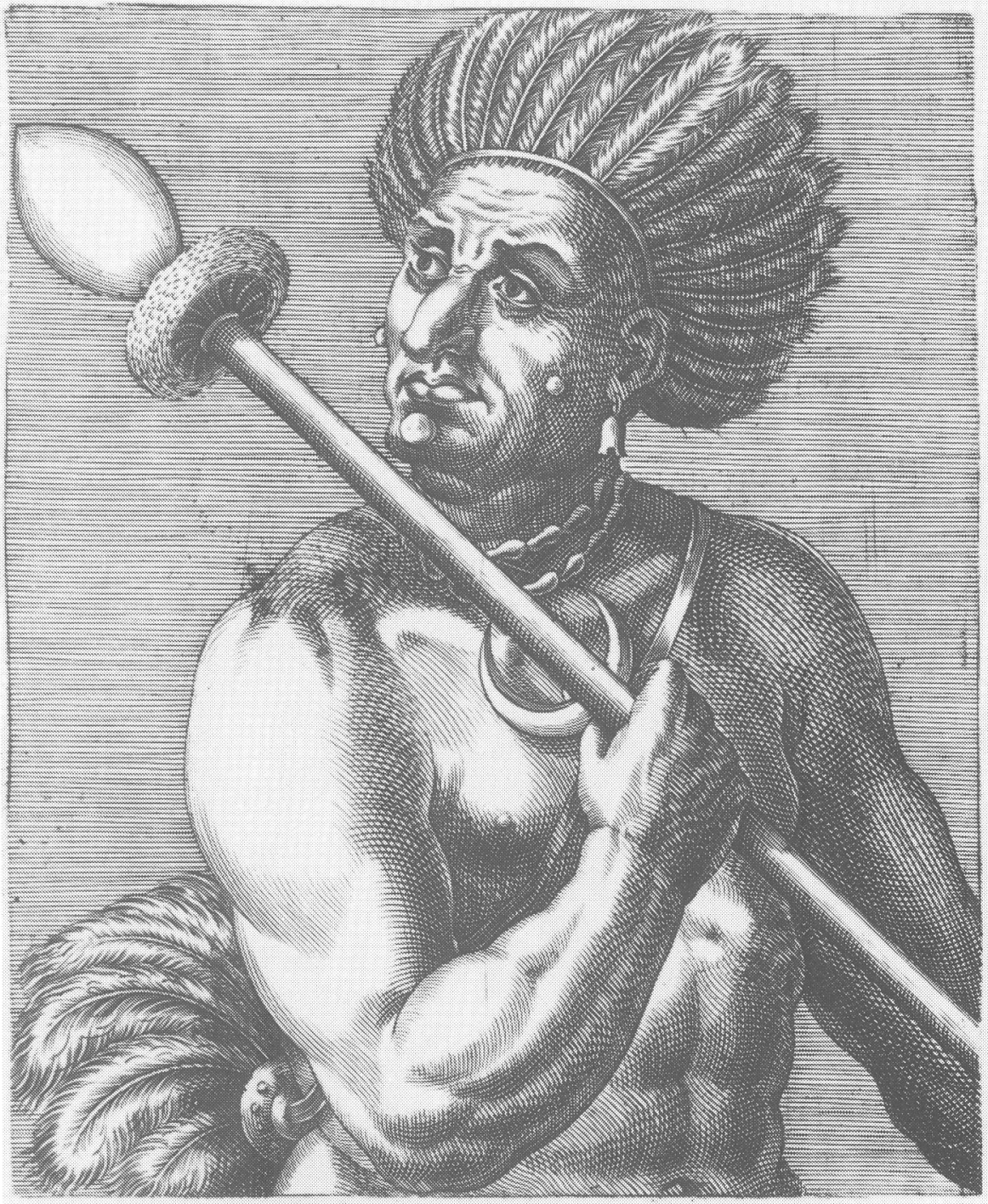

Der Tupinambahäuptling Quoniambec, Kupferstich [vgl. Tafel 10].- Thevet, Les vrais pourtraicts, 1584. 


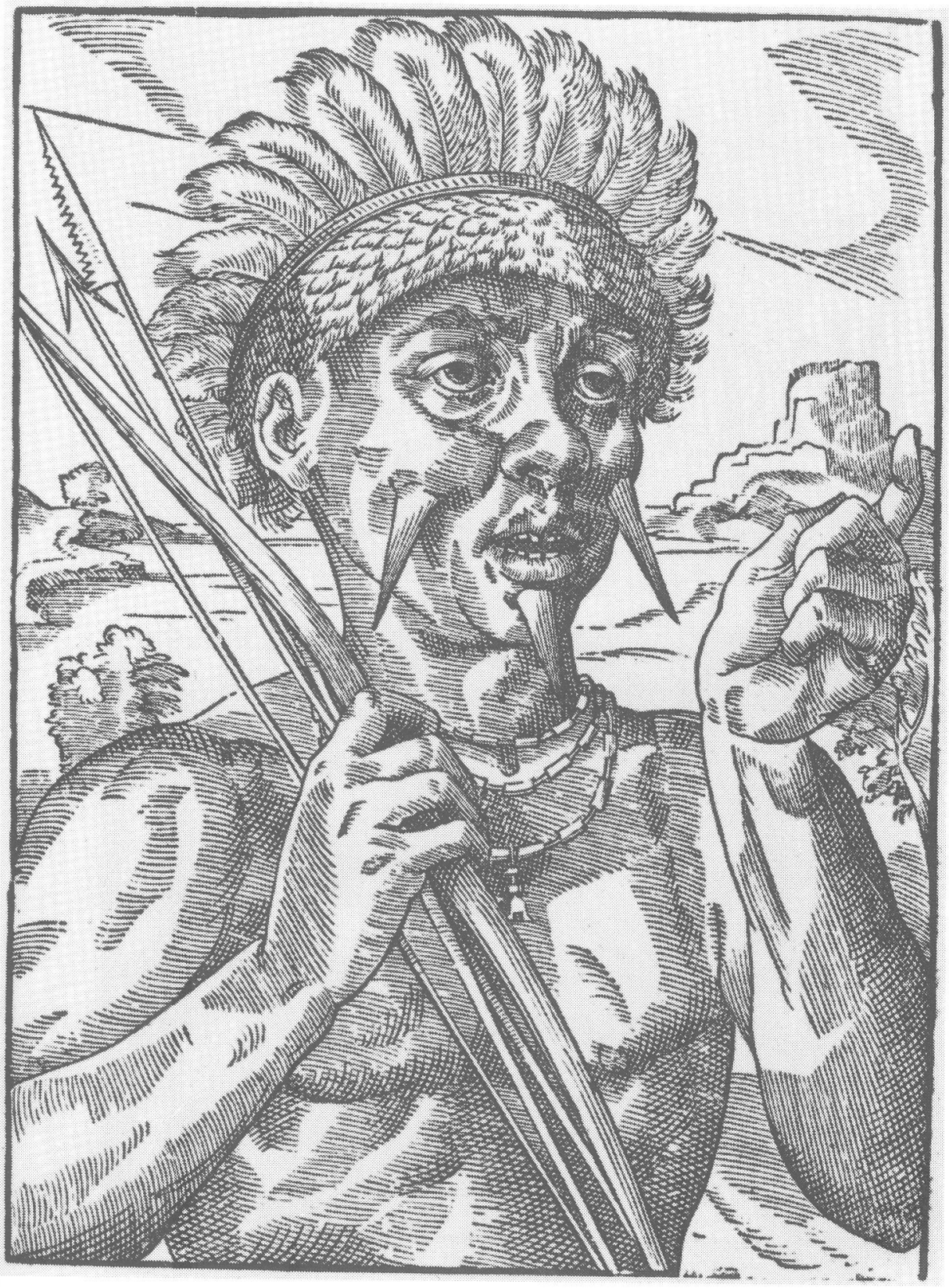

Der Häuptling Nacolabsov aus dem Stamm der canibales, Holzschnitt.- Thevet, Cosmographie, 1575. 

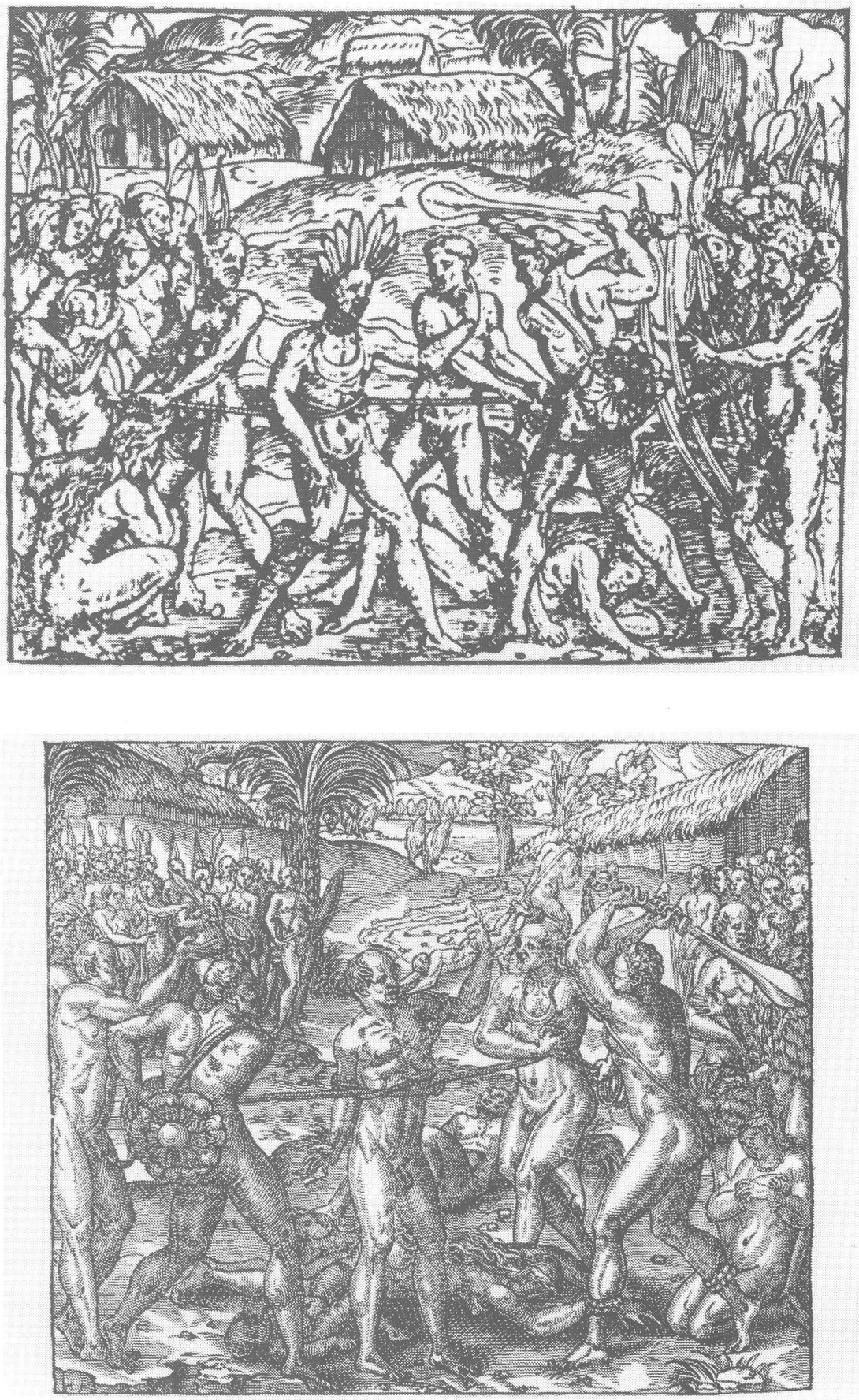

Tötungsszenen [vgl. auch Tafel 14 u. Tafel 26, Abb. 2].- Abb.1: Thevet, Singularités, 1558. Abb. 2: Thevet, Cosmographie, 1575. 


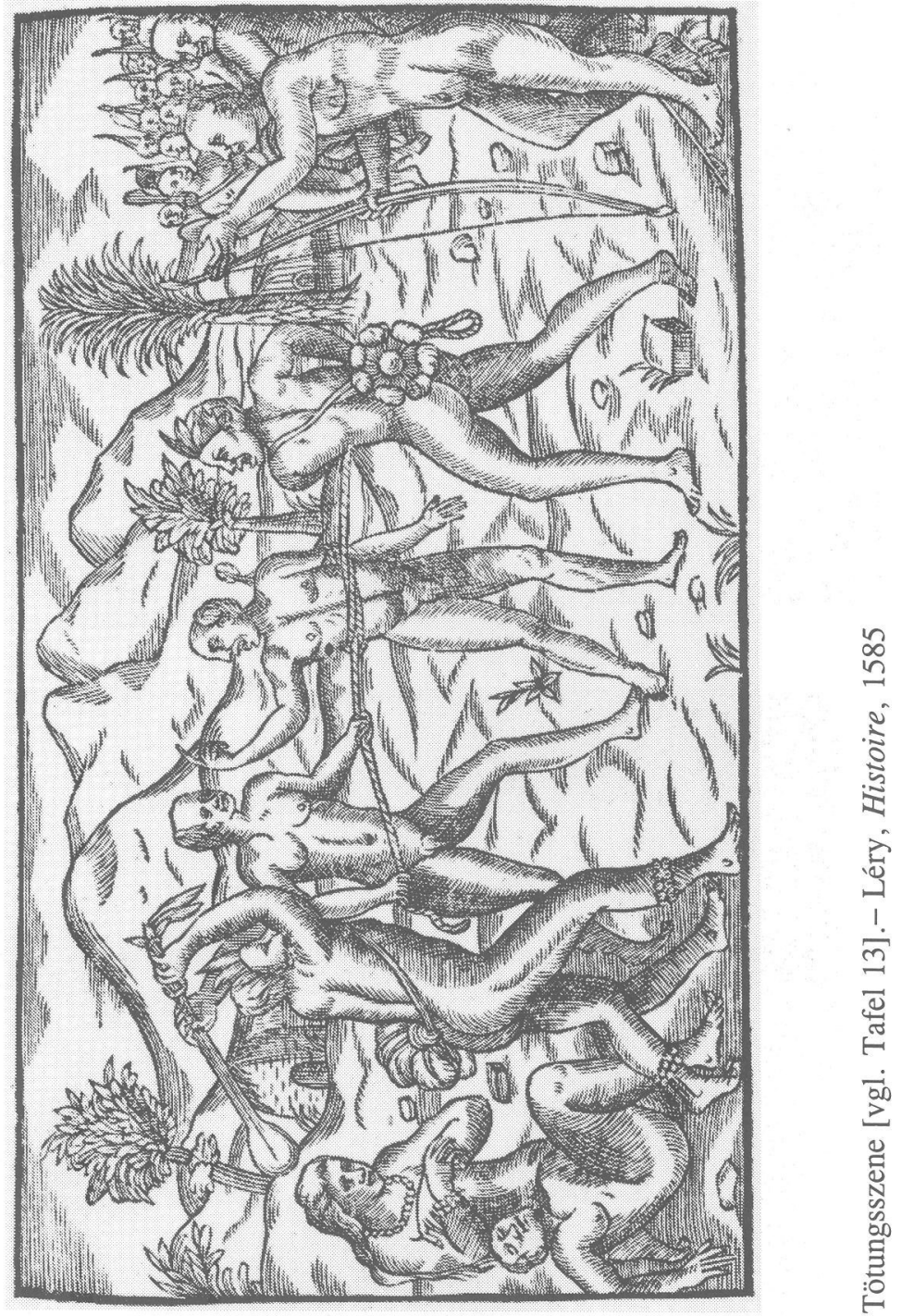



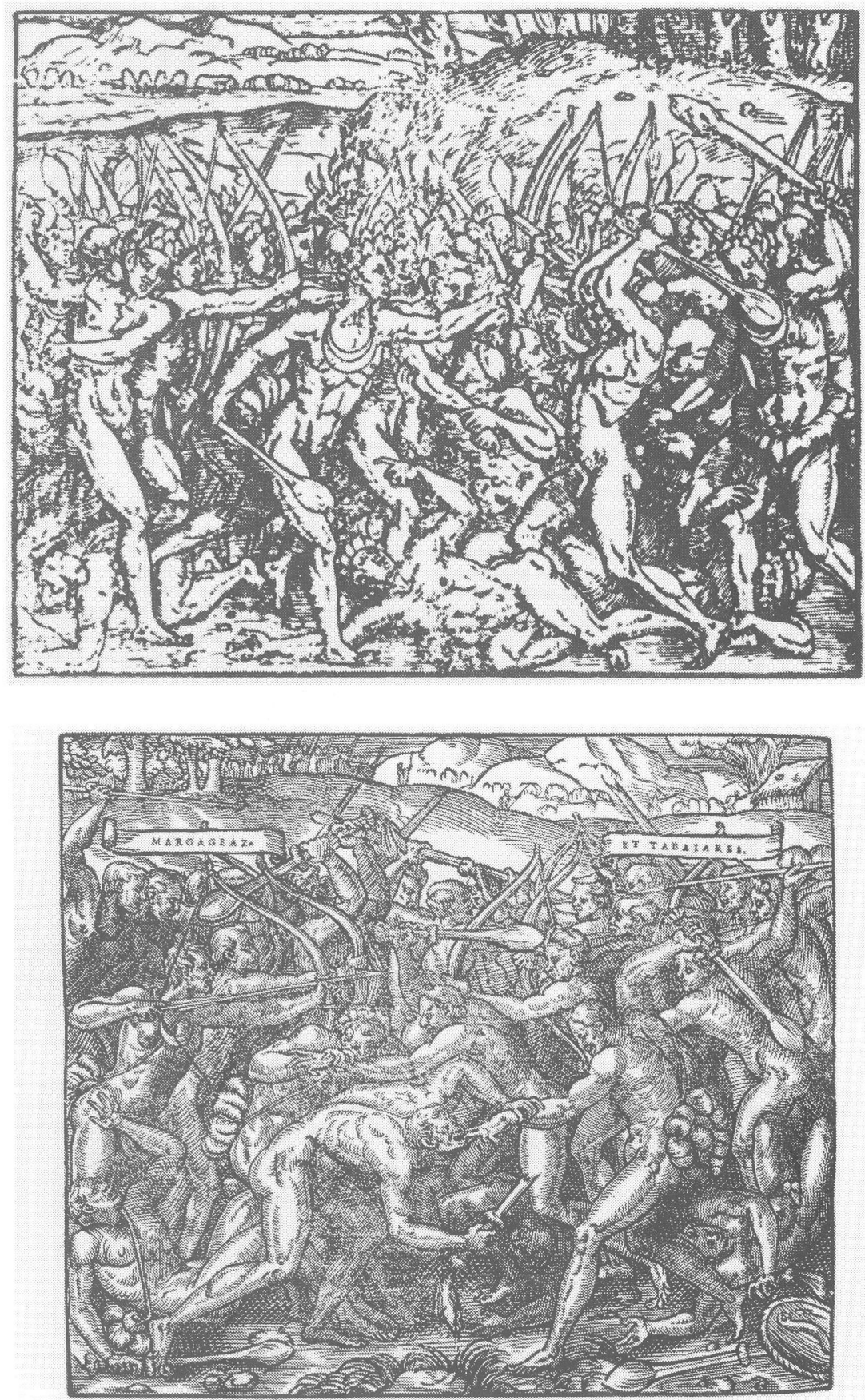

Kämpfe zwischen verfeindeten brasilianischen Indianern [vgl. Tafel 16].Abb. 1: Thevet, Singularités, 1558. Abb. 2: Thevet, Cosmographie, 1575 


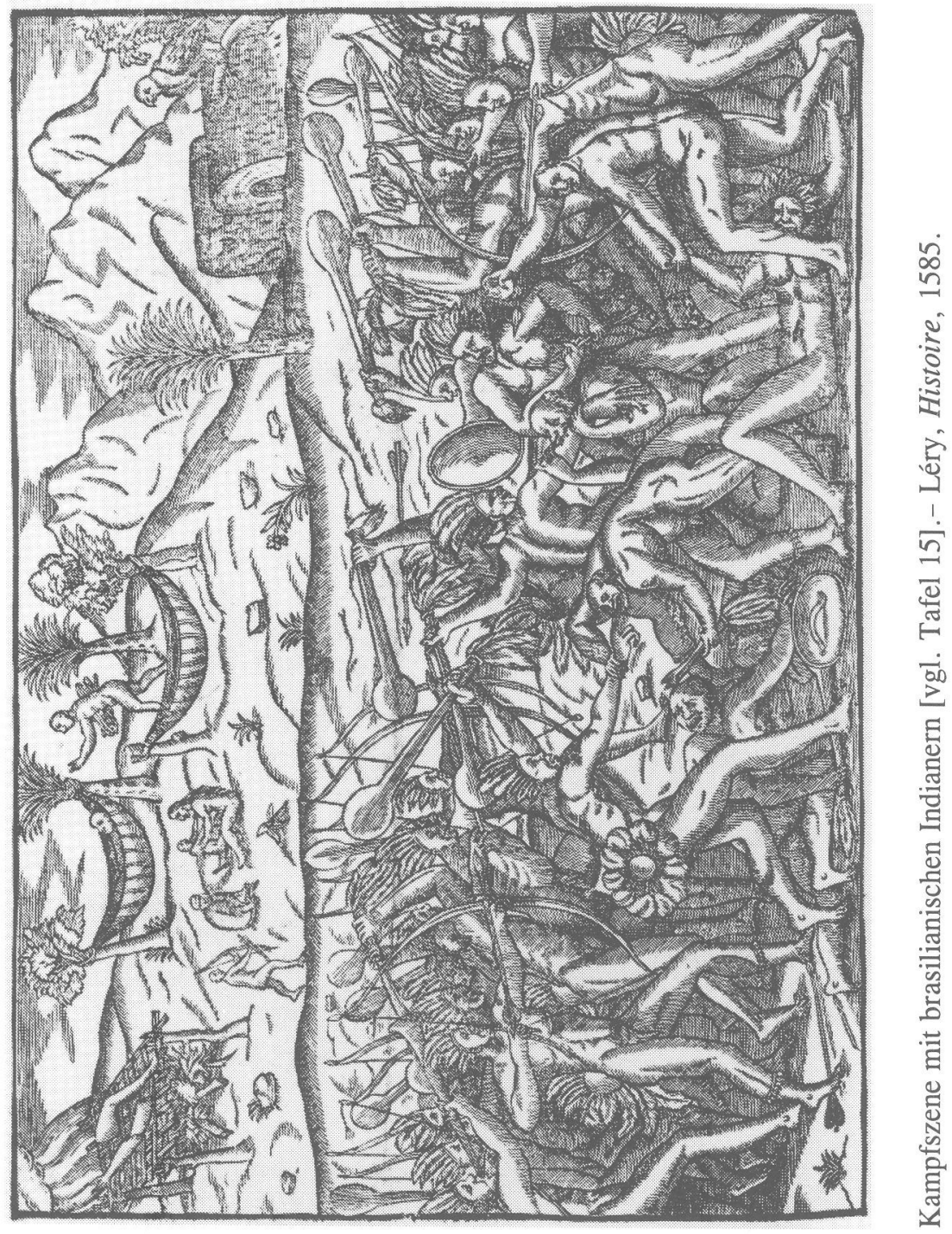




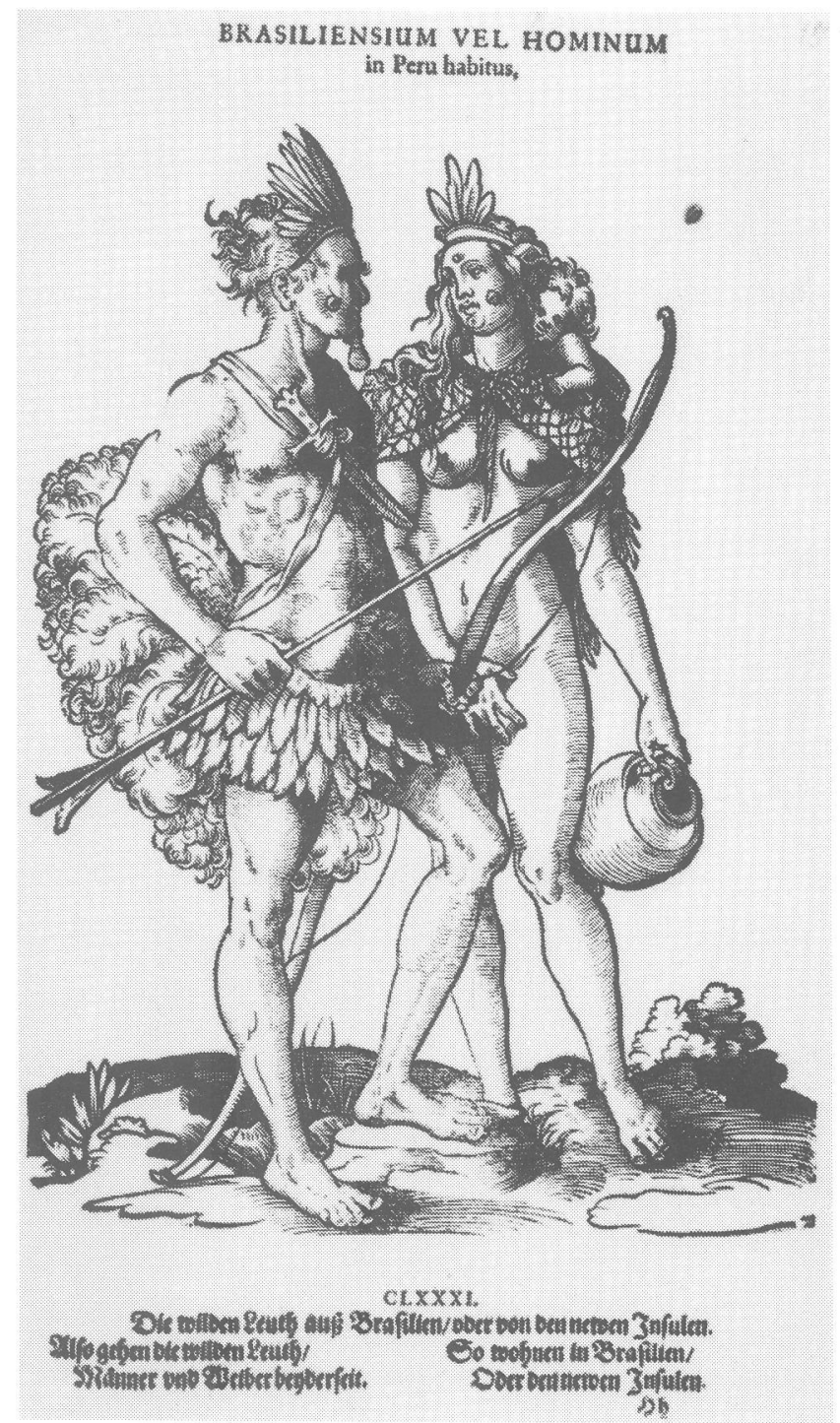

Indianisches Paar [vgl. Tafel 18].- Weigel, Habitus praecipuorum populorum, 1577, Abb. 181. 


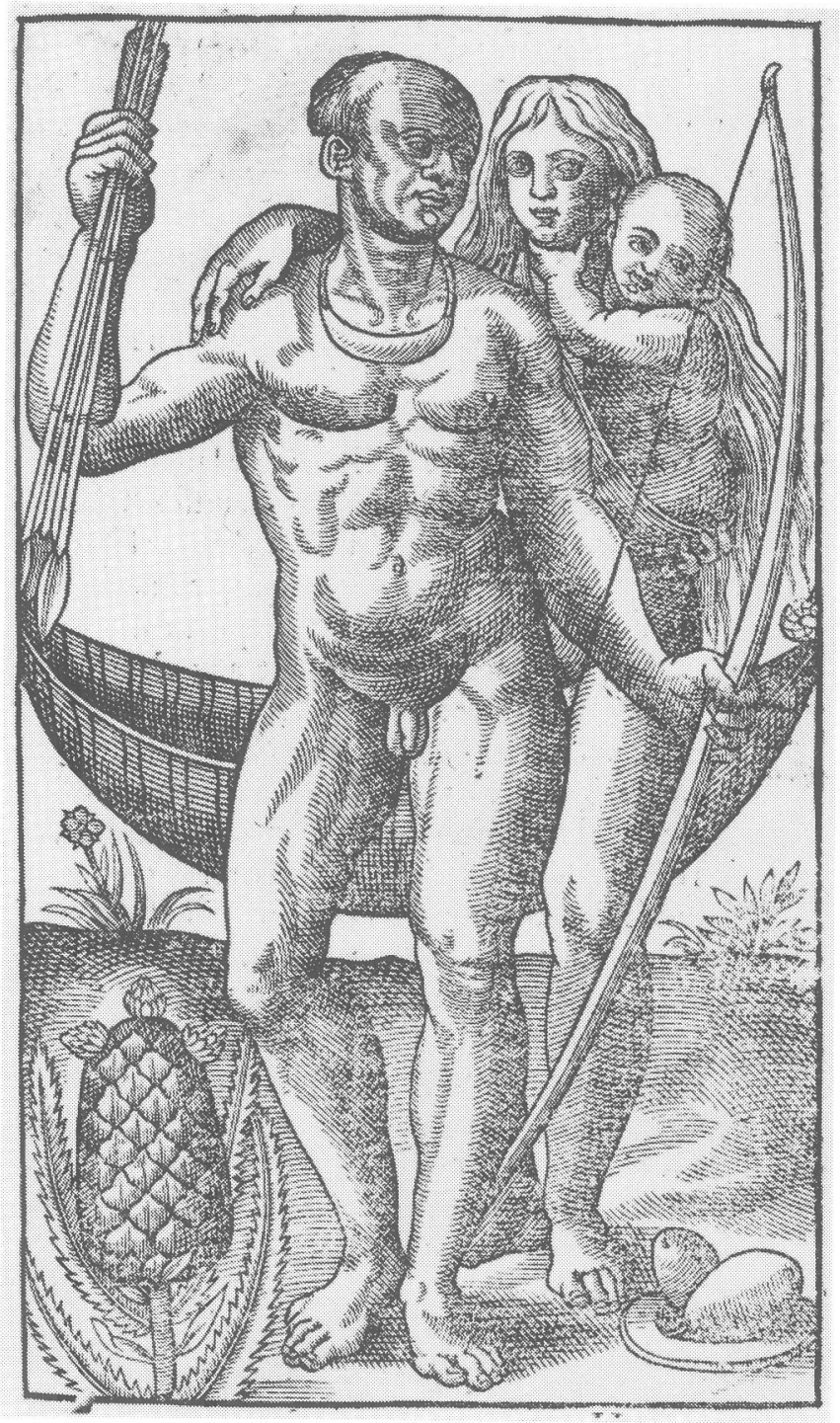

Indianisches Paar [vgl. Tafel 17].- Léry, Histoire, 1585. 


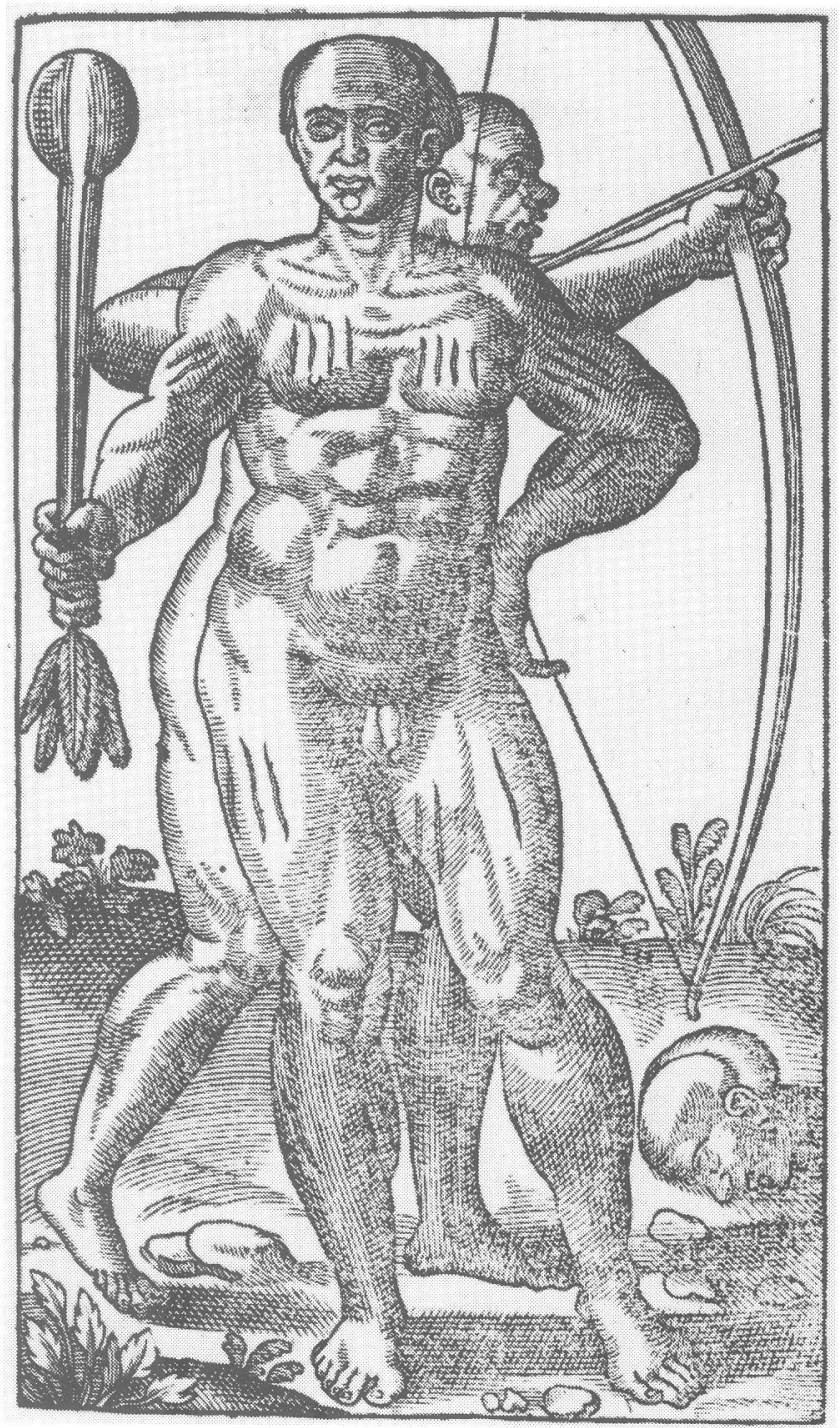

Zwei Krieger mit Pfeil und Tötungskeule.- Léry, Histoire, 1585. 


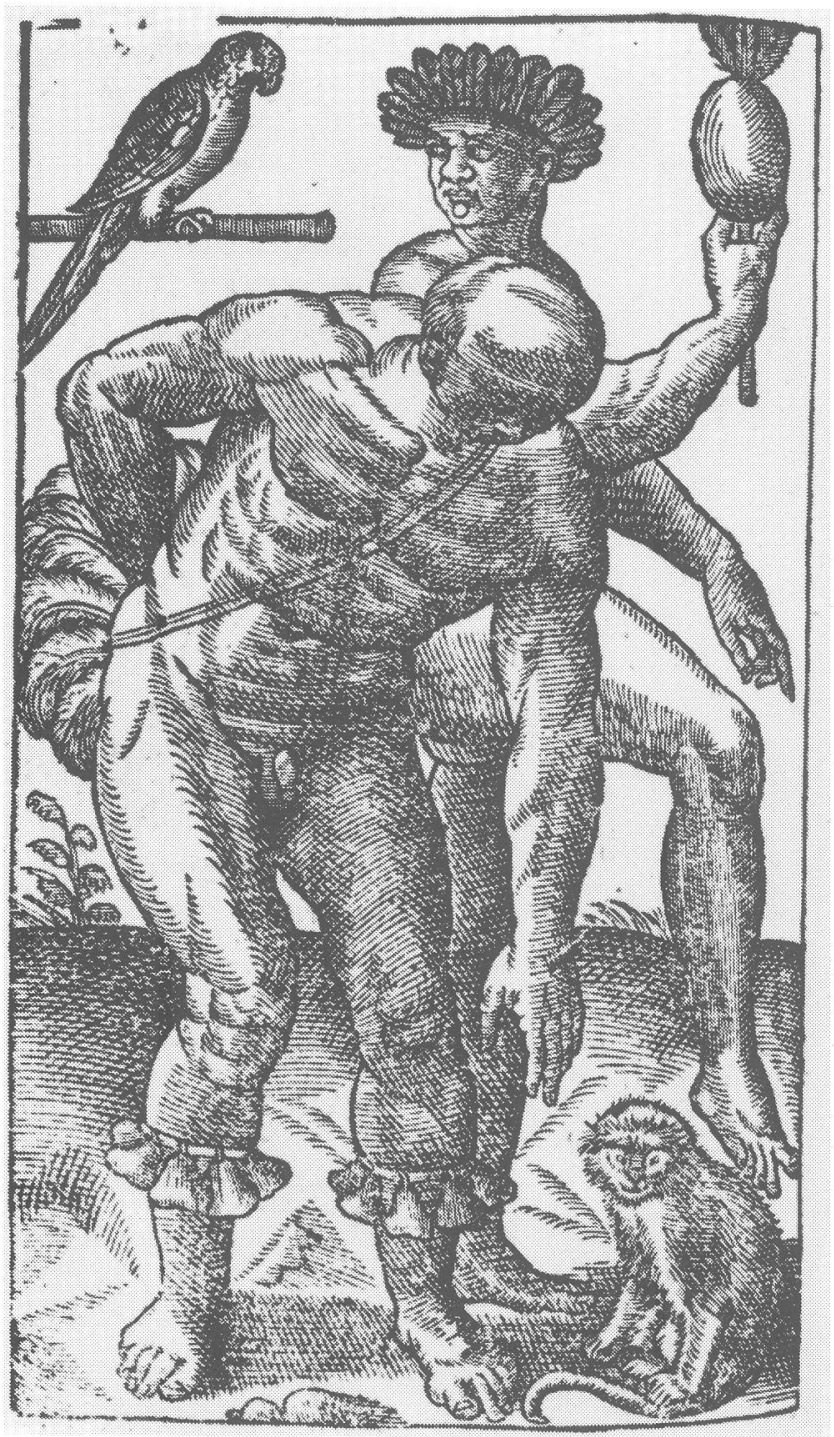

Zwei Tänzer, einer davon mit der maraca [zur maraca vgl. auch Tafel 6, 8 (Abb. 2), 22, 32, 33].- Léry, Histoire, 1585. 


\section{TAFEL 21}

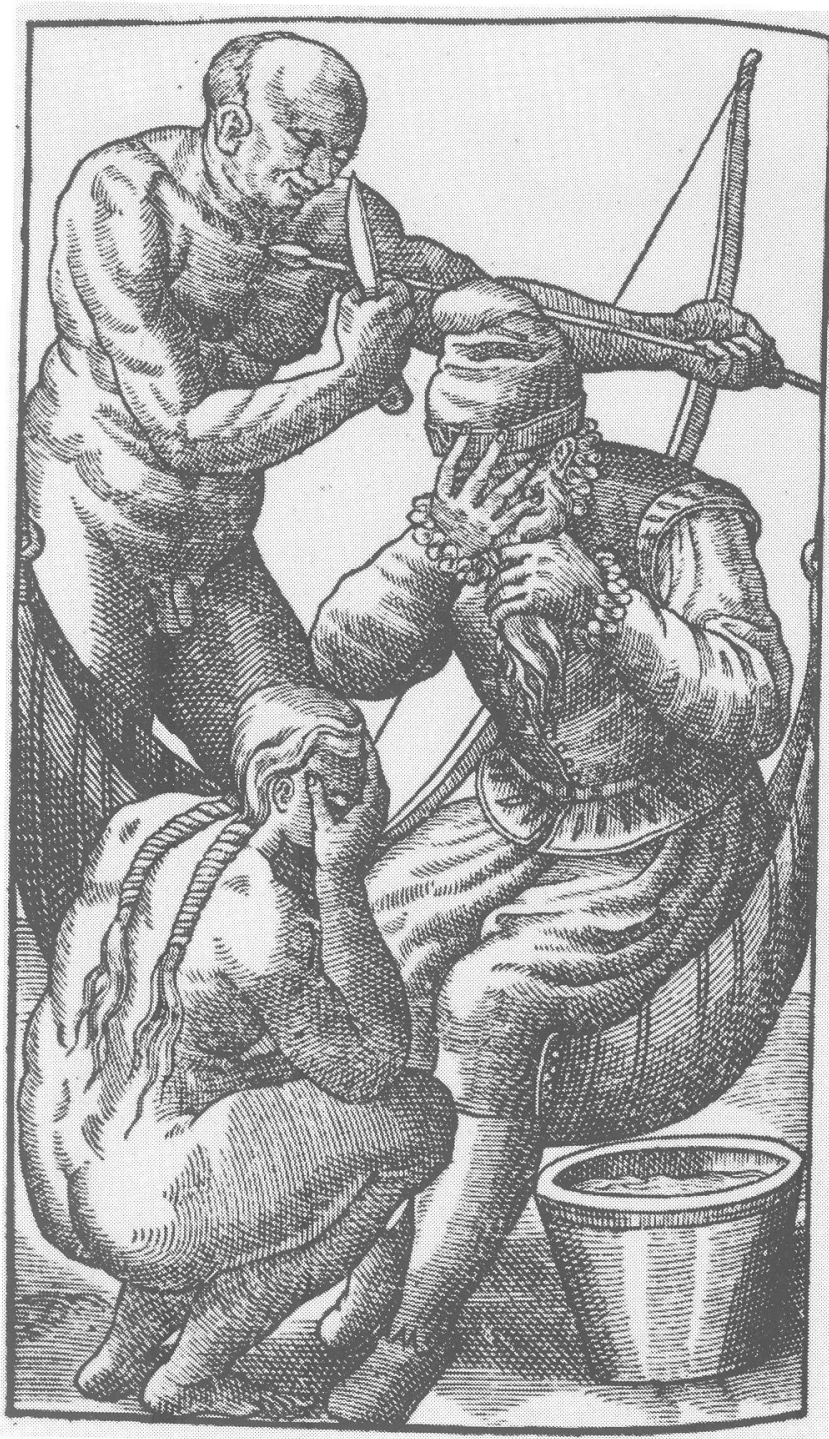

Der "Tränengruß”, die rituelle Begrüßung von Gästen [vgl. auch Tafel 9, Abb. 1].- Léry, Histoire, 1585. 
TAFEL 22

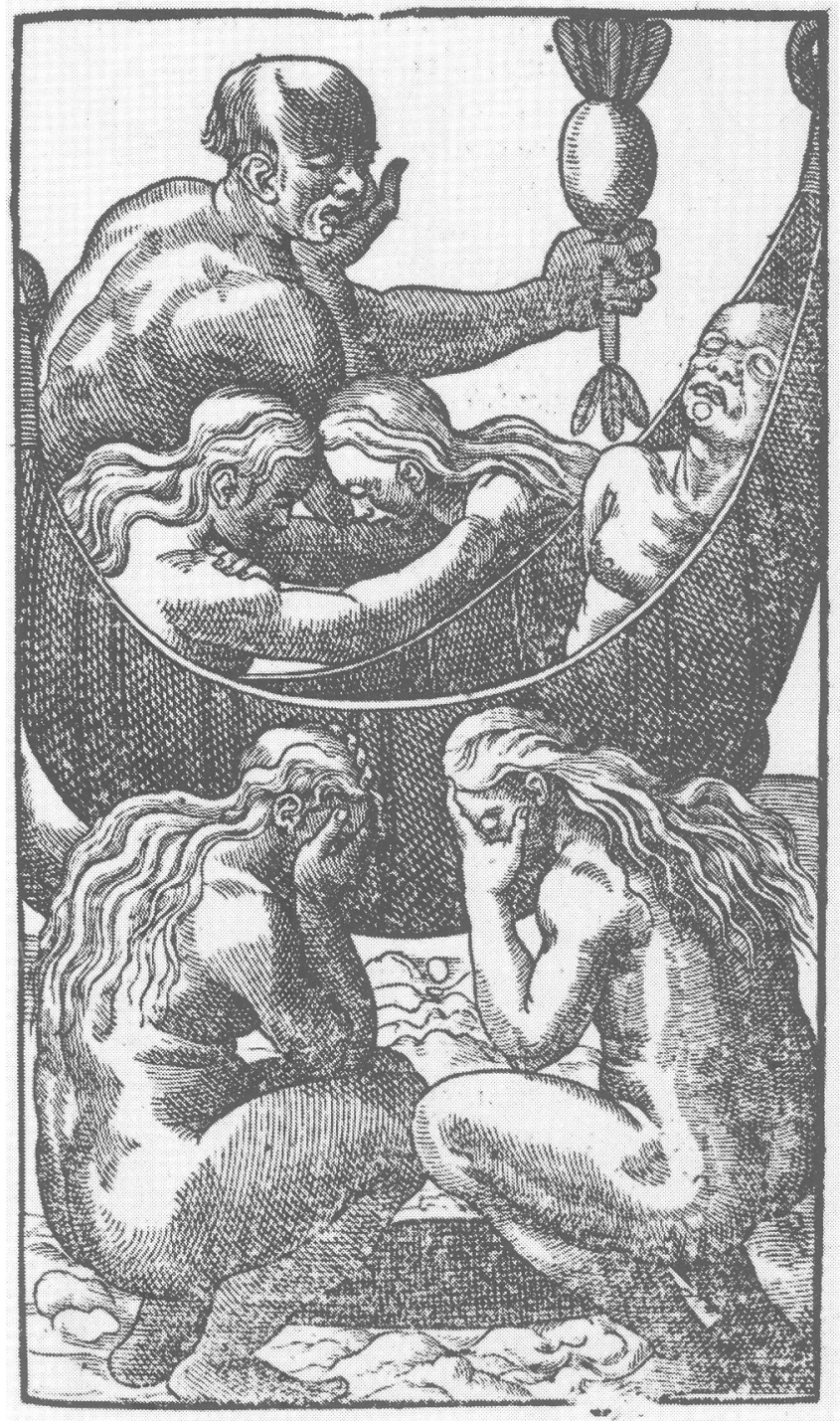

Die Trauer um einen toten Angehörigen.- Léry, Histoire, 1585. 
TAFEL 23
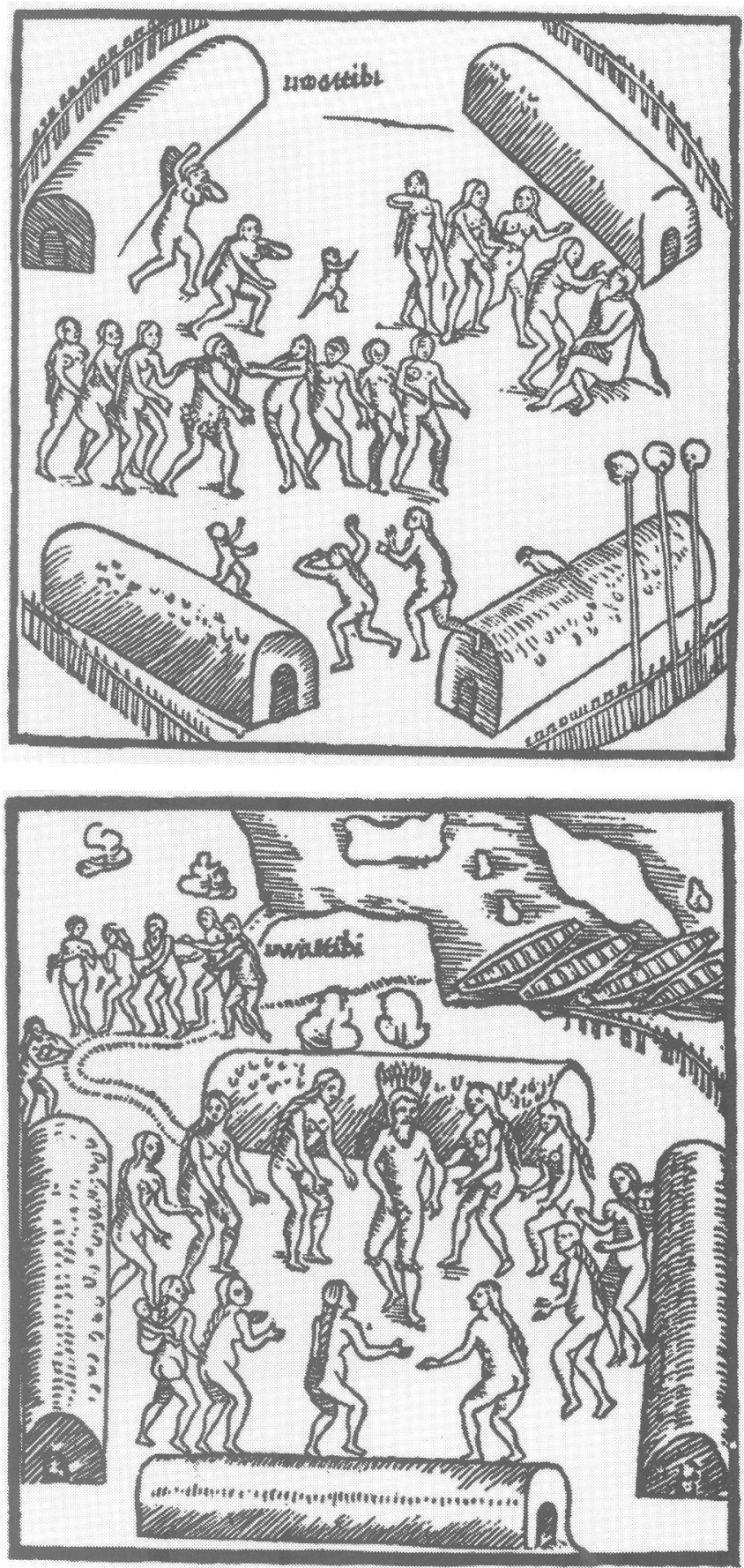

Abb. 1: Der Gefangene wird bei seinem Eintreffen im Dorf von den Indianerfrauen beschimpft. Abb. 2: Der Gefangene führt einen rituellen Tanz aus.- Beide Abb.: Staden, Warhafftige Historia, 1557, 1. Buch, Kap. 22; 24. 
TAFEL 24
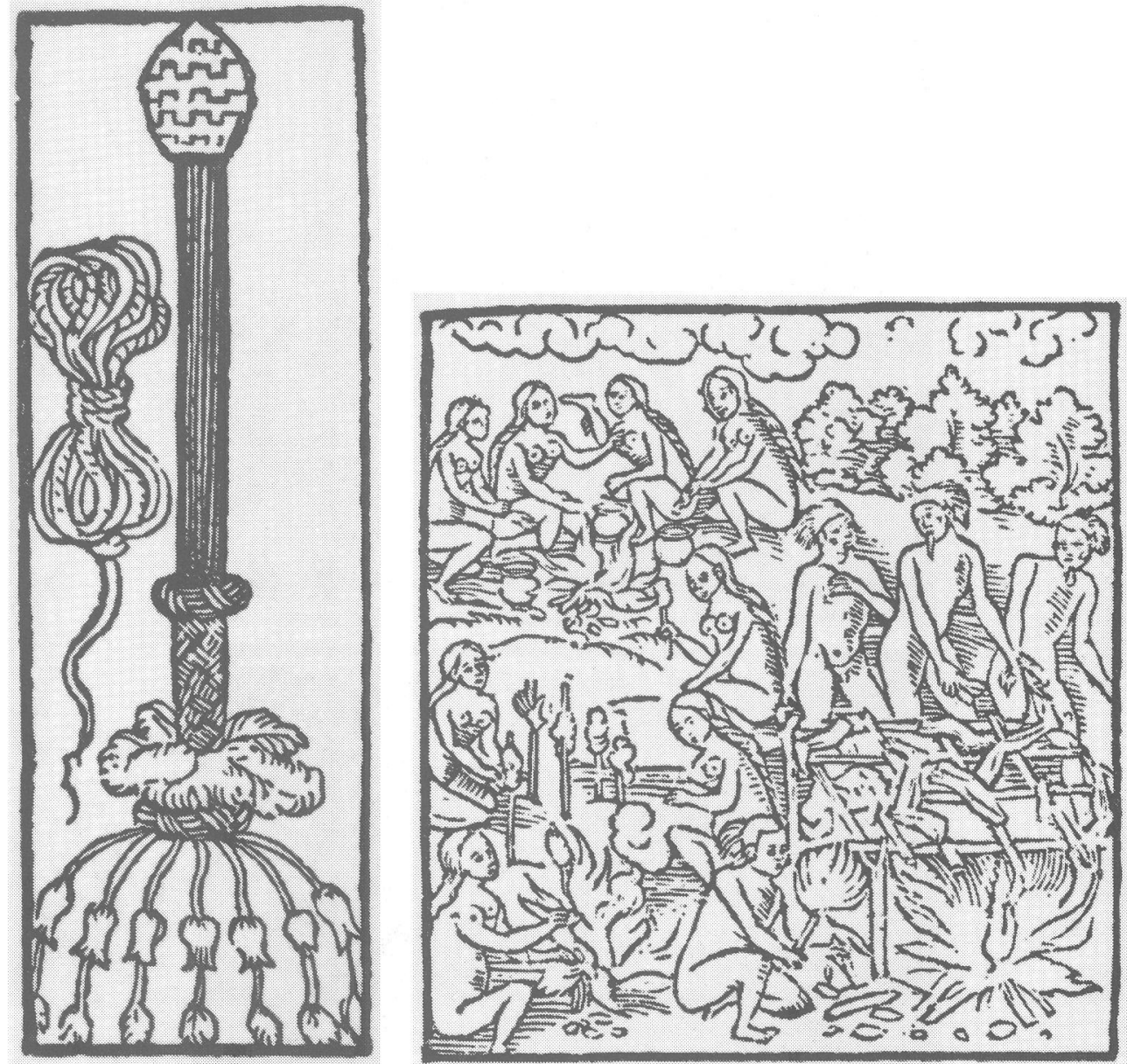

Abb. 1: Die Tötungskeule und der Strick, mit dem der Gefangene gefesselt wird. Abb. 2: Der Grill und die Verspeisung des Getöteten.- Beide Abb.: Staden, Warhafftige Historia, 1557, 2. Buch, Kap. 29. 

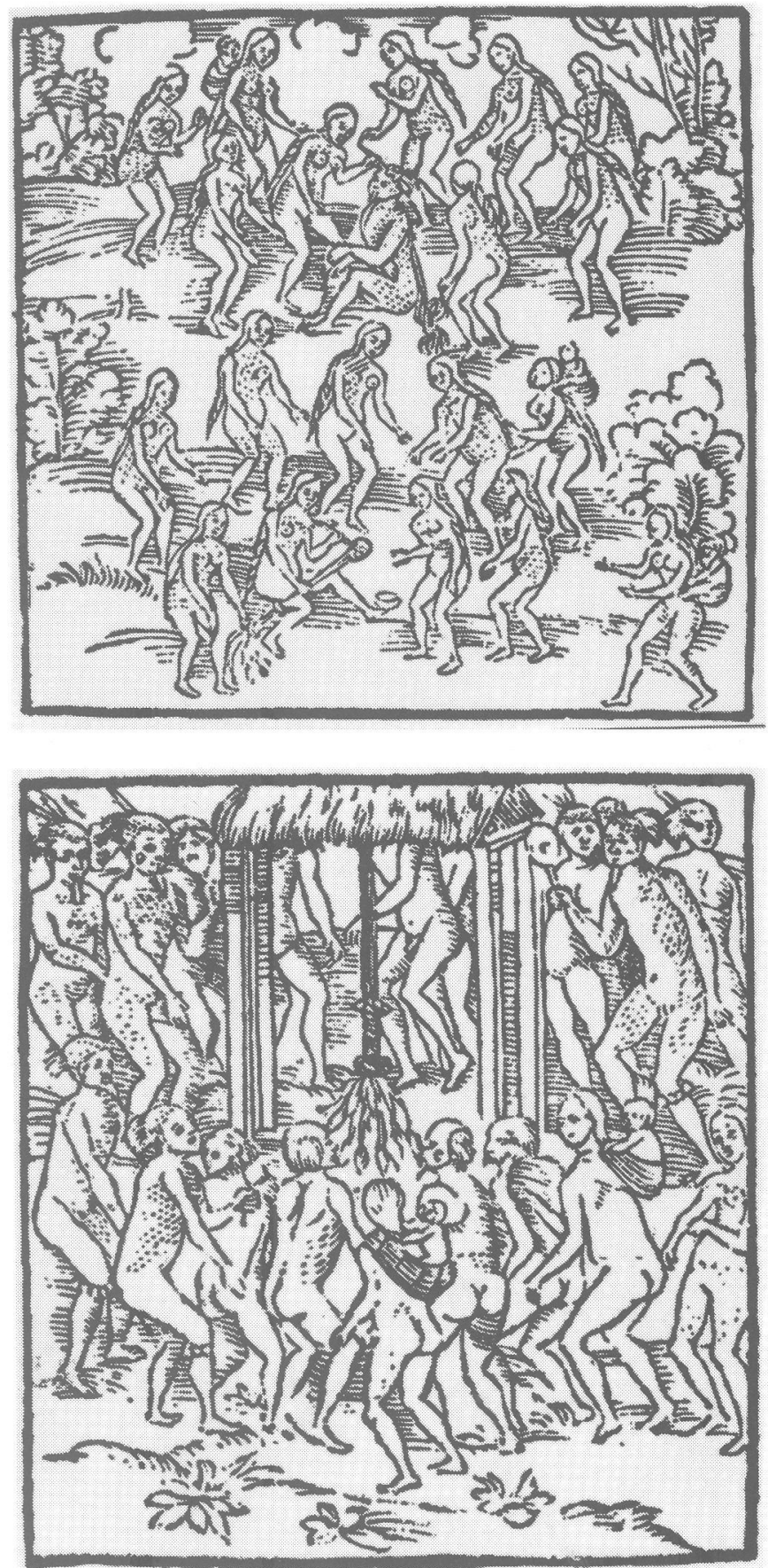

Abb. 1: Die Bemalung des Gefangenen und der Tötungskeule. Abb. 2: Der rituelle Tanz um die Tötungskeule.- Beide Abb.: Staden, Warhafftige Historia, 1557, 2. Buch, Kap. 29. 

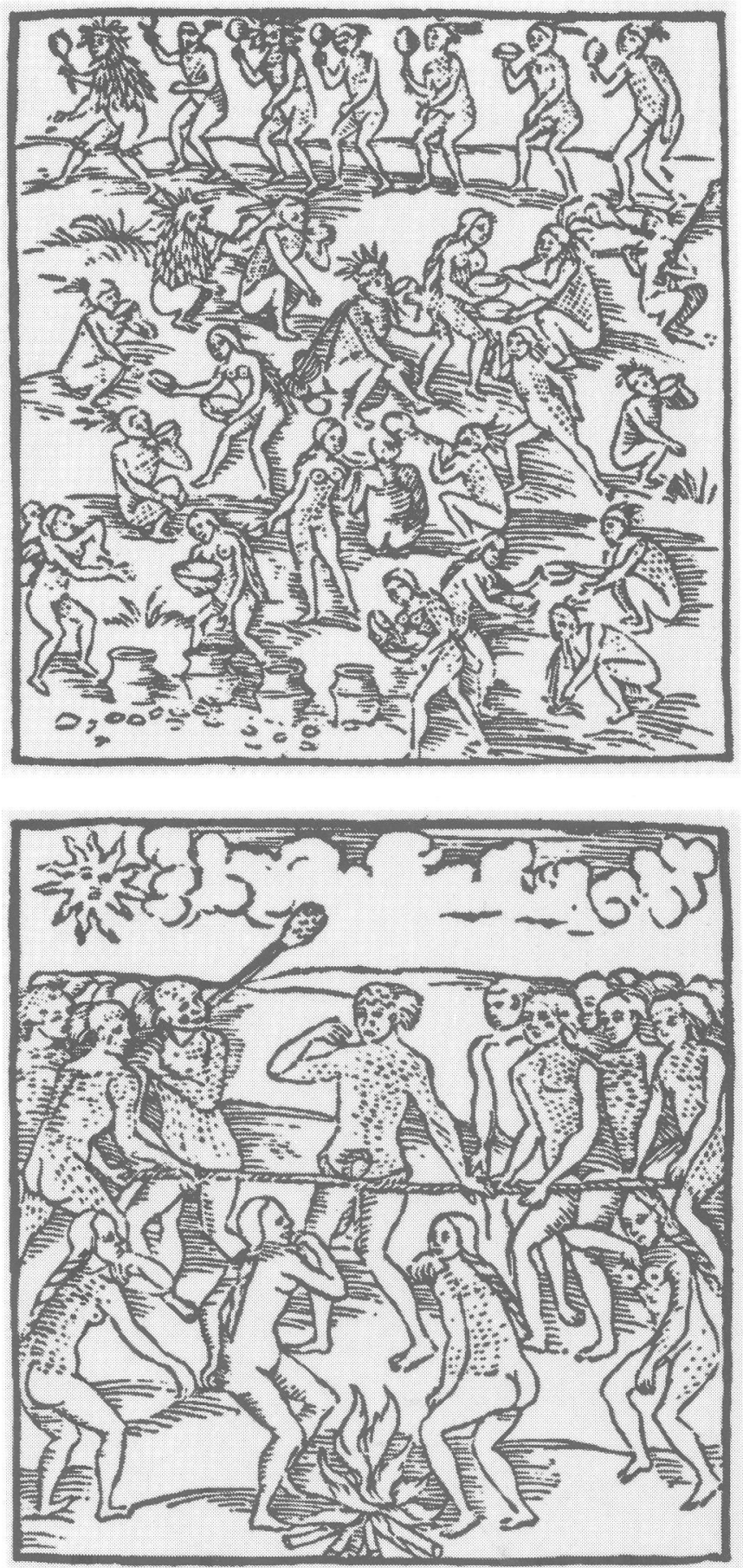

Abb. 1: Der Gefangene nimmt während des Rituals an einem Trinkgelage teil. Abb. 2: Die Tötung des Gefangenen [vgl. Tafel 13, 14, 35].- Beide Abb.: Staden, Warhafftige Historia, 1557, 2. Buch, Kap. 29. 

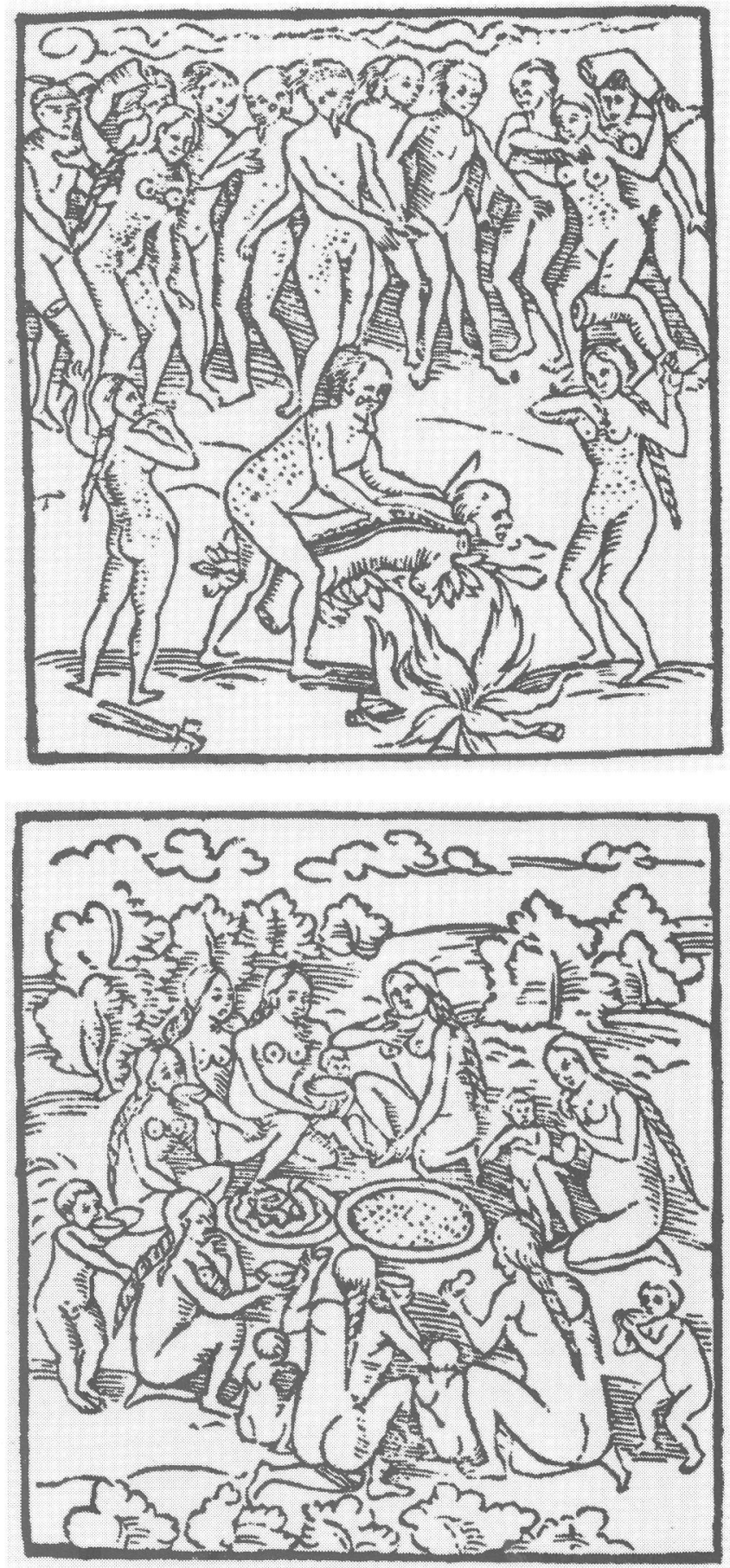

Abb. 1: Die Zerteilung seines Körpers. Abb. 2: Die Frauen verspeisen den Sud aus seinen Eingeweiden.- Beide Abb.: Staden, Warhafftige Historia, 1557, 2. Buch, Kap. 29. 

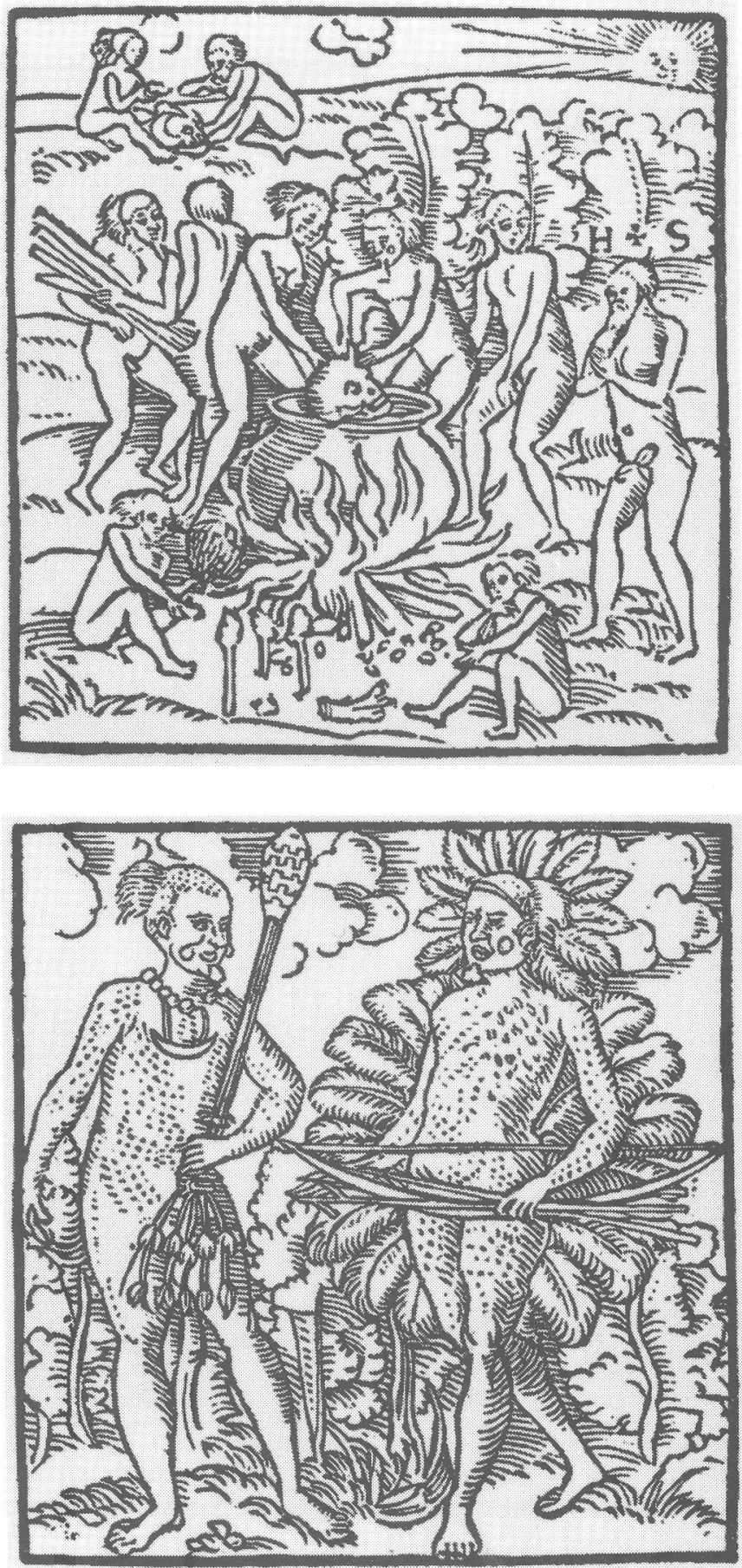

Abb. 1: Der Kopf wird in einen Topf geworfen; rechts die Gestalt Stadens (H.S.). Staden, Warhaffige Historia, 1557, 2. Buch, Kap. 29.- Abb. 2: Zwei Indianer mit Waffen und Kriegsschmuck [Deckblatt des 2. Buchs]. 


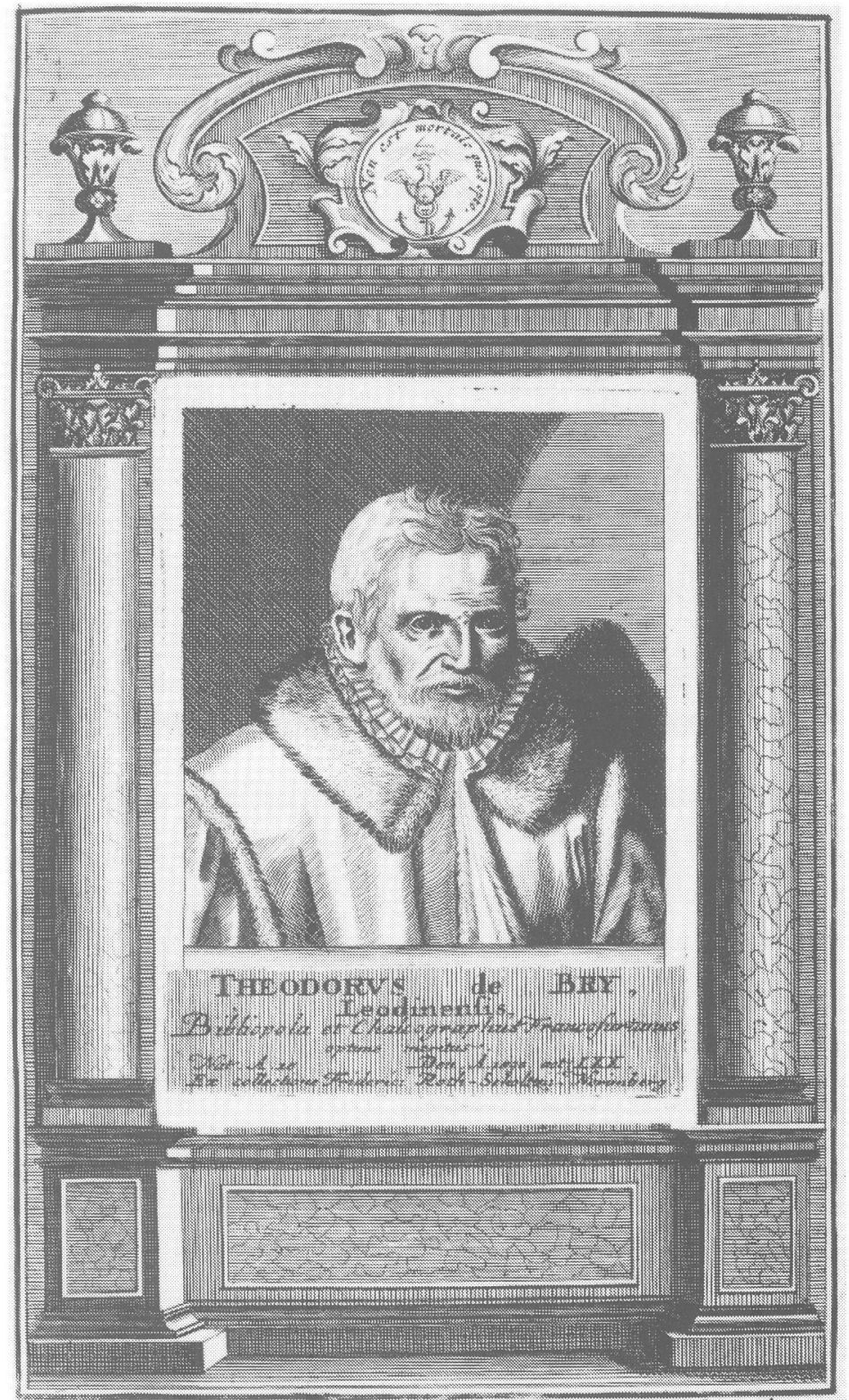

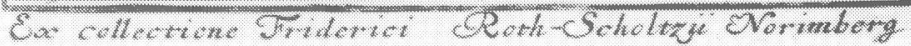

Selbstporträt von Theodor de Bry [Kupferstich].- Dresden, Kupferstichkabinett (B 1554, 2, S. 6). 


\section{Effigies \\ JOHANNIS-T HEODORI DE BRY.}

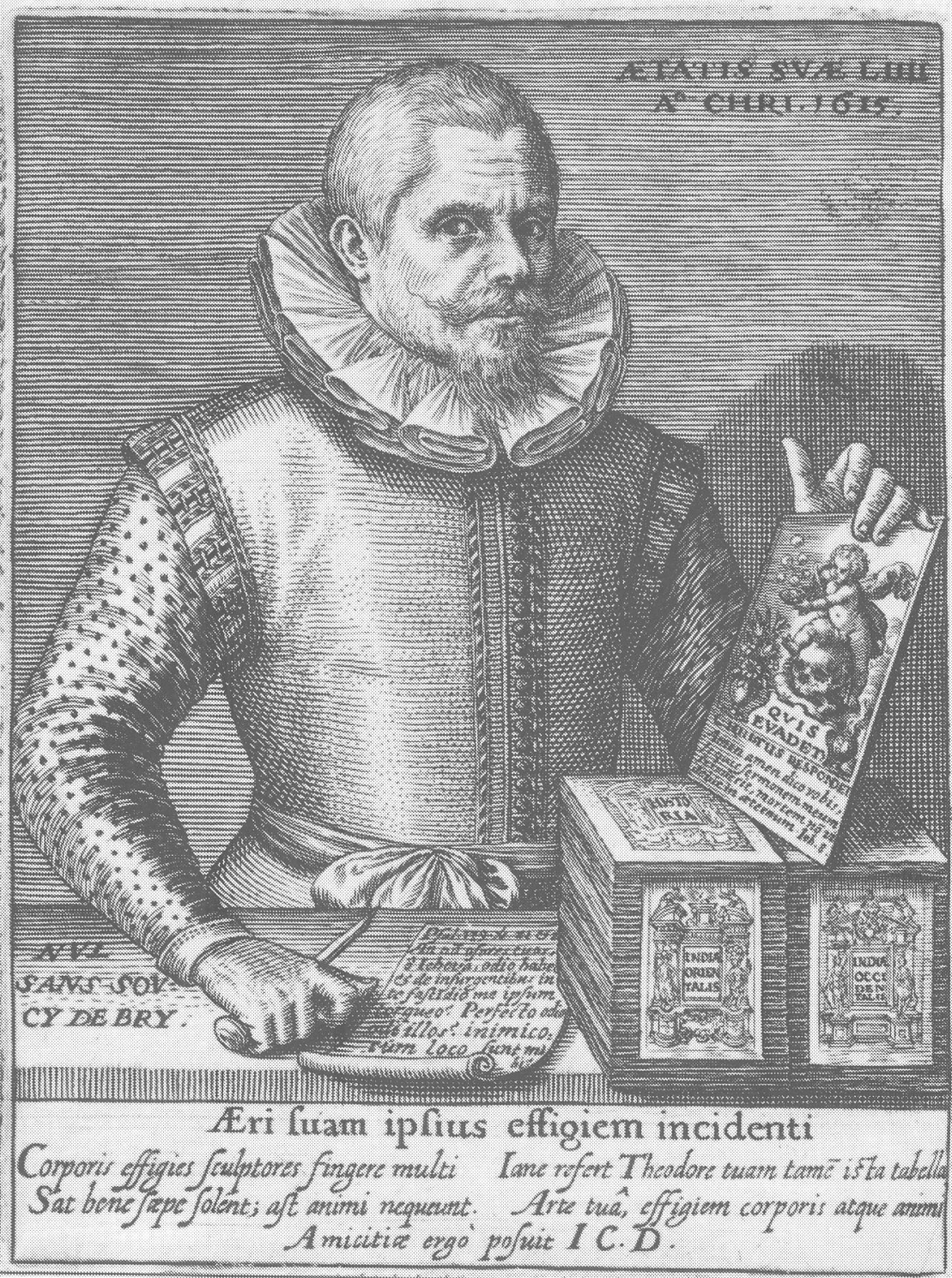

Selbstporträt von Johann Theodor de Bry [Kupferstich von 1615].- Boissard, Bibliotheca chalcographica, 1650-54. 


\section{TAFEL 31}

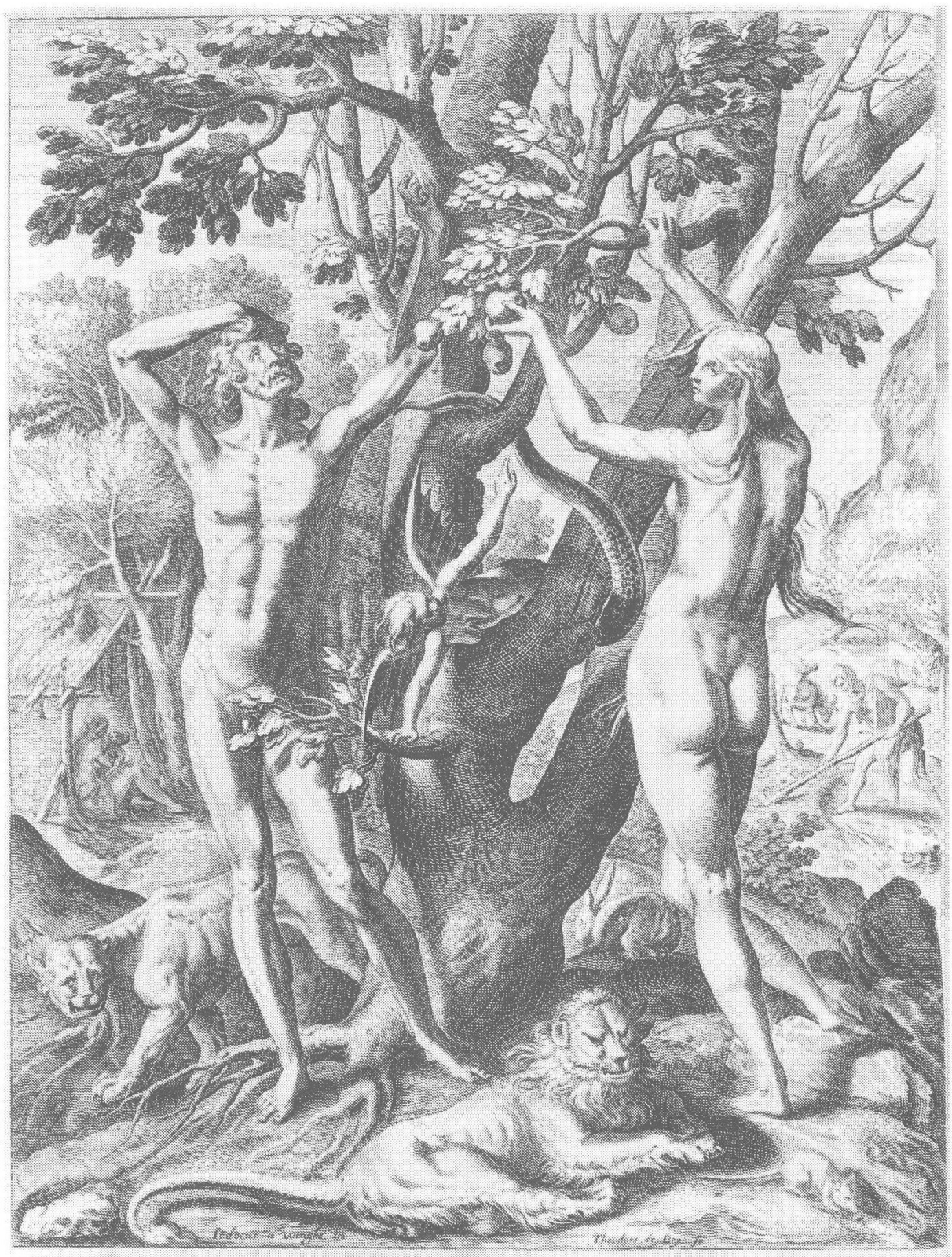

Darstellung des Sündenfalls [Kupferstich].- America (lat.), Vorblatt zu Bd. 3, Frankfurt, 1592 [u. zu Bd. 1, lat. 1590]. 


\section{TAFEL 32}

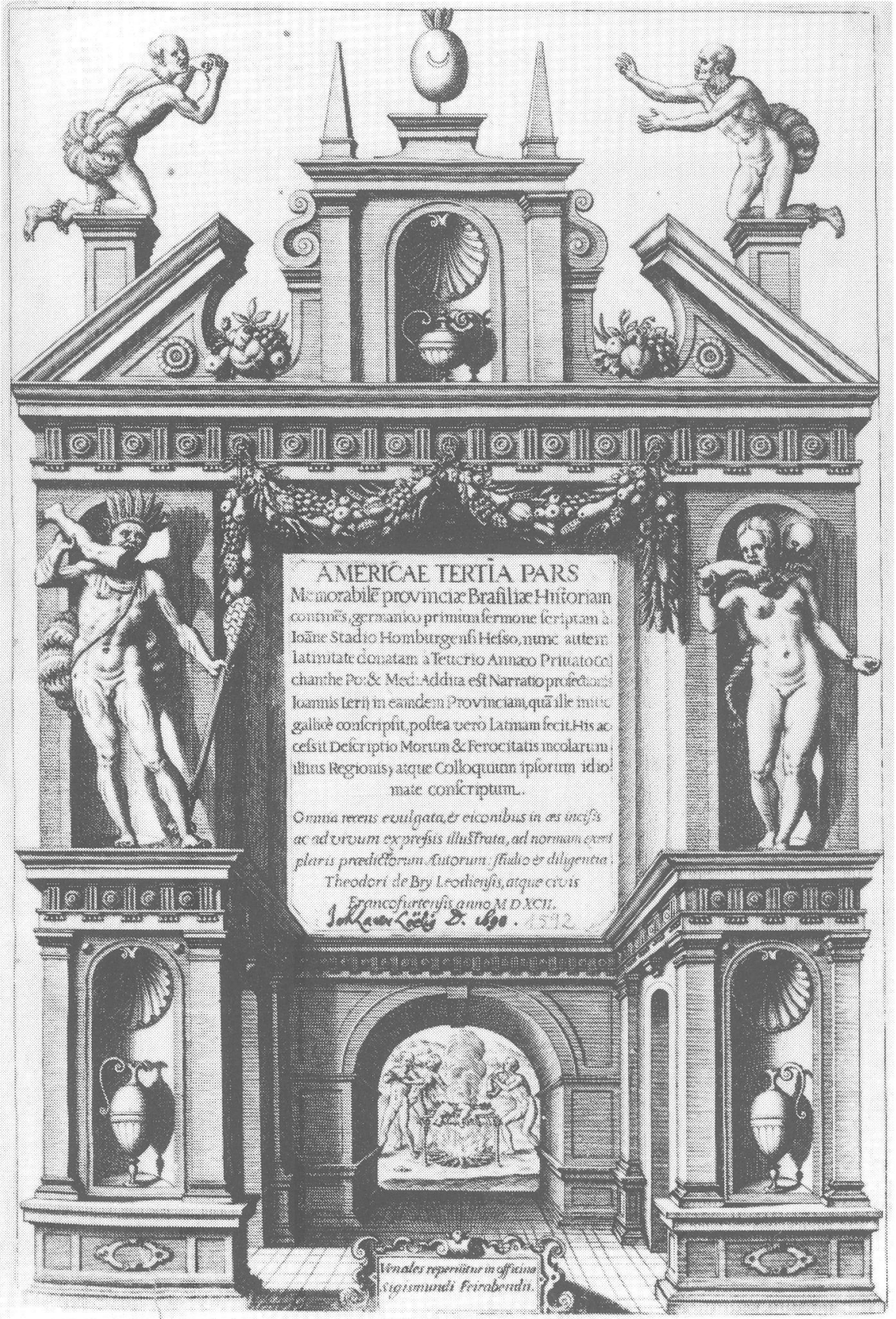

Titelkupfer.- America (lat.), Bd. 3, Frankfurt, 1592 [u. Bd. 7, lat. 1599]. 


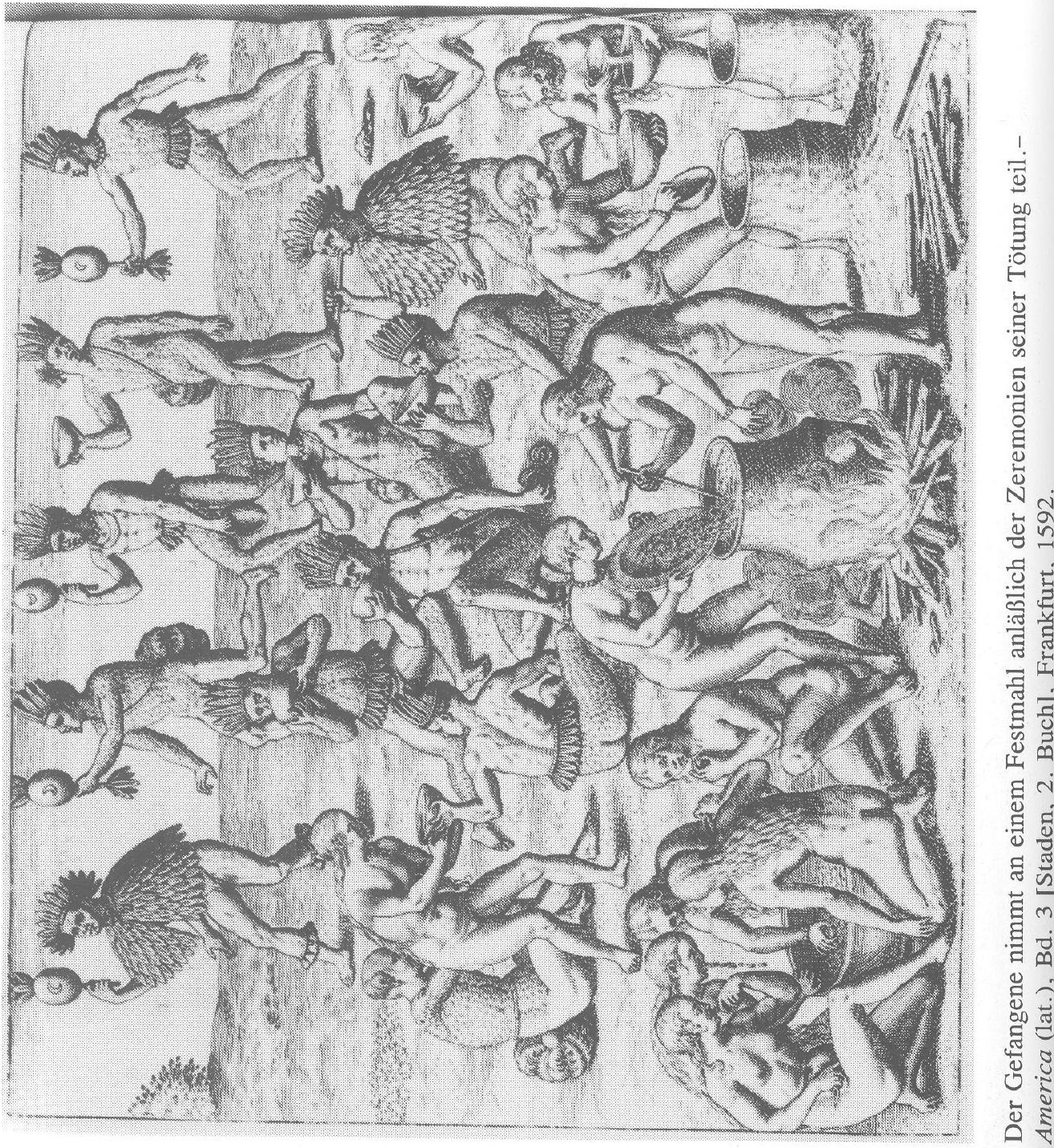




\section{TAFEL 34}

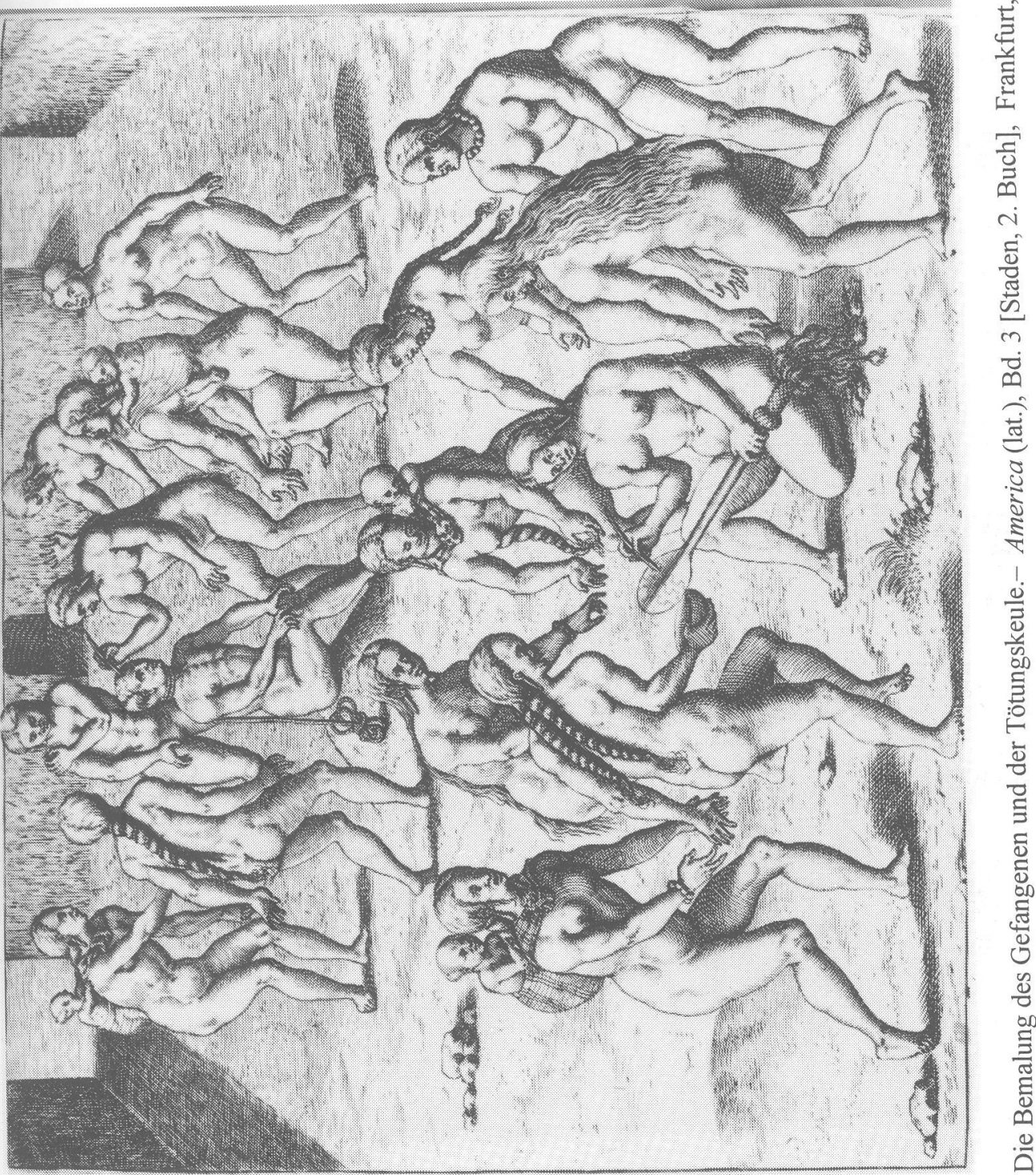

กู

을

造

वृ

त्ञ

ปั)

ฮั

믈

음 


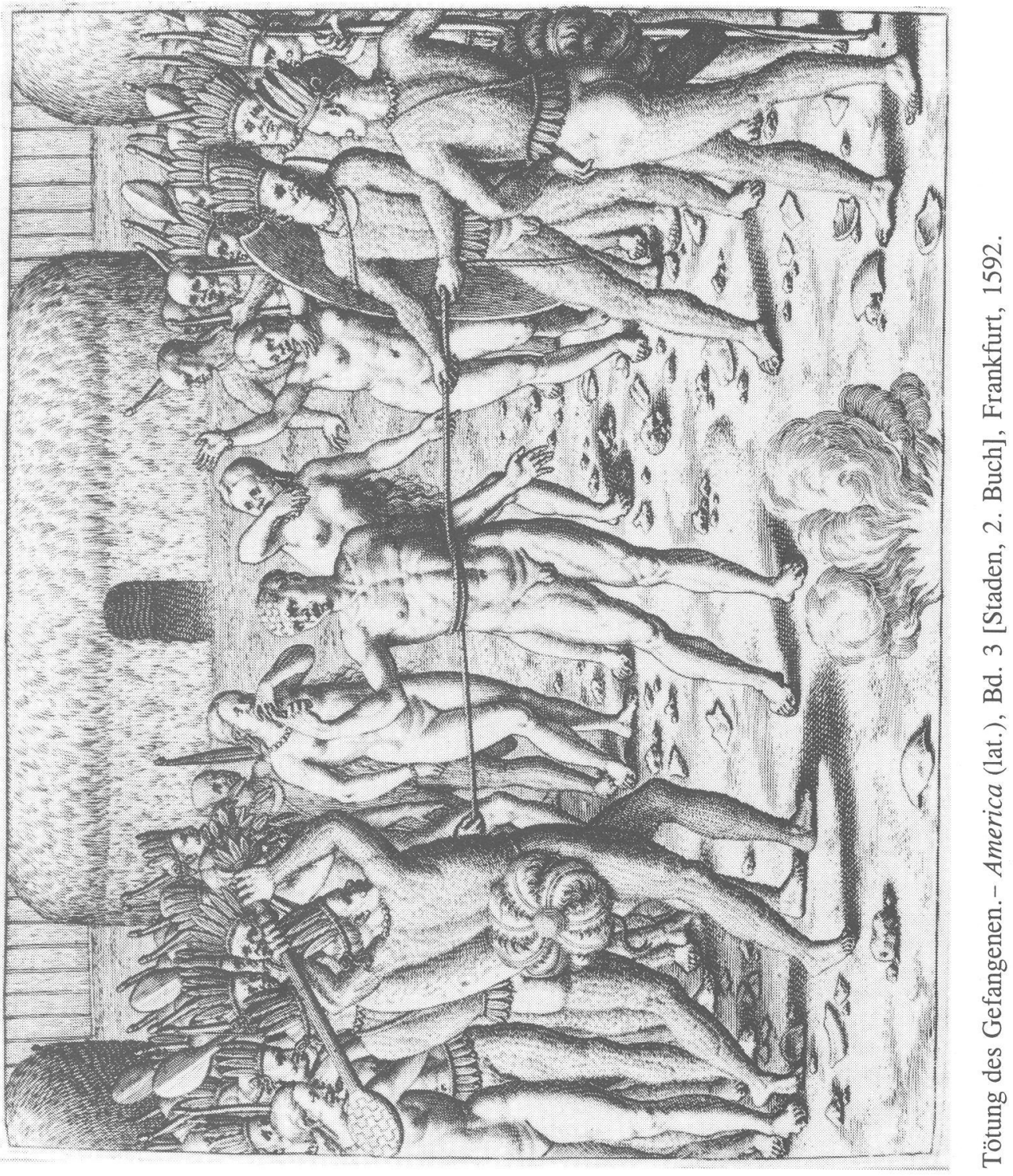




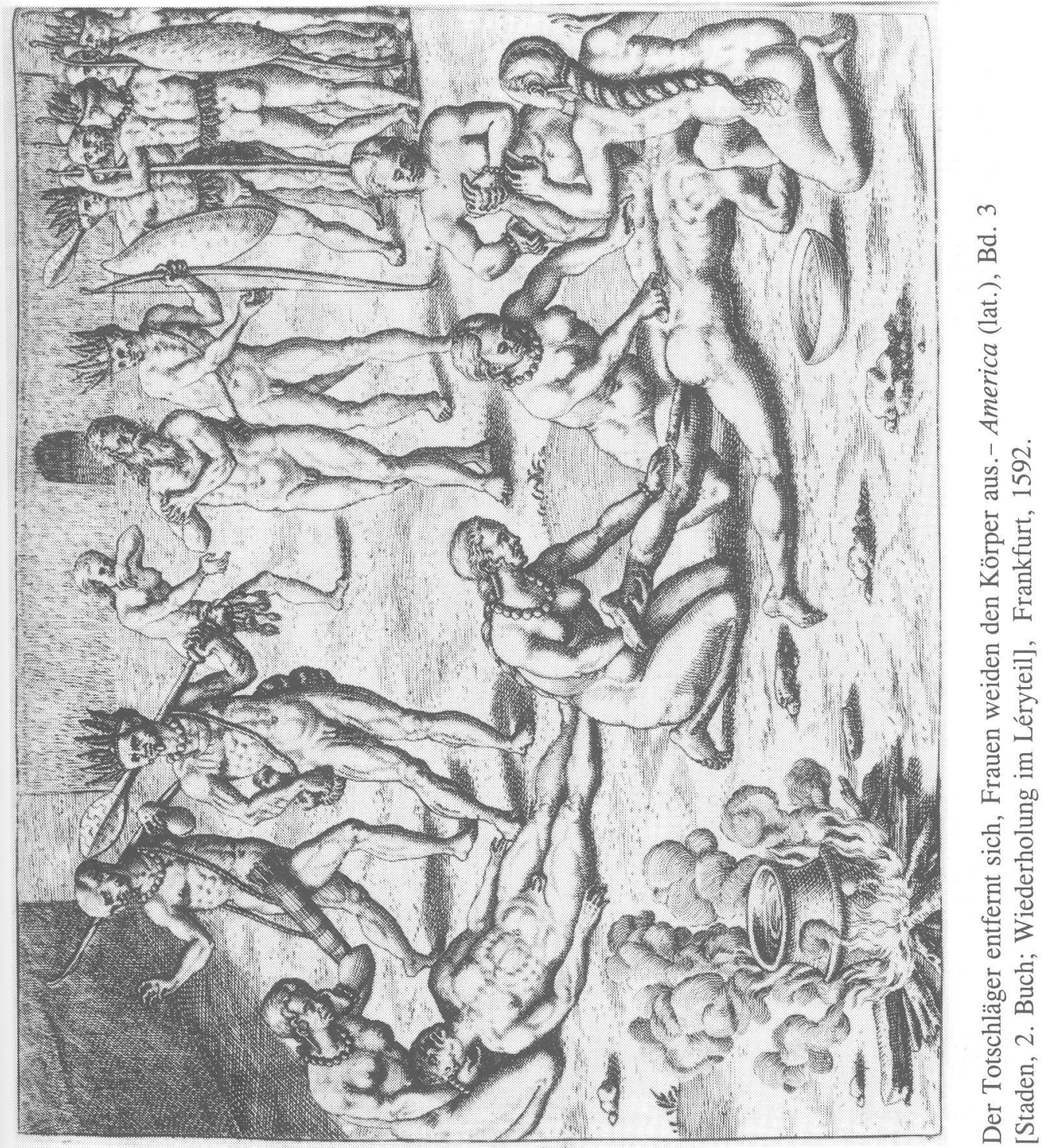




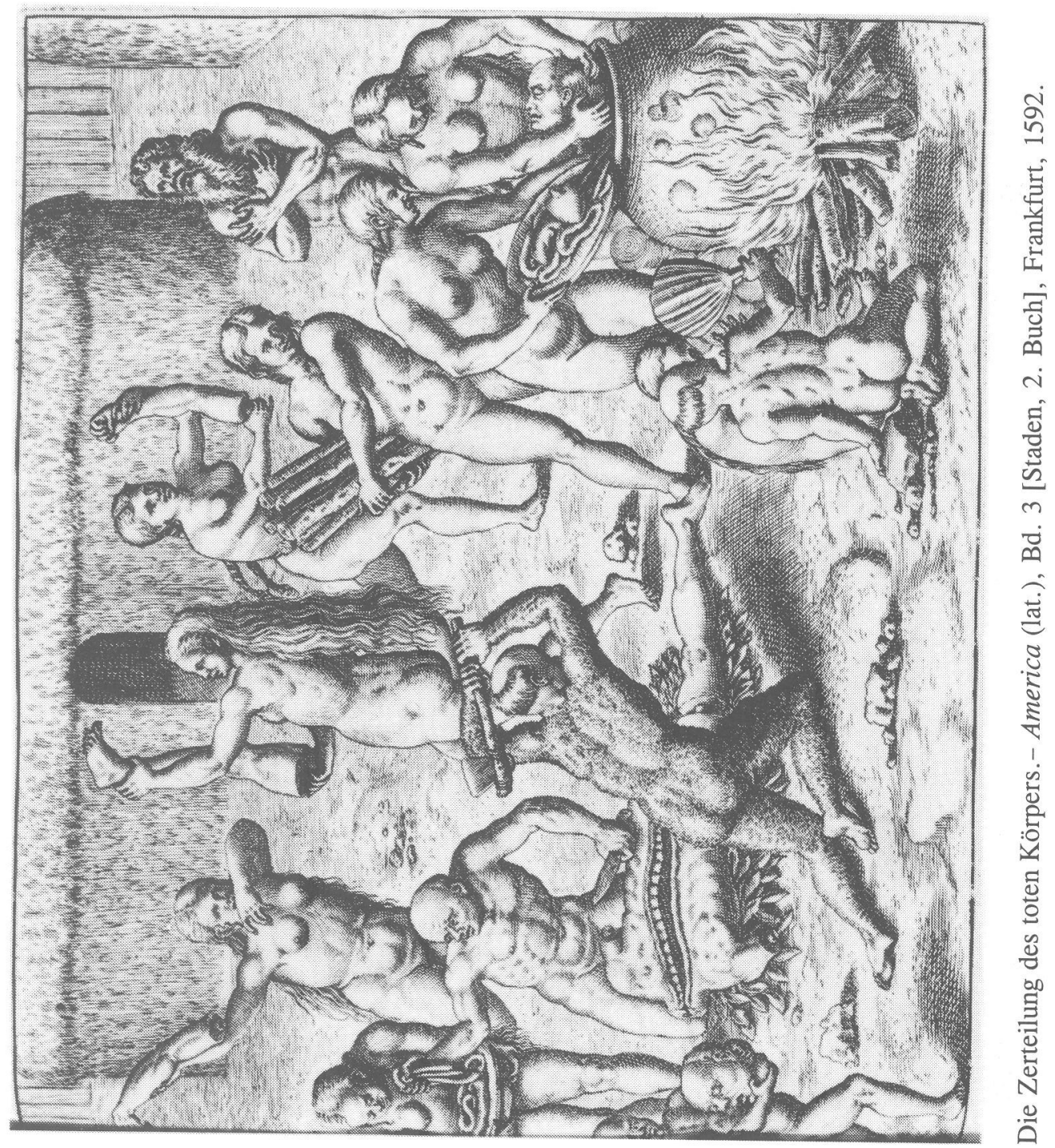




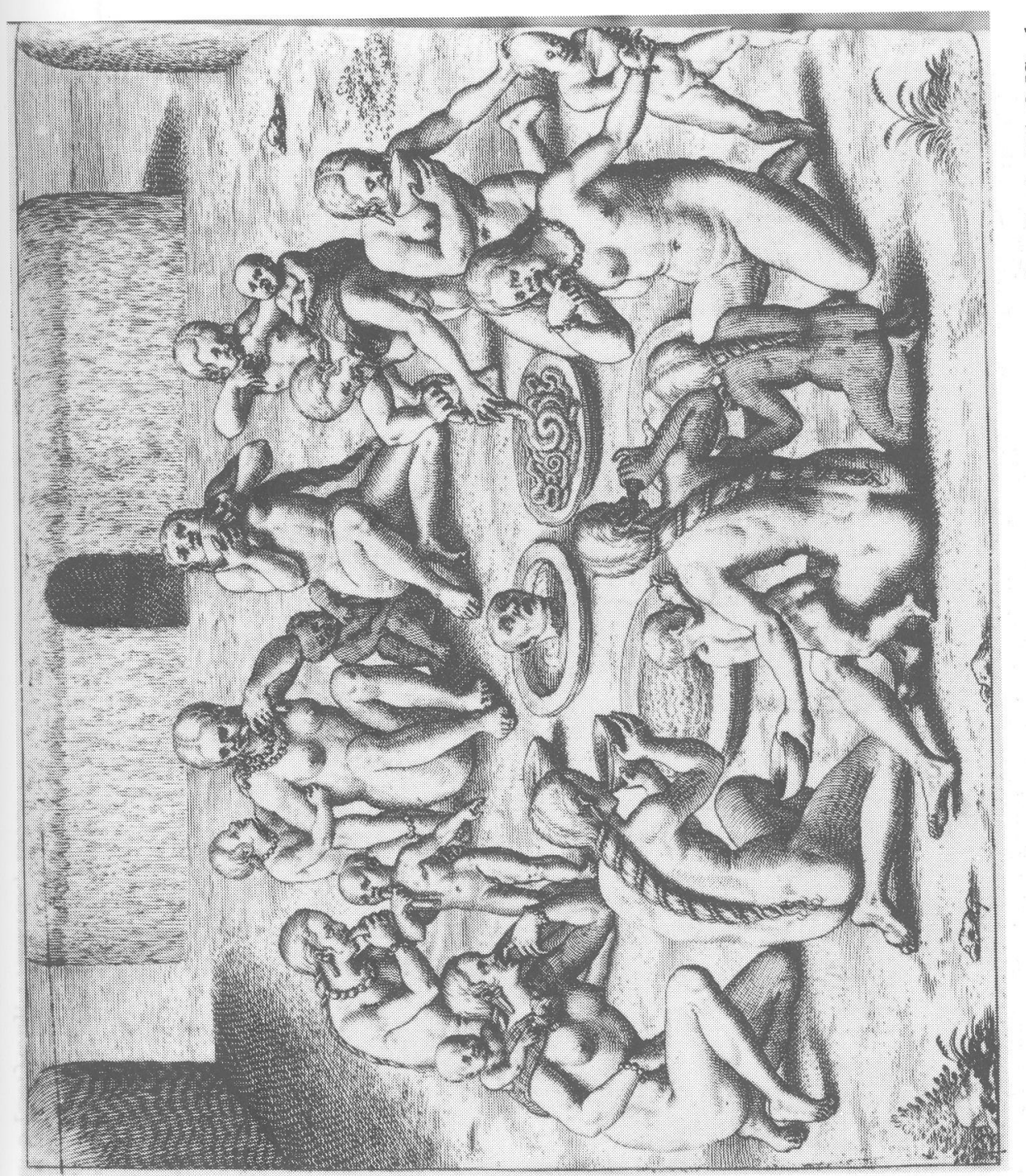

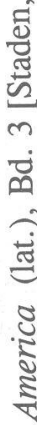

एँं

\&ु

음

文

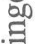

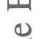

$\stackrel{0}{7}$

"명

क्ष

뭉

구

.

क्षै

$\stackrel{5}{2}$

过

즐

可

률월

ซึ 


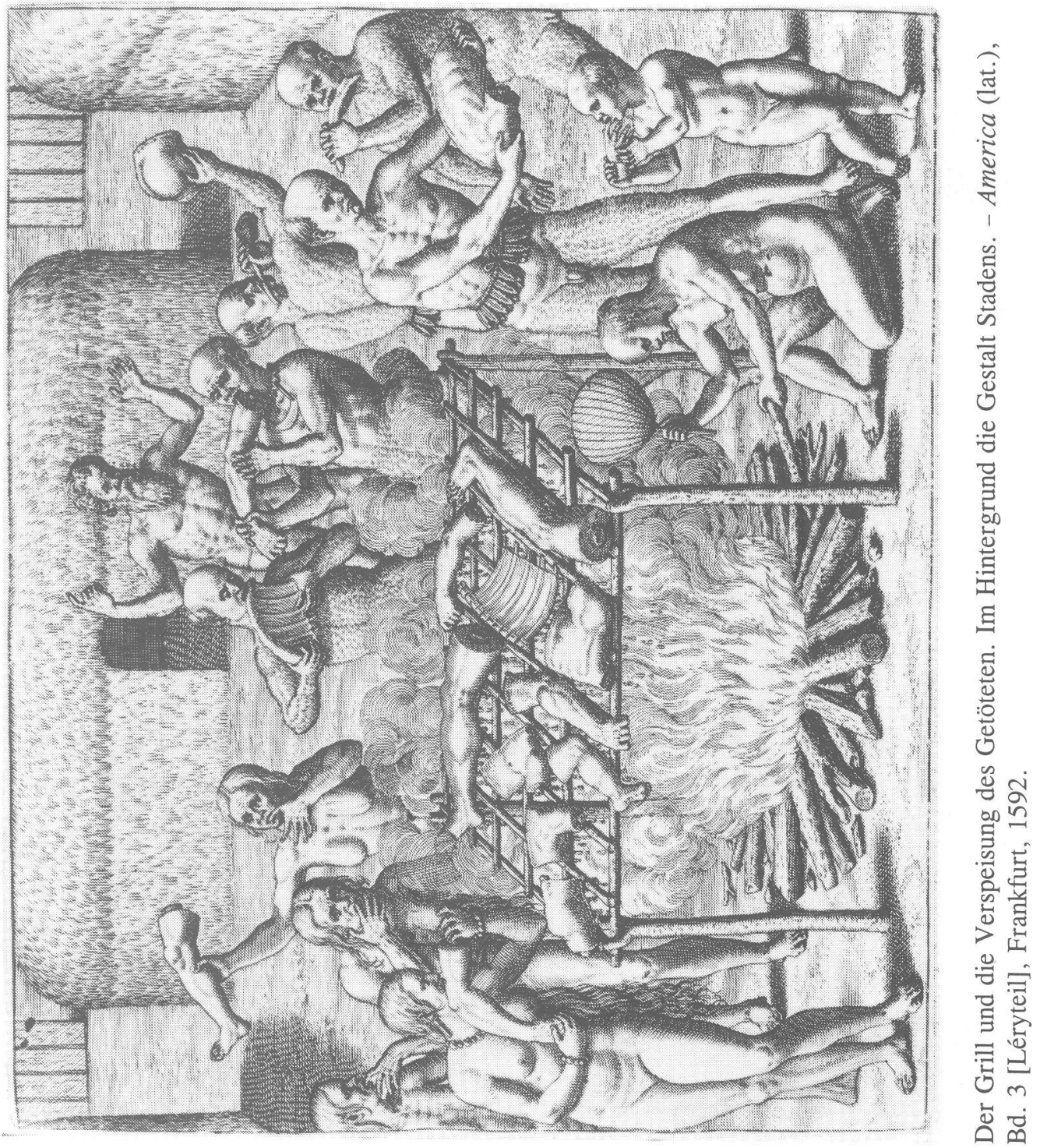




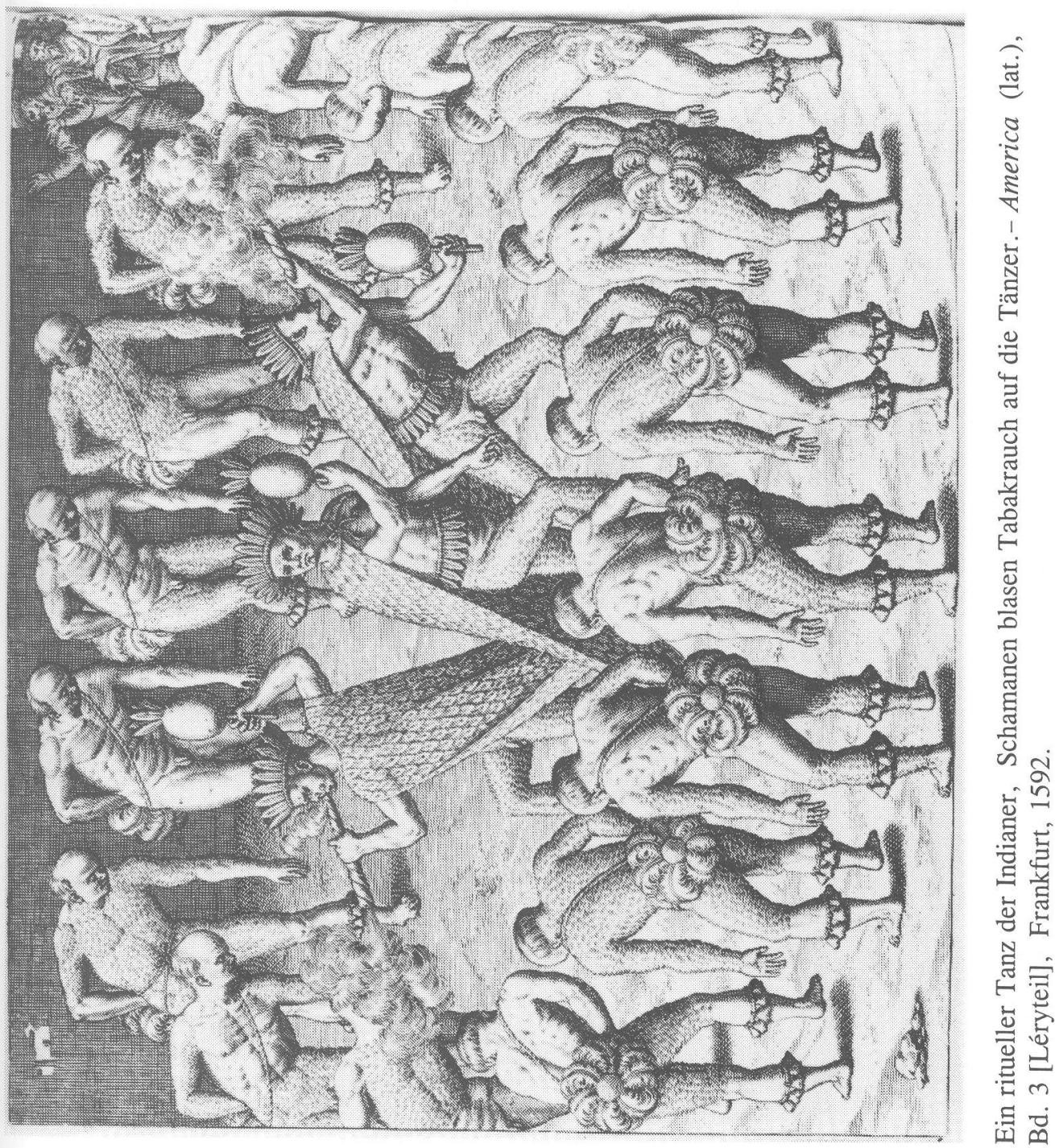




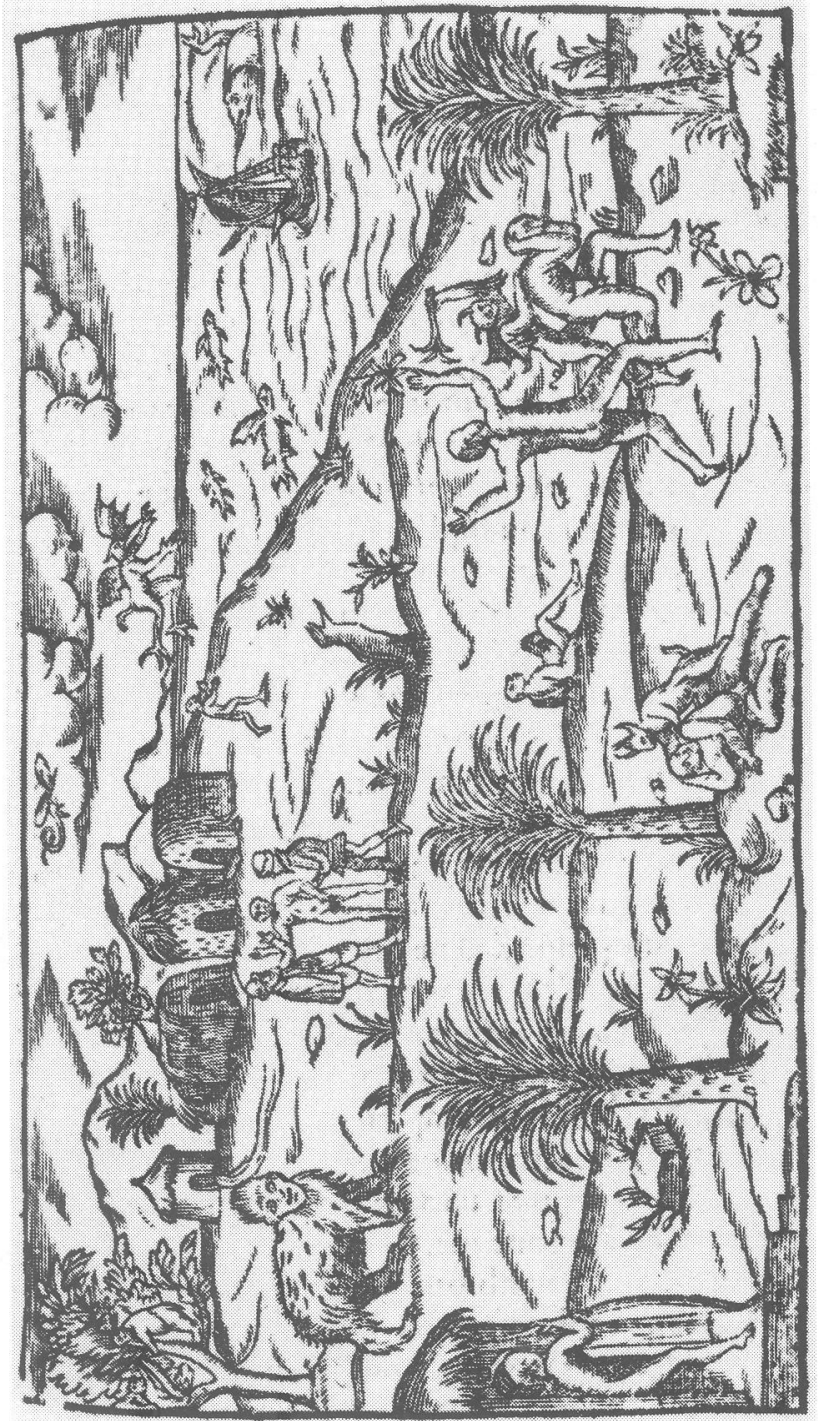

0 


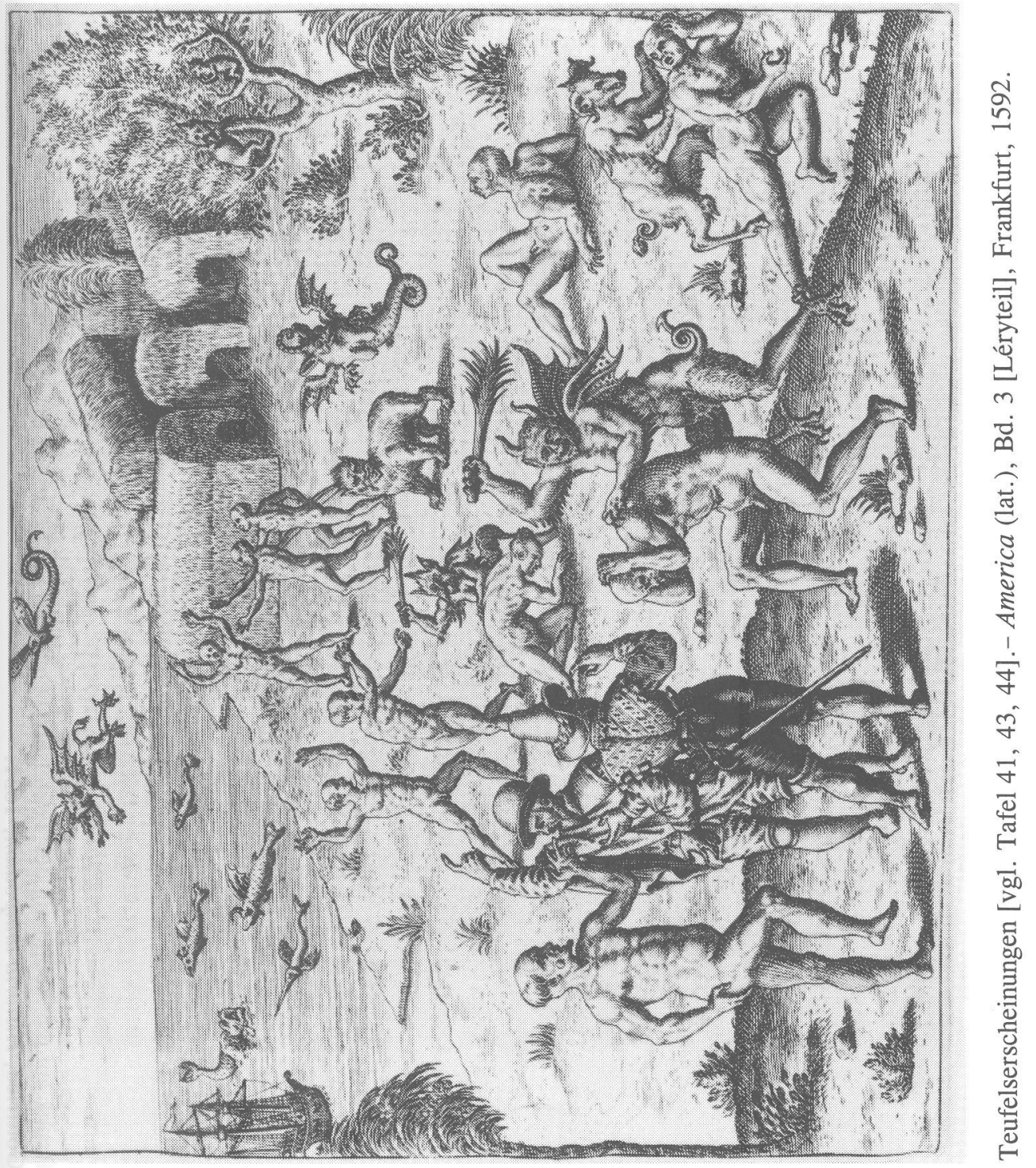




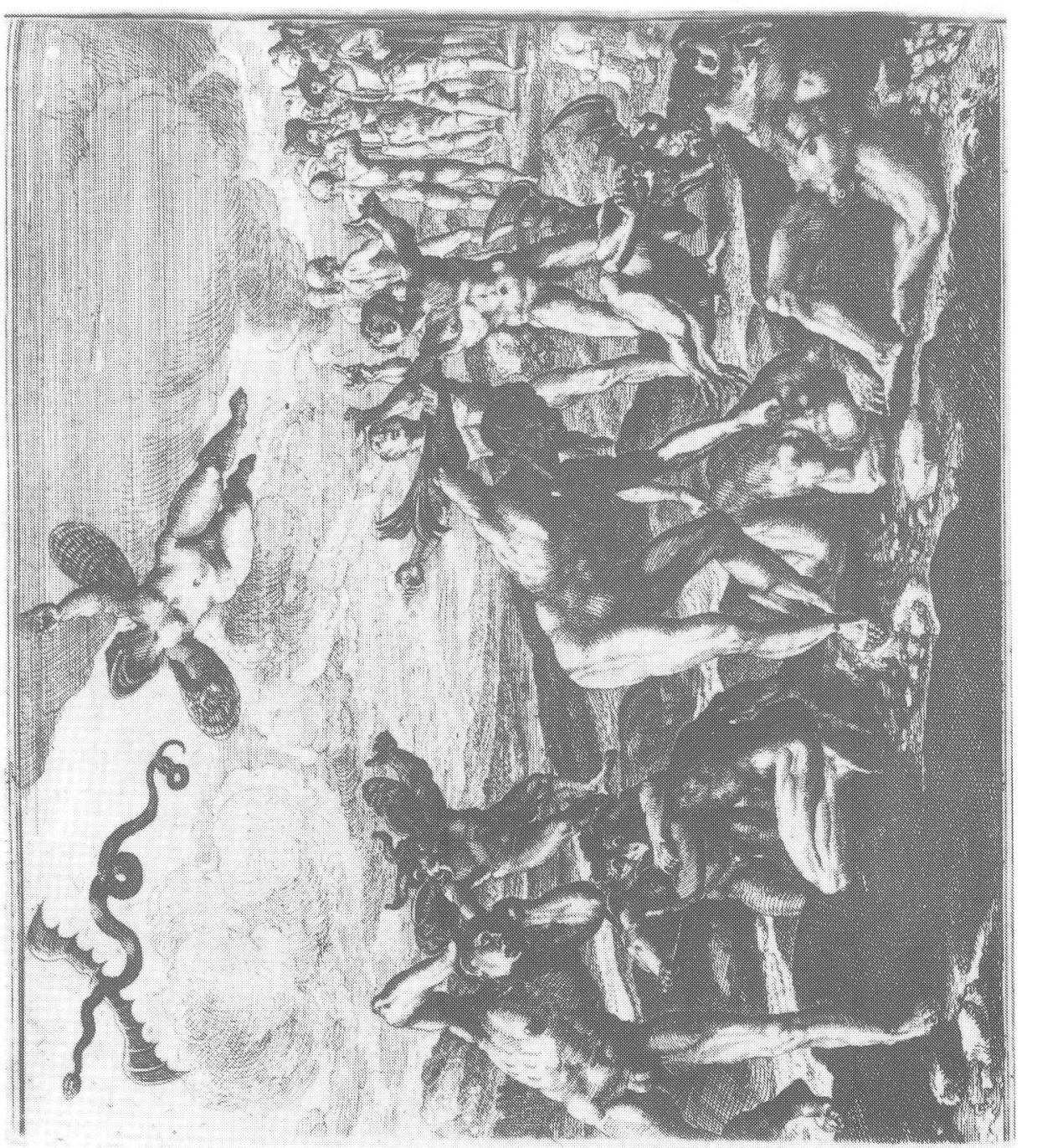

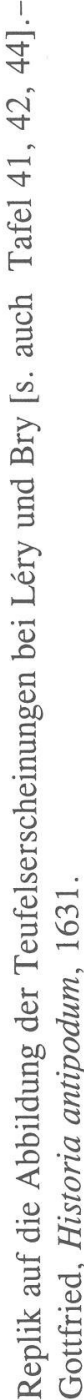




\section{TAFEL 44}
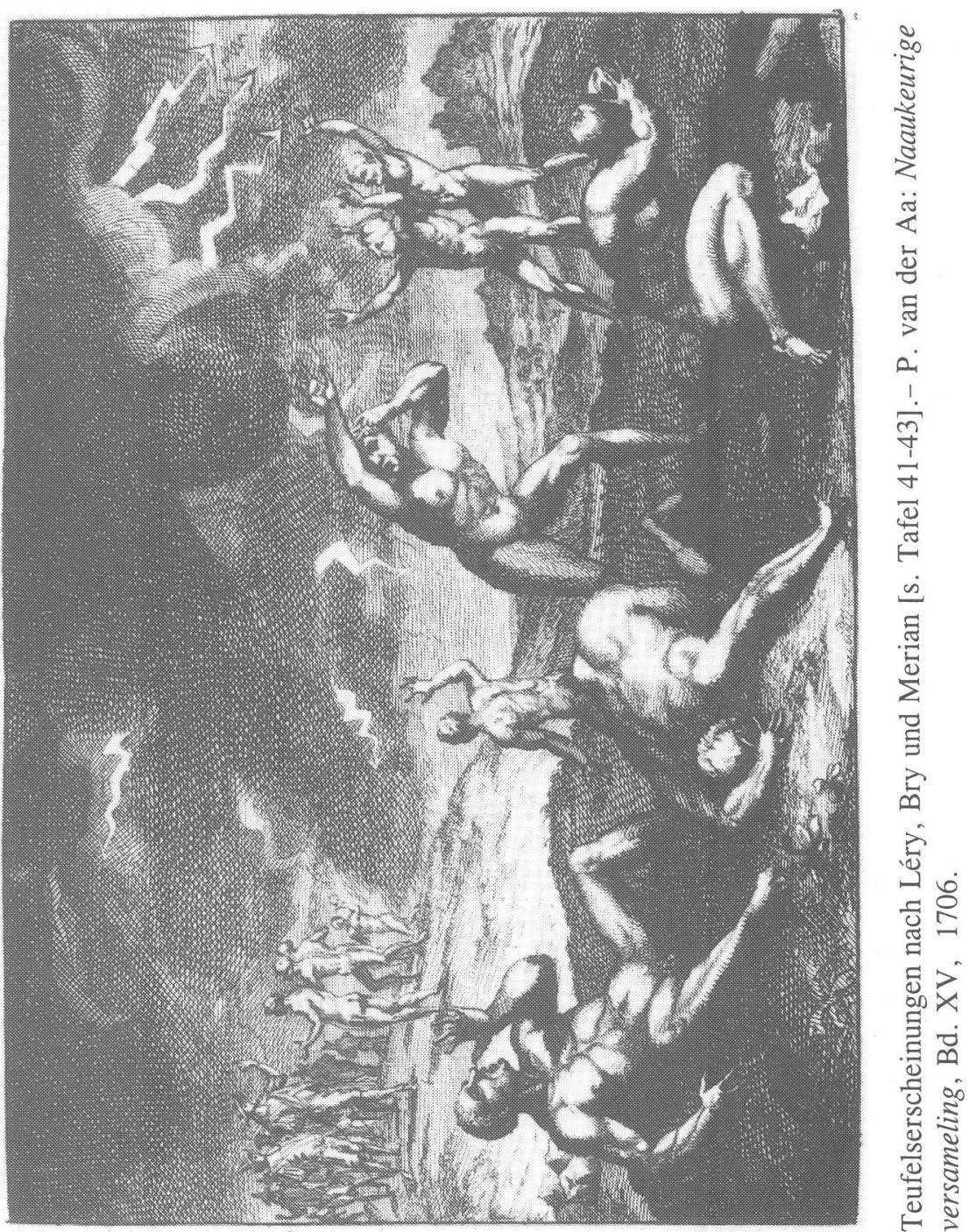





\section{Brasilien in Illustrationen des 16. Jahrhunderts}

Die Arbeit behandelt die ikonographische Tradition französischer und deutscher Brasilienreiseberichte des 16. Jahrhunderts im Hinblick auf den Einfluss ihres Bildmaterials auf den 1592 in Frankfurt erschienenen dritten Band der AmericaSammlung von Theodor de Bry. Untersucht wurden Stadens Warhafftige Historia, Marburg, 1557, André Thevets Les Singularités de la France Antarctique, Paris, 1557/1558 und Jean de Lérys Histoire d'un voyage faict en la terre du Bresil, La Rochelle (i.e. Genf) 1578. Stadens Werk entstand als Erlebnisbericht über seinen Aufenthalt als Söldner in portugiesischen Diensten in Brasilien und behandelt vor allem seine einjährige Gefangenschaft bei den Tupinamba-Indianern an der brasilianischen Küste bei São Vicente; die beiden französischen Werke berichten über eine bald gescheiterte französische Koloniegründung in der Nähe des heutigen Rio de Janeiro in den Jahren 1555-1558. Bry hat in seiner monumentalen Reiseberichtkollektion, die ab 1590 in einer deutschen und einer lateinischen Version erschien, den Text von Lérys und Stadens Werk aufgenommen und sich in den beigefügten Kupferstichen auch vom Bildmaterial der Autoren inspirieren lassen. Die Zeichner oder Holzschneider von Stadens oder Lérys Werk sind nicht bekannt. Nur Thevets Illustrationen können trotz uneinheitlicher Qualität aufgrund stilistischer Vergleiche zumindest zum Teil der Werkstatt des bedeutenden französischen Buchillustrators Jean Cousin (ca. 14901561) und, was seine Cosmographie von 1585 betrifft, seinem gleichnamigen Sohn zugesprochen werden. Die Filiationen des ikonographischen Materials in diesen Büchern wurden in der Forschung bisher noch nicht umfassend gewürdigt. Léry kopiert stellenweise Thevet, bringt aber einige hochstehende, der Tradition der Kostümbücher verpflichtete Personendarstellungen. Einige seiner Abbildungen gehen, wie in diesem Buch erstmals nachgewiesen wird, auf das 1577 von Hans Weigel in Nürnberg mit Abbildungen von Jost Amman gedruckte Trachtenbuch Habitus praecipuorum populorum [...] zurück. Stadens sehr einfache Holzschnitte zeigen neben zahlreichen ethnologisch richtigen Details auch einen starken Einfluss zeitgenössischer Karten. Ein Einfluss von Stadens Illustrationen auf Thevets oder Lérys Werk ist trotz gegenteiliger Meinung in der Sekundärliteratur nicht zu belegen.

Die Arbeit versucht nicht nur die Filiationen des ikonographischen Materials der behandelten Bücher erstmals detailliert aufzuzeigen, sondern auch den ideengeschichtlichen Hintergrund des Bildmaterials in Bezug auf die Aussageintention herauszuarbeiten. Insbesondere in der Reiseberichtsammlung von Bry nimmt das dritte Buch mit den Brasilienberichten eine zentrale Stellung ein, weil es den von der europäischen Kultur noch weitgehend unberührten Einwohner Brasiliens als Gegenbild zum Indianer der mittelamerikanischen Hochkulturen zeigt. Die Stiche enthalten deutliche Hinweise zur Rezeption, die den brasilia- 
nischen Indianer als einen dem Teufel verfallenen, gottlosen Kannibalen zeigen, dessen Unglaube nicht zu entschuldigen ist.

Theodor de Bry hat sich für sein Werk künstlerisch stark von der Ikonographie der drei Bücher anregen lassen, was die vorliegende Darstellung an detaillierten Vergleichen aufzeigt. Der Einfluss Thevets liegt in einigen ethnologischen Details und im strukturellen Charakter der Kupferstiche, die wie bei Thevet eine durch eigene Semantik bestimmte Folge über das Leben der Indianer bilden. Lérys und Stadens Abbildungen wurden direkt als Vorlage für die Kupferstiche übernommen, wobei Bry im Sinne der kalvinistischen Theologie der Zeit das duale Menschenbild Lérys, der den Indianern auch positive Charaktermerkmale zugesteht, verschärft und sie im religiösen Sinne als Verworfene zeichnet, deren Unglauben seine Entsprechung in der barbarischen Sitte der Anthropophagie hat. Dieser ideengeschichtliche Hintergrund beeinflusst auch direkt die Bildlichkeit des illustrativen Materials; so spart Léry die Anthropophagie fast gänzlich aus, während Theodor de Bry wie zuvor schon Thevet in einigen Illustrationen diese Sitte in aller Drastik zeigt. Die Holzschnitte in Stadens vor allem im ersten Teil narrativen Werk wurden von Bry mit Ausnahme einiger theologisch heikler Anspielungen auf den Providenzglauben zum Vorbild genommen, aber durch qualitativ höherwertige Kupferstiche ersetzt. Durch die Einheirat von Matthäus Merian in die Familie Bry und die Weiterführung ihrer Werkstatt wurden die Kupferstiche bis in die Mitte des 17. Jahrhunderts weiterverwendet. Spätere Illustratoren, darunter auch Matthäus Merian in den Bildern zur Historia Antipodum $(1631,1655)$ von Johann Ludwig Gottfried, haben die Bry'schen Kupferstiche kopiert und je nach künstlerischem Zeitgeschmack und geistesgeschichtlichem Hintergrund umgestaltet und damit das visuelle Bild des körperlich wohlgestalteten Indianers bei den Brys bis in das Zeitalter der Aufklärung getragen und eine künstlerische Vorlage für das ideengeschichtlich bis Rousseau wirkende Bild vom bon sauvage geliefert. 


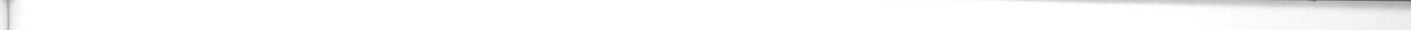




\section{americana eystettensia}

Publikationen des Zentralinstituts für Lateinamerika-Studien

der Katholischen Universität Eichstätt

Herausgegeben von Karl Kohut und Hans-Joachim König

\section{A. AKTEN}

1. D.W. Benecke/K. Kohut/G. Mertins/J. Schneider/A. Schrader (eds.): Desarrollo demográfico, migraciones y urbanización en América Latina. 1986 (erschienen im F. Pustet-Verlag Regensburg als Bd. 17 der Eichstätter Beiträge)

2. Karl Kohut (Hrsg.): Die Metropolen in Lateinamerika - Hoffnung und Bedrohung für den Menschen. 1986 (erschienen im F. Pustet-Verlag Regensburg als Bd. 18 der Eichstätter Beiträge)

3. Jürgen Wilke/Siegfried Quandt (Hrsg.): Deutschland und Lateinamerika. Imagebildung und Informationslage. 1987

4. Karl Kohut/Albert Meyers (eds.): Religiosidad popular en América Latina. 1988

5. Karl Kohut (Hrsg.): Rasse, Klasse und Kultur in der Karibik. 1989

6. Karl Kohut/Andrea Pagni (eds.): Literatura argentina hoy. De la dictadura a la democracia. 1989. 2a ed. 1993

7. Karl Kohut (Hrsg.) in Zusammenarbeit mit Jürgen Bähr, Ernesto Garzón Valdés, Sabine Horl Groenewold und Horst Pietschmann: Der eroberte Kontinent. Historische Realität, Rechtfertigung und literarische Darstellung der Kolonisation Amerikas. 1991

7a. Karl Kohut (ed.) en colaboración con Jürgen Bähr, Ernesto Garzón Valdés, Sabine Horl Groenewold y Horst Pietschmann: De conquistadores y conquistados. Realidad, justificación, representación. 1992

8. Karl Kohut (ed.): Palavra e Poder. Os Intelectuais na Sociedade Brasileira. 1991

9. Karl Kohut (ed.): Literatura mexicana hoy. Del 68 al ocaso de la revolución. 1991. 2a ed. 1995

10. Karl Kohut (ed.): Literatura mexicana hoy II. Los de fin de siglo. 1993

11. Wilfried Floeck/Karl Kohut (Hrsg.): Das moderne Theater Lateinamerikas. 1993

12. Karl Kohut/Patrik von zur Mühlen (Hrsg.): Alternative Lateinamerika. Das deutsche Exil in der Zeit des Nationalsozialismus. 1994

13. Karl Kohut (ed.): Literatura colombiana hoy. Imaginación y barbarie. 1994 
14. Karl Kohut (Hrsg.): Von der Weltkarte zum Kuriositätenkabinett. Amerika im deutschen Humanismus und Barock. 1995

15. Karl Kohut (ed.): Literaturas del Rio de la Plata hoy. De las utopías al desencanto. 1996

16. Karl Kohut (ed.): La invención del pasado. La novela histórica en el marco de la posmodernidad. 1997

17. Karl Kohut/José Morales Saravia/Sonia V. Rose (eds.): Literatura peruana hoy. Crisis y creación. 1998

18. Hans-Joachim König (ed.) en colaboración con Christian Gros, Karl Kohut y France-Marie Renard-Casevitz: El indio como sujeto y objeto de la historia latinoamericana. Pasado y presente. 1998

19. Barbara Potthast/Karl Kohut/Gerd Kohlhepp (eds.): El espacio interior de América del Sur. Geografía, historia, política, cultura. 1999

20. Karl Kohut (ed.): Literatura venezolana hoy. Historia nacional y presente urbano. 1999

\section{B. MONOGRAPHIEN, STUDIEN, ESSAYS}

1. Karl Kohut: Un universo cargado de violencia. Presentación, aproximación y documentación de la obra de Mempo Giardinelli. 1990

2. Jürgen Wilke (Hrsg.): Massenmedien in Lateinamerika. Erster Band: Argentinien - Brasilien - Guatemala - Kolumbien - Mexiko. 1992

3. Ottmar Ette (ed.): La escritura de la memoria. Reinaldo Arenas: Textos, estudios y documentación. 1992. 2a ed. 1995

4. José Morales Saravia (Hrsg.): Die schwierige Modernität Lateinamerikas. Beiträge der Berliner Gruppe zur Sozialgeschichte lateinamerikanischer Literatur. 1993

5. Jürgen Wilke (Hrsg.): Massenmedien in Lateinamerika. Zweiter Band: Chile - Costa Rica - Ecuador - Paraguay. 1994

6. Michael Riekenberg: Nationbildung, Sozialer Wandel und Geschichtsbewußtsein am Rio de la Plata (1810-1916). 1995

7. Karl Kohut/Dietrich Briesemeister/Gustav Siebenmann (Hrsg.): Deutsche in Lateinamerika - Lateinamerika in Deutschland. 1996

8. Jürgen Wilke (Hrsg.): Massenmedien in Lateinamerika. Dritter Band: Bolivien - Nicaragua - Peru - Uruguay - Venezuela. 1996

9. Christiano German: Politik und Kirche in Lateinamerika. Zur Rolle der Bischofskonferenzen im Demokratisierungsprozeß Brasiliens und Chiles. 1999 
10. Inge Buisson-Wolff: Staat, Gesellschaft und Nation in Hispanoamerika. Problemskizzierung, Ergebnisse und Forschungsstrategien. Ausgewählte Aufsätze. Hg. und eingeleitet von Hans-Joachim König. 1999

11. Franz Obermeier: Brasilien in Illustrationen des 16. Jahrhunderts. Unter Mitarbeit von Roswitha Kramer. 2000

C. TEXTE

1. José Morales Saravia: La luna escarlata. Berlin Weddingplatz. 1991

2. Carl Richard: Briefe aus Columbien von einem hannoverischen Officier an seine Freunde. Neu hg. und kommentiert von Hans-Joachim König. 1992

3. Sebastian Englert, O.F.M.Cap: Das erste christliche Jahrhundert der Osterinsel. 1864-1964. Neu hg. von Karl Kohut. 1996

3a. Sebastian Englert, O.F.M.Cap: Primer siglo cristiano de la Isla de Pascua. 1864-1964. Edición de Karl Kohut. 1996

D. LYRIK

1. Emilio Adolpho Westphalen: "Abschaffung des Todes" und andere frühe Gedichte. Hg. von José Morales Saravia. 1995.

2. Yolanda Pantin: Enemiga mía. Selección poética (1981-1997). Prólogo de Verónica Jaffé. 1998 


\section{$\% G F \# B 206 \%$}

Publikationen des Zentralinstituts für LateinamerikaStudien der Katholischen Universität Eichstätt

Serie B: Monographien, Studien, Essays, 11

Publicaciones del Centro de Estudios Latinoamericanos de la Universidad Católica de Eichstätt

Serie B: Monografías, Estudios, Ensayos, 11

Publicações do Centro de Estudos Latino-Americanos da Universidade Católica de Eichstätt

Série B: Monografias, Estudos, Ensaios, 11

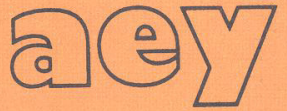

